\title{
Integrating gender and cultural perspectives in Canada's Professional Military Education: transforming military culture through informed leadership
}

\author{
by \\ Vanessa Brown
}

A thesis submitted to the Faculty of Graduate and Postdoctoral Affairs in partial fulfillment of the requirements for the degree of Doctor of Philosophy (Sociology)

Carleton University Ottawa, Ontario

(C) 2021, Vanessa Brown 


\section{Abstract}

This dissertation investigates and invests in the possibility for feminist transformational change within militaries as well as the potential for militaries to be 'forces for good.' The research considers whether militaries can contribute to feminist progress and work towards the cultural inclusion of diverse members within militaries due to personnel's exposure to gender and cultural perspectives within Professional Military Education. The project narrows its investigation to the mid-to-senior graduate level education of Canadian military officers within the Joint Command and Staff Programme at Canadian Forces College. It applies post-modern feminist, intersectional and militarized masculinities theories to understand the military learning environment and to analyze the inclusion and reception of critical theory by military learners. The research draws on contemporary pedagogic literature to make recommendations for optimizing learning environments and professional competencies to facilitate inclusive security and organizational culture change. Acknowledging the context of dominant masculinist and white centering constructions of military identity and socialization, this investigation asks: To what extent are gender and cultural perspectives integrated into mid-to-senior level Canadian Professional Military Education? If and in what ways military socialization and culture shapes the learning environment and the reception of this education? Finally, if and in what ways such learning has facilitated feminist transformations in the military and beyond? The research draws from a feminist critical discourse analysis of six semi-structured focus groups across military and civilian educators, curriculum developers, librarians, and students as well as eight in-depth interviews with military students before graduation and eight follow-up in-depth 
interviews with military graduates after at least three months in command and/or staff positions. The study's sociological ethnographic approach illuminates discursive as well as lived experiences with teaching and learning across staff and students. Findings of the research ultimately highlight that while limited, exposure to gender and cultural perspectives, including critical feminist and anti-racist theories and frameworks has had positive professional effects. Graduate respondents report being better able to think critically about security, operations, institutional policy, and leadership, as well as institutional systems, structures, and culture. Some report being empowered by these concepts to facilitate inclusive security domestically and abroad and to advance organizational culture change. 


\section{Acknowledgements}

For Papa. I'll be loving you always.

I wrote this dissertation in my home office in Toronto, situated on the traditional territory of many Indigenous nations including the Mississaugas of the Credit, the Anishnabeg, the Chippewa, the Haudenosaunee and the Wendat peoples. My place of work and residence falls under Treaty 13 referred to as the Toronto Purchase negotiated between the Mississaugas of the Credit and the Crown. Indigenous peoples of this land are its longstanding guardians. As a person of settler colonial heritage, I benefit from the land, its communities of people, and their knowledge. I acknowledge these privileges and am committed to supporting the ongoing stewardship of Turtle Island and Toronto by diverse First Nations, Inuit, and Metis peoples.

I dedicate this dissertation to my late father, John Brown. My Papa taught me to learn from the perspectives of others, to listen, and to never, never, ever, give up. This project was possible due to the love and support of my father and so many people, especially my family. To my late stepfather Gerry Wapnah, I love you and miss you every day. To my mother, Katherine Brown, thank you for your love. Thank you also for your belief in me and for reminding me that this project is about changing the world for the better, one step at a time. I am thankful and blessed to have another mom, Tena Byvelds, whose long talks and comfort helped me to push forward, no matter the obstacle. This year has been especially hard Tena, but your encouragement helped me to make good on my promise to you and Papa.

To my steadfast, always patient and kind husband. Thank you for your love, humour, and willingness to share your sage wisdom on "just one more paragraph of the thesis." Through the ups and downs, you were there to cheer me on, to give the best hugs and to laugh with me. I am grateful also to Iman, Kathy, Michael and Adam for helping me so much throughout this journey. To Rose, Anastasia, Raabeaa, Tristan, Tamarah, Leyna, Alina, Mikhail, Pratish, Alex and Mario, Brian, Donna, Janice, Galyna, DonnaMarie and Althea, thank you for your friendship and ardent belief that 'eventually, Vanessa will finish the dissertation.' 
To Alan Okros, thank you for your friendship and mentorship. I am humbled by and deeply grateful for the time and effort you have invested in my development as a scholar, teacher, and public servant. This thesis would not have been possible, nor as beneficial to the Canadian Armed Forces, without your encouragement and advice. To my brilliant colleagues at the Dallaire Centre of Excellence for Peace and Security, thank you for your keen interest in this project and eternal optimism. I am blessed to be supported by such a wonderful team of practitioners and scholars. To my colleagues at Canadian Forces College, and in particular, Barbara Falk, Paul Mitchell, Craig Stone, Cathy Murphy, Richard Goette and Eric Ouellet, thank you for your belief in me and this work.

To my supervisor, Neil Gerlach, thank you for helping me to make the right decisions and for believing in me more than I ever could have myself. I will fondly remember your warmth, wisdom, and confidence in this research. To my second committee member, Jane Parpart, thank you for your encouragement, kindness, and long chats over the phone about how to frame the thesis, what the key conclusions are, and how the thesis contributes to the field. To Aaron Doyle, thank you for awakening me to the deep importance of pedagogy and the delicate art of teaching. These ideas were formative in the scoping of this project's research questions and key conclusions.

To the leadership of Canadian Forces College, thank you for enabling me to conduct this research and for championing its recommendations. This project represents the insights and efforts of those who volunteered their participation. My deepest thanks to the military and civilian staff and faculty that supported the research by engaging in focus groups and individual interviews. To the military students, now senior leaders of the Canadian Armed Forces, who volunteered to participate in this sociological study, thank you for your candidness, passion, and drive for meaningful social change. Your pursuit of doing good for the institution, Canada, and the world has made this research rich and hopeful. Thank you for putting your trust in me to represent your dreams and aspirations for a better, more equal future, for everyone. 


\section{Contents}

Abstract........................................................................................................................................ ii

Acknowledgements .................................................................................................................. iv

List of Appendices.................................................................................................................. vii

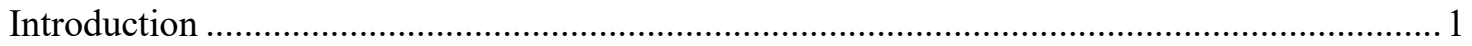

Chapter 1: Theories Guiding the Research.........................................................................21

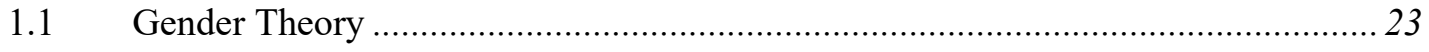

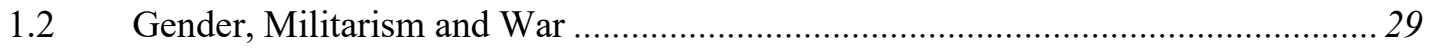

$1.3 \quad$ Gender, the Military and Military Sociology ……………………………………..... 37

1.4 Gender, the Military, International Relations and Feminist Security Studies.......... 42

$1.5 \quad$ Gender Hegemony and Militarized Masculinities ……………………………….... 45

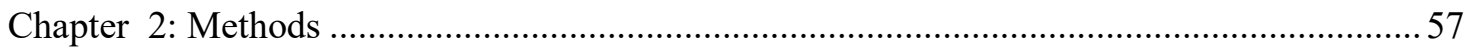

2.1 Determining the Best Methodological Approach for the Research ……………......57

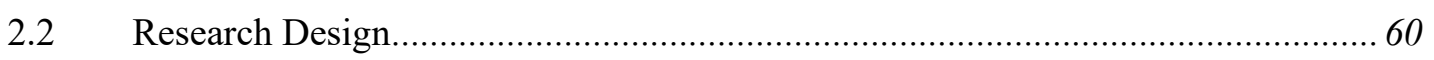

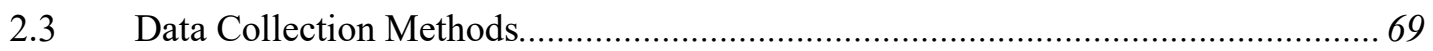

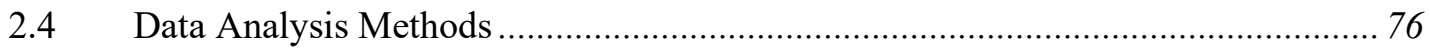

2.5 Assumptions, Forces and Procedures Influencing the Research...............................81

Chapter 3: Hidden Curriculum - Military Social Stratification Transferred to the Learning

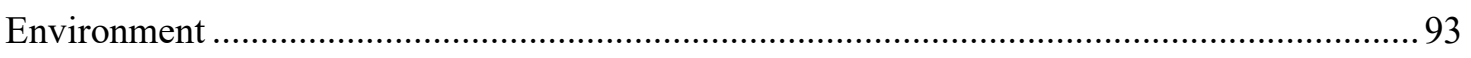

3.1 The Hidden Curriculum ..................................................................................... 94

Chapter 4: Formal Curriculum - Development and Delivery of Gender and Cultural

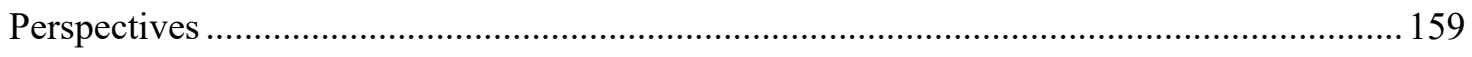

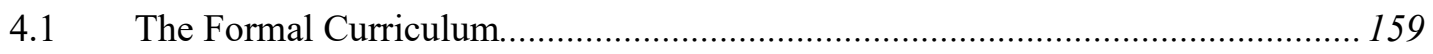

Chapter 5: Gender and Cultural Education and the Transformative Potential of Military

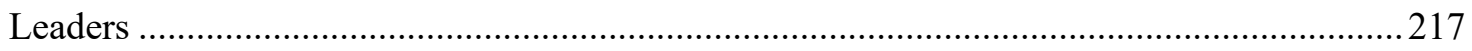

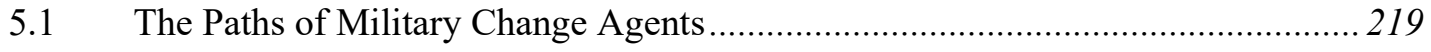

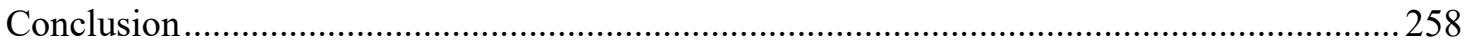

Appendices.......................................................................................................... 277

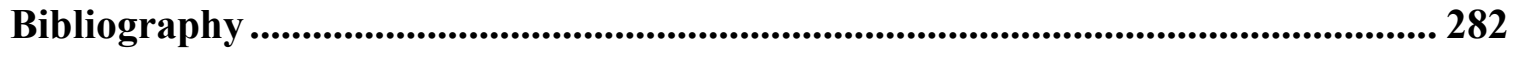




\section{List of Appendices}

Appendix A Ethics Approvals and Supporting Documents.........................274

A.1 Certification of Institutional Ethics Clearance.............................275

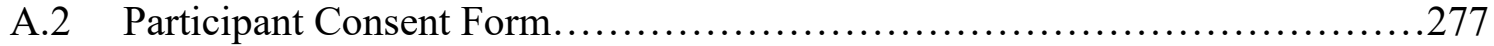




\section{Introduction}

This dissertation investigates and invests in the possibility for feminist transformational change within militaries as well as the potential for militaries to be 'forces for good' (Duncanson and Woodward 2016, 13). Transnational grassroots feminist movements, seeking to address gender inequality and putting an end to the war system, have influenced international norms and laws, as well as the practices of militaries globally (Cockburn, 2011). Since the early 1970s, civil society advocacy by mostly women constituents has lobbied for systematic and collaborative action by states to uphold women's human rights and to prevent and address the differential and disproportionate impact of conflict on women and girls (Kirby \& Shepherd, 2016). Beginning with the World Conferences on Women in 1975 and culminating in the adoption of a series of United Nations Security Council Resolutions (UNSCRs) on Women, Peace and Security from 2000 to 2019, improving the status of women and girls, particularly in relation to contemporary conflict, has been a central theme in global governance (Holvikivi, 2019).

The translation of these UNSCRs into concrete actions by states has varied (George \& Shepherd, 2016). However far from the originating feminist visions for gender

equality by this constituency of advocates (Cockburn, 2011), through the development of National Action Plans, militaries are increasingly being positioned by states as primary agents for facilitating the Women, Peace and Security agenda (Kirby \& Shepherd, 2016). Implementation of these Resolutions by militaries has garnered shifts in the military training and education of many United Nations Member State armed forces to incorporate gender perspectives in military planning and activities (Holvikivi, 2021). 
Indeed, influences from feminist goals within the Women, Peace and Security agenda have brought advances in the incorporation of feminist and critical race theories across key areas of Professional Military Education in Canada. Yet, these changes have been slow and made largely in relation to applications of the Women, Peace and Security agenda in international contexts. Gender related issues particular to the Canadian Armed Forces have seldom been presented and analyzed through feminist and anti-racist perspectives in Canadian military colleges. However, acknowledging systemic cultural issues within Canada, such as rights violations and abuses faced by Indigenous peoples including Missing and Murdered Indigenous Women and Girls (MMIWG) (National Inquiry into MMIWG, 2019) as well as systemic racism and sexism in Canada's institutions, has also influenced the government to expand applications of gender perspectives and intersectionality across all federal departments (Government of Canada, 2018). Moreover, endemic sexual abuse and harassment (Deschamps, 2015) as well as pervasive institutional racism (George, 2016) have challenged military leadership to apply gender and intersectional perspectives to inform plans, processes, policies, and actions, not only to facilitate domestic and international gender equality, but also to achieve transformative organizational changes (Chief of Defence Staff, 2016).

Drawing on federal and institutional mandates, feminist interventions to incorporate gender and diverse cultural perspectives in Professional Military Education are becoming more common in the Canadian context. A small but growing collective of civilian academics and military faculty have worked diligently to better incorporate critical feminist and anti-racist theory and tools within military curricula and pedagogy. Their interventions have been made within the constraints and restraints of competing 
military priorities, systems, and structures, as well as prevailing military socialization and culture. For obvious reasons - including professional duties and ethos requiring deference to military authority and hierarchy, uniformity, normative conformity, group loyalty and service before self - the military learning environment is not always particularly welcoming to critical thinking about military social organization and actions (Brown \& Okros, 2019). Nor is the learning environment especially inviting to examinations of longstanding practices, procedures, and social orders widely believed to be essential to military functioning. In other words, critical perspectives are sometimes seen by military members as insubordinate and contaminating to military identity, purpose, social order and processes.

Canadian feminist and anti-racist scholarship illuminate the ways in which military organization and socialization often transfer and reproduce inequitable social orders built on a foundation of white supremacy ${ }^{1}$ and masculinism in Canadian society (Razack, 2004; Taber, 2015). They note that military violence mobilized by the State has served to uphold the dominance of a privileged few through the maintenance of the world's most oppressive interconnected systems such as patriarchy, colonialism, imperialism, and capitalism (Razack, 2004; George, 2016; Taber, 2015). Sexism, racism, classism, and other culturally constructed systems of power have been actively supported

\footnotetext{
${ }^{1}$ Kenneth Jones and Tema Okun study the manifestation of white supremacy in organizational cultures. They define white supremacy as "the systemic, institutionalized centering of whiteness." Kenneth Jones and Tema Okun, (2001). From Dismantling Racism: A Workbook for Social Change Groups, ChangeWork. In institutions like the military, white supremacy privileges white worldviews, processes, and qualities. This centering of white experience and expectations pushes non-Western and non-white and Indigenous ideas, norms, cultures, symbols, bodies, and practices to the margins. For examples see: Embrick, D. \& Moore, W. (2020) White Space(s) and the Reproduction of White Supremacy. The American Behavioral Scientist (Beverly Hills) 64 (14): 1935-1945.; Gray, Aysa (2019). The Bias of 'Professionalism' Standards, Stanford Social Innovation Review, https://ssir.org/articles/entry/the_bias_of_professionalism_standards; Crenshaw, 1991.
} 
by both the threat of military violence and the material actions and practices of soldiers.

Indeed, militaries themselves are historically male dominated and masculinist institutions. Military cultures are noted for idealizing aggressive, competitive, and combative masculinities as well as promoting the identities, worldviews, and practices of men (Taber, 2015). These masculinities and worldviews are promoted through a 'fighting spirit,' 'warrior identity,' and narratives about 'kicking ass' and 'killing the enemy' (Davis, 2007), often at the expense of forwarding institutional orientations towards diplomacy, negotiation, and compassion.

Yet, militaries are increasingly deployed by states for the purpose of facilitating peace, particularly in response to contemporary intrastate conflict (Kaldor, 2006). Militaries have been used to end wars, protect civilians, and to provide humanitarian aid and disaster relief (Duncanson \& Woodward, 2016). In implementing the Women, Peace and Security agenda, militaries have been mobilized to protect women, girls, men, boys, and non-binary people, particularly those placed in situations of vulnerability in conflict contexts. To this end, militaries are also engaged in the prevention of and protection from sexual and gender-based violence, the recruitment and use of children in armed forces and armed groups, as well as targeted assistance to persons disproportionately at risk or impacted by conflict based on gender and intersecting factors (George \& Shepherd, 2016). At home, the Canadian military has applied gender and intersectional perspectives to provide priority assistance to those most differentially and disproportionately affected by natural disasters and health crises, such as the 2017 flooding in Gatineau Quebec (NDDN, 2019) and deployments to Canada's Long Term Care facilities in the wake of COVID-19 (Brown, 2020). 
In these ways, the military's relation to feminist progress is complicated. On the one hand, the military can be used to support the status quo in terms of the maintenance and reproduction of inequitable power arrangements overseen by the state. On the other, the military is being increasingly called on to facilitate gender equitable peace and security in societies domestically and abroad (Kirby \& Shepherd, 2016). In the Canadian case, efforts toward gender and intersectional equality have taken a turn to also facilitate culture changes within governmental departments. This relatively recent progress allows scholars researching gender and the military to re-evaluate their answers to questions posed by Annica Kronsell, who asks whether militaries might achieve gender equality by adequately "confronting their reliance on masculinity constructs", and whether “"feminism must always be equated with anti-militarism or if military violence committed in the name of enhancing human security can be performed according to a feminist ethics" (2012, abstract).

In examining the application of gender perspectives by militaries, Duncanson and Woodward argue that it is possible to shape the content and process of military engagements in peace and security for good (2016). My research endeavours to push their work forward by examining the ways in which the gender and cultural Professional Military Education of Canadian military leaders has influenced feminist progress within, and whether this learning is setting conditions for military members to support feminist progress in the military and societies through their diffuse and localized military practices. As I explain, influences from international normative frameworks on Women, Peace and Security; Canada's Feminist International Assistance Policy; federal commitments to the application of Gender Based Analysis Plus (GBA+) across all 
departments; and a focus on gender and diversity within Canada's defence policy

(National Defence, 2017), each present the Canadian Armed Forces, military members, and their educators with a solid platform from which they have already begun the work to make feminist progress. Drawing from the insights offered by militarized masculinities, intersectionality, and post-modern feminist frameworks, this research seeks to provide a 'conceptual approach to understand how, and under what circumstances, militaries can change' (Duncanson \& Woodward 2016, p. 11).

To do this, I investigate the integration of gender and cultural perspectives within Professional Military Education for mid-level military leaders of the Canadian Armed Forces. This education is conducted at Canadian Forces College within its Joint Command and Staff Programme. The Joint Command and Staff Programme is a primary conduit through which military members can progress to become senior leaders of the profession. In this Programme, military leaders receive graduate level education, developing literacy in key facets of the profession of arms. A growing part of this literacy is the capacity to understand complex security problems through applications of gender and cultural perspectives.

Focus on these critical perspectives is relatively new in Joint Command and Staff Programme curriculum. As the substantive chapters of this dissertation explain, while this focus is novel at Canadian Forces College, a growing number of faculty including myself, ${ }^{2}$ staff and College leadership recognize that developing essential capacities of leaders often necessitates thinking about complex issues through an intersectional lens.

\footnotetext{
${ }^{2}$ I have been a member of the teaching faculty at Canadian Forces College for the past five years. At the time of data collection for this project, I was a sessional instructor. Last year, I became an assistant professor at the College within the Department of Defence Studies.
} 
These members understand that fostering leaders to use inclusive ways of viewing problems requires teaching approaches that are tailored to the College's military audience. Some educators and College leaders contend that learning about gender and cultural perspectives, as they relate to military problems and operations, better equips military professionals for command and leadership positions by enabling them to understand diverse perspectives within the military and public service. They note that military personnel can apply this skill set to understand the spectrum of experiences in a range of institutional and security contexts.

Additionally, my approach to the examination of gender and cultural perspectives in Professional Military Education intentionally aimed to advance gender equality and anti-racism in the process of conducting the research. To do this, I drew from feminist and anti-racist literatures to inform my research practices, to ground my sociological ethnographic research questions, to look for and interpret common and diverse themes within the data, and to make prescriptive recommendations that forward continued feminist change. Guided by this approach, my investigation sought to understand: To what extent had gender and cultural perspectives been integrated into mid-senior level Canadian Professional Military Education? If and in what ways had military socialization and culture shaped the learning environment and influenced the reception of gender and cultural education? And, if and in what ways such learning facilitated feminist progress in the military and beyond?

The research's sociological ethnographic data was collected from six semistructured focus groups and sixteen in-depth interviews that gleaned observations and lived experiences from staff and students at Canadian Forces College (CFC). Participants 
of the research were recruited through internal College email which solicited volunteers interested in sharing their experiences with the integration of gender and cultural perspectives in the Joint Command and Staff Programme curriculum. It is acknowledged that this sampling method may have resulted in capturing bias supporting the integration of gender and cultural perspectives in curriculum, particularly among individual interview participants. Of note, however, focus groups may have served as a corrective mechanism as their representatives expressed a broad range of opinions as to the usefulness and necessity of presenting gender and cultural perspectives in curriculum. Focus groups and in-depth interviews were arranged across the College's various subgroups of curriculum developers, deliverers, and students to gain a holistic view of the social setting and operant culture. The first set of focus groups with student participants was intentionally gender segregated in order to capture the diversity of gendered experiences among same gender identifying groups. All other focus groups were not gender-segregated but were segregated by occupational subgroups to capture experiential differences among these sets of respondents.

Findings of the research are both striking and significant as they demonstrate not only that feminist progress in militaries is possible, but also that through concerted efforts to support military professionals in learning about the root causes of inequality and the military's role in facilitating peace, military members have been capable of shaping feminist progress institutionally and in societies. Findings of the research show that military members can be important agents for change when: they become aware of and work to confront masculinist institutional norms and oppressive intersectional social orders (Taber 2015; Razack 2004); they commit to a process of 're-gendering' to redefine 
the soldierly identity as inclusive of femininities, masculinities, women, men and nonbinary people, as well as racialized, sexual and linguistic diversity (Woodward and Duncanson 2016; Razack 2004); they reframe professionalism around principles of recognition, equality, empathy, care and respect (Ibid); and they draw on critical feminist and anti-racist perspectives to examine and work to address inequalities within the military, and in societies domestically and internationally.

As the substantive chapters of this dissertation present, the integration of gender and cultural perspectives within Professional Military Education can help military members to support feminist goals. Feminist interventions in Professional Military Education by educators to integrate intersectional perspectives in curriculum and pedagogy have promise precisely because they set conditions for military members to understand and address ways in which gender oppression and intersectional inequalities are perpetuated systemically, institutionally, and interpersonally. Drawing on feminist pedagogies and theories, a small group of educators have assisted in laying the groundwork upon which Canadian military personnel have been able to achieve greater awareness and understanding about social inequalities outside of, but also within the institution.

However, and as will be explained, extant initiatives to integrate these approaches and perspectives in training and education have not been enough. As my research illuminates, the earnest implementation of GBA+ throughout the Canadian military and feminist work by military and civilian faculty and staff to develop more robust training and education on gender and cultural perspectives must be the goal. Moreover, as the findings of my research suggest, the implications of this goal for peace 
and security should not be taken for granted. While feminist progress within the Canadian Armed Forces (CAF) is met with competing and often contradicting worldviews, systems, and structures, this research illuminates how transformational change within the military is more than a possibility by empirically exploring its nascent reality.

In the first chapter, I build the case for the possibility of feminist change in the military by considering feminist thinking on militarism, gender, and security and by investigating the systemic cultural and structural processes that complicate the potential for militaries to be forces for good. Drawing from advances in the field within International Relations, Feminist Security Studies, and Military Sociology, I advance the proposition that there is need to draw increased attention to the process of socialization to military identities, principally through the construction of militarized masculinities. I then present the advantages of applying an intersectional perspective to understand how and the extent to which idealized military identities and hegemonic culture are founded on mutually constitutive power structures of gender, race, sexuality, language, and social class.

Following this presentation, I demonstrate through a post-modern feminist lens how military culture and identity are not static entities, but evolutionary and consistently (re)constructed processes. Gleaning from post-modern feminist theory, my substantive chapters trace the extent to which military members perceive idealized social orders and their social construction through military worldviews, norms, processes, and everyday practices in the work and learning environment. I then follow the ways in which military members conform to, negotiate, and challenge dominant military identities and culture, 
particularly after being exposed to gender and cultural perspectives in Professional Military Education.

Chapter Two establishes this study's methodological approach, research design, and my position as a researcher. It also introduces the participants of the study and the inclusion and exclusion criteria used. In this chapter I describe why I chose qualitative ethnographic methods to collect data and why I used feminist informed Critical Discourse Analysis to interpret the data collected. I discuss the advantages and disadvantages of my methodological approach, as well as the steps I took to mitigate bias and obstacles in the research. Drawing from my experience with the research process as well as my ability to gain a fulsome collection of data and substantive findings through this methodological approach, I underscore the benefits of qualitative, sociological ethnographic, and grounded research to understand the everyday lived experiences of military and civilian members, lived experiences that shape and reconstitute military culture as well as military social orders.

Following the presentation of my theoretical and methodological approaches in Chapters One and Two, I present the findings of the research. Findings draw on excerpts from individual interviews and focus groups to illustrate common themes identified as well as the range of perspectives shared. As outlined in Chapters Three and Four, student and staff participants were asked to share their observations and experiences related to the development, delivery, and reception of gender and cultural perspectives in Joint Command and Staff Programme curriculum. Participants were also asked to provide insight about how they experienced the learning environment at Canadian Forces College, including the extent to which they perceived their interactions with students, 
military and civilian staff, as well as the College grounds, symbols, and artifacts in gendered and intersectional ways. Using feminist Critical Discourse Analysis, and informed by post-modern feminism, intersectionality and theories on militarized masculinity, transcripts of focus groups and individual interviews were analyzed to identify and interpret themes.

Findings in Chapters Three and Four are organized according to observations and experiences with hidden and formal curriculum. Scholarship on hidden curriculum demonstrates the subtle ways that inequities happen through lessons learned from ideas that are not explicitly evident in formal teaching (Giroux \& Penna, 1983). These implicit, or tacit lessons, are noted to shadow what is taught formally. Specifically, hidden curriculum refers to learning that latently reproduces existing social inequalities in societies by transferring inequitable norms, beliefs, and worldviews in the education of students (Brown et al, 2000). Typically, social order and hierarchies within the larger society are reproduced in the classroom in relation to the gender, sex, racialization, sexuality, class and the social positions of students and educators (Giroux \& Penna, 1983). Scholarship on hidden curriculum shows that bias, whether implicit or conscious, about underprivileged groups of people in societies is transferred through discriminatory social practices and relations within teaching and learning (Margolis et al, 2001). Inequalities formed through this hidden curriculum are often harder to recognize principally because imbalances of power in societies become routine and normalized as established cultural 'facts' overtime (Ibid). Studying hidden curriculum renders these mechanisms of power and social hierarchy visible, particularly for those who disproportionately benefit from them. 
Alan Okros, a prolific scholar on diversity and inclusion in the military, uses the following helpful analogy. Right-handed people do not often recognize that they live in a right-handed world, because the world was built to accommodate their specific needs and abilities. Yet, left-handed people constantly perceive they live in a right-handed world because they are faced with the burden of functioning in a system that was not built for them! Hence, left-handed people experience inequities due to the construction of the world in a way that best fits right-handed people. The benefits of living in a world built for them is something that right-handed people often fail to recognize. Their world is perceived as 'normal' or 'the way things are' rather than something that could be constructed differently. These socially constructed right and left-handed disparities are then transferred to the world's institutions, including education institutions, and can be experienced in the learning environment. In the learning environment, inequalities can be noted from the positioning of door handles to right-handed lap-tables in lecture halls. The subtext of this analogy is that inequities within the wider culture transfer to the learning environment both structurally and culturally through a hidden curriculum.

Examining hidden curriculum means that investigators must read between the lines of what is written on paper or presented formally in auditoriums and classrooms. Examinations of hidden curriculum seek to shed light on the implicit lessons that emerge in the context and conduct of education. Investigations of hidden curriculum reveal that structural and cultural inequities materialize in most education institutes and can result in the differential treatment, evaluation, and quality of education for socially disadvantaged groups (Brown et al, 2000). Moreover, contributions from scholarship examining hidden curriculum show that the development and presentation of learning is typically tailored to 
the needs and worldviews of culturally dominant groups, making learning easier for or more relevant to them (Ibid). Professional Military Education institutions are not immune to the effects of hidden curriculum. As recent research suggests, structural and cultural inequalities have been identified in military schools (Kozina, 2015; Jansen and Kramer, 2019).

Chapter Three identifies and examines the themes and collective narratives related to hidden curriculum at Canadian Forces College. It investigates perceptions about what is prioritized in Joint Command Staff Programme curriculum, whose voices are elevated, and whose are omitted or silenced. It also examines what bodies are represented in course texts and in visual cues around the College campus, such as art and photography displayed on the College's grounds. Further it explores the extent to which structures, such as washroom and fitness facilities, and the demographic representation of students and staff are perceived as equitable or inequitable. There are six broad themes identified and analyzed in this chapter. These include: the construction and policing of a narrow and masculinized military identity that upholds 'aggressive,' 'alpha male,' 'combat', 'operator' masculinity; the masculinization of leadership and the prevalence of ideals perceived as contradictory to espoused military professionalism; and the construction of a masculine and white supremacist past to be preserved.

Other pertinent themes speak to male dominance and the underrepresentation of women and visible minorities in the student body, military and academic faculty and leadership, as well as observations of a competitive classroom and masculinist learning environment. Participants also noted perceptions of the infantilization (hence feminization) of students and a lack of trust and confidence in students as professionals. 
Finally, collective rumours of a 'Pink List' were observed and said to be interpreted by some as preferential treatment for women identifying students rather than special selection (or affirmative action) to address systemic barriers for women based on gender disparities within the institution. This theme also related to collective suspicions about gender bias in the selection system used by the services to nominate military personnel to the Joint Command and Staff Programme.

The key findings raised in this chapter are that a particular militarized and masculine identity is reproduced in the education setting, where white, Anglo, heterosexual men, especially within the Army service, and specifically with combat related operational experience, become the idealized and dominant group. Students and staff noted that the worldviews, norms, and dominant culture at the College centered white Anglo warrior experience and pushed other military and cultural identities to the margins of organizational significance. This primacy was not only observable in what gets taught, but also in whose experiences are prized and amplified. The dominant social order was recognized as originating from the larger military culture and was linked to the material underrepresentation of women and racialized members in the student body, faculty, and College leadership. Gendered and racial inequalities were also observed in relation to inadequate facilities for women and virtually no visual representation of women, Indigenous and racialized people in symbols and art, where an abundance of images and symbols of white English men implied colonial white supremacy and masculinism. Student respondents also observed heavy policing of the dominant social order both within and outside of the classroom. 
A promising insight emerged from the observation that learning about gender and cultural perspectives within the Joint Command and Staff Programme enabled students and staff to better perceive inequities, noting that they may not have been able to recognize inequality at the College, within the military, and society without introduction to these critical thinking concepts. From there, many students observed the opportunities that learning about gender and cultural perspectives provided them to challenge their own taken-for-granted assumptions and those of their peers and educators about gender, race, and sexuality, as well as military identity and purpose. Many students and staff explained that they had leveraged the introduction of these concepts to work towards changes in the College's dominant culture, and significantly, to advance feminist transformations in the military and society.

Building on Chapter Three, Chapter Four focuses on the themes and narratives identified in participant observations about formal curriculum. This chapter explores the development, delivery, and reception of curriculum content on gender and cultural perspectives as well as experiences of gender bias in student assessment and evaluation. Themes investigated related to formal curriculum include: the conceptual equation of gender with women; observations of ad hoc, vague, 'check in the box' references to gender and cultural perspectives in curriculum; reports that readings and topics for discussion use largely the perspectives of men as well as colonizing and ethnocentric narratives about conflict and security; and lastly that curriculum rarely integrated diverse cultural perspectives.

Reflections about content delivery and required pedagogy are also outlined in this chapter. Common themes include: military and academic faculty using this dissertation 
study as a platform to request additional tools, training, support and opportunities to gather knowledge about gender and cultural perspectives; observations that understanding gender and cultural perspectives is essential to the success of the profession; reflections about the need for a different pedagogical approach to deliver gender and cultural perspectives in curriculum; observations of gender biased evaluation and assessment of leadership and officer-like qualities; and reflections about the necessity of an adult, student-centered pedagogical approach, particularly to enhance understanding and applications of gender and cultural perspectives.

Insights from the findings from this chapter demonstrate that the incorporation of gender and cultural perspectives in Professional Military Education takes more than an 'add and stir' approach. The success of integrating gender and cultural perspectives depends on the extent to which students and educators are enabled to consider the military as a gendered and racialized institution. The utility of exposing military students to gender and cultural perspectives is also hinged on leadership buy-in for these perspectives and the knowledge and expertise of educators in feminist and critical race theories. The impact of the presentation of gender and cultural ideas to military members also depends on the pedagogical approach applied, with students and staff noting that the development of self-insight took place not just in the formal lectures of educators, but also in their ability to have sustained dialogue and collaboration on these topics with their peers. In this way, findings showed that feminist progress through the actions of military members is essentially tied to deep and persistent learning about intersectional inequalities and how to resolve them. This takes not only the right curriculum content, 
but also the right cultural atmosphere of buy-in and support, the right learning environment, and the right pedagogical methods.

Final thematic areas examined refer to: common observations that the Canadian Forces College has the potential to take a leadership role in the integration of gender and cultural learning among Professional Military Education institutions in Canada and abroad, and that, rather than the informal way that these ideas are presented currently, the College needs a systematic and enduring approach. While Chapter Three and Four investigate the context in which gender and cultural perspectives in curriculum are developed, delivered and received, they also trace what content is delivered, the adequacy of extant curriculum, and also the possibilities afforded by this education for the leadership and practices of military members. Drawing from these findings, Chapter Five investigates the impact of integrating feminist theory and diverse cultural frameworks in the Professional Military Education of senior officers in the Canadian military.

Chapter Five traces narratives emergent in follow-up in-depth interviews with Joint Command and Staff Programme graduates. It explores and analyses themes about how military professionals have understood and applied this learning in their everyday military thinking and work. Significantly, of the participants interviewed, all spoke to the ways in which they had drawn from and applied gender and cultural perspectives to make local feminist interventions. Ultimately, by tracing key themes in the narratives of graduates, the chapter argues that 'what might seem like limited progress, or superficial changes' made by military members could pave the way for meaningful feminist progress both within and outside of the military (Duncanson and Woodward 2016, 11). While it is easy to be critical of the military, a closer look at the potential for feminist change 
through the localized and diffuse actions of motivated military members tells a different, more hopeful story.

The grounded sociological ethnographic research presented in this dissertation intentionally expands upon existing studies of gender and the military. Throughout, a narrative is developed that contributes to a deeper understanding of the construction of gender hierarchy in the Canadian Armed Forces and armed forces more broadly, as it traces how gender stratification in the military is (re)constructed in Professional Military Education and through the context of a military learning environment at Canadian Forces College. More broadly, as this research is anchored in the everyday localized practices of military members, this project works to push conventional top-down studies on gender and militaries that speak at the level of states, institutions, policies, and doctrine into a new and growing terrain. This project starts from the ground up to determine the necessary social conditions and alternative ways in which social relations and actions of military members might influence meaningful change.

Advancing contributions to the field made by Woodward and Duncanson (2016), Higate (2003, 2007), Razack (2004) and Whitworth (2005), this dissertation establishes how social forces constituted at the level of states, institutions and their texts are transferred to and magnified within the everyday interactions and identities of military subjects. However, moving away from representations of militarized masculinity as a static monolith with perpetual ill intent, the research findings show that the dominant order within militaries does not have to be this way (Parpart \& Partridge, 2015). Indeed, the research highlights the very intentional process military members undertake to (re)produce, negotiate, and challenge gender hegemonies within and outside the military. 
Specific to this study's participants, once exposed to critical feminist and anti-racist theories, some military members have demonstrated their capacity to make visible and work to change the normalized production of military social stratification on the bases of gender, race, sexuality, ethnicity, and culture. Findings of this research highlight that once aware of their gendered and racialized socialization to the military as well as inequitable power structures in the military and society, military members can become significant agents for transformational change.

Pushing the study of militarized gender into new territory, this research demonstrates how and in what ways military members have already begun to 're-gender' dominant social constructions in the military and chart diverse paths for the military to be a different force — a force for good. Significantly, findings of the research locate feminist interventions in the local practices of military educators and military members. The key and exciting conclusion put forward is that these localized feminist interventions present an important site for feminist resistance to the dominant gender order both in militaries and societies. The continuous diffusion of military professionals' efforts to make redistributive transformational changes at the local level within the military and within domestic and international societies is work that ought to be leveraged, not overlooked in the creation of meaningful feminist progress. These findings also beg questions as to whether the military can perform according to feminist ethics, and if the military might be capable of positively shaping feminist progress in society. 


\section{Chapter 1: Theories Guiding the Research}

Masculinities, intersectional, and post-modern feminist theories provide the framework that guides this dissertation project. The nexus of these distinct but overlapping investigative lenses shapes the research questions posed in the introductory chapter and guides this project's methodological and analytical approach. Noting that these three sets of theory are each derived from broader disciplines, this chapter begins with a demonstration of how research within this dissertation is situated among related but different bodies of knowledge. To do so, the chapter draws mainly from military sociology, feminist International Relations and its subdisciplines: Feminist Security Studies and Men and Masculinities Studies. Drawing from the trajectory and advances of work from these disciplines, the benefits of the connection among post-modern feminism, intersectional feminism, and militarized masculinities studies to this project is explained.

This chapter is presented in five sections. The first section offers a broad examination of gender theory, setting out key concepts and definitions related to masculinities and femininities, patriarchy, and the gendered and gendering social orders which are constructed, negotiated and maintained in societies. This initial section explores the ways in which gender influences social relations at all levels-from the individual and interpersonal levels to the organizational and institutional levels, to larger societal levels. Drawing from the chosen nexus of theory supporting this study, this section makes the case that it is often patriarchal understandings of gender that work to construct the systems and structures that inequitably organize people locally, nationally, and internationally. From this, the section introduces militarism as a patriarchal 
organizing concept through its close relationship to hierarchical and binary constructions of gender.

The second section maps studies of the interrelationship among gender, militarism, and war. Highlighting principal work that investigates this relationship, this section explores key findings about how conflict is both gendered and gendering; the mechanisms through which societies construct gendered identities around and through potential and actual war; and the implications of gender, militarism and war for social organization, gender roles, and the lived realities of individuals. The third section outlines military sociology's contribution to studies of gender, militarism and war, while the fourth section highlights the advances within this field by feminist International Relations and Feminist Security Studies.

Drawing specifically from feminist International Relations and Feminist Security Studies, the chapter's final section explores the concept of hegemonic gender and the research of feminists who study a particular form of gender hegemony, namely, militarized masculinity. Drawing on more recent applications of militarized masculinity (and militarized gender), the intersectional, post-positivist and post-modern visions of subjectivity and identity ${ }^{3}$ within this work are demonstrated. The chapter concludes by presenting the benefits that drawing from these specific applications of militarized gender, intersectionality and post-modern feminism have had for framing this project's research questions, methodological approach, and analysis.

\footnotetext{
${ }^{3}$ As defined in this dissertation's methods chapter.
} 


\subsection{Gender Theory}

Though the two terms are often conflated in conventional discourse in Canada, the U.S., U.K. and Western Europe, feminists of most persuasions argue that gender is distinguishable from sex (Sjoberg, 2009, 186). Moreover, while examinations of gender are commonly taken to be about the differential treatment and oppression of women, studies about gender seek to improve the status of all people by identifying and working to erode unfair and unequal gender norms and roles because of patriarchal social relations (Cook, 2007, 1; Brown \& Okros, 2018; Dharmapuri, 2011, 58). As such, gender has been defined as "a system of symbolic meanings that creates social hierarchies based on perceived association with masculine and feminine characteristics" (Sjoberg, 2009, 186). These characteristics are socially constructed in ways that are associated, but not essentially so, with biological sex.

Patriarchal societies - those in which social organization is based on men's normative and material control of social, economic, and political power (Goldstein, 2001) — ascribe in varying degrees to a two-sex system (Shildrick, 1997). In a two-sex system, body parts, chemistry, and bodily practices tend to be constructed and categorized in hierarchical and binary ways that stand to classify individuals into two distinct and differentially valued biological sexes—male and female (Beauvoir, 1949). While there is nothing socially essential about sex, the physical materiality of bodies is innate and grounded in what bodies essentially are and what they essentially do (Ibid, $\mathrm{xv}$ ). Yet, the ways in which each body is understood (or made intelligible) in patriarchal societies is subjective, and what is understood as biologically essential to men and women happens through myriad and historical processes of sex socialization to one or 
another category of this sex duality (Butler, 1990). In this way, while sex is generally acquired naturally, ${ }^{4}$ gender is acquired socially. In other terms, though people are born with particular sex characteristics, normatively and socially humans are ever engaged in the process of becoming gendered individuals. Thus, as Simone de Beauvoir notably suggests 'one is not born, but becomes a woman' (1949, xv).

The ways in which differential meaning and value are bestowed upon men's and women's bodies ${ }^{5}$ are socially constructed and normalized in societies through processes of sex socialization. As feminist thinkers have generally suggested, gender is neither natural nor innate (Sjoberg, 2009). Rather, feminist scholarship has argued that gender is a social product, culturally specific and learned (Runyan \& Marchand, 2011, p. 8). Feminist research has come to demonstrate the various ways in which gender is socially constructed in diverse societies, and speaks to the supposition that associations about masculinities, or 'what men do' and femininities or 'what women do' are and have the possibility to be constructed differently (Hacking, 1999). In other words, there is an argument, particularly among feminist thinkers, that gender is a social invention, one that is culturally particular (Goldstein, 2001), and one that is made manifest through the

\footnotetext{
${ }^{4}$ Increasingly aspects of sex can be changed, augmented, removed or acquired through technological and medical advances, and in some more radical interpretations, questions have been raised as to whether sex itself has to a large degree been socially constructed. For more on the social construction of sex see: Butler, 1990; Shildrick, 1997.

${ }^{5}$ The definition of sex that I use throughout this dissertation views sex as a messy spectrum rather than an essential binary as is commonly constructed. In this definition, biological sex is comprised of a mixture of 'anatomical characteristics such as hormones, chromosomes, and sex organs' (Cook, 2007, 1), that is inclusive of female, intersex and male bodies which are not universal and whose composition is subject to change over time. For more on definitions of sex as a spectrum see: Ainsworth, Claire. 2015. Sex Redefined. Nature 518(7539): 288-291. For definitions of binary sex as a social construct and a demonstration of broader definitions of sex categorization and identification see: Carlson, Åsa (2016). Sex, Biological Functions and Social Norms: A Simple Constructivist Theory of Sex, NORA - Nordic Journal of Feminist and Gender Research, 24(1): 18-29.
} 
contextually specific social processes and relations which influence social order and power distributions in societies (Butler, 1986; Cook, 2007; Runyan \& Marchand, 2011).

Indeed, evidence that gender is understood and practiced differently across patriarchal societies abounds, ${ }^{6}$ and further, research suggests that the meaning of gender takes tending, is under constant construction, and is thus subject to change over time (Connell \& Messerschmidt, 2005). Specifically, qualities most commonly associated with masculinity in patriarchal societies:

include strength, protection, rationality, aggression, public life, domination, and leadership. On the other hand, weakness, vulnerability, emotion, passivity, privacy, submission, and care have been traditionally associated with femininity (Sjoberg \& Via, 2010, 3).

In this way, in patriarchal conventions, gender is a relational construct (Schippers, 2007), a construct where femininities are in the continual process of being constructed as oppositional to (Krylova, 2010), lesser than, and in support of, masculinities (Schippers, 2007; Connell \& Messerschmidt, 2005).

As such, gender has a deep and enduring interplay with social power in patriarchal societies. In these societies, masculinities hold a privileged place of dominance and value over femininities (Connell \& Messerschmidt, 2005). Hence,

\footnotetext{
${ }^{6}$ For a classic study of gender across Western cultures see: Beauvoir, 1949. For cross cultural differences in the intersection of both gender and religion see: Winkel, H. (2019) Religious cultures and gender cultures: tracing gender differences across religious cultures, Journal of Contemporary Religion, 34:2, 241251. For cross cultural specificities in gender relations and gender orders in contemporary conflict contexts in South Sudan and Sierra Leone see: Duriesmith, D. (2017;2016;). Masculinity and new war: The gendered dynamics of contemporary armed conflict. Abingdon, Oxon; New York, NY; Routledge. For an investigation of gender and the specificity of gender across state militaries see: Woodward, R. \& Duncanson, C. (2017). The Palgrave international handbook of gender and the military (1st 2017 ed.). London: Palgrave Macmillan.
} 
femininities, and as a consequence the categories 'female' and 'woman,' are argued to be historically constructed as second to (Beauvoir, 1949), other than (Schippers, 2007), or rendered as so insignificant in comparison to men and masculinities that they often escape recognition in modern (and contemporary) universal paradigms (Shildrick, 1997). At the individual, subjective level, while masculinities are associated with male bodies, and femininities are associated with female bodies, gender is descriptive of the characteristics, behaviours, and expected practices of all people (Ibid). In this way, gender is a fluid concept, one in which individuals of any sex can be understood as feminine or masculine based on ascribed, attributed or self-identified characteristics, behaviours and attitudes. And, as notions about gender are changing — each person's relation to gender is dynamic, dependent on context, and under continuous (re)construction (Connell, 1995). In these ways, gender is a construct which structures the material realities, worldview, norms, and practices of all individuals through gendered and gendering social relations of power and dominance. As noted by Dubravka Zarkov and Stefan Dudink "defining gender through such social relations of power means placing gender at the heart of relations of dominance and marginalisation, hierarchy, hegemony, oppression and subjugation" $(2001,47)$. Indeed, and as will be expanded upon later, some feminist scholars claim that gendered and gendering militarism help to legitimate masculinist ${ }^{7}$ social relations of power (Eichler, 2014), and that gender inequality can be causal of conflict and war (Cockburn, 2010).

\footnotetext{
${ }^{7}$ Drawing from Charlotte Hooper, I define masculinism as a social process wherein people learn not to question the "elevation of ways of being and knowing associated with men and masculinity over those associated with women and femininity" and tend to view the status, authority and power of men and masculinity as inevitable, natural, or desirable. Hooper, C. (1998). "Masculinist Practices and Gender Politics: The Operation of Multiple Masculinities in International Relations," in The "Man" Question in
} 
For such larger social unrest to occur as a consequence of gender constructions in societies, gender relations must also influence the structures, systems and cultures of people far beyond the interpersonal level of constructed gender identities. As demonstrated in their volume on Gender and Global Restructuring, Marianne Marchand and Anne Sisson Runyan argue that "gender operates in at least three distinct, yet interconnected, ways" $(2011,8)$. Drawing from Zarkov and Dudink, and to expand Marchand and Runyan's definition to at least four ways, this dissertation supposes that gender operates at: (1) the subjective level, "physically through the social construction of male and female bodies" (Ibid); (2) at the level of organizations and institutions, through gendered/gendering social relations; (3) at the discursive level, particularly ideologically and in doctrine; and (4) symbolically, through signs which denote value, norms, ethics and morality (Ibid; Dubravka \& Dudink, 2001, 47).

My analysis of this project's research findings draws from all four levels, as each overlap. However, the focus of this research starts at the individual subjective level and investigates this level's relation to the remaining three. In particular, I assess how gender constructs at the institutional level, the level of ideology and doctrine, as well as the symbolic level (in military symbols, art, dress, comportment, rituals, and signs) impact individuals at the subjective level. In doing so, I take steps to populate a neglected area requiring empirical insight in the study of professions and within the field of gender and the military. Specifically, I draw on findings of the research to recognize and work to fill in the gaps left by the 'relative lack of attention for the discursive and performative

International Relations, ed. Zalewski, M. \& Parpart, J. Boulder, CO: Westview Press, 31, as referenced in Eichler, M. (2014). Militarized Masculinities in International Relations, The Brown Journal of World Affairs, 21(1): 81-93. 
aspects of professional work' (Muzio et al, 2013, 713) at the subjective level and the lack of study about 'what degree of reflexivity or awareness [ ] actors have about institutional pressures' (Ibid, 715). I have also intentionally set out to contribute to an area identified by Cynthia Enloe, Anita Lacey, and Thomas Gregory that has been limited in sociological and international relations studies on conflict, militarization and gender, namely, research that makes the broader social forces at work at the local level visible. Enloe notes that few studies in the field have recognized and understood "the politicization of everyday life and that a research process from the ground up, of the everyday, allows for recognition of that which is often rendered invisible" (Enloe et al, 2016, 538).

As suggested in this section, the study of gender is "not the study of what men do and what women do and how they might be similar or different' (Dubravka \& Dudink, 2007, 47). Rather, the study of gender is about the ways in which societies, with their structures, systems and cultures, construct value and power in relation to characteristics and qualities associated with masculinities and femininities (Schippers, 2007). For these reasons, and in these ways, this study, with its focus on how gender and cultural perspectives are being integrated, received, and applied by military professionals, is a study about localized practices of gender. Broadly speaking, this study is careful to show how larger forces of gender, militarism and war are (re)produced and subject to feminist change in and through the everyday transformative practices of military professionals. 


\subsection{Gender, Militarism and War}

Academic scholarship from an array of disciplines has illuminated the relationship between culturally specific constructions of gender in war systems ${ }^{8}$ and paradigms of militarism and masculinism internationally. ${ }^{9}$ Some feminist scholarship, particularly from the International Relations discipline, has understood a “'mutually reinforcing dynamic' between militarism and masculinism" (Eichler, 2014, 83). War, (in)security, and the practices of State and non-State actors have been noted by scholars, working within an array of branches of the social sciences, as entrenched in both gendered and gendering social relations of power. Drawing on this insight, I explore the study of gender, militarism, and war within social science more broadly here, while in the following sections I draw specifically from the large contributions to this field by feminist Military Sociology, International Relations feminists and work from Feminist Security Studies. In showcasing multidisciplinary theoretical approaches to and empirical investigations of gender, militarism and war, Joshua Goldstein illuminates the ways in which gender shapes war, and war shapes gender (Goldstein, 2001). Goldstein's analysis of cross-disciplinary work on the subject reveals the large extent to which aggressive and passive gender behaviours and societal expectations are guided by culturally specific

\footnotetext{
${ }^{8}$ I use Goldstein's definition of war here to describe 'lethal intergroup violence' $(2001,3)$. This understanding of war includes both simple and complex societies engaging in violence which is either actual (killing or injuring) or symbolic (posturing or using the threat of violence) in pursuit of social, economic, territorial, or other gains. For war systems and gender see: Reardon, B. (1985). Sexism and the War System, New York: Teachers College Press.

${ }^{9}$ I use Taber's understanding of militarism to mean a process wherein citizens of a society adopt norms and ideologies which support hierarchy, deference to authority, and where members of societies come to view "military solutions as particularly effective" and "see the world as a dangerous place best approached with militaristic attitudes." Taber, N. (2015). Gendered Militarism in Canada: Learning Conformity and Resistance. Edmonton: The University of Alberta Press. p. xviii.
} 
gender roles that are created in and through potential and actual war. Goldstein posits that across all known and documented cultures, men have commonly been guided toward war, and women away from it, based on narrow and constraining cultural constructions of masculinity and femininity $(2001,252)$. His research, drawing on insights from anthropological, historical, sociological, international relations and gender studies, demonstrates that war and the potential for it are common 'near-universally' across cultures, and, cross culturally, wars and fighting in them do not come naturally to men (Goldstein, 2001, 1).

Goldstein's research indicates that regardless of the political, social, and economic systems throughout documented history "men [have] require[d] intense socialization and training" to become warriors (Ibid). Further, the practice of becoming warriors is not a result of men's innate proclivity to aggression and violence, but rather the result of immense cultural pressure and systems of reward, where women often become the content of those rewards (Goldstein, 2001, 1). ${ }^{10}$ Like sex socialization, individuals' relation to war, and identities such as warriors, protectors and protected are not natural (Goldstein, 2001). Rather, these roles and identities are socially constructed, gendered/gendering, and culturally specific. ${ }^{11}$ The creation of gender roles and gender identities related to war and conflict are often tied to culturally constructed and taken-for-

\footnotetext{
${ }^{10}$ For the masculinist warrior and its relation to the Canadian military see: Davis, K. \& McKee, B. (2006). "Women in The Military: Facing the Warrior Framework", in Challenge and Change In The Military: Gender And Diversity Issues, Franklin Pinch, Allister MacIntyre, Phyllis Browne, and Alan Okros Eds. Kingston: Canadian Defence Academy Press, pp. 52-75.

${ }^{11}$ For examples of different conditions in the Canadian context and changing idealized forms of military masculinity among Canadian military members see contrasts in the following research: Whitworth, S. (2004). Men, Militarism, and UN Peace Keeping: A Gendered Analysis, Boulder: Lynne Rienner Publishers,; Duncanson, C. (2015). Hegemonic masculinity and the possibility of change in gender relations. Men and Masculinities, 18(2): 231-248.
} 
granted notions about what men and women ought to do and what they are 'naturally' capable of in different situations (Al-Oraimi, 2008, 130). These roles and identities determine what it is to be 'real men' (Jung, 2008, 50) and 'good women' (Roach Pierson, 1986). Such constructs also provide prescriptive norms and ideals that pressure individuals to 'fit in' and 'conform' to militarized architypes, stereotypes, and ascendant notions of gender (Woodward \& Winter, 2007; Cockburn, 2004).

These notions are situated as they are articulated differently in relation to contexts of security and insecurity, peace, and wartime. Constructed narratives of 'real men' and 'good women' have been crafted, rearticulated, justified and mobilized depending on the contexts of men, women, and gender non-binary peoples' service to nations, states, and economies (Enloe, 2014). They have also been leveraged in support of the changing interests and needs of cultural, ethnic, religious, tribal, political, and social groups (Enloe, 2014, 119; Roach Pierson, 1987, 1986; Al-Oraimi, 2008, 129). Of note, it is sometimes men who prove their warrior masculinity through displays of qualities associated with caring, love, and empathy (Parpart \& Partridge, 2014; Duncanson, 2015). Similarly, in some contexts it is women who are understood as moral, valuable, and good when taking up arms (Roach Pierson, 1986). In this way, the fluidity of gender has been recognized in the shifting embodiments of masculine and feminine qualities related to conflict, militarization, and war and how these are negotiated, are (re)produced and constructed differently across cultures depending on the context.

As cultural historian Leo Braudy's research illustrates, the cultivation of shifting masculinities and complicit femininities that facilitate war, as well as the construction of warrior identities in European and American cultures, are negotiated overtime and related 
to historically and socially specific contexts (2003). Braudy's work specifically explores how cultural constructions of gender in relation to conflict manifest over time. Despite gender's contextuality and malleability in relation to war, Braudy's research shows that most societies nevertheless uphold patriarchal power by similarly advancing particular masculinities as dominant. His work suggests that the idealization of specific masculinities authorizes inequitable sets of sexual and gendered behaviours that subordinate women and some men to other, elite men (Ibid). This inequitable construction of gender can be exacerbated in the process of creating the specific gender orders which come to be understood as facilitating the winning of conflicts and wars (Braudy, 2003).

Feminist scholars, particularly in the field of International Relations, have similarly shown that discourses, practices and approaches in institutions, organizations, states, global orders, economies and war systems are both militarized and gendered in predominantly masculinist ways (Ibid; Sjoberg, 2011; Runyan \& Marchand, 2011; Enloe, 2000). For the purposes of this dissertation, I draw from Goldstein to define the terms masculinist and masculinism generally as "an ideology justifying, promoting, or advocating male domination" (Goldstein, 2001, 1). Illustrating the gendered nature of war, feminist political scientist Iris Marion Young poses that the gendered and gendering militarism of States and international relations are masculinist patriarchal projects. Her work highlights two dominant forms of masculinist ideology and practice that shape war and militarism. These are masculinist suppositions of dominance and protection (Young, 2003). 
Masculinist dominance, Young argues, is 'assumed by much feminist theory'. This is the model of "masculinity as self-consciously dominative" where men display aggressive behaviours in their wish to "master women sexually for the sake of their own gratification and to have the pleasures of domination" (Young, 2003, 4). In the process, men form homosocial comraderies giving them "specific benefits from which they exclude women" and where they "harass women in order to enforce this exclusion and maintain their superiority" (Ibid). This model works alongside another, 'apparently more benign' category—-that of chivalrous masculinity. The chivalrous form is what Young defines as masculinist protectionism.

In this protectionist category of socially constructed masculinity, 'real men' do not seek to dominate others for the sake of themselves. Rather, Young argues that the image presented is of a gallant and heroic man, who faces danger to shield women (and children) from harm (Ibid). He is the protector, who secures the feminized and constructed as vulnerable members of his household (and society) from those wielding the other, dominant category of masculinity. Those who wish to invade or sexually conquer women are considered 'bad men' or aggressors and are subsumed in relationship to the 'good' and justified protector (Young, 2003, 4). In either construction, women and femininities are placed in subordinate positions to men and masculinities, as women (children and other men) are in support of, or are dominated by, elite men and idealized masculinities ideologically, discursively, and materially. Importantly, due to the construction of both categories as masculine (associated with work that men do), an overarching "patriarchal right emerges from male specialization in security" (Ibid). 
As suggested by Young, masculinist categories of domination and protection do not only reside at the level of the normatively constructed nuclear (heteronormative) family. Instead, these social constructions of gender and war constitute social relations of power at the organizational, institutional, State, and global levels. As many feminist International Relations theorists have shown, such masculinist categories of dominance and protection have been expressed in structural and systemic colonial paradigms and practices of Western imperialism. In this intersectional way, the constructed narrative is that the protector archetype of masculinism belongs predominantly to men, of settler or imperial ethnicity, unmarked discursively as such, but assumed to be expressly White, not only in pigment but also in symbolic representation (Razack, 2004; Whitworth, 2004; Taber, 2015; Elshtain, 1987, 1992). As Young suggests, this protectionist ideology has assumed settler/imperial men to be: "knights of civilization aim[ing] to bring enlightened understanding to the further regions of the world still living in cruel and irrational traditions" (Young, 2003, 19).

As Young notes, these constructions often characterize people, particularly of Asian, African, and Latin American societies, as feminine, infantile, and uncivilized (Young, 2003). Moreover, constructed idealizations assume the requirement of submission to the patriarchal headship of Western hegemony (Razack, 2004). As an extension, this relationship has been recognized in the gender(ed)(ing) social organization of power in "international trade and financial institutions, as well as many Western-based 
nongovernmental development agencies" whose work it is to assist societies often constructed in feminine ways as 'fragile' or 'vulnerable' (Young, 2003). ${ }^{12}$

Indeed, as gender theorist Claire Duncanson suggests, “Jean Bethke Elshtain's archetypes of the Just Warrior and the Beautiful Soul serve as a useful shorthand for the elaborate gender ideology underpinning militarism and war" (Duncanson, 2015, 237). Drawing from Elshtain's research, the Just Warrior constitutes a gendered trope commonly used in patriarchal societies. The Just Warrior is a familiar social construction of brave, rational and selfless individuals, burdened with protecting others who are constructed in oppositional terms as naïve, innocent, and vulnerable, or, Beautiful Souls (Sjoberg \& Via, 2010, 4). While the protection/domination models of masculinity differentially impact women and men, and while conflict disproportionately affects women and non-binary people (Ibid, 6), as the work of political scientist Charli Carpenter demonstrates, these same gender constructions of war and conflict often eclipse men's vulnerability and commonly render them as immune to violence, and not worthy of, or not likely to require protection from the same forces (2016).

As Duncanson notes, whatever 'men and women actually do in war', men are nevertheless presumed to "protect their womenfolk, while women remain at home, waiting and weeping" (Duncanson, 2015, 237). Drawing from such common masculinist constructions of war and security, essentialist and stereotypic scripts of gender and war

\footnotetext{
${ }^{12}$ For ideas about infantilization in relation to gender and citizenship see: Berlant, L. (1997). "The Theory of Infantile Citizenship." In her The Queen of America Goes to Washington City: Essays on Sex and Citizenship, 25-54. Durham, N.C.: Duke University Press, as referenced in Young, 2003, 9. For the use of fragile and vulnerable as gendered adjectives used to describe societies affected by conflict, and/or societies affected by social, political, and economic insecurity, see: Tiessen, R. (2015). "Gender Essentialism in Canadian Foreign Aid Commitments to Women, Peace, and Security." International Journal, 70(1): 84100.
} 
often emerge as 'fact', or the 'truth' about women, men and conflict (Tiessen, 2015, 85). ${ }^{13}$ These scripts rely heavily on binary and relational constructs that create and enforce unequal power positions between men and women, protector and protected, soldier and citizen.

Essentialist and masculinist gender scripts of domination and protection are increasingly recognized by feminist scholarship as pervasive in State, transnational, and supranational discourses (Tiessen, 2015; Carpenter, 2016). They have also been recognized as (re)producing, legitimating, or shifting unequal gendered divisions of labour and social life (Cohn, 2008). Some feminist scholarship has pointed to the ways in which war and conflict exacerbate existing, often militarized, gendered divisions (Duriesmith, 2017; Parpart, 2010). At the same time, scholarship has also illuminated how women and children, in particular, might experience forms of liberation from traditional patriarchal norms and roles in conflict and post-conflict contexts (Turshen, 1998, 20; Coulter, 2008; Shekhawat \& Saxena, 2015). Some research has pointed to the complex and contextual gendered realities experienced by subjects impacted by conflict, peacekeeping, and post-conflict reconstruction and how these provide opportunities to deconstruct patriarchal systems, giving hope for social transformation and more equal distributions of power (Duncanson, 2015; Parpart \& Partridge, 2014). However, most scholarship, notably in Feminist Security Studies, articulates a legitimation or rearrangement of militaristic and patriarchal social orders to fit particular contexts of

\footnotetext{
${ }^{13}$ In reference to "regimes of truth" as articulated by Michele Foucault in "Truth and power," in P. Rabinow, ed., The Foucault Reader (Toronto: Penguin, 1980), 75. Tiessen writes that "Discourse plays an important role in shaping meaning in society and forming "regimes of truth." Once a society has internalized perceptions and discourse, social realities and truths are formed, which then serve as rationales for the political actions taken by governments" for example.
} 
(in)security and reconstruction, wherein patriarchy and the dominance of men's social, political, and economic privilege are common (Parpart, 2016).

As the studies of gender, militarism and war noted in this section demonstrate, "the state, the nation, the citizen, the military, the soldier-hero, the enemy, the victim, the front, [and] the home-front" (Dubravka \& Dudink, 2007, 47) are socially constructed in gendered/gendering ways that typically work to ensure the hegemony of specific masculinities in ways that are beneficial to particular men (and some women) and in ways that ultimately constitute an "organizing principle of social life" (Ibid).

Significant bodies of knowledge about gender, militarism, and war have come from the contributions of feminist academics in the fields of Military Sociology, International Relations and its subfield Feminist Security Studies (Wibben, 2011). The section that follows presents their insights. Throughout, a discussion will be offered about the ways in which this research project aligns with and pushes the boundaries of how gender in relation to the military has been theorized and investigated in and through the central tenets of these disciplines.

\subsection{Gender, the Military and Military Sociology}

Military sociology investigates the organization of military/militarized groups and institutions in societies and studies their relation to processes of sovereignty, (state and human) security, conflict, war, (in)stability, peace, culture and more recently, gender. Military sociology has engaged in examinations of the military profession, military organizations, military institutions, and cultures within militaries (Ender, 2013). Military sociologists have investigated militarized groups, organizations and institutions and their 
social practices, processes, and relations through micro, meso, and macro levels of analysis (Segal, 2006). In this way, analyses within military sociology include research and investigation of: social relations within militaries; social relations among militaries; the relations, practices, norms and cultures of defence agents and agencies; military relations with origin and host societies and cultures; and the bilateral, multilateral, international, and transglobal relations militaries engage in and their implications for societies, other militaries, militarized groups, states and non-state actors (Segal, 2006: Ender, 2013).

Military sociology emerged in the United States as a larger subject of sociological inquiry in the wake of processes of social (dis)(re)organization in the aftermath of World War II (Ender, 2013). It is a field which has grown in prominence in the United States, and has since become "an international discipline, with military sociologists around the world, including in western and eastern Europe, Latin and Central America, Australia, India, Japan, Russia, and Canada," (Ibid). Illuminating for this study are the ways in which military sociology has investigated gender relations in militaries (Carreiras, 1995, 1998).

Feminist military sociologist Gerhard Kümmel argues that "the military is a gendered institution, but also a gendering one. As such, the military is principally capable of constructing multiple femininities and masculinities," $(2002,630)$. Kümmel, along with other feminist military sociologists, has demonstrated that militaries across societies are organized in close relation to the socially constructed and idealized roles and practices of men (Sasson-Levy, 2003; Segal, 1983, 1999). Their work shows that 
idealized identities within militaries presuppose the centrality of particular masculinities (Carreiras, 1999; Woodward \& Winter, 2007; Kümmel, 2002; Maringira, 2017).

In the Canadian context, it is military sociologists who first suggested that barriers to women's integration within the Canadian Armed Forces were largely social. For example, Donna Winslow and Jason Dunn's (2002) analysis of the Canadian military revealed that the preponderance of regulative means to integrate women (such as opening up all occupations and roles to women through legal mechanisms and changing procedural doctrine) ${ }^{14}$ did not meaningfully shift the social and cultural barriers constructing military roles, work and identity as essentially masculine. Their work was one of the first to demonstrate how traditional gender roles and ideologies in the military presented social barriers for women's greater participation (Ibid). In these ways, military sociologists who have studied Canadian and other state militaries have offered significant contributions to the study of military professionals and gender relations.

While the contributions of military sociology to the field are significant, observed tendencies of its scholarship have revealed some limitation in investigations of gender. While many sociological theorists have argued that the military is constitutive and constituting of gender relations and orders (Kümmel, 2002; Woodward \& Winter, 2007; Sasson-Levy, 2003), the "central works on the sociology of gender usually omit analysis

\footnotetext{
${ }^{14}$ Using legal means such as the Employment Equity Act, the Canadian Charter of Human Rights and Freedoms and ultimately a Human Rights Tribunal decision which forced the military to allow women to enter into non-traditional roles, constructed over time as hard masculine occupations that had been prized as exclusively male occupations. Winslow, D. and Dunn, J. (2002). "Women in the Canadian Forces: Between Legal and Social Integration." Current Sociology 50(5): 641-67. For historical accounts of women's integration within the Canadian Armed Forces, see: Madsen, C. (1999). Another kind of justice: Canadian military law from confederation to Somalia. Vancouver: UBC Press,; Davis, K. (2007). Women and leadership in the Canadian Forces: Perspectives and experience. Winnipeg: Canadian Defence Academy Press.
} 
of gender in the military" (Segal, 2006, 563). This gap in analysis has been linked to a key tension: that is, a lack of dialogue and understanding between sociologists who study gender and those who are practitioners and scholars within militaries (Segal, 2006; Winslow, 2009).

Others have observed tendencies within military sociology to study women at the expense of studying gender relations. As Donna Winslow's mapping of the field suggests, "for the most part military sociology studies, whether the title has gender in it or not, have usually been about women and the military" $(2009,10)$ and not about gender. Winslow is not alone in this critique. As feminist international relations scholars Joyce Kaufman and Kristen Williams underscore, the tendency is to ask "where are the women" rather than "addressing and challenging gender inequality [which] requires attention to both men and women, to masculinities and femininities, and to the impact of gendered practices and hierarchies" on all people's lives (Kaufman and Williams, 2016, 183, 186-187). As will be discussed in the concluding sections of this chapter, this research project commits to the study of women, men, and gender diverse individuals as well as the study of the relational quality of masculinities and femininities as they are practiced, negotiated, and idealized among its research participants.

Beyond focus on where the women are, some have also criticized military sociology for reifying dominant stereotypes about sex difference. Essentialism contained within sociological research about gender and the military ${ }^{15}$ often tends to suppose that

\footnotetext{
15 These criticisms have also been aimed at scholars in other disciplines, such as International Relations theorists. See Duncanson, 2015. Essentialism and the equation of gender with the circumstances of women have also been identified in national doctrine which incorporates the Women, Peace and Security agenda. Some national doctrine have been noted to equate gender equity with the protection of women and children. For examples in Canadian doctrine, see Tiessen, 2015.
} 
gender is about helping and protecting women (Winslow, 2009) and can implicitly result in the practice of naturalizing women as hapless while positioning men as universally misogynist, domineering, and inclined towards violence (Duncanson, 2015). In this way, studies about gender in military sociology have often been investigations about the circumstances of women and the aggressions of men rather than the broader study of gendered and gendering social processes, systems, and structures of power.

Indeed, sociologist Mady Segal supposes that the limited number of studies about gender and militaries may relate to "anti-military views of many sociologists, especially feminists" and a "lack of knowledge of military organization" (Segal, 2006, 563). In this way, while feminist experts from the larger sociological discipline could presumably add depth and breadth to the examination of gender in militaries through their engagements with these organizations and their practitioners, they are often reluctant to do so. Yet, as will be expanded upon later in this chapter, there is a growing perspective that militaries are important sites for the meaningful transformation of gender inequality in societies (Duncanson, 2015). Contributing to this vision, the findings of this sociological research project are promising. As will be explained in the substantive chapters of this dissertation, the results of this research show that there is a transformative capacity for military leaders to learn about patriarchy and then become change agents of unfair gender orders, both within their institution and in diverse societies through their engagements in peace and security work.

An additional perspective of continued relevance is that gender has been and continues to be overlooked as worthy of study in social science disciplines, including sociology (Winslow, 2009; Runyan \& Marchand, 2011). In this way, scholarship and 
research in the social sciences, and sciences writ large, ${ }^{16}$ is not unscathed by the systems and processes of patriarchy (Sisson- Runyan \& Marchand, 2011; Taber, 2015). Rather, patriarchal relations and systems of power are deeply embedded and reproduced within academia. As such, this dissertation advances work being done within the discipline, and in social science generally, by studying the significance of gender in military learning and work.

\subsection{Gender, the Military, International Relations and Feminist Security Studies}

Alongside the work of military sociologists, feminist International Relations scholarship, often identified as Feminist Security Studies (Wibben, 2011, 591), has examined gender, power, and social stratification across institutions, systems, and structures at different levels of societal organization. In this way, significant contributions have come from Feminist Security Studies scholars' capacity for 'relational thinking.' Relational thinking aims to make visible the interconnectedness of inequality among three domains of social reality and to demonstrate the impact of these interconnected oppressions on subjects and subjectivity. ${ }^{17}$ The three domains of social reality they investigate from a gender perspective are: “the world 'out there' (practices, institutions, structures of social re/production); how we think (meaning systems, ideologies,

\footnotetext{
${ }^{16}$ For examples of the preponderance of patriarchy, sexism and masculinism in the natural sciences, see: Schiebinger, L. (1987). "Skeletons in the Closet: The First Illustrations of the Female Skeleton in Eighteenth Century Anatomy", in Sexuality and Society in the Nineteenth Century, Gallagher, C. \& Laqueur, T. eds. Berkley: University of California Press, pp. 25-57.; Fox Keller, E. \& Longino, H. (1996). Feminism and science. New York: Oxford University Press.; Shildrick, 1997; Harding, S. The Science Question in Feminism. Ithaca, NY: Cornell University Press, 1986.

${ }^{17}$ This is somewhat against the grain from conventional International Relations theory, as first, much International Relations scholarship avoids discussion about gender and gender perspectives, and second, much International Relations scholarship speaks in the abstract about "processes, structures, markets, and states" using the first domain, 'the world out there' as its primary site of inquiry. Runyan \& Marchand, 2011,12 .
} 
paradigms); and who we are (subjectivity, agency, self and collective identities)" (Peterson, 1997, 185).

Drawing from this relational framework, ground-breaking insights from the research of these scholars have come from the shift of their analyses beyond conventional International Relations approaches. Feminists within the discipline note the tendency toward macro and abstract thinking in conventional International Relations. Rather than pursuing more systems-related discussions about "structures, markets, and states", primacy is often given in the discipline to investigations of 'the world out there' in absence of relational investigations of social organization. In response, some have sought to ground their work in practice, primarily by attending to the relational workings of gender and militarization in these three domains, but with specific focus of their impact on 'subjects' and 'subjectivity,' (Runyan \& Marchand, 2011, 9).

With this aim, Feminist Security Studies has begun to underscore the ways in which "gender subordination [is] constitutive of the global political world" (Sjoberg, 2009, 205). This feminist lens, through which gender is considered "a particular kind of power relation" (Ibid, 187) that is "central to understanding international processes" (Ibid), was not understood as such in traditional International Relations studies. Feminists worked, despite resistance from within the discipline, to "characterize gender as 'necessary, conceptually, for understanding international relations; important in analyzing causes and predicting outcomes; and essential to thinking about solutions and promoting positive change" (Sjoberg, 2011, 111).

Drawing from diverse standpoints (Wibben, 2011, 591), feminists within International Relations recognized that much historical examination in the discipline was 
inadequate due to tendencies towards androcentrism and masculinist thinking (Sjoberg, 2009, 186). Examining the ways in which gender matters to international security, some have committed to feminism as a political project (Wibben, 2011, 591). This project ultimately seeks to facilitate the emancipation and empowerment of all individuals with the larger aim of social justice (Ibid). In this way, feminists both within and beyond the discipline have troubled traditional International Relations studies as these have often eclipsed women's and equity seeking groups' practices, presence, and influence in the gendering of world politics (Ibid, 187). Their work has served to question the discipline's conventional methods and theories, as these have also rendered gender relations and inequities invisible (Ibid, 186).

Due to the historical methodological and theoretical barriers posed to feminist work within International Relations, some have opted to present their work as contributions to Feminist Security Studies. Laura Sjoberg traces the subdiscipline's establishment to the 1988 special issue on "Women and International Relations" published by Millennium (Ibid). Since that time, Feminist Security Studies scholarship has consistently worked to demonstrate that "gender is conceptually, empirically, and normatively essential to studying international security" (Ibid, 186).

Indeed, Feminist Security Studies has grown significantly in credence, drawing some of its momentum from international developments, such as the growing resonance of the study and application of gender perspectives to political economy (Runyan \& Marchand, 2011) and to social science more broadly (Sjoberg, 2017). The growing acknowledgement of gender and its role in (in)security is also represented in the uptake of gender perspectives to inform the policies, practices and plans of the United Nations 
(North Atlantic Treaty Organization/Euro-Atlantic Partnership Council, 2016), the North Atlantic Treaty Organization (2012), and many of their partner and Member States (Von Hlatky, 2019). As referenced in the introductory chapter of this dissertation, adding to this forward momentum is the Women, Peace \& Security agenda (WPS). Civil society actors, academics and security practitioners pushing forward this agenda continue to demonstrate gender's relevance to peace and security and have made great strides at placing gender equality at the forefront of security concerns in their organizations and affiliations (Cockburn, 2011). These advancements have given much for feminists investigating international relations to examine and consider.

Feminist Security Studies has also advanced the study of hegemonic gender orders within militaries and armed groups. Drawing from men and masculinities studies, some have developed a suite of investigations on militarized gender. Notably, these focus on militarized masculinity.

\subsection{Gender Hegemony and Militarized Masculinities}

As anti-militarist feminist Cynthia Cockburn suggests, one of the resonating omissions within the WPS agenda is its tendency to omit: "an explicit critique of men, masculinity and patriarchy in relation to militarism, militarization and war (Cockburn, 2011, 8). In her view, gender equality becomes 'little more than an aspiration' without a meaningful focus on the co-construction of militarism and hegemonic militarized masculinity (Ibid). Similarly, gender scholar Carol Cohn's position is that feminist work must attend to the hegemonic 'gender regimes' that are deeply rooted not only in individual wars, but rather in the entirety of the war system (Cohn, 2008). 
Bridging these gaps and omissions, some feminist scholars have turned their attention to the study of men and masculinities in their investigation of the root causes of gender inequalities and conflict. Developed within 'the new men's studies' and within the 'new sociology of masculinity,' men and masculinities theory aims to explicitly name male privilege and to make 'patriarchal arrangements of power' visible (Cornwall et al, 2011, 2-4). Importantly, men and masculinities theory has served to interrogate patriarchal social arrangements by demonstrating how normalized and perceived as 'static' gender identities are in fact alterable social constructs. These studies demonstrate the contextuality and negotiation of gender hegemony and its capacity to change (Ibid).

Originating in the work of Raewyn Connell, the notion of hegemonic masculinity can be defined as a theory describing idealized masculinity within male-dominated cultures (Connell \& Messerschmidt, 2005). The theory is most attendant to studies of male and masculinist power that often goes unnamed and naturalized in societies. ${ }^{18}$ To this end the central tenets of the theory are that: (1) societies are organized into gender orders that "continue to make our world unfair and unequal"; (2) masculinity is relational to power, violence, crime, and privilege, each of which benefit certain men, and subordinate women, other men, youth, and gender diverse individuals; (3) masculinities are not innate but rather socially constructed; and (4) masculinities are stratified in hierarchal orders wherein dominant forms operate in ways that tend to secure the power of specific men (Cornwall et al, 2011, 2, 4).

\footnotetext{
${ }^{18}$ For examples see: Connell, R. (1987). Gender and Power: Society, the Person and Sexual Politics, Stanford, Stanford University Press.; Connell, R. (2005). Masculinities, Cambridge: Polity Press.; Connell \& Messerschmidt, 2005.
} 
Hegemonic masculinity has been used to explain gender hierarchies in structures, systems, organizations, and institutions within societies. ${ }^{19}$ Some have investigated how idealized forms of masculinity come to dominate military gender orders. ${ }^{20}$ They call these dominant forms of gender 'militarized masculinity.' Such scholars have argued that military gender constructions can be differentiated from those in other social contexts due to the processes and conditions under which ordinary people are 'made and molded into soldiers' (Whitworth, 2005; Masters, 2005; Ashe, 2012; Higate, 2007).

As Connell articulates, militaries have historically been the primary institutions for defining masculinity in European and American culture (Connell, 1995, 213). Adding to this argument, Duncanson poses that the ways in which masculinities and femininities are constructed within militaries shapes entire gender orders in societies, noting that the underlying idea that 'men take life while women give it' undergirds most theories of gender difference in patriarchal cultures (Duncanson, 2015). Duncanson suggests that if feminist scholars are to seriously engage in the transformation of inequitable gender

\footnotetext{
${ }^{19}$ For examples see: Connell, R. (2005). Change amongst the Gatekeepers: Men, Masculinities, and Gender Equality in the Global Arena, Signs: Journal of Women in Culture and Society 30: 1802-25.; Hearn, J. (2004). From Hegemonic Masculinity to the Hegemony of Men, Feminist Theory 5:49-72; Higate, P. (2003). Military Masculinities: Identity and the State, Westport: Praeger.; Hooper, C. (2001). Manly States: Masculinities, International Relations, and Gender Politics. New York: Columbia University Press.; Messerschmidt, J. (2010). Hegemonic Masculinities and Camouflaged Politics: Unmasking the Bush Dynasty and Its War Against Iraq. Boulder: Paradigm Publishers.

${ }^{20}$ For examples see: Higate, P. (2007). Peacekeepers, masculinities, and sexual exploitation, Men and Masculinities 10(1): 99-119.; Ashe, F. (2012). Gendering war and peace: Militarized masculinities in Northern Ireland. Men and Masculinities, 15(3): 230-248.; Baaz, E. \& Stern, M. (2009). "Why Do Soldiers Rape? Masculinity, Violence and Sexuality in the Armed Forces in the Congo." International Studies Quarterly, 53: 495-518.; Morgan, D. (1994). "Theatre of War: Combat, the Military, and Masculinities." In Theorising Masculinities, edited by Harry Brod and Michael Kaufman, 165-82. London, UK: Sage; Niva, S. (1998). 'Tough and Tender: New World Order, Masculinity and the Gulf War.' In The 'Man Question' in International Relations, edited by Zalewski, M. \& Parpart, J., pp. 109-28. Boulder, CO: Westview.; Razack, S. (2004). Dark Threats and White Knights: The Somalia Affair, Peacekeeping and the New Imperialism. Toronto, Canada: University of Toronto Press; Woodward \& Winter, 2007.
} 
orders in larger society, they must first work to interrogate and transform existing inequities in the hegemonic gender orders of militaries $(2015,232)$.

Militarized masculinity, as with any hegemonic type of gender, is theorized to be deeply relational to understandings of femininity (Schippers, 2007). In this way, socially constructed understandings of feminine qualities, and women more broadly, are often conceived in essentialist and stereotypical ways that are typically associated with lifegiving, pacifism, and the need for protection (Baaz \& Stern, 2009, 499). These qualities are usually understood as oppositional to notions of masculine qualities that are equally essentialist and stereotypic such as 'protecting, warring, and killing' (Ibid). Such stereotypes define 'appropriate' gender for military professionals, typically idealizing masculine qualities such as "toughness, violence, aggression, courage, control, and domination" (Eichler, 2014). In conforming to this gender order, members often police feminine behaviour and deny feminine experience (Reiffenstein, 2007).

Hegemonic militarized masculinity tends to construct gender orders around an exaggerated warrior identity, where each man, woman and gender diverse military professional comes to be measured against an often unrealistic and unachievable standard of maleness. Indeed, the most prized masculinities within militaries are often very difficult to embody and enact. This difficulty has been shown to be even more acute for women and gender diverse members (Ibid). Whitworth (2005) and Razack (2004) suggest that such idealizations are also embedded in gendered and colonial presumptions of race, ethnicity, and sexuality, where whiteness, Anglo heritage, heterosexism, and masculinity are mutually constitutive of hegemonic gender (Welland, 2013; Woodward \& Winter, 
2007). Such intersectional co-construction has been identified within Canadian and British militaries (Ibid).

Woodward and Winter note that within the hegemonic gender order of the British military in the early 2000s, women and femininities were often 'contained' in ways that subordinated them to men and masculinities (Woodward \& Winter, 2007, 39). In this context, overstatements of women's difference in physical and cognitive ability were "used to consolidate arguments hostile to women's military participation" (Ibid, 57). In this context, 'physical strength, willingness to follow orders and leadership abilities' were constructed as quintessential masculine qualities (Ibid, 57-58). Conversely, women were often viewed as liabilities, understood as too soft physically and emotionally to 'do the job to the required standards' (Ibid).

The construction of masculinities and femininities in this way can create hostile spaces for women, non-binary, and marginalized men in armed forces. Laura Miller, studying gender in the US Army, shows how men, 'despite their training', sometimes used sexual harassment as a covert means of "expressing their disapproval of women's military participation" (as referenced in Woodward \& Winter, 2007, 58). Whitworth (2004) and Razack's (2004) research of Canadian military personnel shows a similar tendency. Their work demonstrates how Canadian military men used sexual violence as a means to subordinate other, often racialized, men and boys (both military and civilian).

Moreover, while militarized gender was not acknowledged within, Marie Deschamps' review of sexual misconduct in the Canadian military describes an "underlying sexualized culture in the CAF that is hostile to women and LGTBQ members, and conducive to more serious incidents of sexual harassment and assault" 
(2015, executive summary). Such studies demonstrate that despite hegemonic gender's contingent nature, culturally dominant forms in militaries have tended to position women and femininities as lesser. Maintaining hegemonic masculinity and male supremacy through acts of sexual dominance (by men and women) may support the particularly pervasive prevalence of sexual misconduct and abuse noted in military organizations. ${ }^{21}$

The link between sexuality and race to constructions of militarized gender in the research referenced here indicates the intersection of multiple forms of power and oppression in the construction of idealized military identity. Indeed, many scholars who study militarized masculinity draw from the tenets of intersectionality theory. As gender scholar Charlotte Hooper notes, examining masculinity in isolation from other systems of power can "obscure rather than illuminate both structural inequalities and progressive changes" (as referenced in Duncanson, 2015, 239). Similarly, Duncanson suggests that an intersectional approach is "vital to ensure that change in gender relations is progressive and that any challenge to hegemonic masculinity is meaningful" (Duncanson, 2015, 239).

Intersectionality can be defined as a theory that examines the connecting and mutually constituting systems of inequality that come to be culturally constructed through overlapping social classifications such as race, gender, class, ability and sexuality (Crenshaw, 1991, 1244-1245). Originating as a critique of identity politics and White feminism in the United States, intersectionality highlights the oppressions that are

\footnotetext{
${ }^{21}$ See for examples: Park, You-me. (2016). The crucible of sexual violence: Militarized masculinities and the abjection of life in post-crisis, neoliberal South Korea. Feminist Studies, 42(1), 17-40.; Parpart, J. L. (2015). Militarized masculinities, heroes and gender inequality during and after the nationalist struggle in Zimbabwe. Norma, 10(3-4), 312-325.; Rosen L. \& Martin, L. (1997). 'Sexual harassment, cohesion and combat readiness in US Army support units', Armed Forces \& Society 24: 221-244.; Taber, N. (2017). The Canadian Armed Forces: battling between Operation HONOUR and Operation Hop on Her, Critical Military Studies; Welland, 2013.; Whitworth, 2004, 2005; Woodward \& Winter, 2007.
} 
produced through the social construction of categories of people. Politicization of the oppression of particular kinds of people, such as racialized or gendered kinds, tended to presume that those within a category such as 'women' or 'African American' were "generically or homogenously dominated or biased against in societies based on difference" (Ibid, 1242). Intersectionality troubles this presumed homogeneity by demonstrating that social hierarchies and social order also exist within broad categories such as 'women' and that these orders are based on multiple and intersecting factors. For example, different groups of women can experience oppressions within the category 'woman' based on their racialization, class, ability, sexuality, among other constructed categories.

Feminist and queer theorist Jasbir Puar poses that "race, class, gender, sexuality, nation, age, [and] religion" are often taken as "separable analytics and can thus be disassembled" (2007, 212). Instead, Puar suggests that intersectionality ought to be understood as an assemblage, or an "affective conglomeration that recognizes other contingencies of belonging" (Ibid, 211). As such, gender and other intersecting oppressions are mutually constitutive and thus cannot be theorized or fully understood separately.

As hegemonic masculinity and the theory of intersectionality each highlight, there are differential experiences of oppression within broad socially constructed categories. Ultimately, intersectionality highlights the emergence of inequality in the construction of gendered, racialized, classed, abled and sexualized kinds, among others. It is both a descriptive and prescriptive theory, as it first makes inequities visible by mapping the 
social processes that create them, and then works to challenge and change these inequitable social processes (Crenshaw, 1989, 1991).

Despite the many important insights of militarized masculinity, there have been cautions of its inappropriate and narrow usage. Some question the way studies of militarized masculinity have tended to present dominant forms of masculinity as static (Hearn, 2004), neither informed by nor relational to other forms of military gender (Demetriou, 2001; Schippers, 2007). Some argue that investigations of militarized masculinity tend to omit the gendered practices, participation and embodiments of women and their role in producing, negotiating, or challenging unequal gender orders (Brod, 1994; McCarry, 2010). Others still note the tendency to eclipse the relational role of femininities in producing, maintaining, and challenging inequitable gender orders (Schippers, 2007, 94-95).

Enhancing the study of militarized masculinity, gender theorist Maya Eichler asserts that the form and content of militarized masculinity relates to the particular contexts in which members find themselves (2014). Duncanson notes that thinkers such as Deleuze and Foucault have argued that while identities are relational, they are not required to be oppositional and hierarchical (2015). Indeed, Duncanson's analysis of the British Armed Forces and Anna Krylova's study of gender in the Soviet military each provide evidence of contextually specific constructed gender identities within militaries that were neither hegemonic nor necessarily oppositional (Ibid; Krylova, 2010). These cases demonstrate that inequitable gender hegemony is not a given, and that unequal hegemonic orders are subject to fail. This insight gives hope for the possibility of more equitable gender orders within militaries where "gender relations could be democratized 
through establishing 'a version of masculinities open to equality with women [and the feminine]'" (Connell, 2005, 853 as referenced in Parpart \& Partridge, 2014). In this way, a feminist post-modern approach to militarized masculinities and militarized gender is appropriate.

A feminist post-modern approach, also referenced in the methods chapter of this dissertation, would presume the co-existence of contextually specific, diverse and perhaps conflicting viewpoints, all of which influence the (de)construction, negotiation, maintenance of, and challenges to normalized and intersectional gender relations and the production of oppressive gender orders within militaries. Drawing from post-modern feminist insights, this doctoral project moves beyond what is typically highlighted by also tracing gender's intersection with culturally specific categories such as occupation, rank, and service. Drawing from the work of anthropologist Anne Irwin, such categories of organization are culturally specific to the military and not typically applicable across other organizational cultures (Irwin, 2009, 498-499). As the findings of this dissertation suggest, gender orders are produced differently in relation to military culture and subcultures found in unit-lines, occupations, and services. However, the dominant, or ideal gender order within the joint learning context at Canadian Forces College often subsumed these diverse gender ideals under the Army, warrior, combat operator form of militarized masculinity.

From these insights, this dissertation investigates not only the production of a hegemonic gender order across the whole of the military, but also seeks to identify and understand openings and fissures within the dominant order due to competing militarized masculinities and femininities, particularly those open to feminist attitudes, ambitions, 
and visions for transformational change. As the substantive chapters of this project demonstrate, illustrating the complexity and messiness of gender hegemony through the presentation of diverse gender and cultural perspectives in curriculum created important opportunities for feminist interventions in the classroom. These interventions helped to create space in which military students could openly consider gender orders in the military and society. These learning opportunities also helped military students to see themselves as agents of change in the pursuit of gender equality, diversity, and inclusion internationally, domestically, and within their organization.

Yet, as the concluding substantive chapter illustrates, some students observed being under-prepared to apply their gender and cultural learning to the full scope of their military work, implying that additional learning on the practical application of feminist and intersectional theory would have been useful. Others were able to use their learning about gender and cultural perspectives in myriad and innovative ways — ones that forward what I understand to be feminist transformations in practices and social arrangements both within and outside of the military. As will be elaborated in Chapter Five, some Joint Command and Staff Programme graduates reported promising localized applications of gender and cultural perspectives to military work. Their experiences demonstrate incremental processes through which they provided catalyst or supportive thinking and practices towards feminist socio-cultural transformations and change within and beyond the military.

This chapter has explored how and why this project's theoretical framework is founded upon theories of militarized gender, intersectionality, and post-modern feminism. Drawing from feminist understandings of gender and its relation to other 
systems of social organization and power, this thesis incorporates thinking about gender, militarism, and war more broadly, and considers the development of gender orders and social hierarchies in the Canadian military. This theoretical scaffolding influenced the investigation of gender hierarchy at Canadian Forces College and shaped this project's focus on the construction of militarized notions of gender, sex, ethnicity, race, occupation, rank, and service. Noted in the substantive chapters of this project, evidence gleaned from qualitative interviews and focus groups illuminates how these factors are mutually constitutive and shaping of a dominant social order which is (re)produced, policed, and sometimes challenged in the learning environment.

As this dissertation demonstrates, drawing from these theories enabled me to identify the construction of a complex social hierarchy at Canadian Forces College and allowed me to recognize the ways in which its members consistently (re)produced, negotiated, or challenged this dominant gendered social order. As will be presented, the intersection of gender, race, ethnicity, service, rank and occupation deeply influenced the ways in which military students and staff presented and received curricula on gender and cultural perspectives. In these ways, this project contributes to a broader understanding of the construction of gender hierarchy in the Canadian Armed Forces and armed forces more broadly, as it traces how gender stratification in the military is (re)constructed in the military's subcultures and (re)produced in the learning environment at Canadian Forces College.

As this research is grounded in the everyday localized practices of military members, this project works to push conventional studies on gender and militaries that speak to the level of states, institutions, policies and doctrine into a new and growing 
terrain. Advancing the contributions to the field made by Woodward and Duncanson (2017), Higate (2003, 2007), Razack (2004) and Whitworth (2005), this study seeks to establish how the social forces constituted at the level of states, institutions and their texts influence the everyday interactions and identities of military subjects and how military professionals (re)produce, negotiate, and challenge gender hegemonies within and outside of the military. Moving the study of militarized gender into new territory, this research also demonstrates how the local practices of military members can present an important site for feminist resistance to masculinist and patriarchal gender orders in militaries and societies as it traces the diffusion of military professionals' efforts to make redistributive transformational change. 


\section{Chapter 2: Methods}

\subsection{Determining the Best Methodological Approach for the Research}

This doctoral study works to explore and understand the lived experiences of military students as well as military and civilian staff within Canadian Forces College, a professional military learning environment through sociological inquiry. The pointed focus of the research is to investigate the integration of gender and cultural perspectives in the Professional Military Education (PME) of mid-level military leaders, as well as the reception, interpretation, and application of this learning by these professionals. The broader focus of this doctoral project is to identify and understand why the social processes and structures, which characterize the current context in which gender and cultural perspectives are being integrated at Canadian Forces College, are organized in the ways that they are, and to ascertain what functions these social processes and structures serve. Drawing from these two foci of inquiry, the research ultimately looks to discover if and how learning about gender and cultural perspectives facilitates feminist progress in the military and in society through informed military leadership.

Military students engaged in PME across the Canadian Armed Forces comprise military members of various ages and ranks, from officer cadets and new recruits to commissioned officers and non-commissioned members. As this study is interested in the intersection of learning, leadership and culture change, the emphasis of this research specifically attends to the learning experiences of the military's upcoming generation of senior leaders. In particular, this doctoral work explores the learning experiences of 
commissioned officers who are in the process of shifting into senior leadership roles across the Forces at the mid-senior professional level of the military chain of command. In the pursuit of investigating the professional education of military leaders, I applied exclusion criteria to the research that limited the scope of analysis to commissioned officers, specifically at the rank of major or lieutenant-colonel, possessing a minimum of 12 years employment in the Canadian military, who were selected to and enrolled in the Joint Command and Staff Programme at Canadian Forces College in the 2016-2017 to 2017-2018 academic years. Students of the Joint Command and Staff Programme belong to a subset of military ${ }^{22}$ professionals who are expected to reach the most senior levels of military leadership over the remainder of their careers. The professional military development that these individuals receive in the Joint Command and Staff Programme is at the higher (graduate) level of learning which is specifically aimed at preparing senior military officers for future "command and staff appointments in the contemporary operating environment across the continuum of operations in national and international settings" (Canada, Department of National Defence, 2017).

In addition to investigating the learning experiences of this group of military professionals, I recognized the requirement of this doctoral research to also explore the deep relationship that academic and military staff have in shaping and facilitating the learning of gender and cultural perspectives by military professionals enrolled in the Joint Command and Staff Programme. Thus, this project also studies the roles, perspectives and practices of civilian and military faculty and staff. Acknowledging that the experience of each member of this learning community, including students, faculty, and

\footnotetext{
${ }^{22}$ Though some civilian professionals have also enrolled, the focus of this study is on military leadership.
} 
staff, is mediated through their diverse positionalities, and upon reflection that their experiences are also shaped by structural, social, and cultural forces within the military and this educational institute, this research endeavours to provide empirical clarity about the following questions:

- If and in what ways might the learning environment at Canadian Forces College be gendered/gendering, and why and how might this impact the integration of gender and cultural perspectives as well as students’ experiences with learning about these?

- Why are the representational compositions ${ }^{23}$ of the College's staff and student bodies the way they are, and how might these influence the integration and reception of diverse gender and cultural perspectives in curriculum?

- Why are the Joint Command and Staff Programme and the learning environment structured in the ways that they are? What is the impact of these structures on social relations?

- And, if and how gender and cultural perspectives learned in the Joint Command and Staff Programme have influenced leaders' thinking and

\footnotetext{
${ }^{23}$ I use the term 'representational composition' to refer to the diversity of community membership. This diversity is inclusive of traditional understandings of the term such as diversity in identities outlined in the Canadian Employment Equity Act which highlights historical processes that have discriminated against and marginalized particular groups in the Canadian work force such as women, racialized peoples, Indigenous peoples including First Nations, Inuit and Metis populations, as well as persons with disabilities (S.C. 1995, c. 44). By using the term representational composition, I am consciously expanding this definition of diversity to include plurality in worldviews, values, norms, sexuality, gender, place of birth and upbringing, language, region, religion, education, political beliefs, socio-economic status, fitness, military socialization and identity related to service, occupation and rank. This term is used intentionally to encompass identities and positionalities beyond the four identities that traditionally comprise Canada's Employment Equity groups.
} 
practices? If so, have these shifts in thinking and practice led to feminist progress within the military, in domestic work, and in international engagements?

These research questions comprised the guiding investigative framework of this doctoral study and shaped the design of the research, the methodological choices I made in data collection, and the theories and frameworks I used to analyse the data.

The following sections of this chapter explain the project's research design in greater detail; describing the methods I employed to collect and create data with the study's participants; and highlighting the critical and feminist principles of data analysis that I found useful for unearthing shared themes and diverse views among participants about gender and cultural perspectives and their integration in curriculum, as well as the social relations and dynamics mediating the reception of these ideas within the learning environment. In addition, in the final sections of this chapter I attempt to situate my positionality, my politics, and my assumptions in relation to the research and show the work I engaged in to consciously and continuously employ an iterative, reflexive, and ethical data collection process.

\subsection{Research Design}

To learn about the context in which this project's guiding questions are located, this dissertation's research design began with information collection about the Joint Command and Staff Programme and a literature review of extant curriculum and curriculum design for the 2017-2018 academic year. A feminist critical discourse analysis of the literature was applied to investigate pedagogical frameworks, learning goals and 
outcomes, evaluation/assessment guides, syllabi, course materials and the methods through which course delivery was employed. This initial information collection and literature review phase was followed by the creation and collection of qualitative data which I derived from semi-structured interviews conducted for this dissertation in the form of focus groups and in-depth individual interviews with members of the Joint Command and Staff Programme student body and Canadian Forces College staff. ${ }^{24}$ Substantive chapters in this dissertation draw from the empirical qualitative data produced in six semi-structured focus groups and twenty-four in-depth interviews. Drawing from post-modern and intersectional feminist theoretical frameworks outlined in the preceding theoretical framework chapter, ${ }^{25}$ my analysis of the data collected in these interviews sought to draw out shared themes - or common narratives, observations and experiences - held among students and staff at Canadian Forces College. Analyses of data also aimed to illustrate the range of perspectives among participants that fell outside of those that were more commonly expressed.

An initial trial set of focus-group interviews (in support of the research in this dissertation) was conducted with students of the Joint Command and Staff Programme

\footnotetext{
${ }^{24}$ Similar qualitative strategies, such as the use and analysis of in-depth interviews, are recommended by military sociologist Deschaux-Beaume as optimal tools for the researcher who aspires to study the social practices of "defence agents" or military service persons and officials Deschaux-Beaume, D. (2012). "Investigating the Military Field: Qualitative Research Strategy and Interviewing in the Defence Networks." Current Sociology, 60(1): 101-117.

${ }^{25}$ Including hegemonic and militarized masculinities theories. For a description of masculinities theory and hegemonic masculinity see: Connell \& Messerschmidt, 2005; Schippers, 2007; For a description of militarized masculinities theory see: Whitworth, S. (2005). Militarized Masculinities and the Politics of Peacekeeping: The Canadian Case. In Ken Booth (ed.), Critical Security Studies in World Politics, Boulder: Lynne Rienner Publishers, p. 89-106.; Sjoberg, L. (2007). "Agency, Militarized Femininity and Enemy Others", International Feminist Journal of Politics, 9 (1): 82-101. Duncanson, C. \& Woodward, R. (2016). Regendering the military: Theorizing women's military participation. Security Dialogue 47 (1): 321.; Duriesmith, D. (2017). Masculinity and New War: Gendered Dynamics of Contemporary Conflict, Routledge, New York. Chapter 3 "Making Men, Making War", pp. 24-41.
} 
enrolled in the 2016-2017 academic year. ${ }^{26}$ The project's research questions were applied to these pilot focus group interviews, but to a more limited selection criteria that narrowed the breadth of participants to only residential students enrolled in the Institutional Policy Studies stream held in the third rotation of the academic year. ${ }^{27}$ These focus groups qualify as previous research, providing additional context and important reference points that are referred to as supporting literature. Findings from the pilot interviews are used to amplify and further validate this project's primary data.

The author was authorized by College leadership to conduct the trial focus groups and produce a corresponding report. Reviewing the content of this initial report, the author was subsequently commissioned to conduct a larger study on the integration of gender and cultural perspectives in the Joint Command and Staff Programme and the learning environment at Canadian Forces College. This commissioned research allowed me to collect this project's primary data and was agreed upon with the mutual

\footnotetext{
${ }^{26}$ The pilot focus-groups were authorized by Canadian Forces College and were conducted by the author as part of her role as a sessional instructor and contracted member of the academic faculty. These trial focusgroups are not formally included in this project, as they were conducted as ongoing curriculum validation of new content in the Institutional Policy Studies stream. However, the themes which emerged in these focus-groups were identified, amplified and confirmed in this doctoral project.

${ }^{27}$ These initial pilot selection criteria were made because the Institutional Policy Studies stream contained the greatest integration of gender and cultural perspectives in the final semester (rotation 3) as compared to the Advanced Joint Warfare Studies stream or the Defence \& Security Studies stream. Rotation 3 is also the semester with the greatest flexibility to integrate gender and cultural perspectives as the content and methods of teaching are more often at the discretion of the College's academic faculty, rather than the discretion of both military and academic faculty. In this third rotation, curriculum and content are encouraged to be as current and topical as possible, and as a result, academics collaborate with military curriculum development officers and military faculty to help them trial, develop and deliver curriculum that may eventually be integrated across the whole of the Joint Command and Staff Programme. As the observations of students and staff in this research project suggest, however, the integration of gender and cultural perspectives in the Joint Command and Staff Programme remains at a nascent stage, with few, and select, academic and military faculty working to include content at different points within and throughout the programme. Myself, and my colleague Dr. Alan Okros, with the support of Dr. Eric Ouellet and Dr. Craig Stone, have worked diligently to integrate gender and cultural perspectives, as well as content on diversity, within the Institutional Policy Studies stream curricula. Some of this content is currently being woven into curriculum throughout the Joint Command and Staff Programme, accompanying curriculum and content that have increasingly educated on these perspectives over that past five years.
} 
understanding between the author and the College that the author would own the rights to all data created in focus groups and in-depth interviews for the study. A formal contractual agreement was made between the author and the College that the data created and referenced in the commissioned report would also be used for the author's doctoral project, and may be used in conference presentations, publications and in future work by the author.

These pilot interviews served as empirical data for the 2017 report I authored (Brown, 2017), and served to assist leadership of the Canadian Forces College in understanding students' experiences with the integration of gender and cultural perspectives in this limited section of the Joint Command and Staff Programme, as well as the ways in which students' experiences with this learning was mediated through the learning environment at Canadian Forces College. The results of this initial report shed light on the reception of existing, but limited, gender and cultural perspectives in Joint Command and Staff Programme curriculum by students. In addition, and importantly, the report made visible the sorts of inequitable gender dynamics (re)produced at the College and revealed implicit and explicit gender biases within extant curriculum as well as within the learning environment (Ibid). Participants within the trial focus groups who reported experiencing aspects of learning and the learning environment as unequal or inequitable demonstrated, in various ways, how current institutional and educational practices may position some students at an unfair advantage academically and professionally. 
The two pilot groups were consciously gender segregated, comprising $(n=10)$ women and $(n=10)$ men respectively. ${ }^{28}$ Gleaning from the tenets of masculinities theory, gender segregated groups were formed purposefully to capture and explore the range of gendered practices and identities among same gender groups as well as those which developed and occurred between them. The trial focus groups set a baseline for common themes discussed among participants, shared behavioural patterns and norms, shared perceptions and experiences within the learning environment and with the integration of gender and cultural perspectives in the Programme's formal curriculum.

The pilot groups also relate to the findings of this dissertation as they demonstrated a range of perspectives which fell outside of those more commonly shared and experienced. As such, this trial research validated insights from masculinities theory, specifically, that while participants identified with and expressed a range of militarized masculinities (and to a lesser degree, militarized femininities), there was acknowledgement among participants of a privileged and idealized, or hegemonic, form of militarized masculinity within Canadian Forces College and the larger Canadian Armed Forces' culture (Connell \& Messerschmidt, 2005; Messerschmidt, 2010; Schippers, 2007). This hegemonic militarized masculinity was most commonly viewed among participants as 'alpha,' ‘aggressive,' ‘operational,' and 'assertive', while also implicitly tied to 'masculine,' 'white,' 'English speaking,' 'straight' and 'old school' members (who were typically men). ${ }^{29}$ Results from the pilot interviews validate the

\footnotetext{
${ }^{28}$ While groups were sex segregated along a binary distinction, this dissertation acknowledges and supports the spectrum of sex. Calls to participate were open to volunteers of all sexes and gender identities. ${ }^{29}$ Though, many women student participants also embodied these specific and idealized masculine practices.
} 
primary data collected in this doctoral study, demonstrating that while the student body had changed due to the change of academic year, hegemonic norms, ways of thought, and social hierarchy were similarly reproduced in and through social relations within the military learning environment.

Additionally, emergent themes drawn from these trial groups included: the 'ad hoc' application of gender and cultural perspectives throughout the curriculum; 'masculinist' or 'male biased' readings; and poorly trained and educated faculty charged with delivering gender and cultural perspectives in course lectures, discussions and seminars (Brown, 2017). Each of these themes suggested that further research may be required which also considered the effects that the work and practices of military faculty, academic faculty and support staff had on the integration of these perspectives within curriculum in the first place, as well as the relative influence that each group had on students' learning and reception of gender and cultural perspectives throughout the Programme.

Building upon the results of the trial focus groups, this doctoral project extends the breadth and depth of the pilot research by conducting a broader and robust series of focus groups and in-depth interviews with students and staff members. To do so, focus group interviews for this dissertation were conducted with student volunteers enrolled in the residential Joint Command and Staff Programme of the 2017-2018 academic year $(n=10 \times 2) \cdot{ }^{30}$ Drawing from the success of the pilot groups, these focus groups were also conscientiously gender-segregated.

\footnotetext{
${ }^{30}$ The previous exclusion criteria applied to the pilot focus groups of enrolment to the Institutional Policy Studies stream within the Joint Command and Staff Programme was removed for the larger dissertation project.
} 
Following these focus groups with members of the student body, additional focus group interviews were conducted with volunteers from the College's military faculty $(\mathrm{n}=8)$, Curriculum and Training Development Officers $(\mathrm{n}=7)$, Information Resource Centre personnel $(n=6)$, and academic faculty $(n=4)$. Supporting these focus group interviews, in-depth individual follow-up interviews were conducted with military faculty $(n=3)$, academic faculty $(n=2)$ and Information Resource Staff $(n=2)$ either at my request or at the request of participants. ${ }^{31}$ Following these focus group sessions, follow-up interviews with students $(n=8)$ were arranged and conducted in two separate intervals.

The first set of follow-up interviews ( $\mathrm{n}=8)$ was conducted to evaluate and understand individual assessments of the learning of gender and cultural perspectives in the Joint Command and Staff Programme that were similar to and different from those ideas expressed within the group setting. These in-depth interviews helped to verify as well as amplify the ideas shared in the focus group setting as well as to ascertain if there were additional observations or experiences within the College's learning environment that participants were reluctant to share with their peers in focus groups. The second set of follow-up interviews $(n=8)$ investigated if and how learning about gender and cultural perspectives in the Joint Command and Staff Programme influenced the leadership

\footnotetext{
${ }^{31}$ The letter ' $n$ ' signifies the number of individual participants. In-depth interviews at the request of staff and faculty took place if participants could not attend the focus group, or if participants wanted to elaborate on themes and observations in the focus-group they attended. Each focus group and individual interview was an hour duration and took place in a safe and mutually convenient location, either on site in the learning environment or over the phone. Focus-groups and interviews were audio recorded with the express permission of each volunteer. Conduct of interviews and data collection were granted approval by Carleton University Ethics Review Board, which follows national standards for the conduct of research involving human subjects outlined by the Tri-Council Policy Statement. The full Tri-Council Policy Statement can be found at http://www.pre.ethics.gc.ca/pdf/eng/tcps2-2014/TCPS 2 FINAL Web.pdf. Canadian Institutes of Health Research, Natural Sciences and Engineering Research Council of Canada, and Social Sciences and Humanities Research Council of Canada, Tri-Council Policy Statement: Ethical Conduct for Research Involving Humans, December 2014.
} 
behaviours and practices of the Programme's graduates, whether this learning influenced the culture change in the units and among the staff that these leaders command and assessed what learning might still be required for these leaders to support transformative cultural change in the military and beyond.

To enable participants to share experiences, observations and perceptions pertinent to this project's research questions, focus groups and in-depth interviews followed the problem centered interview (PCI) method. ${ }^{32}$ This approach aided in ascertaining answers to this dissertation's research questions by focusing specifically on them initially, but ultimately shifting the dialogue over to the participants, enabling them to ask their own questions, create their own dialogue, and allowing the researcher to interject in this dialogue to clarify or focus on aspects of participants' observations that were of relevance to the questions guiding the research. Consequently, this semistructured approach facilitated a negotiated and collaborative narrative among participants and the researcher, garnering a more grounded ${ }^{33}$ and accurate sense of the

\footnotetext{
32 The PCI is a qualitative interviewing strategy that combines the narrative, or story telling, technique of inquiry with a topical mode of investigation. PCIs begin with an unstructured approach, with little intervention from the interviewer, and are followed by a semi-structured component of the interview "that allows for a focus set by the researcher". Scheibelhofer, E. (2008). International Journal of Social Research Methodology, 11(5): 403-416.

${ }^{33}$ This method draws from elements of both a grounded methodological approach and a post-modern feminist qualitative approach. It borrows from post-modern feminist qualitative methods as its research design employs a principled rejection of positivism in favour of constructivist and post-modern ideas that truth is subjective, not objective, relational to individuals' standpoints, social positions, and their unique and shared experiences at Canadian Forces College. For an elaboration on the mutual influence of grounded methodology and post-modern feminist qualitative research see: Olesen, V. (2007). Feminist qualitative research and grounded theory: complexities, criticisms, and opportunities. In A. Bryant \& K. Charmaz The SAGE Handbook of Grounded Theory, SAGE Publications Ltd, pp. 417-435.
} 
diversity of thought and shared perspectives (or truth claims) each held about gender, culture, and learning. ${ }^{34}$

The author submitted findings of the research in a formal report to the Canadian Forces College leadership in 2018. However, the report was originally commissioned by a different cadre of military leadership in 2017. The shift in leadership would present a challenge to the initial dissemination of the research. While the military leadership responsible for commissioning the research desired to learn more about the experiences of the student body and to better understand the reception of gender and cultural perspectives being incrementally incorporated into the Joint Command and Staff Programme curriculum, the leadership that would follow in 2018 had less receptive views.

Due to two year posting cycles within the officer cadre of the military, the final report was submitted to an entirely new set of military leaders with different priorities and expectations. Additionally, as the commissioned report provided information that revealed inequities experienced by students and staff in the learning environment. It is not surprising, then, that leadership at the time was less willing to explore and address the more concerning findings presented. In essence, my commissioned report handed the problems emergent during the tenure of the previous administration to the new administration to resolve. Rather than tackle the findings of the report head on, the response was to keep the report close hold for over a year.

\footnotetext{
${ }^{34}$ The PCI approach is also useful as it allows the interviewer to ask focused and structured questions after the more open-ended component of the interview to seek out answers to questions that may not have been addressed in the initial narrative (Scheibelhofer, 2008, 403).
} 
As the 2018 report presented aspects pertinent to the work environment as well as the learning environment, the Canadian Military Colleges Faculty Association (CMCFA) (the union representing academic faculty at Canadian Forces College) filed for access to information to obtain a copy. The report was then released to CMCFA out of obligation to fulfill the mandate of the Canadian Access to Information Act. In 2020, military leadership at Canadian Forces College changed once again. Upon being given a copy of the 2018 report by the College's Director of Academics, this new group of leaders immediately signaled intent to action its key recommendations. In addition, this contingent of leaders released the report publicly on the Canadian Armed Forces Virtual Library and shared the report broadly via email and SharePoint across Canadian Military Colleges and the Canadian Defence Academy, citing the report as an important guidance document and resource for future research. The report has now been distributed far beyond Canadian Military Colleges and has been used to inform professional development across the Canadian Armed Forces, particularly in reference to addressing sexual misconduct and charting paths forward for organizationally desired culture change.

\subsection{Data Collection Methods}

I prioritized the collection of qualitative data in order to answer this doctoral study's experiential research questions. Specifically, the components of my data collection included an initial "information collection and literature review" as well as 
data collected in semi-structured focus groups and one-on-one in-depth interviews. ${ }^{35}$ The first component of this methodological approach, information collection and literature review, was comprised of the active collection and analysis of literature regarding militarized gender, military culture, and teaching/learning about gender and culture in PME. I then collected and reviewed literature used to conduct the Joint Command and Staff Programme, including curricula, learning objectives, syllabi and assessment guides. This literature was analysed using an intersectional and post-modern feminist approach to Critical Discourse Analysis (CDA). This method of analysis will be explained in greater detail in the following sections of this chapter.

The second facet of data collection focused on what and how students learned about gender and cultural perspectives in the Joint Command and Staff Programme, how and in what ways they experienced the learning environment at Canadian Forces College, as well as if and how they applied their gender and cultural learning in their leadership decisions and practices after they graduated. Student volunteers $(\mathrm{n}=20)$ from the Joint Command and Staff Programme each took part in one focus group of an hour duration. Eight of these participants also took part in one in-depth interview of an hour duration.

In addition, eight students also took part in a final follow up one-on-one interview of an hour duration after they completed the Joint Command and Staff Programme and had taken on leadership or command roles for at least three months. This follow-up method enabled students to observe the integration of cultural and gender perspectives in

\footnotetext{
${ }^{35}$ Similar qualitative strategies are recommended by military sociologist Deschaux-Beaume as optimal tools for the researcher who aspires to study the social practices of "defence agents" or military service persons and officials (Deschaux-Beaume, 2012, 107).
} 
curriculum, learn from them, and then reflect on if and how this learning impacted their decisions and practices as leaders of the Canadian Armed Forces.

Focus groups and individual in-depth interviews were also conducted with academic faculty, military faculty, and support staff. In-depth interviews were conducted with members of these sub-groups for various reasons, including a desire by volunteers to share observations and experiences outside of the focus group setting (anonymously), a desire by volunteers to participate, but due to conflicts in focus-group schedules individual interviews were requested, and/or a desire to expand upon ideas shared in the focus group setting.

\section{Focus Groups}

I drew from the work of Said Haddad, a political scientist and sociologist who conducts qualitative research with military practitioners, to help me define the character of a 'focus-group.' Gleaning from the work of Haddad, I considered the focus-group to comprise: "a group of individuals selected and assembled by researchers to discuss and comment on, from personal experience, the topic that is the subject of the research" $(2013,150)$. Interestingly, and useful to this study, Haddad asserts that with any social science research using focus groups, there is typically the presence of a (false) 'dilemma.' He notes in reflection of work with a research team interviewing military subjects that: The classical dilemma of the focus group technique concerns its purposes: is it used to obtain data produced during the interview or to observe the group and to study the interactions within it? In other words are these two aims (obtaining data and studying group interactions) not compatible with one 
another? In our opinion, it seems artificial to separate the collecting of data during the interview and the observation of the interactions (Ibid). Indeed, in my experience, it would be difficult, and undesirable, to separate the data created in the focus group and the study of the social relations within it.

As such, focus groups were used in this project for the express intent of cultivating and capturing the practice of discussion (Morgan, 1996) a method of great advantage in illustrating social processes and collective attitudes. ${ }^{36}$ The focus group approach to interviews specifically cultivated 'interactive discussions' (Morgan, 1996, 130) which were of great advantage to me in ascertaining social processes and collective attitudes in relation to gendered/gendering social structures, as well as learning about gender and cultural perspectives in the Joint Command and Staff Programme. I chose to use focus groups with military students, military and academic faculty and military/civilian support staff in order to draw out common narratives and repeated ideas that arose among members of each social group (Ginach, 2004, 1). However, I also chose to use the focus group method to observe participants' interactions with one another as a group.

Attention to shared narratives and repeated ideas offered me a sense of the sorts of collective constructions and assumptions made about gender and culture that were commonplace in the learning environment. This gave me a great deal of perspective about what is and might be said about diverse gender and cultural perspectives in everyday discourse at the College. Yet, the focus group setting was also useful as it

\footnotetext{
${ }^{36}$ For an example of this methodology see: Ginach, M. (2004). "War Against or for Terrorism? The Underlying Fantasy Behind the Israeli Pattern of Encounter with the Palestinians" The Discourse of Sociological Practice, 6(1): 1-12.
} 
helped to reveal competing ideas and silences (what was not said, or how silence was used as a strategy of resistance) (Parpart, 2010; Parpart \& Parashar, 2019) about common narratives concerning gender and culture. In essence, this approach to data collection allowed me to identify outliers to dominant assumptions and different practices of resistance to dominant ideas. In this way, the focus group method enabled me to recognize and probe a range of thoughts and practices to do with gender and cultural perspectives $^{37}$ and to discover multiple gendered identities and embodiments that were employed $^{38}$ among participants in the process.

As with any qualitative approach that utilizes interviews, there were setbacks to the focus-group data collection method. These included small disagreements between respondents due to differences in opinion, moments of tension due to speaking about some uncomfortable topics related to gender and culture, and differences in the degree of feelings of ease with participating in a focus-group setting. As Sheibelhofer suggests, problems specific to such an approach may be encountered if interviewees are generally uncomfortable with sharing their experiences (Scheibelhofer, 2008, 410). These problems may be compounded if respondents feel as though they are being judged by their peers.

Other weaknesses in the focus group method of interview included scheduling difficulties (particularly with academic faculty), and less detailed narratives from individual respondents. ${ }^{39}$ This problem was discussed by participants in the academic

\footnotetext{
${ }^{37}$ Drawing from post-modern feminist thought.

${ }^{38}$ Drawing from masculinities theory, hegemonic masculinity and militarized masculinities.

${ }^{39}$ Using a combination of in-depth individual interviews in support of focus groups overcame the setback of having less detailed responses from all participants in focus groups. In addition, individual interviews gave another avenue for some participants' to share ideas that they were reluctant to put forward in the group setting.
} 
focus group as possible resistance by academic faculty to the integration of gender and cultural perspectives in their curricula and teaching practices. The focus group session with academic faculty was rescheduled three times, and only four of the possible 12 fulltime academic faculty members were able to attend. In some cases, academic faculty and military faculty who were not able to attend followed up with me to schedule one-on-one in-depth interviews in place of their participation in focus group sessions.

Having gleaned considerable foresight about these issues with the focus-group method from the experiences of other social science researchers, ${ }^{40}$ I supported the focus group method with in-depth interviews to collect more fulsome and robust data. The indepth interview method helped to alleviate some of the stresses noted here that are associated with the focus group setting and provided essential work-arounds for more practical problems associated with the focus-group method such as scheduling and anonymity.

I think it is also appropriate to note that while there were some uncomfortable moments in some focus-group settings (in particular within the student and military faculty groups), a common theme emerged about the experience of the focus group itself - that sharing opinions in the group was 'therapeutic', 'relieving' and 'fun.' While some participants may have been reluctant to voice otherwise, this sentiment was repeated in the in-depth interview phase and also in informal interactions with me in my daily work at the College. In this way, participants shared their perspectives about the act of

\footnotetext{
${ }^{40}$ For a range of experiences and uses see the multi-author volume: Castro, C. (2013). Qualitative Methods in Military Studies : Research Experiences and Challenges. London: Routledge.
} 
participating in social science research, and often expressed how valuable it was for them to experience 'being heard.'

\subsubsection{In-Depth Interviews}

In-depth interviews have been noted as particularly useful for intersectional, feminist and post-modern social science research (Cuadraz \& Uttal, 1999; Fontana \& Borer, 2012). The in-depth interview method, rather than the structured interview method, is defined by its semi-structured composition, where interviews contain "greater flexibility for phrasing and rephrasing interview questions" as well as space for interviewees to pose "follow-up questions or probes, to elaborate on answers" (Marvasti \& Freie, 2017, 629). Importantly "the in-depth interview is more likely to search for 'inner truths' using only a handful of respondents who share their elaborate stories, accounts, or life histories with the researcher" (Ibid).

In preparing for data collection in this project, I had expected that some volunteers would desire to share ideas with me in an independent interview that they would perhaps otherwise not share with their peers in the focus group setting. In creating the research design for this study, I also wanted a space for participants to share how they felt, or how they each perceived the experience they had, while participating in the focus group. The adoption of the in-depth interview method in support of the focus-group method was consciously done to encourage such self-reflection about inner truth, reflection of what was said, left-unsaid, experienced, and to create opportunities for participants to share ideas that they were reluctant to divulge in the focus-group setting. The in-depth interview method was also used to validate and cross-check themes and 
narratives that emerged in the focus-group, as well as to give participants more opportunities to express their divergent, or diverse perspectives.

\subsection{Data Analysis Methods}

My analysis of the literature and the data derived in focus groups and in-depth interviews used a post-modern and intersectional feminist approach to CDA (Dijk, 1993; Bloomaert \& Bulcaen, 2000). CDA is an interpretive strategy which has been applied by social scientists from diverse disciplines to understand social processes and practices that are enacted among members of a group (Roger, 2011). Specifically, this project closely followed the three-step framework of CDA developed by sociolinguist Norman Fairclough to provide an in-depth and multidimensional discourse analysis of the data collected (Fairclough, 1995).

The first step in this framework is the analysis of discourse as text (Bloomaert \& Bulcaen, 2000, 448) wherein I documented the concerted choices of words used by participants, and the structure of speech or 'turn-taking' they used during focus groups (Ibid). The second step of the framework is "discourse-as-discursive-practice, i.e. discourse as something that is produced, circulated, distributed, [and] consumed in society" (Bloomaert and Bulcaen, 2000, 448). Applying this step, I noted the common narratives and phrases that were repeated by participants to determine the extent to which social practices that produce gender inequality and equality were proliferated through language (and body language) in discussion. Applying the third step, 'discourse-associal-practice,' (Ibid, 449) I traced what hegemonic processes were represented in alliances, discords, body language and silences within focus groups. 
Using a post-modern and intersectional feminist approach to CDA, I was also able to trace notions of power and meaning associated with the learning of gender and cultural perspectives in curriculum from common narratives and world views that emerged among all participants. I used CDA to identify and explore participants' ideas about what gender and cultural perspectives were and how they were taught in the Programme. Doing so was central to the contributions of this thesis to the field of gender and the military, as this allowed me to uncover narratives about how (gender and cultural) power was perceived, and how this power was observed to be distributed in the localized practices and relations among military students and College staff.

Investigating participants' determinations of what gender and cultural perspectives are, what gendered qualities they recognize and embody in military culture, and what gender and cultural practices ought to be present within the military learning environment, also enabled me to capture how experiences of teaching and learning about gender and cultural perspectives had been shaped through already gendered/gendering social practices, discourses and symbols that were observed to be (re)produced by successive student bodies, faculty and staff over time at Canadian Forces College. In many ways, then, this analytical approach to data interpretation enabled me to identify and understand how the inclusion of gender and cultural perspectives in curriculum made visible, and indeed often disrupted, some of the more traditional, dominant, and takenfor-granted normative, cognitive and regulative ${ }^{41}$ ways through which gender and cultural

\footnotetext{
${ }^{41}$ Richard Scott's model of institutional analysis suggests that institutions apply normative, cognitive and regulative means (or social systems) to function, and therefore, any desired/undesired organizational change requires shifts and alignment in all three domains. For details about this model and its applications to institutional change see: Scott, R. (1995). Institutions and Organizations. Thousand Oaks, CA, SAGE.;
} 
inequities were perceived to have emerged in the learning environment by many participants. As a result, applying CDA was a particularly helpful analytical strategy for this research as it helped me to uncover 'dominance relations' in groups that are 'reproduced by text and talk' (Dijk, 1993, 249). Additionally, CDA allowed me to illuminate how social power and inequality were produced, resisted or rejected by particular sub-groups of students, faculty and staff at Canadian Forces College (Ibid, 250). ${ }^{42}$

Guided by an intersectional and post-modern feminist theoretical framework, I applied CDA as a method to recognize and explore how the language choices and discursive practices of research participants illustrated their multiple and complex subjectivities and positions in the learning environment. Moreover, this feminist informed CDA enabled me to trace how participants' unique subject positions mediated their understanding and perception of gender and cultural perspectives in the learning/teaching and facilitation of curriculum. I adjusted the CDA method to fit the needs of this research project by applying a post-modern-intersectional-feminist interpretation of discourse as I sought not only to uncover how gender and cultural perspectives were understood and negotiated by participants, but also how participants' narratives of their understanding were both descriptive and constitutive (Gavey, 2011, 187).

For example, I used this post-modern and intersectional form of CDA to demonstrate the ways in which narratives of participants in focus groups and in-depth

Palthe, J. (2014). Regulative, Normative and Cognitive Elements of Organizations: Implications for Managing Change. Management and Organizational Studies, 1(2): p. 59.

${ }^{42}$ For applications of CDA in feminist studies of Canadian policy (and military policy and practices) see: Tiessen, 2015; Taber, 2015. 
interviews presented descriptive explanations of their 'real' and 'true' experiences with the integration of gender and cultural perspectives in curriculum at Canadian Forces College. Drawing from a post-modern-feminist theoretical standpoint, I used CDA to illustrate the diversity of 'true' and 'authentic' experiences. In particular, I traced themes that showed how students' reception of the learning was not universal, but dependent on their layered identities (such as sex, gender, ethnicity, first language, and sexuality), as well as their diverse beliefs, norms and worldviews (learned through regional, educational, class, religious, familial and social locations and practices).

In addition, I applied this approach to help illustrate how narratives about gender and cultural perspectives were also constitutive. To do so, I sought to unearth constitutive processes by first seeking out participants' narratives of personal and professional gender and cultural perspectives. ${ }^{43}$ This was done by identifying participants' use of specific words, symbols, and gestures as expressions of personal identity (who they are). In addition, I searched for participants' relations to professional gendered and cultural perspectives in their reflection of institutional forces (how they came to be who they are within the Canadian Armed Forces and Canadian Forces College). This line of inquiry draws from Whitworth's (2004) understanding that civilians are made and molded into soldiers through deeply gendered socialization processes such as training, rituals and, in this case, education.

Drawing from militarized masculinities theory, I scanned student participants’ narratives for any reflection of their socialization to a military identity, and importantly,

\footnotetext{
${ }^{43}$ For some participants, personal and professional gender and cultural perspectives aligned, while for others they were more messy, or they did not align.
} 
whether they experienced shifts in identity and behaviour in order to 'become' soldiers, sailors, aviators, military professionals and leaders ${ }^{44}$ during the Joint Command and Staff Programme. I also investigated whether participants perceived dominant gender and cultural perspectives at the College, and from there, whether or not they identified with or rejected these in their speech, narratives, and practices. Through these means, I used a post-modern-intersectional-feminist approach to CDA in order to uncover both descriptive and constitutive narratives, including how and if learning about gender and cultural perspectives shaped new possibilities for the ways in which students and staff members actively constructed their identities as military professionals, learners, educators and leaders.

Finally, I drew significantly from Nicola Gavey's formulation of a feminist poststructuralist informed CDA in that this research is "interested in discourse only insofar as it is a way of understanding the cultural conditions of possibility for being in the world" (Ibid). In other words, I did not want my interpretive approach to the research to be limited to an analysis of speech and text alone. My research questions are about how gender and cultural perspectives are being integrated in the Joint Command and Staff Programme at Canadian Forces College and if and how the learning of these have led to culture change in the military. As such, my analysis explored how military professionals' experiences with teaching and learning about gender and cultural perspectives were mediated through the military institution's already culturally specific and gendered structures, norms, symbols, policies, processes, and practices. In this way, my questions

\footnotetext{
${ }^{44}$ Drawing specifically from: Razack, 2004; Whitworth, 2004; Parpart \& Partridge 2014; Schippers, 2007 ; and Taber, 2015.
} 
required thinking about why these structures developed in social practice, and as Butler notes, how they are 'performed' in the processes of 'doing' teaching or 'doing' learning at Canadian Forces College (Butler, 1990). These performances are indeed discursive, but they are also represented symbolically and through social relations beyond text and talk.

\subsection{Assumptions, Forces and Procedures Influencing the Research}

\subsubsection{Assumptions}

Drawing from work done by scholars such as Whitworth (2004), Razack (2004), Davis et al (2007), and experts such as Deschamps (2015), I understood and presumed that gender inequality was a social fact for the Canadian military in complex, contradictory, implicit and sometimes explicit forms. My doctoral project contributes to this body of knowledge and validates the presence of gender and cultural inequities at Canadian Forces College through the observations and experiences of military and civilian participants. Indeed, I have personally experienced and observed myriad ways in which people (military and civilian) grapple with and negotiate gender inequality and inequity at the College, specifically in pursuit of teaching and learning about gender and cultural perspectives in the Joint Command and Staff Programme.

My experience as a senior sessional instructor at Canadian Forces College and my work at the College to better integrate gender and cultural perspectives within Joint Command and Staff Programme curriculum have made me cognizant of the many gender related disparities in power that exist at the College and the ways in which specific 
gender scripts have been utilized as social capital among students and staff. ${ }^{45}$ Keeping with ethical considerations of this dissertation, I have insider knowledge about the learning environment that is not used in this project, but informed my research questions. Throughout the research process, I was also given information that participants requested not be reported formally or captured in my data. These experiences provided context to the exploratory areas considered in this dissertation but are not directly referenced. In my experience as an educator, I have also observed that extant curricula and the learning environment at Canadian Forces College implicitly, and sometimes explicitly, idealize certain gendered qualities of leadership, professionalism, and soldierly identities. ${ }^{46}$ This personal experience and narratives shared with me for the purpose of my own understanding were advantageous to knowing what lines of inquiry were important to follow in-depth.

As the findings in the substantive chapters of this research suggest, culturally ascendant qualities of leader, professional and soldier, typically associated with 'macho' and 'bravado' forms of masculinities, tend to institutionally favour a narrow conception of maleness. This idealized maleness is constituted through competitive and assertive masculine characteristics and behaviours, a centering of whiteness, and often a preference for the English language and culture. My observations, and the narratives and experiences of many of this project's participants, identify the ascendency of these specific qualities

\footnotetext{
${ }^{45}$ Details about gender and cultural inequities will be discussed in great detail drawing from this project's qualitative data, however, I have written about these in my research at the college. This research is available here: Brown, 2017, 2018.

46 These observations are similar to findings in the following research: Febbaro, A. (2007) "Gender and Leadership in the Canadian Forces Combat Arms: Perspectives of Women Leaders," in Women and Leadership in the Canadian Forces: Perspectives and Experience, Karen D. Davis Ed. Canadian Defence Academy Press, 93-138.
} 
as common place within Canadian military culture writ large. Interestingly, many participants observed such idealizations as taking place far more acutely at Canadian Forces College than in other military environments.

While I made assumptions about the fact of gender and cultural inequalities in the military, I also made assumptions about my role and purpose as a researcher in this space. 'Good' social science research has often been framed through the positivist ontological supposition that an objective 'truth' is waiting to be discovered by the researcher. In this way, science, and indeed social science, has been historically predicated on the idea that 'truth' is universal to all and can be experienced and replicated in the same way by all, regardless of the contexts and personal histories through which truth is experienced by individuals. Post-modernists, however, reject the supposition of a universal truth and instead suppose the preponderance of diverse and particular truths - truths which are differentially experienced and co-constructed among the researcher and research subjects. $^{47}$

Scientific methods often presume that impartiality and objectivity are goals which the researcher ought to and can reasonably obtain in the research process. However, postmodernists reject this premise and contend that the researcher's abstraction from the construction of knowledge is not possible, questioning whether this abstraction from the production of knowledge is even desirable. ${ }^{48}$ As meaning and understanding in this dissertation project have been co-constructed between the researcher and her research

\footnotetext{
${ }^{47}$ Gavey, 2011; Olesen, V. (2007). "Feminist Qualitative Research and Grounded Theory: Complexities, Criticisms, and Opportunities," in The SAGE Handbook of Grounded Theory Feminist Qualitative Research and Grounded Theory: Complexities, Criticisms, and Opportunities, Antony Bryant \& Kathy Charmaz Eds. SAGE Publications Ltd, pp. 417-435.

48 Ibid.
} 
participants, this research is biased towards post-modernism and post-positivist

suppositions about the subjectivity of truth. I presume that my positionality as a

researcher has bearing and influence over the products of my research. ${ }^{49}$ I assume that

my positionality cannot be uncoupled from the research process and that my positionality

and my biases will have shaped the research in ways in which I could not reasonably

foresee or imagine. While I presume these processes to be true of any research process, I

have taken steps to confront and challenge my implicit biases using bias interruption

techniques ${ }^{50}$ and ongoing consultation and collaboration with peers and research

participants. I have also taken steps to mitigate the undue projection of my positionality

onto the research through the application of national standards on ethical research design

principles and practices. $^{51}$

Just as this doctoral work is guided by post-modernism, it is also intersectional

and feminist. The fact that this work is shaped by these theoretical characteristics means

that the questions, analyses, and conclusions therein are biased towards social justice.

\footnotetext{
${ }^{49}$ I am drawing from Gavey's research on the subject of 'objectivity' and 'subjectivity' of the researcher, or, analyst. $(2011,185-186)$.

${ }^{50}$ There are several excellent implicit bias and bias interruption workshops and modules available online through departments of the Government of Canada, such as Status of Women Canada and work of scholars from Harvard and Stanford as well as not-for-profit women's networks. These modules and workshops are good tools to help researchers understand what possible biases, norms and worldviews they possess that might negatively influence critical thinking. Drawing on these was helpful for me in working through my personal preconceived notions, as well as understanding how my privilege and marginalization affect my understanding and decisions in the research process. For examples see: Status of Women Canada,

"Unconscious Bias-Additional Resources", available at https://cfc-swc.gc.ca/gba-acs/bias-prejugeen.html; Government of Canada and Canada Research Chairs, "Unconscious Bias Training Module," available at: http://www.chairs-chaires.gc.ca/program-programme/equity-equite/bias/moduleeng.aspx?pedisable=false; Bias Interrupters, "Toolkits" and "Survey", available at:

https://biasinterrupters.org/bias-at-work/; Stanford University, Vice Provost for Faculty Development and Diversity, "Interrupting Bias, Strategies that Work," available at https://facultydevelopment.stanford.edu/interrupting-bias-strategies-work; Project Implicit, "Implicit Association Test," available at https://implicit.harvard.edu/implicit/canada/background/index.jsp.

${ }^{51}$ Adhering to CUREB-A ethics protocol and principles in Canada's Tri-Council Policy Statement: Ethical Conduct for Research Involving Humans.
} 
This project intends to enable recognition and redistribution of power (Fraser, 1997) to facilitate meaningful socio-cultural transformations at Canadian Forces College and the larger Canadian military. In this way, the research questions guiding this project assumed that there were social processes and practices that were requiring, and capable of, change. Though biased toward change, this research is informed by previous empirical studies which, knitted together, demonstrate a long history of gender inequality in the Canadian Armed Forces and illuminate how sustained systems of patriarchy, ethnocentrism, men's dominance and cultural practices of racism, heteronormativity, sexism, and misogyny within the institution have differentially impacted military professionals along intersecting axes. $^{52}$

Most studies about gender and cultural inequity in the Canadian Armed Forces are largely descriptive. These typically illuminate the fact of gender and cultural inequity among members of the Canadian Armed Forces, posing more questions than answers about how to achieve social justice and how to recognize inequality and redistribute social, cultural, and institutional power more equitably among personnel. Drawing from these inquiries, this study presents a variety of descriptive views about gender and cultural inequities, but also highlights participants' prescriptive ideas about how to achieve equality and social justice within the institution. As such, the study raises a range of descriptive and prescriptive insights about the recognition and redistribution (Fraser,

\footnotetext{
${ }^{52}$ For examples see: Madsen, 1999; Davis 2007; Razack, 2004; Whitworth, 2004; Winslow \& Dunn, 2002, Deschamps, 2015; Chief of Military Personnel (2016). Canadian Armed Forces Progress Report on Addressing Inappropriate Sexual Behaviour, http://www.forces.gc.ca/en/caf-community-supportservices/sexual-misconduct-progress-report.page\#viprevent; Statistics Canada (2016). "Sexual Misconduct in the Canadian Forces, 2016" November 28, http://www.statcan.gc.ca/dailyquotidien/161128/dq161128a-eng.htm
} 
1997) of power at Canadian Forces College. It illuminates co-constructed pathways between the researcher and participants towards transformative change at the College and within the larger military institution. In this way, the researcher presumed (alongside many of her research participants) the transformational possibility of interventions toward gender and cultural equality and equity through the professional education of senior military leaders at Canadian Forces College. This common narrative was present despite the equally common recognition that the College remained an institution in which women's integration and the inclusion of racialized and linguistic minorities were tenuous..$^{53}$

\subsubsection{Reflexivity and Positionality of the Researcher}

Through my ongoing work with the College over the past five years, I have been immersed in its social reality and involved in a process of socialization to its institutional norms, practices, and culture. Despite this time, I remain ignorant to many of the nuances of military and service cultures. In this way, I toe the liminal line of being both an insider and outsider within the College and the military institution. Additionally, my position as a woman scholar entering the military field also conditioned my position as a researcher. These qualities influenced the reception of my inquiries into participants' experiences

\footnotetext{
${ }^{53}$ Women have low representation at the Canadian Forces College primarily due to difficulties in enrollment under a system of eligibility derived from merit lists which use members' superior officers' evaluations of their yearly performance to determine their acceptance. Performance evaluations are based on members' "physical fitness, supervision of subordinates, leading change, accountability, initiative, leadership and dedication" (Gray, 2008, 287). These somewhat subjective eligibility criteria may constitute gendered and cultural barriers for diverse members to be recognized as valuable candidates. This is in addition to the Canadian Armed Forces difficulty in meeting, what some argue is an already low threshold of representation for the three designated Employment Equity groups in the military, inclusive of women, visible minorities and Indigenous peoples.
} 
and stories of learning about gender and culture in the Joint Command and Staff Programme. Similar to the experience of military sociologist Delphine DeschauxBeaume, being young and a woman often presented positive attributes for my research within this defence society. Specifically analogous are Deschaux-Beaume's reflections that "the very technical aspects wrapped up in opaque jargon were graciously explained to us, unlike what happened to a male colleague asking the same kind of questions" (Deschaux-Beaume, 2012, 111).

As a researcher conducting sociological inquiries of French and German militaries, Deschaux-Beaume reflects on her experiences as a young woman entering these "mostly masculine" spaces (Deschaux-Beaume, 2012, p. 111). Deschaux-Beaume posits that her position as a young woman researcher granted her access to "information on the social practices and representations of the military and diplomatic actors" (Ibid). Similarly, as a consequence of my age, sex, gender identity and relative ignorance of institutional norms, practices and policies as a civilian outsider, I was able to ask seemingly simplistic questions and generate very detailed answers in response about common, taken-for-granted rituals and social relations within the military and at Canadian Forces College.

As Deschaux-Beaume contends, her gender and age granted her an advantaged ability to obtain unguarded and clear responses from her participants (Ibid). Again, I observed similar attitudes and willingness, particularly when being introduced to technical terms, longstanding practices, and norms unique to Canadian military or service cultures. With the recognition that every researcher's experience within the field is unique and contingent upon the people, context, and conditions that make up the 
processes being observed, Deschaux-Beaume's experience and her specific qualities were akin to my own and proved to be similarly beneficial.

Finally, my continued role as an academic and instructor at Canadian Forces College have put me in a unique position to observe diverse as well as dominant gender practices and norms within the College's formal and informal educational practices. As Brown and Syme-Taylor argue:

Research suggests that female academics are in a privileged position of seeing the male as norm (feminist standpoint) in the military and in academia. Female academic interactions with PME expose hegemonic masculinity, through their experiences in PME they reveal gender practices, and also have an opportunity to reflect on their responses to these (Brown \& Syme-Taylor, 2012, 459).

Teaching and doing research at Canadian Forces College over an extended period of time has indeed enabled me to recognize my feminist standpoint and perceive the hegemony of the 'male as norm' point of view. While the student body changes from year to year, the structural and cultural gendered aspects of the College that have helped to shape professional education have been relatively consistent. I have witnessed that inequitable gender and cultural norms and practices are rarely challenged formally and thus remain characteristics resistant to change.

The layered aspects of my identity, my gender presentation, sex, position as a junior scholar, and age (all less common in Canadian Forces College culture), coupled with the privileges of my whiteness and English as my first (and only) language (more common in Canadian Forces College culture) have attributed to my situated experience as 
researcher. I find that my complex place and position at the College, and my insider/outsider relationship with research participants have generally put me in good stead. My identity as a civilian academic, on contract as a senior sessional instructor at the time of data collection, made me less of a known commodity compared to full-time professors and staff. As a result of my precarious employment, low status, and intersectional identity, respondents may have perceived little to lose in sharing their experiences. The fluidity of my work between teaching and research at the College has been such that I am understood as 'different' from other staff and faculty as well as 'nonthreatening.' My junior academic rank, and my status as a PhD candidate, both privileged and disadvantaged me depending on the context. Overall, though, I found these blurred lines, however contradictory and messy, to have been mostly positive assets throughout the data collection process and complimentary to the integrity of my research.

I have also recognized that as a woman, a civilian and academic, I am an intersectional anomaly at Canadian Forces College. Drawing from Winslow and Dunn, I do not view women's integration woes at the College as a mark of deficiency in capability (2002), but rather the consequence of tacit gendered structures and implicit gendered cultural understandings of what comprises merit. Findings from the research indicate that there are systemic cultural barriers which could implicitly determine women and racialized members as unsuitable for enrollment. Cultural norms which enact genderbased discrimination elsewhere across the CAF (Davis, 2007, 6) also impact the College. It may be that some senior officers' biased assumptions about women's weakness (physically and cognitively) (Reiffenstein, 2007, 5; Winslow and Dunn, 2002; Febbraro, 2007, 93), their motivations for service (Davis, 2007, vii, 80), their dedication to service 
(Ibid); as well as some senior officers' additional scrutiny over women's physicality (Febbraro, 2007, 126-127), and preferences for masculine qualities of leadership (Bradley, 2007, 142-143; Febbraro, 2007, 94), contribute to men making the cut over women.

In addition, I am one of three contracted women academics who lecture regularly for the Joint Command and Staff Programme at Canadian Forces College. Only two women are in permanent teaching roles as associate professors. Only two of the twelve military faculty are women. The representation of women enrolled in the residential student body has hovered around fifteen percent over my tenure at the College, far below the twenty-five percent benchmark set as a goal by the Canadian Armed Forces (Government of Canada, 2017b).

In the pre-COVID context, students and staff generally knew me as 'the gender person.' As such, many members of the College community would stop by my office to share their experiences, frustrations, and triumphs in relation to gender and cultural equity. These shared observations influenced the research questions for this dissertation but were not included as primary data.

It is important to note, however, that at the time of data collection, the context was such that military members had the luxury of debating the relevance and utility of gender perspectives to military work and culture. If data collection had of occurred in the current context of the military \#metoo movement, coupled with calls to examine institutional racism, there may have been more incentive for military members to represent themselves as buying into gender analysis and intersectional thinking. In the contemporary moment, it is no longer socially acceptable to overtly diminish or sideline 
gender issues. Moreover, demonstrating in-depth in knowledge about gender and cultural perspectives may be viewed as a way to advance members' careers. In hindsight, the context in which the research was conducted may have provided a unique moment wherein honest deliberation about the impact and relevance of gender and cultural perspectives could take place. Consequently, the desire to maintain the status quo was a viable option to freely express for some participants, while others presented aspirations to promote gender and cultural perspectives without being incentivized by the advantages that doing so could provide today.

While the College continues to be a white centering and male dominated space, College leadership and staff have begun to take (some) strides to set (some) conditions through which women, Indigenous and racialized people might gain greater acceptance as teachers, learners and leaders. As this doctoral project ultimately suggests, much more is to be done. So, it is with this hopeful outlook that this dissertation contributes to ongoing social, structural, and cultural transformations at Canadian Forces Collegetransformations that might one day produce meaningful impacts for all aspects of military professional development, work, and culture.

\subsubsection{Commissioned Research and Ethics Approvals}

Leadership of the College and the Canadian military's research authority Director General Military Personnel Research and Analysis (DGMPRA) authorized me to conduct focus groups and interviews with professional military students, academic staff, and military staff as part of ongoing curriculum evaluation. The collection of data for this doctoral study and the commissioned report for Canadian Forces College was determined 
by DGMPRA and College leadership as a contribution to ongoing curriculum validation of the Joint Command and Staff Programme. Beyond this initial approval, Carleton University Research Ethics Board-A (CUREB-A) provided ethical clearance to conduct focus group and in-depth interviews for this doctoral research project. CUREB-A approved of this doctoral study's research plan, methodological approaches, and data collection procedures, deeming them as compliant with Canadian national standards for conducting ethical research according to principles of the Tri-Council Policy Statement: Ethical Conduct for Research Involving Humans.

I think it apt to highlight that the commissioning of the 2018 report and facilitation of this doctoral project is illustrative of the College leadership's support of ongoing work across Canadian Defence Academies to integrate gender and cultural perspectives into PME and development programming. This integration is pursuant to policy and direction from senior military leadership in the Canadian Armed Forces as well as Government of Canada policy which forwards the mainstreaming of GBA+ and the core principles of United Nations Security Council Resolution 1325 on Women, Peace and Security in Canada's Defence institutions. ${ }^{54}$ Important for this dissertation project is evidence of an increasing recognition in the military institution and of its PME institutes that the ability to understand and apply gender and cultural perspectives is beneficial to the profession, military professionals, and to those the institution is tasked to protect (Ibid).

\footnotetext{
${ }^{54}$ See: Canadian Armed Forces and Department of National Defence (2016) "CDS Directive for Integrating UNSCR 1325 and Related Resolutions into CAF Planning and Operations.”; Government of Canada, 2017, Canada's National Action Plan on the Implementation of UNSCR 1325 and Related Resolutions (CNAP), available at: https://international.gc.ca/world-monde/issues_developmentenjeux_developpement/gender_equality-egalite_des_genres/cnap_wps-pnac_fps.aspx?lang=eng
} 


\section{Chapter 3: Hidden Curriculum - Military Social Stratification Transferred to the Learning Environment}

Student and staff volunteers for this study were asked to share their observations and experiences related to the development, delivery and learning of gender and cultural perspectives in Joint Command and Staff Programme curriculum. Participants were also asked to provide insights about how they experience the learning environment at Canadian Forces College, including how they perceive their interactions with students, military and civilian staff, symbols, and artifacts. The following three chapters outline common themes across focus group discussions and interviews as well as the diverse and shared narratives related to these themes. This chapter identifies and examines themes and collective narratives about hidden curriculum. The next chapter focuses on themes and narratives in reference to formal curriculum, while the last follows the perceptions and applications of gender and cultural perspectives in the curriculum by graduates of the Joint Command and Staff Programme. Each of the following three chapters draw on excerpts from individual interviews or focus groups to illustrate common themes identified as well as the range of perspectives shared.

Findings were organized by common or repeated themes as well as outliers. Common themes were identified by recurring observations, experiences, and reflections. Themes were identified originally using NVivo software, which I later abandoned in favour of reading transcripts in Microsoft Word while marking repeated occurrences using coloured text and comment boxes in the margins. NVivo software was good in identifying commonly used words and turns of phrase, but not particularly adept in finding like sentiments and discourses using a variety of linguistic choices. 
Drawing on feminist post-modern theory, intersectional theory and men and masculinities theory, I searched for themes in relation to military gender, racialization, socialization, identity, norms, behaviours, worldviews, and practices. I also searched for common themes derived from repeated ideas and expressions within discourses of participants as well as informative outliers demonstrating diversity in perspective.

Themes emergent that I had anticipated finding were on male dominance, white supremacy, masculinist ideologies and worldviews, as well as hegemonic gender. Themes that I had not anticipated were sexual and racialized harassment and abuse within the learning environment, a gendered social stratification across military service and occupation, and a use of gender perspectives and cultural learning to understand military identity and purpose. The following substantive chapters elucidate these thematic findings in turn.

\subsection{The Hidden Curriculum}

Using the Critical Discourse Analysis method, informed by post-modern feminism, intersectionality and hegemonic masculinities theory, transcripts of focus groups and individual interviews were organized into broad themes and subthemes. Six broad themes were identified as being commonly discussed among participants in relation to a hidden curriculum observed in the learning environment at Canadian Forces College. Within these broad themes, subthemes were identified. Subthemes include repeated and commonly deliberated subtopics as well as diverse opinions about the larger themes cited. Broad themes are identified and organized into subthemes as follows. 
The first theme explores a common observation of a narrow masculinization of leadership at Canadian Forces College and the enforcement of masculine ideals that were noted to contradict doctrinal understandings of professionalism (Government of Canada, 2009). Subthemes related to the narrow masculinization of leadership and the enforcement of masculine ideals include: the dominance of an 'aggressive,' 'alpha male,' 'combat', 'operator' masculinity and pressures to conform and adapt to normalized 'competitive' behaviour through behavioural cues, hardline rules, and sanctions associated with this narrow masculine ideal of 'professionalism.' An additional subtheme is the idealization of whiteness, English speaking, and directive (or assertive) masculinity as well as praise for poor behaviours associated with masculine bravado, machismo and 'misogyny' rather than other forms of masculinity that are more collaborative and inclusive. Finally, participants spoke of the relative impunity for forms of inappropriate sexual behaviour expressly prohibited within Operation HONOUR and acknowledged that the Canadian Forces College is a 'masculinist' institution.

The second theme interrogates the practices and symbols at the College that demonstrate an implicit desire for the preservation of a masculine and colonial past within the Canadian military. This cultural norm at the College is recognized among some participants to be prioritized over presentations of present-day aims toward greater diversity in the military and is noted to be idealized above commitments to an inclusive future to be achieved. Subthemes of the masculine past to be preserved include: the idealization of behaviours, symbols and visual representations which express 'aggressive,' 'alpha male,' 'combat operator', and 'transactional' leadership styles; symbols and images of historical combat maleness and masculinities; a preponderance of 
visual and symbolic reference to British, Anglophone (neo)colonial masculinity; specific and narrow masculine comportment; and traditional heteronormative social role expectations of male breadwinners, female caregivers, and idealizations of service over self and family.

The third theme focuses on the underrepresentation of women and men's dominance at Canadian Forces College. Related subthemes include: the low representation of women within the student body and the presence of 'special selection measures ${ }^{55}$ to raise the numbers of women students. Observations include questions about the protocol and the misogyny elicited by colloquially referring to special measures as the 'pink list.' Many participants observed that special selection measures at the College are enigmatic and shrouded in secrecy and that efforts to keep special measures hidden often elicit rumours about women and cynicism about the barriers experienced by women in the military. Some observe that confusion about the need for and purpose of special selection creates further skepticism about the capacities and merits of women generally, and led some members of the College to pursue, expose, and diminish the achievements of students enrolled through special measures. Related to this subtheme are common expressions of confusion over why the College must still rely on employment equity to promote the greater integration of women in the Joint Command and Staff Programme. Finally, another subtheme focuses on observations of the limited presence of women in military leadership, military faculty, civilian staff positions, and academic

\footnotetext{
${ }^{55}$ For over two decades, the Canadian Armed Forces and Canadian Forces College have relied on affirmative action style employment equity to assist in maintaining a modest representation of women students enrolled in the Joint Command and Staff Programme (Government of Canada, 1997).
} 
faculty as well as limited representation of women guest speakers and subject matter experts.

The fourth theme explores participants' collective identification and brainstorming of ways to address potential gender bias within the nomination system for selection to the Joint Command and Staff Programme. The subcategories of this theme include speculation that the low representation of women on the course is a social and structural issue at the level of selection boards and observations that the selection process may contain implicit bias against women's selection while implicitly privileging men. This observation by students and staff is historically true. A report evaluating the selection process to the 'Command and Staff Course', now Joint Command and Staff Programme, found that systemic barriers in the selection process hindered women's candidacy and ultimately their selection to the course. The recommendation of this report was to continue special selection of "deserving female candidates that would not otherwise be selected" due to unresolved systemic obstacles (Government of Canada, 2006).

Participants also commonly argued that the Canadian Forces College ought to serve as an example for the rest of the Canadian Armed Forces by promoting higher representation of women in positions of leadership. Many expressed that the College ought to at least meet the military's minimum 25 percent target for women's representation across all staff and student roles (Government of Canada, 2017b). Student and staff expressed that a review should be undertaken to assess if and how selection of candidates to the Joint Command and Staff Programme contains gender bias and whether 
social and structural barriers noted in previous studies continue to affect the candidacy of women for selection. ${ }^{56}$

The fifth theme regarding hidden curriculum highlights collective observations of a masculinized classroom and learning environment. The subthemes for this category comprise: idealizations of competitive discussion styles and behaviours; deference to the 'alpha male' role (which can be performed by men and women); idealization of competition over collaboration in syndicate discussions; a privileging of students with fewer familial obligations and responsibilities; the privileging of white, Anglophone, masculinity; and the presence of 'mansplaining'.

Lastly, theme six explores a common perception among staff and student participants of a general lack of trust and confidence in students as professionals. The subcategories of this theme include: consistent messages to students by College leadership about the expectation of maturity, responsibility, and ownership over their learning, while paradoxically exerting a high degree of control over student learning and socialization in the learning environment; student participants often report feeling babied by staff; some students and staff observe issues with rigid, predetermined schedules; some students and staff recognize problems with having little unscheduled space- time to reflect and collaborate over learning; students and some staff observe few opportunities for student driven inquiry, reflection, and critical thought; some students and staff observe that course evaluations can be biased and may be predetermined by

\footnotetext{
${ }^{56}$ Calls for a broader qualitative review of candidate selection beyond the results that could be garnered from the limited quantitative data available by number of women enrolled by year was recommended by researchers in the 2006 report (Government of Canada). To the author's knowledge, this more substantive qualitative review has not yet been conducted.
} 
trade, occupation and rank and gender. Drawing from the observations of participants, a common perception is explored where participants note that social hierarchy and control over students has an intersectional flavour, where power equates to leadership, and where leadership is expressed through masculinist, ethnocentric, gendered and racialized operational qualities.

\subsubsection{Theme 1: The Narrow Masculinization of Leadership}

Data presented in this section illuminates commonly cited issues related to dominant cultural constructions of leadership and professionalism at the Canadian Forces College. Many student and staff participants recognize that the College is both a male dominated and a 'masculinist institution.' Perceptions that Canadian Forces College is a masculine institution stem from observations of male domination and preferences for androcentric thinking. The College has been referred to as a masculinist institution, as participants perceive a cultural reproduction of meaning and practices that value and uphold the dominance of men and a particular form of hegemonic militarized masculinity over other competing forms of militarized gender. Many participants, both staff and students, note how masculinist cultural understandings about gender and the military profession held at the College shape the learning environment, influence what is taught and influence how course content is delivered.

Observations that the Canadian Forces College is at once a male dominated and masculinist institution are illustrated in the following dialogue among academic faculty: 
Participant One: It just means to me that the CFC is a masculine institution.

Not just CFC, but the Canadian Armed Forces as a whole, so CFC has not made that transition.

Participant Two: There are women here, and there are certain occupations that are over-represented by women like the library and the administrative staff.

Participant Three: So, I have a question for you [Blank], because you said "where are all the women?" and you talked about the masculinist institution of the CAF. Would you go as far as to say that CFC is a masculinist institution?

Participant One: Yes.

Participant Three: Okay, I would agree (2018, Focus Group Interview, April). This dialogue among academic faculty serves as an example of a common theme across subgroups that gender inequality amounts to more than the underrepresentation of women at Canadian Forces College. Indeed, it points to inequality in gendered social relations.

Observations of staff and student participants in this study illuminate a variety of ways in which masculinist presumptions and social relations manifest in discursive, symbolic, and material choices dominant within the culture at Canadian Forces College. These choices lead to gender inequality in the learning environment. Overwhelmingly, participants of this study recall masculinist perceptions and inequitable gender relations which uphold the power of particular groups over others. As some note, these relations are often demonstrated through language. 
The following discussion among women student participants in a focus group reveals a range of feelings about masculinist choices in speech with reference to the regular use of men's pronouns. Their dialogue suggests recognition of the use of masculinist language but with different interpretations of meaning and impact:

Participant One: That's funny because we had conversations that they'd never thought of where they would start out with "GENTLEMEN. .." right?

Participant Two: That's not even something that I notice. Someone was mentioning the General today saying 'guys' all the time, but that doesn't bother me.

Participant Three: What bothers me more? "GENTLEMEN! and lady." (Women Students of the Joint Command and Staff Programme, 2018).

Critical analysis of this conversation denotes examples in which women students observe that masculinist choices were practiced routinely through discourse. Drawing from postmodern feminist theory, while the use of men's pronouns such as guys and gentlemen are common in the English language, when speakers refer to mixed gender groups in professional environments, the use of men's pronouns shifts the tone of language to emphasize men as universal, thus normalizing women as the exception. Yet, as observed by one student, pointing out the token woman in the room could demonstrate an intention to separate, isolate, and mark as exception 'femininity and womanhood' within the profession. Doing so, intentionally or not, creates gender inequality through discursive practices of cultural segregation. It is possible, however, to make active choices to use language that is inclusive of all genders using terms like 'team.' 
Similarly to Goldstein's arguments, some participants note that efforts to erode masculinist language are more difficult when foundational ideas and concepts like 'war' and 'security' within the Joint Command and Staff Programme curriculum are themselves imbued with gendered assumptions and meaning (Goldstein, 2001). As the following observation from an academic faculty member suggests, gender inequality is often embedded within discursive frameworks that have inferred gendered meaning, ones which perpetuate the maintenance of patriarchy through masculinist thinking:

When we use language like military and war and those kinds of words, there are ways of thinking, literatures, modes of thought, methodologies that go along with those things. . That's a problem. I think that just reinforces what you [focus group member] said, that it becomes even more inherent that assumptions tend to be masculinist and male (Academic Faculty Canadian Forces College, 2018).

As this observation demonstrates, there are areas within curriculum that, if approached using gender and cultural perspectives, could facilitate greater inclusivity in the learning environment and create opportunities for students to gain valuable professional knowledge. These examples demonstrate that intentional choices about gender neutral language and thinking about how key concepts in curriculum contain tacit gendered meaning could push the 'yard sticks' toward gender equality and inclusivity in both thought and practice within the learning environment. In many observations, it was stated that doing so would enable the College to confront problematic gendered assumptions about conflict, security, military work, and the military profession. 
As one military faculty member explains, gender inequality at the College may be a product of larger military socialization, where discriminatory behaviour and practices are learned over time, and therefore are more difficult to recognize:

There are things that maybe aren't as blatant. Things that maybe we have come to accept as normal based on military culture, based on our own upbringing. Maybe that seems right to us because that's what has been right in the past. So, we have developed blinders to the way that we are discriminating (Academic Faculty Canadian Forces College, 2018).

Razack (2004) and Whitworth (2004) make similar claims that military socialization aims to transform ordinary citizens into soldiers using intense pressure to embody particular qualities of masculinity, sexuality and whiteness. Building on this point, some participants suggest that some norms at the College marginalize certain members on the basis of sex, gender, ethnicity and language. Such norms demonstrate intersectional social power (Crenshaw, 1991) that tends to promote particularly 'aggressive' 'alpha male' identities.

Related to the observation of a masculinist culture at Canadian Forces College is the perception of a gendered operations/support paradigm, wherein behaviours which promote rivalry and competition over collaboration are common. An example of the dominance of this paradigm and its consequences are elaborated by two women students in individual interviews:

Oh no, it is not equal. But, the rivalries inside the military are very prevalent at JCSP. . . There is definitely a bias towards the combat arms, but that is the reality. It is not just a JCSP thing. . I think there is an order in the military, 
and I think it is reproduced in JCSP (Woman Student Joint Command and Staff Programme, 2018a).

Similarly, the second participant argues that a cultural hierarchy exists at the College where:

Operators are the most important and they are always right. . . I have even heard people say, “I don’t care, you are just going to support wherever we decide to go." . . . It is viewed as a competition (Woman Student Joint Command and Staff Programme, 2018b).

As these observations serve to amplify, a common premise across participant groups is the observation of a hierarchical operator/supporter paradigm which creates a potent us versus them division within the learning environment. This social hierarchy is seen as privileging the knowledge and opinions of members in operational occupations, creating inequality in the classroom.

Building on the social hierarchy between operator and supporter occupations, some students and staff participants observe that this constructed social order is also deeply gendered. As the following excerpts illuminate, some participants identify the common supposition that operational occupations are understood as masculine, while support occupations are perceived as feminine within the larger Canadian Armed Forces culture. This gender division of military occupations in the military has transferred to the learning environment, creating conditions for a patriarchal interpretation that operators are 'more masculine', better suited to 'hard' military work, and hence, more valuable to the profession. 
The tendency to equate masculinity with operational trades and femininity with support trades is explained in comments by two women students in individual interviews:

Like even in the discussion today when the men were saying "well, we will train the soft trade." I was like "Argh!" I know women in the country that we partner with will largely come from the support trade, but that doesn't mean they are 'soft' (Woman Student Joint Command and Staff Programme, 2018a).

There is bias that we see in the combat arms where operators will be viewed as having more leadership. They are viewed as capable of leading people to war. Whereas supporters are viewed as maybe a bit more, "they are good at their job, they are technicians rather than leaders." There is a grading within the different trades and I think that came out in some ways at the College... Women fall in the same category as supporter, because support is considered a 'soft' trade (Woman Student Joint Command and Staff Programme, 2018b). Participants of this study observe that this hierarchy is not only present in the ways in which students and staff organize themselves according to gender and trade, but also in the cultural primacy and masculinization of operations and warfighting at the College as reflected in the prioritization of operations within curriculum.

As one student participant suggests:

The only thing we learned about was the operator trade. We didn't really look at all the supporter trades, and I am not just talking about logistics. Like signals, cyber, engineering. It was always the operator. . Because of the way of the military culture is with operators 'doing all of the work', we forget 
about the supporters and how supporters are treated sometimes. I think that may be one example of how gender came out in terms of 'supporters are more feminine' and 'operators are more masculine.' [Operators are] tough alpha male[s] (Woman Student Joint Command and Staff Programme, 2018a). As these excerpts help to illustrate, a common theme across participant groups was the construction and maintenance of social hierarchies reproduced by staff and students through curriculum, activities, and other social relations at Canadian Forces College.

The cultural, symbolic and discursive emphasis on 'warfighting' operations often implicitly signaled such operations as more generally in the masculine domain. Moreover, a tacit meaning observed and resisted, particularly by student participants in support roles, is that operations are constructed as masculine practices that only some military professionals can do, and those who embody this operator masculinity are habitually valued as higher in the social hierarchy constructed at Canadian Forces College. Based on learning activities chosen, the College may be (unintentionally) constructing and reifying an operational/masculine vs. support/feminine social hierarchy. In this way, the hidden curriculum being received assumes that operator men, embodying directive and alpha masculine qualities, are the most prized and idealized in the learning environment, as well as within the larger military institution.

In addition to influencing course content, some participants perceived gender bias in the evaluations of students. Some observed a tendency in which operators were given academic and professional advantage. As women students in this exchange note, there may be a bias among military faculty to assess students according to pre-existing expectations linked to occupation: 
Participant One: Plus they just give you your predetermined mark before even showing up.

Participant Two: You are a Combat Arms student, so you are going to do really well.

Participant Three: Yeah, top student (Women Students of the Joint Command and Staff Programme, 2018).

While many participants noted a constructed gender social hierarchy present at Canadian Forces College, most presumed that little would be done to change this power arrangement as they recognized the same sorts of rivalries and gendered perceptions has a ubiquitous and longstanding history across the military.

However, some participants across students and staff argued that the social hierarchies which exist within the larger military culture were often exacerbated within the learning environment at Canadian Forces College. This intensification of social stratification is perceived to facilitate conditions for more intense practices of exclusion and dominance. For instance, a participant from the Information Resource Center staff notes that:

There is a noticeable hardening of gender lines, and there is a noticeable hardening of diversity lines. There is a noticeable hiding of how people deal with each other in ways that are not inclusive. I find that it has created within the student body a very toxic environment, and on the staff side I find a very toxic environment. . What concerns me is that [there have been] two individuals who are and have been directly affected specifically along the ethnic and diversity lines as well as gender. People who have chosen to 
retreat from the College rather than to deal with it because they didn't feel that, at the senior leadership level, there was anything more than a "now, now, everything is just fine" approach (Information Resource Centre Staff, 2018).

Similarly, the worsening of gendered divisions is noted by a woman student participant:

But my peers, who seem to think that I am okay, but I am not that good, think that every time I get something, they say it's because I am a woman. I have never had that rubbed in my face so much than while I have been at JCSP (2018b).

These reflections help to illuminate a shared theme across participant groups that it is within the College environment where some students and staff are confronting gendered and racialized discrimination in ways that are unprecedented elsewhere in the military. That in fact, there may be processes unique to the culture of the College that fuel struggles for dominance, impose masculinist thinking, and facilitate inequality and discrimination.

Many participants across focus groups and interviews could recall instances where students and staff have experienced pressure to behave in competitive and sometimes unprofessional ways to gain professional advantages. Recollections among students and staff of an expectation for students to behave in ways that contradict the military's values to "respect the dignity of all persons" (Government of Canada, 2009) were frequent. For example, some students and staff observed feelings of intense pressure to prove their 
masculinity by drinking heavily at the mess as well as feeling obliged to compete aggressively in contact sports. As highlighted in the perspective of this student:

I don't think that they are overtly and intentionally trying to push a masculine quality to it . . . but I've never seen PT and Sports pushed to such a level . . .The notion of the old boys' club, you know, "we'll stay late and drink", and all the different drinking clubs that there are fosters the notion of that old boys' club (Man Student Joint Command and Staff Programme, 2018). This reflection accounts for some of the ways in which hidden curriculum includes normalized and ritualized practices associated with 'boy's clubs': rituals such as hard drinking and contact sports are expected to be largely practiced by men. Drawing from masculinities theory, pressure to participate in 'manly' practices illustrates socialization to culturally dominant conceptions of idealized masculinity in militaries (Razack, 2004; Whitworth, 2004). ${ }^{57}$

Important to note is the significant effect that behaviour, attitudes, and practices of faculty have on students and the culture at Canadian Forces College. In most cases, student participants observed military faculty's positive influence on their learning and professional development. However, the following observations among women student participants help to demonstrate a common perception that the gendered actions and perceptions of a few military faculty had negatively impacted student experiences and behaviour:

\footnotetext{
${ }^{57}$ For examples of pressures to participate in practices associated with militarized hegemonic masculinity such as heavy drinking and competitive contact sports within other professional militaries see: Woodward and Winter, 2007; Zeigler \& Gunderson, 2005.
} 
Participant One: I've also heard [military faculty] who taught here for more than this course saying we are somewhat of a disappointing course. We are not at the mess drinking and partying like the other courses. Our course is very lame in that way.

Participant Two: [blank] told me this yesterday.

Participant Three: It's true, we are "lame geek class"? What?

Participant Four: We're professionals, right?

Participant Three: We're too professional.

Participant One: We're not impressing them enough with that [drinking and mess participation].

Participant Two: A lot of what we do socially is because [military faculty] want and insist that we do (Women Students of the Joint Command and Staff Programme, 2018).

This dialogue reveals the significant power relations that exist between students and military faculty. As one participant states explicitly, much of what students do socially results from pressure to meet the often gendered expectations of military faculty, even when these expectations run contrary to students' own assessments of professionalism. The following perspective from a military faculty member reveals how clear the connection can be between poor behaviour carried out by students and what students perceive to be the desires of military faculty: 
We have had a "migrating gym equipment issue" over the last week ${ }^{58} \ldots$

What came back to me was that one of the reasons that may have occurred was that students are getting the feedback from somewhere that they are a 'lame course.' So, this was their reaction to that. . . What are we communicating culturally to them that they believe that they. . . had to do something like move gym equipment? (Military Faculty of the Joint

Command and Staff Programme, 2018).

This reflection shows that messages students receive from military faculty have a direct relation to poor behaviours meant to escape the labels of geek and 'lame' ${ }^{59}$, terms which are feminized and understood as oppositional to commonly cited ideals of 'alpha,' 'operator,' masculinity.

Observations of social rewards for poor behaviours were made by military faculty, civilian staff, and student participants. In each case, participants noted that inappropriate behaviours tended to be celebrated, ignored, dealt with quietly, or dismissed by senior leaders of the College. Three participants of this study reported either experiencing or witnessing harassment and Operation HONOUR forms of sexual misconduct at Canadian Forces College. Two participants refrained from reporting such instances through the formal Chain of Command, choosing instead to remain silent, or to confront issues of harassment by peers personally. In these cases, remaining silent or personally taking quiet action were preferred to avoid being perceived as 'weak', to avoid

\footnotetext{
${ }^{58}$ Students moved gym equipment so that it could not be used/found. The 'migration of gym equipment' was a way to protest the label of 'soft academic' and to prove their 'tough military member' status to military faculty.

${ }^{59}$ Noting that this is an ableist term and should not be used in any context.
} 
assumptions about 'not being a team player,' and to avoid career altering or ending consequences for the complainant and the harassing party.

The following dialogue among women student participants describes an incident of inappropriate sexual behaviour at the College which took place between members of the student body:

Participant One: I don't have a female on my floor, which is okay, but when all my undergarments are in the wash, everyone knows whose underwear it is. Participant Two: In my opinion, because I am Army, I am used to being with males and sleeping in tents with males and you know so it doesn't bother me. Participant Three: I understand what you are saying about them moving your laundry ahead and them being immature and making comments about the colour of your bras and you have to worry about if you get all your underwear back or not.

Participant Four: Wait, but is that happening? [skeptical in tone]

Participant One: Yep, it's happening (Women Students of the Joint Command and Staff Programme, 2018).

The presentation of this incident is not intended to result in an investigation of inappropriate behaviour or to incite punitive measures, but rather to demonstrate that inappropriate sexual behaviour at Canadian Forces College is not always reported or known, and thus it is in the interest of the College to continue to educate students and staff about conduct, consent, gender, sexuality, and appropriate behaviour.

One case of harassment, highlighted by College staff, was reported to the College Chain of Command. However, the minimal punitive measures taken by the then-Director 
of Programs only intensified the poor behaviour of the aggressor. The dialogue in the following excerpt describes relative impunity for this case of reported harassment. I went to the then-DOP about a particular individual and outlined the misconduct. I was assured that the individual would be removed. Well, he was removed, not from the campus, but he was removed from his job for one day. Then was appointed back and became even more obnoxious from that point on ... The issue then becomes that the College starts to be divided into the misogynist camp, and the 80 percent who work well together (Information Resource Centre Staff, 2018).

This experience of reporting inappropriate sexual behaviour demonstrates that, despite clear policy direction, sexual misconduct was met with relative impunity. This impunity was noted to weaken the credibility of the leadership and may have deterred others from reporting issues.

Similar to observations about the handling of sexual misconduct, a common perception among some staff and students is that the messages espoused in formal policy are not necessarily reflected in social relations at the College. The following insight from a student participant provides an example:

I think to some degree we keep being messaged that we are enabled and empowered... We are being informed that "we are hearing what you have to say" and "we are eager to hear what your feedback is." To a great degree, that is being talked about, but often it is not put into action. What happens is it doesn't really matter. What happens is that people are like, "okay." [shrugs 
shoulders] (Woman Student of the Joint Command and Staff Programme, 2018a).

This and the previous excerpt reveal common feelings of frustration and disappointment when policy measures of the Canadian Armed Forces are not put into action or followed in practice at Canadian Forces College. As Operation HONOUR recognizes, "harmful and inappropriate sexual behaviour is a real and serious problem for the Canadian Armed Forces" (Government of Canada, 2015). The experiences and observations presented above illustrate that norms related to inappropriate behaviour may be transferred from the larger military organization as they are reproduced within the culture at Canadian Forces College. Reflecting on this facet of hidden curriculum at Canadian Forces College, the commitment to "enhance education and training on harmful and inappropriate behaviour" requires critical thought and follow through (Ibid). Educating staff and students about sexually inappropriate behaviour must be part of a larger commitment of the military to learn about gender perspectives and intersectionality. This means to seriously consider and challenge inequitable and mutually constituting gender, sexual, racial, and linguistic social power at the College.

The overarching insight tied to the observations in this section is the cultural normalization of particular forms of social power expressed through militarized gender. Commonly identified behaviours and norms illuminate the hegemony of 'aggressive', 'competitive', 'alpha' and sometimes 'misogynistic' masculine qualities within Canadian Forces College culture. Participants across staff and students commonly recognized that the practice of 'alpha' or more 'aggressive' masculinities enabled men and women of the staff and student body to gain degrees of social and professional power. Moreover, 
participants note that behaviours that are perceived to contradict these gendered social expectations are often policed.

Examples of 'yelling,' bullying, 'aggressiveness' and 'assertiveness' were referenced across all participant groups. These were deemed inappropriate for the learning environment, yet in some cases, these behaviours were perceived to be encouraged by some members of military faculty. These observations are coupled with the recognition by some participants of the presence of racial, linguistic, gendered and sexualized ostracism, chilly climates, or more blatant teasing and harassment in the learning environment.

Specifically, some participants observed shaming, discrimination, and harassment of minority groups within the College. Women, French speaking and racialized members either shared these experiences in focus groups and interviews or were observed to be those most detrimentally affected. Indeed, I directly observed bullying and shaming among participants of the women student focus group as well as among members of the military faculty. Three out of ten women students of the focus group raised their voices, laughed at others mockingly for seeing value in gender perspectives, and vocalized their skepticism about experiences of sexual abuse in the military shared by members of the group. Similarly, one member of the military faculty focus group raised their voice to me about the timing of the interview, stating that the meeting was being held in the midst of a busy time of the academic year. Other members of the military faculty focus group intervened, noting that the timing of the interview was in relation to other interviews scheduled with students, academic faculty, and staff within a four-week window and that the meeting date and time was not a deliberate slight against military faculty. 
In addition, the narrative that "this is a lame course" stemming from a member of the military faculty seems to have pushed students to behave poorly to combat the perception that they are somehow lesser than previous student bodies. The implication of the narrative led some students to feel intense pressure in the learning environment to behave in ways that would supplant perceptions that they were excessively academic and feminine. Statements such as "we're lame" and "we are a geek class" were used repeatedly in the women student focus group. Ultimately, these sentiments represent the social construction of an artificial binary and gendered division between 'academic' and 'military' identities.

Professional and academic identities seem to have been culturally constructed as oppositional at Canadian Forces College, where to be 'tough,' you cannot be a nerd. Toughness is often equated with the ability to be aggressive, competitive, and sometimes misogynistic in accordance with the colloquial but salient gendered assumption that "boys will be boys." Nerd and geek are presented as feminized characteristics of the academic identity and are often used to position academic identities as out of touch with and contaminating to operational imperatives and mission success. This identity contrasts with constructed professional ideals at the College by representing scholarly qualities such as reading, writing, critical thought, collaboration, and empathy as contradictory to the soldierly identity. Professional military qualities that are commonly identified as hegemonic by participants seem to esteem action over thinking, competition over collaboration, aggression over empathy, Army service over Navy and Air Force, and operator over support occupations. 
These qualities are also gendered, particularly gendering constructs of 'professional' as masculine and 'academia' feminine. Drawing from the observations of participants, members of the College seem to encounter conceptual dilemmas when confronted with the expectation to be both professional and academic. In this way, observations of students and staff denote social friction related to the presence of cultural pressure to choose one identity over the other, as 'professional' and 'academic' are relational in that they are largely being understood as binary gendered identities, both opposed and mutually exclusive. ${ }^{60}$

Drawing from Connell and Messerschmidt as well as from Schippers' definitions, hegemonic masculinity is a relational concept, one that measures itself against binary and opposing feminine characteristics. In this way, what hegemonic masculinity is relates to what other masculinities and femininities are not (Connell and Messerschmidt, 2005; Schippers, 2007). It is interesting, then, to consider the full spectrum of gendered ruling relations (Taber, 2010, p. 8) that have been constructed in order for this particular and contextually specific hegemonic masculinity to be idealized and legitimized within the learning environment at Canadian Forces College.

\subsubsection{Theme 2: A Masculine Past to be Preserved}

Participants across staff and students recognize the significance of military work and the sacrifices made by members of Canadian Armed Forces personnel over the

\footnotetext{
${ }^{60}$ The expectation, or norm of dissonance may also be a long-standing cultural tradition at the College, where students learn they must re-enact practices of defiance in military history. The legacy of Air Force piano burning at the College is a prime example.
} 
course of Canadian military history. All volunteers involved in this study demonstrated deep respect for the many accomplishments of Canadian military professionals, past and present. While students and staff recognize work done and sacrifices made by diverse personnel in Canadian military history, presentations of the efforts of marginalized groups, such as women, Indigenous and racialized people, were observed to be less common. In addition, many observed cultural tendencies to preserve anachronistic military traditions that are perceived to be symbolically or discursively exclusionary. Observations were made that although the Canadian Armed Forces comprise diverse populations of Canadians, very few honours, symbols or visual imagery at Canadian Forces College represent this diversity. The accomplishments and contributions of women, Indigenous and racialized groups, for example, were observed as strikingly absent at Canadian Forces College.

Common observations across students and staff were made about the prevalence of Second World War achievements, British historical influences, and the celebration of white Anglo men in war in visual and symbolic representations at the College. While participants overwhelmingly regarded historical events and the Canadian contributions of military personnel in the past as important, many also called for greater emphasis on current achievements, and an inclusion of diverse figures in symbolic and visual imagery, as well as increased learning about and presentation of diversity in the Canadian Armed Forces. This common narrative is illustrated in the following example voiced by a student participant:

I think the College is based in the historical fact of the military, we draw all of our lessons learned, we draw everything from a historical military context 
which is clearly male dominated... We were talking about representation here, and we were talking about how many women there are here, and washrooms and things. . You look at our command papers, anything that we are doing, it is clearly through a dominant, male-centric, historical institution and that is reflected in today's teachings and everything that we do (Man Student Joint Command and Staff Programme, 2018).

Observations of the predominance of white English-speaking men in positions of authority, in visual representations, as well as in literature at the College alluded to in this observation were also commonly noted across participant groups. The depiction of current combat masculinities framed within the style of Canadian military traditions, was also recognized as common.

While these representations are significant to Canadian military history and the identity of the Canadian Armed Forces, many participants observed that depictions were solely of men, and largely operational. The overrepresentation of Army contributions was also observed to suggest the impression of pushing the work, norms, and culture of all other personnel to the margins of significance. For many student and staff participants, the emphasis on Army norms and culture over Navy and Air Force ones is important to gender relations. Most understood a more competitive, rather than collaborative leadership/command style in the Army. In addition, a common theme across participants was the recognition of a tendency for Army norms and culture to be combat and operator centric and having pointed or directive (giving orders) social relations rather than collaborative and dialogic ones. Of consequence, such narrow representations of the Canadian Armed Forces around an Army combat operator ideal contain symbolic or 
hidden meaning for many participants. The following exchange among student participants serves as an example:

Participant One: We had Gertrude Kerns' work displayed all the way down the hallways. . I It's all men. And that was her choice, right? She didn't choose to draw any women COs, Commanders, and there were some in theatre at the time.

Participant Two: Yeah, and in another way if we look around here in this room. We talk about Churchill among the Marines, you know, it is kind of something from the past. Should we just put the past aside in order to better integrate women?

Participant Three: I don't think it's about putting it aside. I think it's about fair representation (Men Students of the Joint Command and Staff Programme, 2018).

Many respondents noted the absence of women, Indigenous and racialized people in symbols, artwork, and reading material. This absence was commonly understood to demonstrate that the College had chosen to prioritize tradition over the inclusion of diverse groups.

These observations, as well as others common in focus groups and individual interviews, show that in many cases, participants understood the absence of diversity in visual representations at the College as antiquated and, perhaps unintentionally, exclusionary. By extension, some participants perceived the emphasis on tradition as bolstering rather than deconstructing barriers faced by diverse personnel. Some participants likened visual imagery to the cultural promotion of traditional conceptions of 
men as breadwinners and women as housewives at the College and idealized outdated conceptions of service above family and self.

The idealization of traditional gender roles and the observation of a past to be preserved are presented in the perception of this student participant:

But there are undertones as well with gender roles. . . We generally fit a model that assumes the man is working and that the woman is at home looking after the kids. That goes back to the point about participation. We participate at the expense of our, if we have families, our partner staying at home looking after the kids at night, be it male or female. So, what message do we send when "Oh, no, just come out and do this . . . because your wife will stay at home and look after the kids?" (Man Student of the Joint Command and Staff Programme, 2018).

Participants also spoke of tendencies for some members of the student body to assert traditional assumptions about familial responsibilities and priorities within the military.

One example of this dynamic can be noted in the experience of a student participant shared in the focus group setting:

Someone was just saying that to be a good professional in the profession of arms you need to live, breathe, and do everything military. So, I said, "So when I am at home not thinking about anything to do with work and I am focused on my family, I am not being a good professional?” And they said "yes." Then I wished I had of retracted that because I thought, "okay, so now you don't think that I am good at what I do, because when I am at home I am fully engaged with my kids and not thinking about work. . . what are all you 
people thinking about me and my commitment and my loyalty to the organization?" (Women Students of the Joint Command and Staff Programme, 2018).

These experiences and observations are descriptive of commonly identified practices that reproduce and maintain historic modes of social organization and patriarchal power structures within the larger military institution, but that are amplified in the context of learning at Canadian Forces College.

Drawing from these experiences and observations, participants also describe the transformational potential of intentionally highlighting diversity in the military and changes to traditional conceptions of the family in course material, artwork, and symbols at the College. In focus groups and individual interviews students and staff often engaged in critical thought and discussion about alternative representations the College. A common narrative was that the College could better depict a vision of the desired future of the Canadian Armed Forces within Canada's Defence Policy—namely, to be an institution with "well supported, diverse and resilient people and families" (Government of Canada, 2017b, p. 12) by showcasing in symbols and in curriculum the work of diverse members with different experiences, perspectives, situational factors, and identities.

\subsubsection{Theme 3: The Underrepresentation of Women and Male Dominance}

A common theme, overwhelmingly recognized across all subgroups of participants as problematic at Canadian Forces College, is the underrepresentation of women in most roles and occupations. The Canadian Forces College has maintained 
historically low representation of women within its student body. Prior to 1989, women were not permitted to serve in operational occupations, making it difficult for women to be selected for enrollment in a programme in which 60 percent of the seats had been designated for operational occupations (Goldenberg, 2006). Irina Goldenberg's (2006) report for the Department of National Defence contends that women have historically been underrepresented in Command and Staff programmes at the College due to a variety of systemic issues. Susan Gray (2008) asserts that barriers to women were primarily due to difficulties in enrollment under a system of eligibility derived from merit lists which use members' superior officers' evaluations of their yearly performance to determine their acceptance.

Gray writes that performance evaluations are based on members' "physical fitness, supervision of subordinates, leading change, accountability, initiative, leadership and dedication" (2008, p. 287). In her assessment, these qualities may have been structured and evaluated in ways that inadvertently privilege men (Ibid). Moreover, she notes that these qualities are subjective in nature, opening up the assessment of merit to ways that could privilege masculine behaviours, masculine leadership styles, and gendered assumptions about members' dedication and accountability, particularly in view of traditional notions of family and gendered domestic responsibilities (Gray, 2008).

Representation of women in the programme in comparison to men remains low, accounting for tough decisions in recent years as to how to arrange classroom compositions when, in some cases, there have not been enough women students to account for more than 1 out of 10-13 students per classroom. Drawing from the author's 2017 report to the Canadian Forces College, some women student participants had noted 
an observable shift in classroom culture when two or more women out of 10-13 were present. As a result, College leadership sought to increase the critical mass of women in classrooms by ensuring that at least two women were placed together, but, because of their low enrollment, some classrooms maintained $100 \%$ representation of men as a result.

Women focus group participants voiced concern about the way the placement of women into classrooms was handled. The following statement serves as one example:

Well you know we have to make sure that we don't have a single girl in the syndicate because we don't want to make them feel isolated or left out [sarcasm]. Nobody looks in the back of my truck before I leave to make sure I'm not the only girl there. Because I am fucking Commander, and this is what they pay me to do. If I have an opinion and a guy is talking over me then I should be able to find a way to get around that because we are all senior majors. . . I'm sure everyone has been in a male dominated work environment before (Women Students of the Joint Command and Staff Programme, 2018).

There was a range of opinions about the rationale as well as impact of the current distribution of women across classes. As the observation above suggests, one common belief held by some women students is that the placement of two or more women in classrooms was done to safeguard women, hence reifying stereotypes that women require special treatment, accommodations, and protections. Others, including students identifying as men, perceived these changes as an attempt to increase chances for diverse perspectives in discussion. Interestingly, pilot interviews for this dissertation project 
identified feelings expressed by several women students that having more than one woman in a classroom would level the playing field for them, as they perceived that strength in numbers increased their credibility, visibility, and influence in discussions (Brown, 2017).

However, the problem of how to compose classes according to gender remains a contentious issue simply because there are not enough women enrolled. As suggested by a woman identifying student in an individual interview, the level of women's representation in the student body is:

Terrible. There are what like, 25 women on the course. 25 out of 130 ? Not even a quarter? That's nothing. . . The way that they are distributing us across syndicates is an issue, and the big issue is that there are just not enough female students. If they want women to go up in rank and be represented, then you need to bring women on the course (Woman Student of the Joint Command and Staff Programme, 2018b).

While some participants resisted changes to syndicate composition, other participants noted positive outcomes. Observations of participants from the student body and staff indicate a common perception that a higher representation of women students often increased diversity of thought in classroom discussions and tended to raise more challenges to taken for granted assumptions based on comparatively higher instances of differing gender perspectives.

These assessments are presented in the following statement of a student in the focus group setting: 
When I find a difference and a change is when there are two or more women in the room. I think the biggest times when I sit back and reflect on how I respond is when either of those two females speak. Actually, I am almost a little bit more passionate when I have a counter point, or even when I have an agreeing point. So, it is actually a dynamic that I am watching carefully (Women Students of the Joint Command and Staff Programme, 2018).

Similarly, Academic Faculty observe a change from a masculine dominated environment to a more inclusive environment when more than one woman student is present in class or when more than one woman military member and student are present:

Participant One: I think the military is very good at treating their female officers as peers, but when the female officer isn't in the room then they have an entirely different behaviour.

Participant Two: But you need to have more than one. The dynamic is completely different. In seminars, for example, the discussion is very different when there is more than one female student.

Participant Three: How about zero women on some Advanced Joint Warfare Studies courses?

Participant Two: That's what I am trying to say. One and zero are pretty much the same. The dynamic is still masculine. It's a masculine way of behaving (Academic Faculty Canadian Forces College, 2018).

These perspectives contribute to a common perspective that the learning environment benefits from the greater representation of women, and the related assessment that there simply are not enough women enrolled in the Joint Command and Staff Programme. 
Noting that the low representation of women is a longstanding issue, special selection for the increased representation of women enrolled in the Joint Command and Staff Program began in 1997 in accordance with Canadian Armed Forces General Orders (CANFORGEN) \#053/97. The CANFORGEN was issued to address "systematic barriers impeding the career development of female officers" (Government of Canada, 2006, abstract). To adjust for systemic barriers, five additional seats were reserved "for the five most deserving female candidates that would not otherwise be selected" (Ibid, p. 1). The special selection protocol was intended to be implemented temporarily until systematic barriers towards women were identified and resolved.

After over two decades, improvements to the representation of women enrolled in the Joint Command and Staff Programme have been slow. Enrollment for women students is at a higher level than the early 2000s, up from an average of 5-7 students between 2000-2005 to 18 students in 2017-2018 (Government of Canada, 2006).

However, the increase in women's representation in real numbers also reflects the growth of the Programme overall during that time from 96 students in 2000-2005 to the roughly 130 students per year currently. Women's representation has grown from 5 percent at its lowest between 2000-2005 (Government of Canada, 2006) compared to close to 14 percent in the 2017-2018 academic year.

Confusion and frustration about the special selection process to increase women's representation was a consistent theme across students and staff. Of note, the special selection measure is problematically and colloquially known as "the pink list" among members of the College. This gendered term tends to remove the implication that women require special selection due to continued systemic barriers impeding their enrollment 
and instead infers that representation problems are women's problems (or problems with women). The following exchange between student participants reveals a common narrative:

Participant One: Own it. Don't make it this rumour thing. . That's what the College needs to do.

Participant Two: Makes me think that when we get these jobs it is open to second guessing. If I get to XO of the ship, do I actually deserve XO of the ship? If I went out to sea last year, did I actually deserve that or am I just making a quota?

Participant One: You want it because of your merit, you don't want it because you're a girl.

Participant Two: It discredits a reputation that you just built over 15 friggin' years. You get one job that maybe you did get by merit, but one pink list rumour, one quota rumour and all that good reputation is up for grabs (Women Students of the Joint Command and Staff Programme, 2018).

Indeed, this dialogue reveals how stigmatization about employment equity and the "pink list" sometimes creates a hostile environment for women, where their merits are questioned, and where their presence is viewed as removing opportunities for 'more deserving' men.

Negative consequences for one participant revealed in an individual interview included prolonged harassment by a peer:

There has been someone in one of the three rotations. . someone who was a hater. He told me from the beginning that I was probably there for the pink 
list because my career was going too fast. I know for a fact I wasn't. But, how do I defend myself from that? There was no fixing that asshole. . . He was sure to never say it out loud in front of people. He was smart enough to say it in private. That is not the College's fault. If I want to deal with it through the Chain of Command I can. But, it is also part of being recognized as being strong and valuable to the Army, is to deal with this stuff myself (Woman Student of the Joint Command and Staff Programme, 2018a).

The experience of harassment recounted here reveals how ineffective messaging about special selection measures sets conditions for women's capacities as professionals to be questioned and may have exacerbated misogynist thinking about women and their place in the military.

An Employment Systems Review report by a consulting firm in 2004 had similar findings to the observations of this dissertations' study participants. The review noted that some Canadian military members recognized the importance of the special selection measure and believed it to be a "justified employment equity initiative," while "others believe[d] that it is not fair, may lead to stigma and perceptions that women are selected based on less rigorous standards, and that the measure should be dropped" (Ajilon, 2004; as referenced in Government of Canada, 2006, p. 21). However, the report found that "the main issue is not with the special selection measure itself, but rather with the general lack of understanding as to why positive measures such as this one exist for the purposes of employment equity" (Ibid). 
While the observations of the 2004 report are validated by perceptions of this study's student participants, confusion about the use of special selection also remains common even among academic faculty:

Participant One: I am just thinking about the total number of women who have been loaded onto the course. It really hasn't changed that much. In 1999-2000 there were about 25 women on the course.

Participant Two: Yes. It's like it hovers between 9-12\%.

Participant One: My question is, with the history of bringing women into the College in I think 1976, and there is the institution of the pink list, and we still have used the pink list this year. . If you took the pink list away would we still have the numbers?

Participant Two: No.

Participant Three: We wouldn't have enough loading on, and loading is complicated because it is decided by service, branch and different groups get different numbers.

Participant Two: Well you are loaded on the basis of your potential for promotion and career advancement. I am not sure if the pink list contributes to that or not. If there is an institutional desire to have more women promoted, they have to come through here (Academic Faculty Canadian Forces College, 2018). ${ }^{61}$

\footnotetext{
${ }^{61}$ Academic Faculty also note that the special selection measure has been used to accommodate service couples. In one Academic Faculty's observation, depending on the year, the measure is used more or less depending on the quantity of service couples selected to enroll. This measure includes the loading of men in the Programme when their woman identifying spouse has been nominated for enrollment.
} 
As the last perception of this exchange notes, future generations of senior leaders of the Canadian Armed Forces' must first be educated at the Canadian Forces College to claim the institution's top positions such as the Chief of the Defence Staff. Yet, it is questionable whether efforts are being made to ensure that women have a fair chance to participate in this future. In this way, the College stands as a gatekeeper: one which can either reinforce existing obstacles for women in the profession, or one which can work to challenge and change systemic structural and cultural barriers to their career advancement. If leadership of the Canadian Armed Forces intends to improve fairness and inclusivity within the profession, more needs to be done to identify and root out gender inequalities. Moreover, the existing mechanisms to increase the representation of women in senior leadership must be more robust and intentions to improve employment equity measures and protocols must be made transparent and clear.

Currently, the Canadian Forces College employs two women academic faculty members in an indeterminate teaching capacity. Women also have limited representation as sessional instructors and lecturers; the author is aware of three women contracted in such roles in addition to herself over the past three academic years. Participants from students and staff observe the need for higher representation of women in academic roles. As one student participant noted:

If the College is unable to hire more women, then maybe get more women guest lecturers. There are a lot of knowledgeable women from universities in Toronto, Kingston, Montreal and Ottawa. If we are flying people in anyway, why not seek out knowledgeable women as well. In the long term I think 
there should be a better balance in terms of men and women teaching

(Woman Student of the Joint Command and Staff Programme, 2018a).

Similar observations were made across subgroups of participants about women's representation among military faculty.

In the 2017-2018 academic year there were two women military faculty, representing less than ten percent of this group. This representation is a significant improvement over previous years, which had no representation of women in these roles. Many participants observed that having women military faculty was important to their overall experience on the course, and in some perspectives, participants saw room for greater increases in women's representation, as demonstrated in this exchange among student participants:

Participant One: We need more [military faculty] that are women here at the College, because it is all about perception. Having people that are quality individuals whether they are men or women in that position that are seen constantly, all the time, makes a difference. Having more women [military faculty] would go along way.

Participant Two: Even more, female academics (Men Students of the Joint Command and Staff Programme, 2018).

In addition to the low representation of women identifying students, academic and military faculty, there are also very few women employed as military staff at the College.

Overall, the representation of women across the majority of occupations within the institution falls far below the twenty-five percent goal across the Canadian Armed Forces. In the perspective of an academic faculty member: 
My attitude is that we need more women here, both on staff and in the student body. I am not sure if it is $51 \%$ to be in line with society, or if it is some critical mass, like the $25 \%$ arbitrary quota. Clearly, there are not enough women here. I think as far as gender awareness, it is all about exposure and role modeling (Academic Faculty Canadian Forces College, 2018).

While participants overwhelmingly recognize a requirement to increase representations of women at the College across the board, many viewed these increases as complementary to other ways to increase women's presence as role models and specialists. Included in these observations is the perception that greater representation of women, as well as individuals with greater diversity in experiences and identities, would contribute to more robust learning opportunities for students and staff. As one military faculty notes, "we don't do a good job at making sure that we have people who represent different communities and different points of view. We have academics who tend to all look the same" (Military Faculty of the Joint Command and Staff Programme, 2018).

Despite low representation of women, as well as Indigenous and racialized groups at Canadian Forces College, many participants observe that going forward the College could take strides to lead the charge in investing in and increasing diversity. Many participants across sub-groups at Canadian Forces College shared a common perspective that the College could take steps to make itself the leading institution in the integration of diverse peoples.

A subtheme across groups regarding the need for greater diversity was the requirement to receive formal support and resources for integration initiatives from the higher Chain of Command. From the perspective of one military faculty member the low 
representation of diverse members "can be fixed. That [takes] simple direction from higher [Chain of Command].” Some participants pointed specifically to leadership within the Canadian Defence Academy as well as to the Chief of the Defence Staff as capable of making these goals tenable. Yet, the College must first take the initiative to raise these issues up the Chain of Command to receive critical support and resources.

Common assumptions about the benefits of the increased representation of diversity illustrated in this section, however, require critical reflection. Some shared suppositions may work to essentialize and reify socially constructed stereotypes about gender, race, and culture. Beliefs including the idea that increasing the representation of women and diverse groups equates to more robust discussion, and the notion that women and racialized individuals possess (innately) distinct gender and cultural perspectives were repeated across participant groups. While such suppositions may be well intentioned, they are often presented as broad and sweeping generalizations, ones which underestimate institutional socialization to gendered and cultural ideals.

Insights from intersectional, post-modern feminist and men and masculinities theories suggest that it is more accurate to recognize that one woman's point of view does not represent the perspectives of all women. That, rather than universal categories of identity, women, ethnic, cultural and linguistic groups are composed of individuals with multiple and intersecting experiences and identities related to power and status in societies. Identification with and ascription to multiple and intersecting 'kinds' of people organizes societies into hierarchies that can support material inequalities among women and other similarly broad categories of people (Butler, 1990). 
The reflections of some participants illuminate a cultural tendency to universalize and create ideological dualisms between men and women, Francophone and Anglophone, international and national students and staff, as well as operators and supporters in ways that often exaggerate essential, or inherent, difference. These generalizations may work to reify socially constructed gender, racial, and class binaries through the use of essentialist assumptions - such as the perspectives that women serve to improve the behaviours and thinking of men and that women can enlighten men with the 'feminine' or 'woman's' perspective on a given issue.

Gleaning from intersectional and post-modern contributions, women might be better understood as a loosely related group of individuals, connected by socially prescriptive understandings of sex and gender that have also been shaped by socially constructed and intersecting identity and experiential conditions (Crenshaw, 1991; Puar, 2007, 212). The intersecting identity and experiential conditions of each woman contributes to the development of their unique situated knowledge ${ }^{62}$ and positionality. This intersectional lens through which each individual views the world, if enabled to be shared and received with respect and dignity in a group setting, may contribute to multidimensional learning about and understanding of complex security and social realities.

\footnotetext{
${ }^{62}$ Situated knowledge refers to a post-modern critique of epistemologically objective knowledge. It defines the supposition which rejects 'objective truth', in favour of a point of view in which knowledge is contextual, contradictory, complex and fluid. Situated knowledge presumes the potential of feminist objectivity, in so far as it can be located among situated critical knowledges. These critical knowledges create some common standpoints and possibilities for shared understanding. For more on situated knowledge, see: (Haraway, 1988).
} 
Drawing from the insights of men and masculinities theory, a common quality among women, men and non-binary individuals within the military is their intense socialization to the profession (Goldstein, 2001). All members learn how to be military professionals through their engagement with dominant institutional perspectives, cultural practices, and norms. Through socialization processes within the military, women (as well as men, non-binary and racialized individuals) have often reported shifting their gendered qualities, practices and perspectives to fit dominant ideals of military masculinity and identity (Razack, 2004; Reiffenstein, 2007; Taber, 2015; Whitworth, 2004; George, 2016). In these ways, presumptions that increased representation of women, Indigenous and racialized members will cause shifts in dominant behaviours, contribute to diversity in perspective, and facilitate culture change, may take for granted the deep impact of military socialization. As such, the 'add and stir' analogy — that higher numbers of diverse groups inevitably equates to greater social equality—-falls flat.

Diversity in thought and perspective as well as transformations in culture within the Canadian Forces College involves more than increasing the representation of people with diverse identities. Active identification of and intentional thinking about the military's socio-cultural power structures and systems is necessary. Such structures and systems constitute the ruling relations that contribute to inequalities, social hierarchy, and power that privileges particular bodies, worldviews, experiences, identities and modes of being soldiers, sailors, aviators and professionals. Deliberate examination of sociocultural power in the military includes a critical assessment of the military's role in the cultural (re)production of patriarchy, colonialism, racism, sexism, misogyny, and white supremacy - all of which contribute to the lived reality of civilian populations that the 
military is tasked to protect, Canadian Armed Forces professionals themselves, as well as students and staff at Canadian Forces College.

\subsubsection{Theme 4: Addressing Potential Gender Bias within the Selection System for} Enrollment

As noted above, special selection measures were created in relation to an assessment of persistent inequality and systemic barriers for women in the Canadian Armed Forces. In this section, a theme across participant groups emerges that questions whether there are systemic barriers in the selection process itself and asks whether evaluations are biased towards masculine behaviours and men's qualities. This theme is illuminated in the following exchange among students:

Participant One: I know that efforts have been made for a few years already, but saying next year 50/50, well where are you getting these women? I think this would be biased. It would be completely biased.

Participant Two: So, I agree with you when you say that, however, the underlying assumption under that entire train of thought is that the selection process and system was unbiased to begin with.

Participant Three: It's a construct. It is a construct that is fed by an evaluation system that assumes it is not biased. This system is largely driven by the supervisor. The senior officer that signs off on the PER, and that's what feeds the 'objective' evaluation system. I mean, if you consider that the overwhelming majority are male dominated supervisors. .." 
Participant One: But it goes to who gets here, who gets into the institution, and then who gets into the College. If you are saying "oh we may not be getting the best." Well, 'the best' according to what standards is really important. When you consider the evaluation system, what is 'best'? (Men Students of the Joint Command and Staff Programme, 2018).

Akin to the observations of academic faculty in the previous section, this exchange points to the possibility of gender bias in the evaluation system used to nominate military personnel for enrollment to the Joint Command and Staff Programme. In doing so, participants question whether the low representation of women is caused by institutional social barriers to women's professional advancement, and by extension they ask whether gender biases are leading to the preference for men over women for nomination.

These suppositions could be supported by research that demonstrates the slow rate of growth for women's representation in leadership roles within the Canadian Armed Forces (Davis, 2007, p. 93). A study in 2002 revealed that despite employment equity policy and structural changes, women's representation across all ranks experienced marginal growth since 1989, with the Air Force showing the highest integration of women, followed by the Navy and Army (Davis, 2007). Other research suggested that attrition for women was six times higher than was the case for men in more masculinized trades such as the combat arms (Winslow and Dunn, 2002). Women's representation across the military has not grown significantly since the 2002 study, hovering at 15 to 16 percent of the total Forces (Davis, 2007, p. 93).

While dated, Winslow and Dunn's (2002) research remains relevant as further increases in women's representation have been marginal, particularly in senior leadership 
(Government of Canada, 2019), and importantly because this work uncovered that barriers for the greater integration of women across the Forces were largely social such as, endemic sexual misconduct as well as traditional conceptions of gender and the military, gender roles, and familial obligations (Davis, 2007, p. 76-80). These observations remain common themes presented in this dissertation. As this study demonstrates, social barriers to the integration of women are deeply cultural. Barriers to the cultural inclusion of women and their greater representation have been related to stigma about women, femininities, and the military as well as masculinist views that are present to varying degrees depending on the unique cultures and subcultures within the military’s services and occupations (Winslow \& Dunn, 2002).

The following exchange among student participants presents similar observations, noting that the degree to which gender biases and women's integration are present is relational to service and occupation:

Participant One: For my occupation in general, and in health services in general, we are female dominated. Mostly, right? We are going to be more so in the years that come. The ratio now for most of those professional schools is $75 \%$ or better for women. However, most leadership positions are filled by males, not all of them. Over half of our Lt. Cols. are females right now. Are there any hindrances in peoples' occupations that you can identify that potentially have a gender bias?

Participant Two: MARS. Like, we have had one female Captain of a major war ship. And I think just begrudgingly this year they have finally made a female a Commodore. 
Participant Three: Begrudgingly [snickers]

Participant Two: Well I say begrudgingly because I was privy to some of the internal politics that happened around that (Men Students of the Joint

Command and Staff Programme, 2018).

This dialogue signals the perception that gendered divisions within occupations and trades continue to happen both horizontally, across occupations and trades deemed more feminine or masculine (like health services versus the combat arms), as well as vertically, where men continue to dominate positions of leadership and authority across all services and occupations. This observation could illuminate that similar barriers exist today as they did a decade or more ago, when at the time it was said, "women are beginning to be appointed to senior operational leadership positions in the $\mathrm{CF}$, [but] have not progressed in large numbers to the most senior ranks, particularly in the combat arms" (Febbraro, 2007).

As noted in the observations of participants above, the low numbers of women in mid-to senior level leadership positions may have an effect on the number of women available to be selected for nomination to the Joint Command and Staff Programme, but in addition to this, there may also be institutional cultural norms which idealize maleness and particular (subjective) masculine qualities, advantaging particular men over women, non-binary members and other men (Taber, 2009; George, 2019).

Similar sentiments were shared by a participant within a student focus group. In this case, the participant recognizes an intersectional marginalization present within the culture of the Army: 
I think we still have a huge cultural bias on most everything, the intelligence side, the Army side, and it is based on the, I mean you see it predominantly through gender, but it's across the board... We are trained to think and perceive things in a very narrow way. When we assess people, when we look at them, if they don't fit what we perceive as having the right characteristics? When we talk about command and commanders being command-centric, I think we still see and judge in an ethnocentric manner. . That bias, I think is there throughout everything, be it what job you give someone, how you assess them, and I certainly see it reflected on boards in any assessments in the places I've worked in the last few years (Men Students of the Joint Command and Staff Programme, 2018).

This and the preceding observations recount the ways that service and occupational subcultures develop specific forms of gendered and racial ideals about what constitutes a model professional. As this student observed, such biases may materially impact members' candidacy for promotion, and the ways in which they are evaluated. By virtue of being women or 'different,' some participants observe that diverse members are placed at a disadvantage in some services and occupations. From these observations, then, it is not unreasonable for participants to suspect that the nomination process for the Joint Command and Staff Programme may also suffer from similar bias, posing barriers to the increased representation of women, Indigenous and racialized groups at Canadian Forces College. $^{63}$

${ }^{63}$ This is an area that is beyond the scope of this project but requires further investigation. 


\subsubsection{Theme 5: Observations of a Masculinized Classroom and Learning}

\section{Environment}

A consistent theme across participants from the student body, academic and military faculty and staff was the recognition of masculinist practices in the classroom and within the larger learning environment. Idealizations of more 'aggressive' and 'alpha' masculinist control over dialogue was noted as common and disruptive. This common theme among participant groups identified cultural tendencies toward competition over collaboration in some syndicate (discussion group) settings. In the perspective of some student participants, the prevalence of competitive group dynamics was heavily dependent on social cues and direction students received from military faculty members, as well as the number of 'alpha' personalities in the classroom.

Student participants note in many cases that most students have learned to use 'alpha' and 'aggressive' masculine qualities to gain credibility and to help establish their points of view in syndicate discussions. This gendered social dynamic is highlighted in the following dialogue among student participants:

Participant One: I think that there is probably a significant percentage of women in the military that take on more masculine characteristics and shy away from vocalizing a gendered perspective period, so that they can fit in.

Or, the reverse, they may not participate as much because they are so outnumbered.

Participant Two: The women here have learned to succeed in the Forces in a male dominated environment. So, they know. You are not dealing with 
someone ignorant of the dynamics of learning. They know how to communicate. They know how to say things in a way that will get their point across (Men Students of the Joint Command and Staff Programme, 2018). The second statement is particularly revealing, as it signals the observation of the requirement for women in particular to reorient their gendered communication styles and performances to fit cultural norms in order to be successful. At the same time, this statement does not signal a desire for the organization to shift or change in any significant way, or for the military to become culturally inclusive. As such, this narrative may indicate complacency or comfort with diverse groups being required to adjust to the military's idealized gender and cultural norms.

Some participants suggest that particularly 'alpha' and 'aggressive' masculinity is common in the gendered actions, discourse, and performances of students from the combat arms. Both student and staff participants noted an idealization of Army operator gender archetypes at the College. The following observation from a student participant provides an example:

The people that speak the most are the alpha. They tend to cut other people off who are trying to speak up. And that is for both men and women. . . From what I saw, the people who were more prone to take over the conversation were mostly combat arms. They kind of have the attitude that "I know best" (Woman Student of the Joint Command and Staff Programme, 2018a). Pressures for students to behave in a more aggressive, 'alpha' fashion, is revealed in the following observation by a student in an in-depth interview: 
If someone is trying to intimidate me and raise their voice and show their power, I can do the same thing. I will raise my voice too. I can do that. But, if someone is just arguing with me, I will stay calm, and be like "okay, this is my point of view. . . If I have to really get out of my shell and be a bit more rude, afterwards I am asking myself if I was too rude. That's not like me. They will think I am a bitch, because that is the association they make. If a guy does it, it's okay. He is just showing his power. If a girl does the same thing, she is a bitch (Woman Student of the Joint Command and Staff Programme, 2018b).

These reflections illuminate a gendered double bind faced by some women at Canadian Forces College and is reflective of similar experiences of women in the Canadian, British and American militaries more broadly (Tait, 2020; Woodward and Winter, 2007). This student recalls feeling pressure to present behaviours that are 'not like her' and are more aggressive and more masculine in quality in order for her perspective to be recognized as legitimate. Paradoxically, however, when these gender behaviours are practiced by women, they are observed culturally as inappropriate and result in women being perceived as 'bitchy' and unprofessional. In essence, the reflections of participants in this section signal that much attention is being paid to the gendered practices and behaviours of women at Canadian Forces College and demonstrates pressure being felt by women to adapt and change to fit the learning environment's masculinist and male dominant culture. $^{64}$

\footnotetext{
${ }^{64}$ Similar findings in investigations of military gender relations in British and Australian militaries have been noted in academic research. For examples, see Woodward and Winter, 2007.
} 
Observations of the practice of 'alpha' gender presentations in syndicate and their relation to directions by military staff have also been observed. This relationship is presented here in a statement by a student participant in an in-depth interview:

I do think that some of the [military faculty] have strong biases towards certain trades. . . But there is definitely the need to speak loudly. Interrupting is okay ... the way some of those discussions were run was extremely unprofessional. . . But, that was very often encouraged. . You wouldn't survive in the real world if this is how you would provide your comments in a meeting or in a group discussion. So, why do we do it at the College? Is it a gendered thing? I don't know. It is definitely something the guys feel more comfortable doing (Woman Student of the Joint Command and Staff Programme, 2018a).

Similar perspectives are illuminated in the following exchange between student participants:

Participant One: We're graded by the [military faculty], and depending on the [military faculty member], very differently. My first [military faculty] was very much a participant and would sit with us and partake in the conversation. [The next had a] very different approach on leadership and how to do things — which changed how you think. . .the white male who is standing over me ticking me is the one judging how you think, how you sit, how you talk and how you present yourself. That has tremendous impact on anyone, and when you speak French, and someone right away corrects you for doing that, that affects everyone. That micro aggression: "everyone who is French, or 
Franco speaking, has to leave and go to another room because we have to sort out the bilingual problems you guys have" well, what does that say?

Participant Two: That was brilliant. That was awesome [sarcasm].

Participant One: How is that inclusive and how does that help the bilingual problem within the College? It's not everyone who speaks French who has the problem and they need to leave! Then the micro aggression and things that go on at this school, when you start to pick at it, is huge! (Men Students of the Joint Command and Staff Programme, 2018).

This exchange also reflects the ways in which members of the College are signaling intersectional dominance, where white, English speaking staff and students with particular masculine qualities become most privileged. The perspective of 'microaggressions' directed at French speaking students is another common theme perceived by some participants as a mechanism through which linguistic and cultural divisions have been amplified within the culture at the College.

While observations in this section explore the ways in which hegemonic masculinities are enacted by members of the College, some staff and faculty have observed gender practices in which men in particular have asserted dominance over women in the classroom and in the work environment. Practices of 'raising voices,' questioning authority, and mansplaining were commonly noted. An illustration of this subtheme is outlined in this exchange among academic faculty members:

Participant One: I sat for hours in a gender and security topic ... and there were two students presenting, one of whom was a woman, and she was repeatedly and consistently silenced and mansplained by her male co- 
presenter in a way that was shocking, obvious, patronizing and appalling. As a result, he will get a shitty mark. Maybe that's what it will take, I don't know.

Participant Two: I have seen that in [academic and military staff] meetings. So.

Participant One: Yep. The mansplaining is crazy here (Academic Faculty Canadian Forces College, 2018).

Similarly, some women student participants perceived having their ideas dismissed because of gendered assumptions.

As this exchange among student participants reflects, some women students have learned from experience what to share and what not to share in group discussions due to gendered stereotypes as well as masculinist worldviews that are dominantly held:

Participant One: There were things, because I was the only female in my syndicate that I would not say in front of a group of men because they would, from a stereotypical perspective say "yeah, but you're just a girl so." Participant Two: Oh, that's blanketing them. Woah. You didn't give them the opportunity to not be that?

Participant One: I did.

Participant Two: Okay, and they let you down.

Participant One: Correct (Women Students of the Joint Command and Staff Programme, 2018).

In this instance, one woman participant reflects on choosing silence as a strategy to fit in, knowing that her feelings and ideas had been dismissed for gendered reasons in the past. 
In this way, silence and voice determine power and hierarchy in this context and indicate a high level of social policing of speech and behaviour on the basis of gender.

Observations about the strategic use of silence also emerged in pilot interviews with student participants, where some women students identified practices of being ignored, silenced, or dismissed by men as a mechanism to reinforce established hierarchies and power in the learning environment (Brown, 2017). Silence has often been used as a powerful way to protest or to endure the existing social hierarchy by students. For example, in my role as a sessional instructor in the 2016-2017 academic year, I observed a group of women students wearing very fashionable feminine civilian clothing, and an allied man wearing 'metro' clothing, on days where military dress was made optional rather than required. After asking these students about this practice, they explained that they used 'dress up Fridays' as an expression of role reversal and power. Women members of this group styled themselves 'the mean girls' and demonstrated behaviourally and visually different ways of being 'a soldier.' They used this silent method of protest to demonstrate that they were fed up with the status quo. The same year, some women students set up an extra-curricular yoga practice directly beside a scheduled rugby practice to demonstrate different ways of expressing athleticism that are not as traditionally masculine or idealized in the military context. While my personal observations are not a part of this study's primary data, they are illuminating to the context in which this study's participants are situated. As Jane Parpart and Swati Parashar (2019) explain, silence is sometimes a very important strategic method in the military as well as many other institutions to deal with inequity. 
As Jane Parpart argues, silence can be used as method of protection and as a "tool when voice was either silenced or inoperative" $(2020,317)$. Parpart also notes that silence can constitute an important form of agency and a method of power (Ibid). Drawing from Xavier Guillaume's work on the subject, she argues that practices of silence can destabilize relations between powerful and less powerful, and that silence can challenge "established notions of hierarchy and power" (Ibid). The practices reported in this study's focus groups and those that I observed in my daily work indicate a collective use of silent, often symbolic, strategies to interrogate or work around the masculinist and male dominated social hierarchy at Canadian Forces College.

Observations of these sorts of gendered ruling relations are also keenly observed by staff and faculty. As the following reflection from a member of the Information Resource Centre serves to demonstrate:

One of my best and worst examples ... would be someone storming into the library. . . and looked at our network manager who is a very competent woman and said "I want to see your network manager now!" She said, "oh, that would be me." And he said: "no God damn it, I don't want some data entry person, I want the network manager!" ... So, there is a dynamic where we expect women to have different roles, but there is not as much recognition of the competence of women to have those roles. You notice it in the students. Some students have adapted to the constructs of how their colleagues communicate. Others who have chosen different ways often struggle (Information Resource Centre Staff, 2018). 
This perspective illustrates some of the ways in which the learning environment becomes a deeply gendered space, where competition, 'aggression', and male dominance may be encouraged or facilitated by ongoing gender hierarchies and gender role expectations in the larger military culture, hierarchies and roles that are sometimes exacerbated as they are reproduced at Canadian Forces College.

Interesting to note, scholarship from men and masculinities and international relations theorists demonstrate that gender inequality and patriarchal social relations often worsen in conflict contexts (Duriesmith, 2017; Parpart, 2010). Drawing from reflections across this study's participant groups, perhaps this insight can be extended to militarized contexts and environments where preparation for war is ever present and where militarism is associated with patriarchal power. In the context of learning about war readiness in the Joint Command and Staff Programme, patriarchal gender roles and male dominance are constructed in reportedly hardened and rigid ways, experienced by some students and staff as intensifying their exposure to gendered, racial, sexual and cultural inequality and discrimination. Aggression and competition, while beneficial on the battlefield, may not translate appropriately to learning in the classroom.

Thinking about this point, military faculty within focus group and in in-depth interviews debated the merits of competition for learning. As one military faculty member argues: It has always intrigued me why this college . . . has a form of assessment that is competitive in a syndicate discussion. It's not objective. . . It is very difficult to judge academically. There are those who like to dominate the discussion, while there are others that feel that they can't get a word in. . It's too competitive to be objective amongst the group, because it doesn't account 
for people who may not feel comfortable in that environment (Military

Faculty of the Joint Command and Staff Programme, 2018).

This example is demonstrative of a common theme across students, civilian staff, military and academic faculty that a culture of competition and related frameworks for assessment set conditions for rivalry, opposition, and aggression among students and that these tendencies may exacerbate existing intersectional social hierarchies in the learning environment. As suggested by two military faculty, Canadian Forces College could valuably draw from the way classroom participation is evaluated in other Professional Military Education institutes. They note that these insights may illuminate useful and alternative ways of designing more inclusive classrooms (Military Faculty of the Joint Command and Staff Programme, 2018). Educators and senior leadership at the College might also draw from academic research on setting conditions for equality in learning environments. ${ }^{65}$

There are a range of feelings that were presented about 'healthy' competition among military faculty. As one military faculty member argues, a competitive environment is often perceived to have advantages for the conduct of war. Principles and theories about warfighting are perceived by College leadership, military faculty, and some academic faculty to be key learning areas at Canadian Forces College. In defence of warfighting, one military faculty identified the perception that gender and cultural

${ }^{65}$ For examples see: Brown, Cervero, \& Johnson-Bailey, 2000; hooks, b. (2016). Section II: \#BlackGirlFeminism: Existing, teaching, and learning on the edges and beyond. Meridians: Feminism, Race, Transnationalism, 15(1): 109.; Enns, C., Sinacore, A. \& Scholars Portal. (2005). Teaching and social justice: Integrating multicultural and feminist theories in the classroom (1st ed.). Washington, D.C: American Psychological Association. 
considerations detract from the real purpose of the Joint Command and Staff Programme; to prepare its students for war. This military faculty member posits that:

The main goal is to prepare for war. I think that we need to have clear lines of operation at this College. And, to understand if this perspective matches one of these lines of operation. If it does not, I can trust military faculty to control syndicates and to prepare for war. Other considerations are very interesting, but I am not sure that we are staying in a good line to think about a lot of other problems which offer us invisible enemies. When I read the paper [Brown Report, 2017], I am fighting against an invisible enemy. I find it very difficult to deal with that (Military Faculty of the Joint Command and Staff Programme, 2018).

As this statement illustrates, an additional theme among some participants is that the purpose of the College is to develop war fighters or warriors, rather than the officially stated purpose, to prepare students for "command and staff appointments . . . across the continuum of operations in national and international settings" (Government of Canada, 2019b). This formally espoused learning objective for the Joint Command and Staff Programme signals an expansive Programme in which warfighting is but one component among others.

Piecing together the themes presented in this chapter helps to make visible an apparent larger ideological struggle within the culture at Canadian Forces College. Namely, that a conceptual tension exists between those that perceive the military's purpose as fighting in wars and those who construct the military identity as a warrior, versus those who conceive of the purpose and identity of the military in other ways. This 
broader philosophical struggle over the identity and purpose of the military seems only to intensify desires for some members of Canadian Forces College to maintain the dominance of a deeply gendered and racialized operator and war fighting identity over other military identities.

As illuminated by the observations and experiences of participants, the cultural (re)production of the war fighting identity at Canadian Forces College is often embodied in more 'aggressive' and 'alpha masculine' ways. While dominant, this war fighter, alpha operator and masculinist archetype is not the only identity that is enacted at the College. As will be detailed in the following sections, a range of gendered identities and expressions emerge. That in fact, there are many (often marginalized) identities in competition for belonging within the College's learning environment.

In contrast to those who are resistant to feminist ideas, those who perceive the merits of thinking about diverse gender and cultural perspectives also seem more comfortable with questioning the legitimacy of the idealized warfighting identity. This critical thinking about the warrior identity, and the warfighting purpose of the military, may be rightly perceived by others as destabilizing and contaminating to traditional assumptions about the military profession, the rationales used to perpetuate the institution, and the identities that have served to validate these. Undermining social constructions of power and privilege based on gender, racialization, sexuality, ability, and social class is precisely the point of feminist thinking, and much feminist thinking has focused on the use of the military by the state to enforce these social orders in societies (Cohn 2008; Cockburn 2011; Enloe 2014). 
In this way, the 'invisible enemy' to the dominant military identity, and to warfighting as the primary purpose of the military, may indeed constitute gender and cultural perspectives. After all, it is through these perspectives that learners develop insight about power and the way that it is distributed in institutions and societies. It is through these perspectives that military members learn to question taken-for-granted assumptions within the military, and these questions may create uncertainty about the legitimacy, viability, and appropriateness of dominant conceptions of military identity and purpose, particularly in relation to the current cultural and operational contexts in which the military and its members are engaged.

\subsubsection{Theme 6: Perceptions of a lack of trust and confidence in students as professionals}

A common theme noted across participant subgroups is the perception of mixed messages from College leadership to students about adult learning. Many student participants observe that the College promotes the idea that students are mature, responsible, and ought to take ownership over their own learning. Yet, students perceive messages that in fact, they are often not trusted by their Chain of Command, that they are presumed to be immature and require close monitoring by military faculty. As a result, some student participants recall feeling 'babied,' observe being given little space to determine their own learning, and assert that their schedules were full, rigid, and developed by faculty and staff rather than themselves. 
Some of these recollections are explained by a student participant in an in-depth interview:

Oh, I think it is meant to put the students in their place. Realize that the [military faculty] and the staff, that what they say is the rule of law. . Don't question it. Don't think for yourself. . . I don't feel in control of my learning (Man Student Joint Command and Staff Programme, 2018a).

Another student participant echoes the sentiments above, explaining how military faculty can intensify perceptions of mistrust and infantilism felt by students:

I would say at least half the students are disillusioned with the College right now and the way that [curriculum] was presented to us. Some of the things we have talked about is the babying of senior officers. It is not creating broad thinkers and people that analyse their thought process (Man Student Joint Command and Staff Programme, 2018b).

These examples help to illustrate a common theme among student participants, namely, the presence of a rigid social hierarchy between students and military faculty and intense social control. In addition to social hierarchies produced among students based on service, occupation and trade as well as gender, race, sexuality, language and ability, there are overarching social hierarchies that draw on these principles but are also based on rank and chain of command. The modes of social control over students based on rank and command structure observed include: the intensity of loading schedules with formal class activities during working hours, and informal social activities after working hours and over some weekends; tendencies to strictly manage and control student discussions in 
classrooms and auditoriums; and observations that there are few opportunities for students to take ownership over their learning and professional development.

Participants also reported experiencing the negative impacts social control on their ability to learn and think critically. For example, some students observed that the prospect of allowing 'subordinates' the freedom to make their own choices often runs contrary to normalized rank structures and the chain of command in the military:

I think the College treats JCSP like your basic trade courses, your basic training. They don't treat us like senior officers. They treat us very much like lieutenants on the course, before you're trade qualified and everything has to be regimented and ordered. They don't give anyone leeway to use their free range of thinking (Man Student Joint Command and Staff Programme, 2018b).

Validating this reflection, another student participant notes:

I found that I enjoyed the topics on some of the papers and wanted to put more into it, but there is no time to do that when all of your time is taken care of and planned out in a spreadsheet that the program director has (Man Student Joint Command and Staff Programme, 2018c).

These perceptions of power and hierarchy in the learning environment demonstrate how over-programming and attempts to control learning may have impeded the degree to which critical thinking and professional development are possible at Canadian Forces College. This form of social control also has a gendered flavour, where being babied is experienced as a feminization of students constructed as in need of close surveillance and scrutiny by the masculinized patriarchs of military faculty and leadership. 
Drawing on the key emergent themes in this chapter on hidden curriculum within the Joint Command and Staff Programme, it is vitally important to recognize what approaches to pedagogy are required for the types of learning that the College has set out to develop in its Joint Command and Staff Programme. If Canadian Forces College is indeed an institution which prizes the development of critical thinking, it must set the right conditions for it. While key principles of critical thinking are taught to students at the beginning of the academic year, a common narrative among both staff and students is that students are often not allotted the space or the scope to put critical thinking into practice. Crucially, the larger issue recognized widely by students and staff is that extant practices of pedagogy reflect the transfer and reproduction of often exacerbated social hierarchies and social power arrangements within the military. In the views shared across participant groups, the College requires deep and meaningful introspection and work to develop more horizontal power distributions in the learning environment. Reorganizing social order from hierarchies to communities of thought could better set cultural conditions for students to develop and express critical thought.

As a result, recognizing the ways in which the transfer of military social hierarchy and power dynamics can impact Professional Military Education is an important first step to creating inclusivity and deep learning. Additional steps would be to consider the baseline knowledge of senior military professionals (Kenyon \& Hase, 2001; Hase \& Kenyon, 2007; Knowles, et al, 2015), their socialization to the military and military identities (Razack, 2004; Whitworth, 2004), and to understand that students have developed their own theories about the world before they enter the learning environment. 
Dominant social constructions in Canada and in the military shape the cultural conditions through which students filter and receive curriculum. Hence, priming the learning environment for success takes applying principles of a student-centered andragogic framework. Such principles move away from universal (positivist) theories as to 'how the world works' and toward intersectional and post-modern feminist (post-positivist) theories that engage students in developing questions and understanding about 'why the world works in specific ways' and for whom.

Setting appropriate social conditions for students to apply critical thought allows them to investigate the mutually constituting political, economic, gender and cultural forces that shape (in)equality and (in)security. Doing so would enable military professionals to learn how to identify and challenge the 'socially unjust social structures, policies, beliefs and practices' of the societies and institutions in which they live and work (Tiessen, 2018). Related to this, pedagogical approaches must be mindful of the perspectives, positions, and situatedness of students (the forces that shape their ontologies) and challenge how and why students have constructed knowledge in the ways they have (to make visible their epistemologies) (Canning, 2010). A more horizontal and student-centered approach could help to guide students away from searching for the right answer (usually signaled by military faculty, academic faculty and dominant students in the room), and toward a more critical examination of what ought to be considered in order to ask the right questions (using more democratic and collaborative means) (Kenyon and Hase, 2001). 


\section{Chapter 4: Formal Curriculum: Development and Delivery of Gender and Cultural Perspectives}

\subsection{The Formal Curriculum}

The integration of gender and cultural perspectives in the Joint Command and Staff Programme has been met with varying degrees of success and challenges. The observations and experiences of this study's participants with developing, delivering, and learning about gender and cultural perspectives in the formal curriculum are organized into eight broad themes. Each broad theme has a series of subtopics which are organized into subthemes. The following broad themes and subthemes identified in the transcripts of focus groups and individual interviews with this study's participants are as follows.

The first theme encapsulates the common misconception among staff, faculty, and the student body that 'gender means women.' This theme is articulated in a subtheme about confusion over the meaning of gender is broken down into corresponding subthemes including observations that within curriculum, gender is most often discussed in relation to 'women's issues', specifically in relation to women's recruitment, retention, accommodation and integration in the military. Another subtheme is the observation that gender is often conflated with the Canadian military's sexual violence policy Operation HONOUR, with the implied understanding that Operation HONOUR is really about 'punishing men for victimizing women,' rather than a policy which engages all military personnel in addressing, raising awareness about, and preventing sexually inappropriate behaviour and sexual violence within the institution.

The third subtheme is the observation that gender and cultural learning would be better focused on how policy, institutional structures, and social relations within the 
Canadian Armed Forces can differentially impact personnel with diverse genders and sexes. The fourth subtheme presents the observation that learning would be more effectual with a focus on how gender perspectives relate to the military profession, as well as to domestic and global security and defense. The remaining subthemes for this theme include observations that there is a requirement for learning about what gender really means, and what sorts of gender perspectives are important for students to recognize and act upon in their work. While required, women's representation and integration in militaries and societies alone cannot solve issues related to gender power, gender inequalities and patriarchy. Finally, learning about gender and gender perspectives is essential to understand the social systems, structures, and relations which cause (in)equality and (in)security.

The second theme captures common references to the ad hoc and vague introduction to gender and cultural perspectives in curriculum. Subthemes include: observations that teaching gender perspectives seems like an afterthought or a "tick in the box"; that gender is often viewed as a 'flavour of the day'; that gender and cultural perspectives are poorly integrated within curriculum; and that the application of gender perspectives ranks low among other military priorities. Finally, the relationship between gender perspectives and cultural perspectives is limited in curriculum but is observed to be an important area of investigation for the military profession.

The third theme is derived from collective observations that readings and topics for discussion across curriculum use largely male perspectives and masculine narratives about conflict and security and rarely integrate cultural perspectives. Subthemes include observations that: readings and concepts focus largely on male authors and men's 
contributions to the military profession; narratives about conflict, war, peace, insecurity, leadership and command have masculine undertones and gendered implications for ways forward; and that there is limited integration of cultural perspectives in readings and course content.

The fourth theme examines common perceptions that additional tools, training and opportunities for staff and faculty are required for them to gain competencies on gender and cultural perspectives. Subthemes include the common reflection by academic and military faculty of being ill prepared to facilitate gender and cultural learning, and the request by military faculty to be provided with better tools and training to facilitate learning and inclusive classrooms.

The observation that understanding gender and cultural perspectives is essential to the success of the military profession is the fifth broad theme discussed in relation to formal curriculum. The corresponding subthemes identified are that implementing Canada's defence policy 'Strong, Secure and Engaged' ${ }^{\prime 66}$ requires an understanding of gender and cultural diversity so that the institution can better reflect the society for which it serves. Another subtheme indicates that gender and cultural perspectives are essential to the success of domestic operations and missions. The final subtheme highlights that understanding gender and cultural perspectives in international operations and missions is tantamount to the development and maintenance of international peace and security.

\footnotetext{
66 'Strong, secure and engaged' is in reference to Canada's Defence Policy wherein the policy states that the Department of National Defence and the Canadian Armed Forces will make Canada 'strong at home', 'secure in North America', and 'engaged in the world.' Canada. Department of National Defence. (2017). Defence Investment Plan 2018, Strong, Secure Engaged: Canada’s Defence Policy, sec. 1.1.
} 
The sixth theme exposes common experiences of gender bias in the assessment and evaluation of leadership and officer-like qualities in the Joint Command and Staff Programme. Subthemes include: associations of leadership with hegemonic military masculinity constructed in the culture at Canadian Forces College; assessments of leadership and officer-like qualities as equated to masculine practices such as heavy drinking at the mess and participation in competitive contact sports; assessments that privilege students with traditional patriarchal family arrangements and obligations; and gender biased assessments of leadership and officer-like qualities which evaluate students on the basis of erroneous or false information.

The seventh theme highlights common observations about the need for a cohesive pedagogical approach to deliver gender and cultural learning. The first subtheme relates to observations that: more robust and cohesive teaching on what gender is, what gender and cultural perspectives are, and why they are useful to military professionals is needed. The second subtheme references the narrative that teaching approaches must provide opportunities for students to apply gender and cultural perspectives to $21^{\text {st }}$ Century problems that are relevant to the military profession, including in institutional, domestic, international (post)conflict and humanitarian contexts. The final subtheme captures observations that direct links need to be made between Canadian Armed Forces and government of Canada policy and gender perspectives and that students must have opportunities to apply GBA+ throughout the Joint Command and Staff Programme.

The final theme presents common observations that an adult and student-centered approach is both desired and noted as necessary to learn about gender and cultural perspectives. Subthemes include perceptions that the Canadian Forces College poorly 
executes the adult-learning approach, the perception that current power structures and social orders at the college pose barriers to adult and student-centered learning, and that more horizontal distributions of power are needed. Another subtheme is that the development of critical thinking requires the College to provide more scope and space for students to share their professional experiences, to collaborate and to engage in selfreflection. As an extension, student participants note that ultimately it is these facets of adult learning that enable the sorts of shifts in institutional and personal philosophies that enable desired culture change within the military and beyond.

\subsubsection{Theme 1: The Misconception that Gender Means Women}

Addressing the misconception that gender means women is particularly important for the profession of arms. As noted in the introductory chapters, gender-based inequalities among and between men and women, boys and girls, and non-binary people often manifest or are exacerbated in conflict and post-conflict contexts, creating differential degrees of (in)security among those privileged by gender constructs, and those marginalized by them (Parpart, 2010, 2015; Duriesmith, 2017, p. 16-17). Thus, understanding gender and gender perspectives enables military professionals to ask the right questions about conflict, and determine best ways to address insecurity.

While most staff and students recognize the significance of gender and gender perspectives to military work, participants showed a good deal of confusion and frustration over what gender and gender perspectives are, as well as uncertainty about the relevance of gender to the military profession. Across focus groups and in-depth interviews is a common conflation of gender with women, and if not with women, then a 
conflation of gender with men and women. What is commonly mistaken is the supposition that gender is about biological sex, when, as defined in the introduction and theory chapters of this dissertation, gender refers to the production of social order in relation to feminine and masculine traits associated with biological sex that are culturally constructed in societies.

A poignant example of gender highlighted by participants in the preceding chapter is the construction of 'alpha' 'operator' 'warrior' masculinity, a category which describes a particular construct of masculinity that works to organize social order and hierarchy at Canadian Forces College. As described by participants, this gender category is commonly used by both men and women to gain social power and advantages. Though, in patriarchal societies, masculinities are more readily ascribed and associated with men. Thus, it typically takes a great deal more effort for women and non-binary people to fit masculine ideals. In this way, gender is fluid and can be enacted by persons of any biological sex to create powerful hierarchies within communities of people. Drawing on men and masculinities theory, and illuminated by examples in the previous chapter, it takes effort to maintain gendered social orders, and because these orders are socially created and reproduced, they are subject to change over time (Connell \& Messerschmidt, 2005).

Feminist theory specifically challenges patriarchal power, noting that more value is awarded to men and masculinities in most societies. Patriarchal power grants most men special privileges over women and non-binary individuals and bestows certain men privileges over other men (Ibid). Some feminist theory, such as liberal feminism, works to gain equality for men and women within existing systems and structures of societies, 
while other more radical feminist theory seeks to deconstruct, or challenge, systems and social structures that privilege men in the first place (Hacking, 1999).

What participants overwhelmingly note, however, is a tendency to confuse gender with women. This confusion leads to frustrations when considering gender perspectives and applying gender analysis. As the following perspective of a military faculty member notes:

We have a tendency in this group to talk about gender equaling women. Alright, but gender equals much more than just women. So, when we did the case study and they wrote on gender in Colombia, that whole paper started to focus on women and women's rights in Colombia. When we talk about gender, we need to broaden our perspectives ourselves as in "this is actually broader than just a women discussion" (Military Faculty of the Joint Command and Staff Programme, 2018).

A similar observation is made by a student in an in-depth interview:

A lot of times when we talked about gender in the military, the discussion about Operation HONOUR always comes back. And, Operation HONOUR is not just about women. So, they associate the two together, the same way they associate gender with women (Woman Student Joint Command and Staff Programme, 2018a).

These observations of the conflation of women and gender are also present in understandings about Canadian Armed Forces’ policy. 
For example, in an exchange among women participants in focus group, members noted the difficulties which arose out of the belief that Operation HONOUR is a policy about misconduct against women:

Participant One: No, Op. HONOUR is about sexual harassment. It is not about being a woman.

Participant Two: But, it is the interpretation of it on the course. Because if you ask your comrades and military faculty, they really make it about women. Participant Three: I agree $100 \%$ and that is one of the things that I corrected in my syndicate. It's not about me guys, it's about the behaviour, right? Like, they're like "oh yeah, we should really stand up for women and make you feel better." And, no, it's not about me because I could harass you, right? Or a male on male, or a female on female. But, they make it gender specific (Women Students of the Joint Command and Staff Programme, 2018). One of the consequences of conflating policy like Operation HONOUR with the problems of women is that a spotlight is placed on women as they become understood culturally as a problem to be fixed. Some students note that the practice of making social problems about women has tended to put into question women's capacities to perform professionally.

Many participants posit that if gender and gender perspectives were better explained at the beginning of the Programme, problems stemming from confusion over these ideas would be avoided. This perspective is reflected in the following statement by a student participant: 
I think the way that gender is being instructed is not well explained, people still don't understand the difference between masculinity and femininity as traits and what that means from a gender perspective. . People associate gender with men and women. . A lot of people are getting fed up with talking about gender, but I think they just don't understand what it means and that is why we need to talk about it more (Woman Student Joint Command and Staff Programme, 2018a).

In addition to this narrative, a common perception among some participants is the importance in knowing the difference between increasing women's representation and challenging systemic gender inequality.

As noted in the preceding chapter, increasing women's representation in male dominated roles and occupations is one of many solutions needed to resolve intersectional systemic inequality. Exploring gender inequality allows people to see how diverse women, men, girls, boys, and non-binary individuals come to be systematically advantaged or disadvantaged in societies through socially constructed structures, systems and relations of dominance.

This student reflects upon teaching about the difference between increasing women's representation versus thinking critically about gendered social systems and structures:

We had a person who came in to speak to us from the University of Ottawa explaining the concept of 'women in' versus 'gender and.' If we had a definition like that at the beginning, it would have been so much better. I think the perception has been that "we need to integrate women in the 
military." Well, no. There is more to that because men can be affected by different policies in different ways than women are... I think that is what is lacking on the course. Most of the presentations we have had is on 'women in' and not gender (Woman Student Joint Command and Staff Programme, 2018a).

These perspectives show a common narrative that while gender and gender perspectives are important for military professionals to understand, they are not well defined in curriculum. Participants note that there are few opportunities for students to think about gender and apply gender perspectives to key topics in curriculum.

\subsubsection{Theme 2: Ad hoc, Vague, 'Check in the Box' Content on Gender and Cultural Perspectives}

Many participants among students and staff reported that gender and cultural perspectives were presented in an 'ad hoc' fashion, were perceived to be the 'flavour of the month by the Chief of the Defence Staff,' and were of low priority to the military. A range of emotions and opinions regarding gender and cultural perspectives were expressed among participants across staff and students. Some participants noted attempts by the College to better integrate gender and cultural perspectives and determined that the integration of these would be beneficial. Others highlighted the mandate to integrate gender perspectives in curriculum, citing recent directives by the Chief of the Defence Staff which obligate members of the Canadian Armed Forces to understand and utilize tools such as GBA+ in all areas of military work. Other students and staff expressed apathy or hostility towards learning about gender perspectives. 
Some students recall having never been exposed to gender perspectives until they arrived at the College and were ultimately disappointed that the curriculum did not explore gender perspectives in more coherent and in-depth ways. One example of this perspective is further explained by a student participant:

We were forced to do GBA+. . I I had never heard of gender perspectives. I had never heard of 1325. I have never heard of any of that. Then there were a couple of lectures that touched on it ... Kind of shoving it down our throats and "this is it" and never touch it again. If it was more thematic, if it was more [integrated] in the curriculum. . . If it was a general theme throughout other things. It was kind of thrown into [the Operational Planning Process]: "Did we look at a gender perspective? Check." This didn't really change our thinking on the OPP. It wasn't really taught as part of the other courses. Where are all the leadership and command examples? ... I know it's new to the CAF, but if it were more institutional, then it would just naturally be brought up. . . That would resist that fatigue that we have (Man Student Joint Command and Staff Programme, 2018c).

This observation of the ad hoc and vague introduction to gender was highlighted by members across participant groups.

Akin to this student's observation, some perceptions of fatigue by students were commonly noted. Phrases like 'gender fatigue' and 'gendered out' were sometimes expressed or observed to have been expressed routinely at the College. Drawing on the perspectives shared in this section, a common but false presumption that students have a clear picture of what gender and gender perspectives mean has resulted in students' 
frustration and fatigue when they are tasked to think about gender and apply gender perspectives to military examples but are unable to.

As a result, a common desire is expressed across many student and staff participants to learn, once and for all, what gender and gender perspectives are and how to apply them. In addition to the narratives noted thus far, the desire to learn about gender is presented in the following exchange among students:

Participant One: I think there definitely needs to be effort to add to the curriculum and make gender learning more dynamic. Because, Op.

HONOUR, these sorts of things have been around for a while now and there is a risk of it becoming white noise. I think that is part of the problem... Participant Two: These problems just continue to perpetuate themselves unless we alter [gender learning] and make it meaningful. The GBA+ training [PowerPoint deck] to be honest with you is a bit of a joke. It was not a whole lot of value added. The concept is of course value added, but the delivery was very poor on that piece.

Participant Three: I took the GBA course like we all did, and I remember reading it that way too. I have no idea how to integrate this into my daily job. None whatsoever. I tried in class to make a comment about it, and I was corrected within three seconds that I was completely missing the boat entirely. And I was like, thanks for telling me, I still have no idea, so now I am just going to stay quiet.

Participant Four: And that's true. Talking about the delivery piece. I was talking to a student who is writing a DRP [Directed Research Paper] on a 
human resources issue. I asked that person if they thought of doing a gender analysis for different segments of the population, not just sex, and they were like: "No. It's completely irrelevant." I was taken aback, you know, "really?!" The policy that we have affects different people in different ways and you don't think that's worth looking at? So, even though most of us had this training before we came to the college, and we had it again, it's still not sinking in. I think that the delivery has something to do with it (Men Students of the Joint Command and Staff Programme, 2018). ${ }^{67}$

While some students recall not understanding gender and not feeling prepared to use GBA $+{ }^{68}$ some students also reported having the same feelings about United Nations Security Council Resolution 1325.

As this perspective from a student participant in focus group reveals, despite directives to integrate 1325 and GBA+ across all Professional Military Education and professional development (Chief of the Defence Staff, 2016), integration is minimal at Canadian Forces College:

We were just looking at what's coming up in the next class, and some of them were like, what's UNSCR 1325? I don't know anything about this. So, it goes to show that a lot of people don't know about the different tools that are out

\footnotetext{
${ }^{67}$ In the years since these interviews took place, additional curriculum and lectures have been dedicated to gender perspectives and applications of GBA+ in the Joint Command and Staff Programme including in relation to leadership and policy.

${ }^{68} \mathrm{GBA}+$ is a tool used to investigate the different impact of policy, operations and security contexts on men, women, boys and girls. The Chief of the Defence Staff, General Vance, ordered that: "By 31 Mar 19: Through the framework developed and executed by the UIWG, the requirements of CNAP, UNSCR 1325, and related resolutions are fully implemented and integrated across all CAF operations and institutions, such that GBA+ is incorporated as a routine and common element of all CAF activities, policies, education, professional development, and programs" (my emphasis in italics) (2016). However, gender-based analysis, and intersectional analysis, are not yet 'fully integrated' as a 'common element' in JCSP education.
} 
there and whether or not they exist. We are at a level now where I was actually surprised to hear people say "I don't know what 1325 is.” . . . But they don't just need to know that it exists, they need to understand it as well (Woman Student of the Joint Command and Staff Programme, 2018b). The assessment that gender perspectives and gender learning ought to have been integrated already, yet have not, is a common assessment among military and academic faculty as well as curriculum developers.

The following exchange between the author and a military faculty member illustrates an example of this point:

Interviewer: In what ways have gender and cultural learning been integrated into JCSP in your opinion?"

Participant: They have not. Notwithstanding CDS direction that we were to, that all Canadian military professional education institutions were to integrate GBA+. All we did was change the name of one lecture. We changed the name! The content didn't change. [We] gave the exact same lecture on 44 as [we] did in 43. [We] just changed the title from societal influences to gender influences. That was it. You know. It's important! It's a thing here. And the CDS has told us to do it and we are not doing it. Notwithstanding the fact, going back to [blank's] point that we have been asking for it. Right? (Military Faculty Member of the Joint Command and Staff Programme, 2018). Other observations across participant groups develop a common narrative that some academic and military faculty are equally confused by gender and gender perspectives. One member poses the following question to fellow academic faculty in focus group: 
Here is a question for you guys. Do you think all of our colleagues down the hallway really get what this is about? Do you think they really understand the difference between sex and gender? Do they get that, very fundamentally? I am not convinced they do. I think it goes to our own comfort level. I think that in the future we are going to be expected to do more of this, we all have to up our game a little bit (Academic Faculty Canadian Forces College, 2018).

Similar conclusions are drawn in this reflection by a curriculum developer:

If people don't buy it, that's because they are being bludgeoned with the wrong stuff and being taught by the wrong people who don't have the proper qualifications to deliver any of this stuff. And it is being done in a haphazard way: "hey, you're female, you can teach this" and that is not the way you do it (Curriculum Developers of the Joint Command and Staff Programme, 2018).

These observations reveal that many participants from students and staff assess that there is a requirement for Canadian Forces College to better integrate and develop understanding about gender and gender perspectives, but that to do so staff and faculty need additional education and tools. Most also elucidate shortcomings in levels and depth of knowledge about gender by many staff and faculty, signaling a need for additional expertise in these areas.

Some participants observed dissonance or apathy to gender perspectives among some staff and students. As illustration, the following discussion among two academic faculty members describes difficulties the author encountered in scheduling a focus group 
with academic staff. Difficulty in retrieving positive responses ultimately resulted in poor turn out for this group: ${ }^{69}$

Participant One: I find it really pathetic that Vanessa had to put out this call for participation in this group three times. Three times. And the answer back wasn't "can we please change the date so I can come" or "Vanessa, how about x or y date?" No, the answer was "no, I am not coming." Do you know how most people responded by "they are not coming"? Most people responded by sending an email to me apologizing. That's not the right answer. That was more appalling than had I not received their apologizing emails. Like somehow this is [my] problem in the department. What the hell dudes? Clearly, that makes me think that a number of people who really need to be here to hear this discussion are precisely the people that are not here ... I think it is something we all have to reflect on.

Participant Two: Some people just accept [gender perspectives] because the power structure is favourable to these topics, but deep-down people are not convinced. That's what it is. It's something that exists. Since the start of the emergence of rights in modernity, people adjust to [minimum required change] but [think] this is my limit, I will not go further. This is why we will experience either active resistance or passive resistance. It is part of the game, there is no question about that (Academic Faculty Canadian Forces College, 2018).

\footnotetext{
69 The first faculty member in this conversation waived anonymity in order for these perspectives to be shared in this dissertation and for broader publication. I am indebted to this participant, and all the participants who supported this project by volunteering to participate.
} 
While these statements speculate about why most academic faculty did not respond to several invitations to attend a focus group on the integration of gender and cultural perspectives within the Joint Command and Staff Programme, poor turnout demonstrates the need for further discussion among this group to understand reservations against integrating these concepts. For example, further qualitative research with this group could illuminate potential fear of a loss of power by exposing gender and racial inequalities among academics, or that an examination about gender and cultural perspectives requires academic faculty to stretch and potentially change some of their approaches. ${ }^{70}$

Common to these assessments about the misunderstanding of and resistance to gender perspective was the recognition that when gender topics are presented, they can be delivered in an accusatory and negative manner at Canadian Forces College. Accusatory tones are argued to create challenges to open discussions about gender perspectives among some students and staff. As one student elaborates:

One thing that is bothering me right now is I feel that the guys feel threatened by it. We teach it in almost an accusatory way. So, if the guys feel threatened by it, whether it lumps them into a category of 'bad guys' or whether their careers will be affected because they are not women, I think we have to be careful about the narrative that is being pushed. It is about opening minds for people to understand what they are doing sometimes without necessarily realizing it. My colleagues are not misogynist rapists. They are guys being

\footnotetext{
${ }^{70}$ In contrast, all military faculty members volunteered to participate in a focus group for this study. Moreover, those military faculty who had scheduling conflicts followed up with me on their own to arrange individual interviews over the phone. Turnout was excellent for all remaining groups, and in particular, the author had maximum capacity for the participation of students in focus groups and had to turn away volunteers for follow-up in-depth individual interviews.
} 
guys not knowing that they are living in a right-handed world (Woman

Student Joint Command and Staff Programme, 2018a).

Validation of these feelings and suggestions on how to make gender perspectives and gender curriculum more positive were deliberated across other participant groups as well.

As presented in the conversation that follows among curriculum developers, a positive presentation of gender and cultural perspectives may entice more students and staff to see their utility to the profession:

Participant One: A lot of times when you come to an educational facility, these things are presented to you as a problem to be addressed. Gender problems. Gender is a problem. Those psychological aspects of a problem, gender equals problem. That slows you down and stops you from considering the great things that come out of GBA+, gender and inclusion, gender and diversity. I think a lot of folks just check list gender as a problem and shut down. Instead it could be approached as "I did it! I included gender diversity and my organization will be better because I will help out $50 \%$ of my population and maximize my pool of talent. That's how businesses approach it today.

Participant Two: That is a challenge we have in terms of the receptiveness to including gender perspectives and diversity within the curriculum... All the messaging they have got is we are doing this because we are terrible at this. . .You know what, you are immediately setting up a defensive posture by telling me what I do wrong. . . My soldiers they go out and engage with the local populace and if they see that it is a segregated society between men and 
women, they say "hey, can we get a female to come with us on patrol and work with the citizens and children"... They intuitively do this already. . . but we are building it formally because we see the value in what they are doing. That's how we should be framing it, not 'we suck' (Curriculum Developers of the Joint Command and Staff Programme, 2018).

Drawing on these perspectives, it is imperative that curriculum developers and deliverers strike an appropriate tone when presenting gender perspectives within the Joint Command and Staff Programme. Educators responsible for integrating gender perspectives in course curriculum require comprehensive knowledge about gender, and the ways in which gender perspectives relate to military work, military environments, operations, and security. They must also understand how mid-level officers will respond to different approaches and to use methods that create openness to novel ideas that may contradict dominant views.

\subsubsection{Theme 3: The Presentation of Male Perspectives and Masculine Narratives}

Some participants among students and staff assessed that readings and course concepts presented in the Joint Command and Staff Programme tend to promote almost exclusively men and masculine points of view, drawing predominantly from men identifying thinkers and men's work. Some students as well as some academic faculty perceive a dominance of masculinist thinking and undertones about conflict, war, peace, security, leadership and command.

Some of these themes are expressed in this statement by a student participant: "With respect to the gender toning of the readings, I haven't noticed anything other than 
the fact that it is mostly male perspectives on a lot of stuff" (Man Student of the Joint Command and Staff Programme, 2018). One member of the academic faculty notes that "one of the assumptions that is a cause for this, and again it is an assumption, is that men are most interested in military affairs and women are not. Of course, we know this isn't the case" (Academic Faculty Canadian Forces College, 2018). In this way, binary and gendered thinking about the interests, desires, and worldviews of men and women about military affairs may work to reify gender hierarchy. Doing so may push the participation of women and non-binary individuals in the military to the periphery and construct certain military roles, responsibilities, and abilities as those that are implicitly best left to the men.

Some students and staff note that to challenge masculinist assumptions about conflict, war, military work, command, leadership, peace and security, peoples' latent biases must be made visible to them and examined. Many students and staff have recognized masculinist thinking and practices in the perpetuation of the dominance of men and masculinities, in cultural exclusions of racialized and linguistic minorities, and through ethnocentrism. In this way, implicit biases are symptomatic of larger cultural problems related to deep-seated colonial and patriarchal systems that endure and are made use of at the College, within the Canadian Armed Forces and in Canadian society. Thus, in order to challenge and change these unequal social systems and to stop their perpetuation in the learning environment, it behooves faculty and leadership to seriously examine these systems, to make their reproduction and function at the College visible, and to work towards gender and cultural equality. 
Related to the implicit biases noted above, some participants across students and staff observe a lack of cultural perspectives in the Joint Command and Staff Programme. In many cases, participants perceived the promotion of narrow world views, beliefs, and norms throughout curriculum. The following statement of a student participant helps to explain this perception:

One thing I was disappointed in seeing was that it was mostly around religion. Yes, religion is a big piece of what makes a culture, but there is so much more. . . I like the word intersectionality. That's actually something from my other Masters' Program that I thought was really good. . . We looked at the gender dynamics, sexual dynamics, sex differences between men and women, age, and how all of this affects a community. . . I think we are staying away from that perspective for some reason (Woman Student of the Joint Command and Staff Programme, 2018b).

These feelings are shared by many members of the student body and are explained in a different way by another student participant here:

I guess when we did all the case studies and a lot of country studies, it was always the official view of the country. It was never taken from different perspectives. So, I guess this was the one accepted view of the conflict. It was never, "Okay, here is what several organizations have published on this issue" (Man Student of the Joint Command and Staff Programme, 2018). While most students observed a lack of cultural education at Canadian Forces College, academic faculty participants confirmed that this is the case. 
Corroborating the statements of students above are observations among academic faculty that there is a significant need for the integration of cultural learning in curriculum:

Participant One: I will add one thing. If you see a consensus about the fact that more awareness about gender is needed, I think that the cultural aspects are even more needed. Everything you say about gender you can say ten times from cultural perspectives. There is none.

Participant Two: The closest thing we have to culture in our curriculum in [Defence and Security Studies], which is exactly the closest thing we have to gender which is one seminar.

Participant One: But I think that cultural aspects regarding the way the institution is managed should be taken into account as well. It is very important for young officers who are selected because we see their potential to be strategic leaders in the future, to have a clear understanding of the society they are supposed to serve through the State (Academic Faculty Canadian Forces College, 2018).

What these observations and perceptions in this and previous sections show is that existing curriculum would benefit greatly from intentional integration of cultural and gender perspectives. While there is a common perception that cultural perspectives are significantly lacking in the Joint Command and Staff Programme, students and staff assess that what learning there is on the subject has been positive. 
Despite few opportunities to learn about cultural perspectives, the following observation from a student participant illuminates the ways in which these ideas are perceived as important to military professional development:

It has been opening up my views on the world and how countries interact. Understanding cultures and how having that background makes a difference [for] analysis of deployments in different countries, there are cultural aspects behind it. That was something that resonated with me (Man Student of the Joint Command and Staff Programme, 2018).

Aside from the few mentions of cultural perspectives above, there were few assessments of the integration of cultural perspectives within curriculum, as limited content on cultural diversity was formally presented.

Reflecting on a discussion about cultural perspectives and diversity in the Canadian Armed Forces, one curriculum development officer cited the impact that deeper understanding of institutional cultural perspectives would have for students:

We had one conversation about recruitment and retention. . . [students] were talking about the fact that we are not reaching our diversity goals, and I looked at them and said "do you honestly think that there is a lot of diversity in North Battleford, Saskatchewan where we are recruiting from?

(Curriculum Developers of the Joint Command and Staff Programme, 2018). This reflection is insightful and illuminates how structures and systems in addition to social relations help to maintain and reproduce the dominant culture of the military. As the following participant from the Information Resource Centre suggests, reflecting on dominant practices, implicit assumptions, and cultural norms within institutions can 
unearth problematic behaviours and social norms which tend to create gendered and cultural exclusions. Identifying problematic systems, structures and bias and challenging them would set conditions for a more inclusive learning environment at Canadian Forces College.

As they observe:

People who you want to be part of the larger public service . . . represent communities that the CAF is interested in recruiting from. [Yet] they don't go out into those communities, and the narratives that they use are not positive to those communities and their resources. Everything from how you are treated if you are not the same as everyone else to conduct that is deemed to be inappropriate. That is a powerful instrument, again, one that we as an institution tend to be too insular to understand that at a senior military professional education institution in the Canadian Forces, what conduct is acceptable here is viewed by the staff as conduct that is acceptable across the Canadian Forces. Therefore, why would I trust my son, daughter, cousin, or friend to join the Canadian Forces? (Information Resource Centre Staff, 2018).

What is demonstrated in this observation are a range of tendencies to preserve the dominant culture of the military.

As this participant informs us, dominant cultural narratives about gender and race inform (discriminatory) social behaviours and draw from a mutually reinforcing network of regulative, normative, and cognitive systems and structures, procedures and practices, beliefs and worldviews. As noted in this dissertation's theory chapter, there is an 
interplay of regulative, normative, and cognitive organizational functions that are imbued with the logics of patriarchy and cultural superiority. These organizational functions have a specific and exclusionary gendered and ethnocentric ontology that is consistently in the process of reproduction at the institutional level down to the interpersonal level. It may not be surprising then, that if there are exclusionary systemic, structural, and social practices which disavow cultures constructed as 'different' at Canadian Forces College, that there may be also be resistance to the presentation of alternative cultural perspectives in curriculum.

Participant groups also reported that awareness about intersectional exclusion at the College and within the Canadian Armed Forces more broadly could create important discussion about the need to rethink status quo narratives of institutional inclusion. Indeed, organizational focus has often been on the weak individual prone to racism and sexism. The notion is that systems of oppression, such as sexism and racism are the problems of 'bad apples' within the institution, rather than viewing racism and sexism as related to systemic, structural and cultural commitments to patriarchy and white supremacy (CDS 2015; CAF 2020). The reflections of participants in this section show that additional attention and resources are required to better understand these forces of inequality at the societal and institutional levels, and to integrate gender and cultural perspectives within the Joint Command and Staff Programme as a first step in the military's work to change them. ${ }^{71}$

\footnotetext{
${ }^{71}$ The Canadian Armed Forces has committed to the achievement of United Nations Security Council Resolutions on Women, Peace and Security. These Resolutions have been translated into specific requirements of the military to work towards gender equality, the greater participation of women in the Forces, and the application of gender-based analysis plus in all plans, policy and actions (Government of Canada 2017; CDS 2016).
} 


\subsubsection{Theme 4: Military Faculty Request Additional Tools, Training, and Support}

A common narrative among military faculty is the perception of being illprepared to facilitate gender and cultural learning. Leveraging the knowledge that both a formal report to senior leadership of the college, and a doctoral thesis were being written using the data collected in their focus group, military faculty made a special appeal to request additional training, resources, and tools to raise their knowledge and skill sets on gender and cultural perspectives. To aid in the search for tools, some members referenced programmes at other Professional Military Education institutions which they perceived could better prepare them to facilitate this learning.

An example of feeling ill-equipped to facilitate gender and cultural learning and the desire for added support is reflected by this military faculty member:

The direction has come out that we are supposed to integrate it, but there has been no training of the trainers. So, we all had the GBA+ [module] experience ... [but] there are no tools to allow us to help [students].

Whatever reading we do, and whatever talk amongst ourselves [ ] is really the blind leading the blind. As well, there has been no other direction. Do this GBA + course, do Bystander training, and have a discussion about Operation HONOUR. Without those tools we are not going to be able to influence the students here (Military Faculty of the Joint Command and Staff Programme, 2018).

In addition to training and education, military faculty attest to being under resourced to adequately prepare for gender and cultural curriculum. 
Such lack in resources is outlined the following exchange:

Participant One: I am just saying that manning priorities of the CAF have an impact on this institution with regard to this discussion. So, if you are going to change GBA+, you have got to man us to do some more work in that environment and have a discussion of how we weave GBA+ into the greater discussion, and should we?

Participant Two: I look around and think "am I the right person for the job that I am in?" Well, I am a warm body and I am trying really hard, so I think that goes a long way. But, do I have all the tools, regardless of what is coming across in curriculum to do all this? No... If this were important there would be more emphasis and more support here (Military Faculty of the Joint Command and Staff Programme, 2018).

Perceptions of being under resourced and inadequately prepared for the integration of cultural and gender perspectives were repeated observations of military faculty and shared by some participants among the student body.

As illustrated in the thoughts of this student:

I think it is either academic or military. Nothing against the [military faculty].

They are great people, but they are not experts in the field. . Sometimes it feels like they are students, they are learning at the same time as we are (Man Student of the Joint Command and Staff Programme, 2018).

In addition to observations that military faculty and academic faculty require training and education on cultural and gender perspectives, military faculty also noted a desire to learn techniques to develop more inclusive classrooms. 
In relation to perceptions of students and staff on the author's (2017) report to the College which drew on pilot interviews with students used as contextual literature for this dissertation, military faculty are now looking for ways to encourage greater collaboration in syndicate discussions. Validated in focus groups and interviews for this project, data from the 2017 report showed that some syndicates tended to promote competition over collaboration.

After reading the 2017 report, military faculty participants shared observations in focus group of competitive social relations in syndicate discussion. As a result, some military faculty requested enhanced training for inclusive classroom management techniques. This narrative is explained in further detail by a visiting international military faculty member:

So, at my College we run a three day [session] called the insight program. In this they teach a number of important behavioural techniques to people like active listening, participating in a group environment, push pull techniques, coaching methodologies for [military faculty] and others. [Military faculty] would have facilitator training, so you are more attuned to the behaviours and non-verbal cues in a room. We don't do any of that here (Military Faculty of the Joint Command and Staff Programme, 2018).

Gleaning from the assessments of students and military faculty in this section, a common observation is made that competition and exclusionary tendencies are reproduced in existing classroom dynamics. Noted across participant groups was a narrative that additional resources, training, and education are required for military and academic 
faculty to deliver Joint Command and Staff Programme curriculum in inclusive and informed ways.

\subsubsection{Theme 5: Gender and Cultural Perspectives are Essential to the Success of the Profession}

In focus groups and in-depth interviews an overwhelming majority of participants attested to the deep relevance of gender and cultural perspectives to the development of peace, security, and effective military professionals. References to Canada's defence policy (2017) and claims within it about the importance of an inclusive military that maintains a culture of respect were often used by participants to demonstrate greater need for military leaders to understand and apply gender and cultural perspectives to improve their work as well as relations among personnel.

A common understanding argued that applying gender and cultural perspectives is essential to the success of Canadian Armed Forces missions and operations within Canada and abroad. The following excerpts describe how participants across groups saw benefit to learning and applying cultural and gender perspectives in areas of military work and security. As this Information Resource Center member observes, reactions to a case study which asked students to apply gender and cultural perspectives ranged. However, there were positive learning outcomes:

Some [students] were skeptical and fighting the case study, but the majority, and often... the younger officers were really very engaged because this is what they notice when they are deployed. These are the discussions. . . shared experiences, the out of the box thinking about issues that they need, because 
these are the sorts of issues that they will have to work with when they leave the College. [It is] the College framework that is in fact limiting their ability to explore and share (Information Resource Centre Staff, 2018).

This and the preceding perceptions suggest that gender and cultural perspectives are of great benefit to students. However, each caution that the existing ways in which gender and cultural perspectives are being integrated present limitations to students' abilities to learn about them. As will be expanded upon in subsequent sections, choosing the right pedagogical approach for desired learning outcomes, such as the ability to apply gender and intersectional analyses across all military work, is integral. The right teaching approach can set appropriate learning conditions for students to develop understanding and adequate capabilities in these areas.

Yet, the nascent benefits of applying gender and cultural perspectives to military work in newly developed curricula are observed by this curriculum developer:

We created an ad hoc sit rep or int rep ... specifically about atrocities and GBA+, as well as vulnerable populations, and we watched to see what [students] would do with it. . Actually, [they] are adapting to this quite quickly (Curriculum Developers of the Joint Command and Staff Programme, 2018).

Another curriculum developer phrases the benefits of applying gender and cultural perspectives to military work this way:

I think if the students are doing their planning well, and the staff guide them well, they will need to consider what kind of issues they will face at the integration of [different] cultures. . It is interesting to understand too that it 
is not the Canadian culture that we will be facing overseas, so how are we equipping [students for] those issues ... Everybody has a story, I am sure, if they have been on operations before in countries where the culture regards women differently in positions of authority and power. These are real things we need to consider (Curriculum Developers of the Joint Command and Staff Programme, 2018).

These observations each show that the integration of gender and cultural learning is deeply important to the effectiveness of Canadian military operations. They reveal that gender and cultural understandings broaden thinking about security and allow military professionals to better assess the diverse security contexts, needs and interests of women, men, girls, boys and gender non-binary people of different cultures and intersecting identities. In this way, such learning can aid military members to achieve their commitments to Women, Peace and Security (CDS, 2016) by determining and developing innovative and tailored strategies for domestic and international military engagements. These areas of professional development and education are gaps to be filled within the larger military context, areas that the military as an institution has recognized are key for its facilitation of advances to security on an international stage (Government of Canada, 2017a; 2017b). 


\subsubsection{Theme 6: Observations of Gender Biased Evaluation of Leadership and Officer-Like Qualities}

Military faculty are tasked to assess leadership and officer-like qualities of students enrolled in the Joint Command and Staff Programme. The content of these assessments is outlined as follows in the Directing Staff Handbook (2017):

Leadership: This category highlights the opportunities which students have to demonstrate their leadership qualities in both curriculum and non-curriculum activities. Leadership opportunities can be found in Annex K [which lists participation in largely sport and social activities]

Officer-Like Qualities: The category comprises all the qualities and traits of personality and character relevant to effective leadership [including integrity, loyalty, conduct, dedication and courage] (Joint Command and Staff

Residential Programme Officer, 2017).

Many student participants observed that assessments of 'good' leadership and officer-like qualities are often tied to 'aggressive', 'alpha' masculine behaviours and practices. Many military faculty also recognized that the leadership and officer-like quality components of evaluation are subjective and often associate leadership qualities with men's practices and how well students embody qualities associated with hegemonic masculinity at the College. Some students and military faculty explained that students tend to be assessed on how well they 'fit in' and the extent to which they socialize in activities which have been historically male dominated and masculinized, such as events focused on heavy 
drinking at the mess and playing competitive contact sports. ${ }^{72}$ Two women student participants recalled instances where their leadership and officer-like qualities were assessed using erroneous or false information. Other students noted that assessments of leadership and officer-like qualities tended to privilege students without familial obligations and students who live on campus.

The following excerpt presents an example of these perceptions in the words of a student:

Every single social function is themed around drinking. Every single one. Heavy drinking. And for the first few months I was like “no, I just don’t want to." Then it was a half stigma, you know “oh, that person doesn't drink. Are you going to accuse me for not drinking?"... When everything is themed around people staying as late as possible drinking as much as you can, that's not my choice social environment (Man Student of the Joint Command and Staff Programme, 2018).

Similar observations were held by some military faculty as represented in this example:

So, whether it's sort of the functions that go on at the mess, or the things that we highlight for JCSP to take on in terms of leadership, it is my personal feeling that we highlight a lot of consumption and aggression. The two most lauded teams around here are hockey and rugby, and we do a lot of drinking at the Mess. If that's not your thing, then it can be very unwelcoming ... [on

\footnotetext{
${ }^{72}$ Activities that have been noted elsewhere as practices forwarding hegemony of particular masculinist military masculinities: Duncanson, 2015; Whitworth, 2004.
} 
sports days] we had people that were broken. . I mean these are all very intelligent people, we can do things that don't require aggression and perhaps have things that require more thinking (Military Faculty of the Joint

Command and Staff Programme, 2018).

Observations of feeling pressured to drink heavily and display aggressive masculinities through sport are also substantiated by students in the 2017 report (Brown). In the report, women students observed the gendering of leadership qualities in sport. As previously mentioned, in my daily observations, I noted that some (mostly women) students challenged the dominance of masculinized sports by organizing a yoga session on the field directly beside a regularly scheduled rugby game. This event was meant to materially redistribute male dominated space and symbolically highlight how specific masculine practices are lauded and esteemed as leadership qualities at the College often eclipsing alternative gender qualities, embodiments, and practices in the process.

Indeed, in focus group interviews students noted the tendency for evaluations of leadership and officer-like qualities to marginalize students with families and those who live off campus:

Participant One: See you will see men who won't participate for the same reasons. You have an activity that is organized on Monday nights and the two men who have wives and the wives are not military they can't come because they have family stuff.

Participant Two: It's not just the 8-4 when kids are in school. We have to go above and beyond those hours to get favourable assessments for that course part at the end. 
Participant One: All these social activities for this assessment are based on the assumptions that don't account for spouses working. My wife can't come to any of these things because she works during the day. . . She is a professional. She works every day. So even a Thursday night activity. . .There is an expectation that spouses, when they follow you on this course, that they generally don't work, whether that is a man or a woman (Men Students of the Joint Command and Staff Programme, 2018).

As these students note, evaluations of leadership and officer-like qualities often reinforce patriarchal hierarchies and masculinist views about family responsibilities.

These perceptions are further demonstrated in the following exchange among student participants:

Participant One: I think the point was brought up that the 1950s mentality of how society runs is dominant.

Participant Two: I can't speak to your experience, but I am a single parent and I think there are others here as well. ..When I go in with some single parent issues, which are kind of unavoidable, because I don't have any family in Toronto ... the response is usually . . .eyeroll 'okay it's accepted' to just full blown “well, can't you hire somebody?" or "why can't your mom come down?"

Participant One: And you are not alone. I've heard the same thing from others.

Participant Three: I don't want to poke you on that, but what is the link with that and with gender here? 
Participant Two: Because I'm doing a woman's job. That's the attitude from superiors: "What's wrong with you? How come you don't have a woman in your life to take care of that?" (Men Students of the Joint Command and Staff Programme, 2018).

Along with observations about the privileging of students with fewer familial and domestic responsibilities, some students note that there is a propensity by military faculty to evaluate students based on gendered and preconceived assessments of their leadership and officer-like qualities. Others report extremely problematic assessments of leadership and officer-like qualities which were inappropriate or patently false.

Demonstration of an inappropriate evaluation is illuminated in this exchange among women students:

Participant One: In my first roto report I had that I dressed as a penguin for Halloween. How does that make me a good leader in my job?

Participant Two: They actually wrote that in your report?

Participant One: Yes. Written in the report (Women Students of the Joint

Command and Staff Programme, 2018).

In another discussion among women student participants, evidence of false information used to assess leadership and officer-like qualities is given:

Participant One: Mine wrote that I was "good on and off the rugby pitch."

Participant Two: [Laughs] What?!

Participant Three: That's pretty embarrassing.

Participant Two: But, you are really good at playing rugby. [sarcasm]

Participant Three: On and off the pitch! 
Participant One: On and off the pitch. [sarcasm]

Interviewer: So, just to be clear, you don’t play rugby.

Participant One: Yeah, that was why it was such a joke!

Participant Four: Oh, you don’t play rugby?

Participant One: NO! (Women Students of the Joint Command and Staff

Programme, 2018).

Students' experiences of the ways in which leadership and officer-like qualities are evaluated point to deeply subjective and gendered assessments of this criteria. Leadership of women is reported to be assessed in inappropriate and superficial ways or associated with only masculine embodiments and practices.

Those who reported false or erroneous assessments were typically women. And, drawing from insights of the 2017 report (Brown), such gendered errors were also made the prior year, when, for example, two women students were mistaken for each other and given each other's assessment instead of receiving their own. This may suggest that some military faculty are not recognizing the contributions of women in the Joint Command and Staff Programme, to the point where some women's practices are perceived as so insignificant that they are interchangeable.

Students are not alone in the perception that military faculty make inequitable assessments and evaluations. Members of military faculty also perceive issues with the way they are relegated to judge leadership and officer-like qualities of students. Their reflections about grading students on these qualities show deep frustration about the subjective way in which they are made to evaluate students as a result of unsuitable 
formal guidance on what qualities constitute leadership in the military learning environment:

Participant One: There is no rubric as far as I know on how we assess leadership. But it is an assessment. There are reports that we give [students] in each rotation. I think it is just a subjective feel by the [military faculty] based primarily on, were you a syndicate leader in a formal role, were you an informal leader within a syndicate. Were you leading sports teams? Were you organizing things, and I suppose I could see how there might be a gendered perspective or lens to look at this in terms of "well you know they are leading these competitive sports teams, the hockey team," and this and that. Those people are really getting the advantage whereas someone else who is showing leadership in other ways isn't getting recognition.

Participant Two: It's a fundamental failing we have. I said that when we sat down for the first time at board. It needs to be quantified somehow. There needs to be a delineation so people can understand how they are receiving their assessment. That was something I was looking at for next year. I have a real issue with it. I expressed that to DOP [military Director of Programmes] and I have been very blunt with it. It is a mistake. . . I don't see any issue, if you have someone who shows up here to do strict academics and spend time with their family. That's fair ball. . . There is nothing wrong with assessing it, we have to tell them how we are assessing it (Military Faculty of the Joint Command and Staff Programme, 2018). 
In this exchange, military faculty have pointed to the ways in which leadership and officer-like qualities have and continue to discriminate students on the basis of gender.

The tensions between military professional and academic identities highlighted in the previous chapter are also relevant here. Addressing and challenging assumptions held at the College that academic and military identities are oppositional and mutually exclusive could make assessments of leadership and officer-like qualities less confounding and more inclusive. Qualities of academic achievement, for example, in tutoring, mentoring, developing inclusivity in the classroom, in presenting novel ideas and strategies in academic work, each demonstrate ways in which leadership could be understood as both academic and professional, scholarly and officer-like. Drawing on the observations of students and military faculty, this section has illuminated that the leadership and officer-like quality components of assessment and evaluation require deep reflection as they tend to reify patriarchal and masculinist ideals and translate into material inequalities in the experiences and evaluations of students.

\subsubsection{Theme 7: The Need for a Cohesive Pedagogical Approach}

Observations among student and staff participants point to the requirement for a more robust and cohesive approach to delivering gender and cultural perspectives in Joint Command and Staff Programme curriculum. Participants from all subgroups interviewed saw need for curriculum to define gender and culture, explain the variety and complexity of gender and cultural perspectives, and give opportunities throughout the Programme to apply these to the full range of military engagements, practices, relations, planning and policies. 
Many students cited a desire to apply gender and cultural perspectives using tools such as GBA+ to assess the differential impacts Canadian Armed Forces policy and operations have on diverse groups within and outside of the military. Participants from academic and military faculty, curriculum developers, the Information Resource Centre as well as students perceived a requirement to analyse command and leadership through gender and cultural lenses. As will be elaborated in the following section, academic faculty in particular perceived space within the Joint Command and Staff Programme in which to dedicate a one credit core course that would explore the significance of gender and culture to the practices of the military profession, and to look specifically at the 'gendered military and security.'

As one academic faculty member asserts, to set an environment that is welcoming to the integration of gender perspectives within the Programme, "we don't want just the ‘add gender and stir”’ approach (Academic Faculty Canadian Forces College, 2018). Instead, gender perspectives need to be presented in the Programme in ways that are "implicit" and "explicit". Drawing from this perception common in the academic faculty focus group, gender and cultural perspectives need to be integrated across the Programme at "opportune moments [otherwise students] aren't going to be exposed to it" (Ibid).

There are several ways in which to integrate gender and cultural perspectives more formally and explicitly within Joint Command and Staff Programme curriculum. One way is to develop a core course specifically on gender and cultural perspectives of the military and security. As will be demonstrated more fully in subsequent sections, developing a core course on gender and cultural perspectives would give students a deeper understanding of gender and culture and a clear picture of how people with 
diverse gender and cultural perspectives are impacted differently by (in)security, conflict, policy, and the decisions of military leaders. This learning would be graduate level learning, intensive, and would be the first of its kind among Professional Military Education institutes in Canada.

An additional method could be to create tailored modules about the relation of gender and cultural perspectives to key ideas and subjects within each core course offered within the Joint Command and Staff Programme. This option could allow each core course to focus directly on gender and cultural learning in discrete packages which cater to central ideas already presented. If taking this approach, however, the College must be careful not to reproduce mistakes outlined in this report of 'add gender and stir', ad hoc curriculum, and the perpetuation of misunderstandings about the meaning of gender and culture as concepts. In addition, these discrete modules must ensure that they do not work to reify stereotypes and inequitable social hierarchies related to diversity, gender, race and culture.

The third option is to mainstream gender and cultural perspectives across all core courses. Mainstreaming is possible but is more difficult to put into practice and monitor as it relies on a concerted effort across faculty and staff to understand gender and culture, to be knowledgeable about a range of gender and cultural perspectives, and to identify areas where these could be integrated across key facets of curriculum. This option may also be the riskiest, as the potential to pay lip service to these perspectives, rather than to present them in nuanced and fruitful ways is greater. This risk is part of the fundamental failings of the mainstreaming approach: the tendency to depoliticize gender equality and to underestimate resistance to it (Cornwall and Correa, 2008). 
Historically, the mainstreaming method has suffered from presumptions that all members of a given institution possess the will and capacity to change their ways (Parpart, 2014). In many cases, mainstreaming gender perspectives across other departments and institutions has been met with resistance, apathy, or has not produced the desired effect (Tiessen, 2007). Typically, in order to fit mainstreaming into dominant structures and systems within institutions, without ruffling feathers and to continue momentum for at least some positive change, the ambitious political objectives of transformative gender equality have been downplayed (Cockburn, 2011).

Research on gender mainstreaming in development agencies and governmental departments has argued that the hard work of cultural transformation required for gender equality is often truncated into simplistic procedural tools and checklists in pursuit of gender mainstreaming (Parpart, 2014; Cockburn, 2011; Tiessen, 2007). In making gender accessible, mainstream, and of use for everyone, political projects for transformative social (gender) justice have often been silenced (Cockburn, 2011). Indeed, critics of gender mainstreaming argue that the feminist struggle for gender equality has been altered significantly, co-opted or removed entirely (Ibid). In particular, Cockburn contends that gender mainstreaming has been divorced from the ways in which it was initially understood by the mostly women civil society and NGO actors - who did the lion's share of the "groundwork, the diplomacy and lobbying, the drafting and redrafting" of United Nations Security Council Resolution 1325 (2011, p. 1).

For gender mainstreaming to work, and in particular for it to work in the ways expected by these founding women, it must diligently chip away at all power relations of social injustice, "including those of militarism" (Cockburn, 2011, p. 7). Cockburn posits 
that gender mainstreaming requires "unrelenting struggle for transformative change in gender and other power relations" (Ibid). Tiessen further argues that gender mainstreaming requires challenging and transforming the “"deep structure' of gendered organizations" like the military, involving interventions which push for the "political and attitudinal changes necessary for altering the status quo" (Tiessen, 2007, p. 174).

The second fundamental failing in applications of gender mainstreaming is the tendency to underestimate of the level of social labour required to break down dominant systems of gender power and the very real resistance to doing so (Parpart, 2014). Often, gender mainstreaming obligates all professionals to take on responsibility for promoting worldviews and agendas that may belie their own personal perspectives and philosophies (Ibid). As such, this method operates on the false presumption of ubiquitous and shared personal desire for institutions like the military to fundamentally challenge and change the often patriarchal and racist ways in which they construct structural and social power. However, doing precisely this is required if institutions are ever to be inclusive and to break down barriers for equality more than superficially (Tiessen, 2007). Therefore, the presumption that mainstreaming would work 'as each member is motivated to do so' may be untenable at Canadian Forces College as many participants already note profound resistance to cultural change, widespread misinformation about gender, ethnocentric attitudes and in some cases, support and celebration of misogynistic behaviours and practices.

If an approach to mainstream gender and cultural perspectives across Joint Command and Staff Programme curriculum is taken, it must be done in a considered, careful, and systematic way so that the failings of gender mainstreaming elsewhere do not 
befall the College. In these ways, there are benefits and draw backs to each of the suggested strategies to better integrate gender and cultural perspectives in the Joint Command and Staff Programme. As such, benefits and risks of each strategy must be weighed judiciously. Regardless of the chosen approach, academic and military faculty require additional education, resources, support, and relief from other duties to develop requisite expertise for the effective development and delivery of these perspectives.

\subsubsection{Theme 8: An Adult, Student-Centered Approach to Learning}

Learning about gender and diversity also requires a pedagogic approach which allows students to think critically about themselves in relation to others. This reflexivity in learning is necessary to confront preconceived and taken-for-granted assumptions, stereotypes, and attitudes about others. Much of how learners come to critically understand other people is through a deeper understanding of themselves, their socialization, and their biases. To understand their own socialization and assumptions about people within a professional military academic context, learners require an inclusive environment — one in which they can critically examine and challenge personal philosophies and worldviews with their peers (Canning, 2010).

Developing critical reflection about gender, diversity, and inclusion, then, necessarily requires a collaborative, co-constructed and dynamic environment that fosters collaboration rather than individualistic processes of meaning making (Brown \& Okros, 2020b). Developing shared and fluid understandings of knowledge, particularly about oneself in relation to others, is an example of how students can use gender and diversity 
frameworks to engage their critical thinking skills. To facilitate this level of learning, students require a great deal of autonomy in the learning process (Kenyon \& Hase, 2001).

This means that educators require teaching approaches that are appropriate for adult learners. In the Professional Military Education of mid to senior level leaders, adult learning approaches that leverage the wealth of knowledge and experience of students is optimal (Ibid). As the following perspectives from student participants demonstrate, while the Canadian Forces College may promote the idea that it delivers andragogic learning, it may actually be struggling to do so:

Participant One: I think the school is missing the boat. They really need to look at what exactly it is they want us to learn and then teach to it. Not throw a thousand pages of bullshit at us, where we have to tease it out. Participant Two: All the comments that most people don't do the readings are correct.

Participant Three: You know what I mean when we talk about this whole adult learning paradigm. Yet again, in the military, we say that we do adult learning. We don't do adult learning (Men Students of the Joint Command and Staff Programme, 2018).

These assessments by student participants illustrate a common narrative among students of frustration about the perceived absence of adult learning at Canadian Forces College. Identifying areas for improvement, this section outlines some best practices outlined in scholarship about adult education, and in particular, andragogy for military professionals. 
Approaches geared specifically to adult learners require focus on students' learning goals and desires. They must be supportive of students' engagement with each other and facilitate an environment that is open to students' critical self-reflection (Kenyon and Hase, 2001). This conception of teaching constitutes a student-centered approach to learning (Samaroo, 2012). The following reflections by students show how this approach is present in some aspects of learning at in the Joint Command and Staff Programme and areas where improvements could be made:

Participant One: It would be nice to have a little bit more free time to say "oh that was really interesting, let's look up what else is on this subject." [Instead] it's you read. You get the requirements done. You do the discussion. You move on.

Participant Two: I am embracing it and learning as much as I can in the moments that I have. But, I think that my comment is that I learn more from the papers than I learned from anything else, because I had to read something that was at least something that was leading me to somewhere. Then that raised a question, and then I ask how can I answer that question. . . So it's almost a self-discovery. Versus, you know, force feed you eighteen hours of reading a week to cover stuff we are not even talking about or that are relevant ... They are not relevant to my job, so why am I reading it?" (Men Students of the Joint Command and Staff Programme, 2018).

Drawing from this perspective and common narratives among student participants, selfreflection and student-determined research increase intrinsic motivation for learning among students. Drawing from Kenyon and Hase $(2001 ; 2007)$, this is precisely because 
learning is centered on the student's needs, goals, and learning aims in relation to their profession, identities, and career aspirations (Kenyon and Hase, 2001).

Student-centered methods to teaching carefully shift the role of the teacher from a disseminator of knowledge to a conduit through which students determine their own learning (Samaroo, 2012). Moving away from a teaching style which focuses on students' engagement with specific content, a student-centered framework embeds the teacher in students' collaborative efforts to generate new knowledge (Kenyon and Hase, 2001).

In other words, in collaboration with their teachers, students determine the content of their learning. The expectation and desire for this type of learning is presented in the reflection of this student:

The subjects I think are adult subjects. The way some [Faculty] are going about presenting the learning, and the back and forth [in aims], I don't think is quite there. I expected to have more say, influence and freedom, in the way I went about the learning and the topics. It's rigid. Less of what I expected from a military institution. (Man Student Joint Command and Staff Programme, 2018a).

As this participant suggests, adult learning allows the student to take a larger share of control over the form and content of what they learn. The student is responsible for guiding the research, even if the general areas of research are mapped out for them. In adult and professional education, such a configuration of learning, and the turn of roles in which teachers and learners play, has been described as heutagogy.

Heutagogy is a learner-centric inquiry driven approach that allows students to develop the kind of self-determined thinking about gender, diversity and inclusion which 
is predicated on communication with others, self-insight and self-growth (Blaschke, 2012). First advanced by Stewart Hase, a professor and Doctor of Psychology, and Chris Kenyon, a Royal Australian Air Force Wing Commander, heutagogy was created as a teaching strategy which would allow adult learners with professional experience to develop critical thinking capabilities by enabling them to determine how and what they learn in relation to $21^{\text {st }}$ century problems, technologies, communication, complex communities, and cultures of people (Kenyon and Hase, 2001). Noted as a selfdetermined approach to learning, heutagogy emphasizes two principles. These are collaboration and challenging personal philosophies (Canning, 2010). Heutagogy is very much a post-positivist and constructivist approach to learning as it aims "ultimately to influence a shift in thinking within [learners] and those that they work with" (Ibid, 59).

The focus on a 'shift in thinking' and meaning making would be of great benefit to Professional Military Education at the Canadian Forces College, where senior military officers enrolled in the Joint Command and Staff Programme have been tasked to engage in critical thinking about leadership and command, and leadership and command philosophies (ethics, values, practices) in relation to contemporary peace and security contexts (Government of Canada/DND, 2017, i). As its emphasis is on shifts in thinking through the practice of self-reflection and collaboration, adopting a heutagogic approach supports initiatives led by the Chief of Defence Staff in creating a "leadership-driven culture change" (Chief of the Defence Staff, 2015, 16.a) in the military, one which champions equity, inclusion, and respect among Canadian Armed Forces members (Government of Canada, 2017b). 
The implementation of heutagogy can also address concerns about gender biased learning environments at Canadian Forces College (Brown, 2017). Considerations that facilitate collaborative rather than competitive learning environments, for example, could influence greater gender equity in the classroom. Using a heutagogic approach, the College could retool the syndicate environment to be one in which the primary focus is on collaboration and inclusion rather than on competition and the performance of idealized gender roles for higher marks and professional evaluation reports. Focusing students' efforts in syndicate discussions toward the collaboration required to confront and solve complex security problems and puzzles may also help to mitigate gender and cultural hierarchies and exclusion in the learning environment by working to level the playing field and through honest attempts to restructure transferred social hierarchies from the larger military for the purpose of critical thought and learning.

As participants of this study commonly note, extant pedagogic approaches continue to set conditions in the learning environment where social hierarchies based on gender and cultural divisions are constructed among learners. As demonstrated in the previous chapter, dominant 'alpha' embodiments of gender cited often by participants of this study include tendencies to talk over peers, use of orders or pointed comments, ignoring the insights of others, and creating a chilly climate for certain members of the student body. As demonstrated throughout this chapter and the last, student participants reported experiencing or observing gender inequality in the learning environment.

Many women and some men student participants reported experiencing or having observed colleagues being deterred from contributing to class discussions because of gender and intersectional dynamics in the College's culture. Some reflected that they 
were less willing to participate in class discussions as a result. Some women students also recalled being perceived as less professionally capable by their colleagues and were often left out of dialogues regardless of their expertise. As noted, some women student participants reported being harassed for their views, and in some cases, for their success in the profession by their peers on the basis of being women. These problematic conditions within the learning environment at Canadian Forces College were observed by many student and staff respondents to contribute to and encourage competition, masculinist thinking, and exclusionary behaviour. Taken together these behaviours ultimately work to normalize and reproduce intersectional inequality and the construction of social hierarchies based on white supremacist and patriarchal norms in the process of learning.

In this way, the contributions of this study's participants have helped to make visible the social forces which construct an inequitable culture at the College and point to the ways in which this exclusionary culture may be maintained, or even exacerbated by existing masculinist structures of learning and pedagogic choices. As the author has argued, in addition to the better integration of gender and cultural perspectives in curriculum, the greater representation of Indigenous members, members with diverse ethnic and linguistic backgrounds and women, a different pedagogic approach is required. Heutagogy may present one way forward in this domain to diminish masculinism in the structure of learning. This pedagogic approach could facilitate supporting conditions for gender equality and cultural inclusion in the learning environment. While heutagogy is a relatively new method of teaching adult learners with 
professional experience, studies have emerged that demonstrate in what contexts and under what conditions the approach has been successful, embraced, or resisted.

Some analyses have revealed that decisions to implement and practice heutagogy have been determined through gendered norms, values, and ideologies (Samaroo, 2012). As heutagogic learning involves shifting the authority over learning from the instructor to the learner, this approach is also inherently about reconceptualizing power. In this way, facilitating students' desire to learn using collaboration, self-insight and self-determined critical thought may be difficult for faculty who are in greater positions of power over students, faculty who desire to structure students' learning in areas of their specific expertise, and faculty who prefer to employ directed rather than participatory forms of delivering knowledge (Ibid). As Samaroo's (2012) doctoral study indicates, these preferences may also be value laden and culturally specific.

Samaroo traced the practice of heutagogy at a southern university in the United States. This research indicated that in various culturally specific contexts across the university, gender bias against a heutagogic approach was evident. Samaroo's work illuminates that teaching styles associated with heutagogy had been resisted in traditionally masculinized disciplines such as business, while they had been more readily embraced in traditionally feminized disciplines such as education and health (Ibid, 51). As an extension, quantitative analyses of the same academic institution showed that women faculty, faculty with training in teaching, and faculty teaching graduate courses had more favourable attitudes and assessments of heutagogic approaches (Samaroo, 2012, 51-56). 
This research shows that the acceptance of heutagogy had a gendered flavour which depended on the specific cultural context of this Southern American university. As such, studies such as this one reveal the importance of considering how approaches to teaching emerge in relation to the gender norms and values of educators and departments. Moreover, it is useful to see how the unique culture of each education institute maintains different gendered constructs and (re)produces different gendered evaluations of learners, teachers, and teaching styles, and how teaching practices, philosophies and methods are often reflective of existing power structures in institutional culture.

In this way, it is essential for practitioners and designers of Professional Military Education at Canadian Forces College to view the learning environment as already situated within a unique and very gendered military culture. For example, Whitworth (2004), Razack (2004) and Davis (2007) have each contributed significant work which illuminates the privileging of specifically Anglo, white, aggressive, 'warrior' forms of masculinity by members of the Canadian military. And, as Febbraro's research about women leaders in the combat arms reveals, these masculine idealizations have impacted approaches to and idealizations of leadership. Febbraro's (2007) study indicates that more iterative, communicative, and facilitative styles of leadership had been constructed within the Canadian Armed Forces as 'feminine' and undesirable, while autocratic approaches to leadership had been idealized as 'masculine' and constructed as more 'effective'. In this way, while some women leaders may enact similar leadership styles to those dominant among men, stereotypes that "women are not suited for leadership positions" and gendered ideals about leadership as directive rather than collaborative persisted in unit 
subcultures (Febbraro, 2007, 93). Febbraro posited that in the Canadian military context the "“'effective leader" remain[ed] masculine in content" (Ibid).

Therefore, as the culture at Canadian Forces College is informed by the larger military institution, teaching and leadership practices which are extolled as more masculine may be culturally preferred. For example, student-centered learning has the potential to be perceived negatively at the Canadian Forces College precisely because it forwards qualities in the learning environment that are less competitive, combative, directive, and authoritative (read as less masculine), and more supportive, facilitative, and collaborative (read as more feminine) in relation to the military's existing gendered culture, norms, values, and practices.

Consequently, it is crucial to acknowledge the extent to which gendered assessments of learner-centric approaches are situated within larger frameworks of professionalism, institutional closure, and institutional culture. As an analysis of this study's data through intersectional, post-modern feminist and men and masculinities theories demonstrates, the Canadian Forces College is deeply influenced by the masculinist cultural norms, values, and traditions of the larger military. Such institutional constructions of knowledge, ways of doing things, and values are themselves gendered and often ethnocentric, and thus, contribute to the ways in which students learn. In developing greater appreciation of the hidden curriculum present at Canadian Forces College, in the transfer of intersectional social orders and paradigms, leadership, faculty, staff and students can work together to identify and challenge the 'deep structures' (Tiessen, 2007) that reproduce the social hierarchies which make members lives unequal and unfair. 
Through student-centered approaches that are collaborative and construct more horizontal power distributions, this community, built for the higher education of military professionals, may be able to establish and produce alternative ways of belonging, ways centered on transforming problematic personal and institutional philosophies through mutual recognition and respect (Dean, 1995). Doing so could serve to lay down foundations for an inclusive place to learn, a place where students are afforded the space and tools to develop the critical thinking capabilities desired by Canadian Armed Forces senior leadership.

For these reasons, it is important to underscore that, contrary to dominant notions, the Canadian Armed Forces is not in fact gender neutral. As Davis argues, while the Canadian Armed Forces encourages well intentioned gender-neutral policies and language, assumptions of gender neutrality have actually had the effect of burdening women to change. Her work reveals how women identifying Canadian Armed Forces members come to experiment with their gender embodiments, often downplaying their feminine traits and amplifying masculine behaviours to be perceived as competent in their work and to gain the acceptance of military men (Davis, 2009, 436). Davis' work indicates that values, norms, and practices within the military institution (of which the Canadian Forces College is embedded) remain tied to masculine and men's standards of behaviour and leadership. Assumptions of gender neutrality within the military have often put the onus on women to change their behaviours and identities to fit existing cultural norms. The expectation is for women to reproduce male models of behaviour and identity, while concurrently allowing problematic gendered values, norms, and practices to go on as normal, and to be so common that they are imperceptible for most members 
(Ibid). As this study illustrates, assimilative social practices in the Canadian military writ large have also been observed as common place and often more acute at Canadian Forces College.

As demonstrated by the assessments of students in the 2017 report (Brown) and corroborated by students and staff participants of this dissertation, implicit masculinist and ethnocentric assumptions and practices remain at work at Canadian Forces College. Thus, existing gendered ideals may pose social barriers to embracing gender and cultural difference as well as institutional change. Forwarding the work that the College is doing to make gender and cultural inequalities visible and to confront them as they emerge, leaders of the College could pay special attention to the ways in which student-centered learning comes to be accepted and resisted using gender and intersectional analyses. For example, asking questions about why there might be resistance to changing current norms of teaching and course delivery could illuminate how extant practices and policies at the College relate to social (in)equality. The author concludes this section by offering some thoughts from academic faculty participants:

Participant One: I think you have to assume some resistance, but your responsibility is not to dwell on it or react to it. You have to assume the better angels of our nature to some degree.

Participant Two: And those who resist would be the minority, I think.

Participant Three: Yes. I would agree.

Participant Two: We like to do our jobs well. 
Participant One: You do have to educate the resisters too, and what better way to do that then to have them teach it? (Academic Faculty Canadian Forces College, 2018).

\subsubsection{Theme 9: Canadian Forces College can Lead Professional Military} Education Institutions in the Integration of Gender and Cultural Perspectives

Canadian Armed Forces, Department of National Defence and Canadian government policy (Government of Canada, 2017a, 2017b; Chief of the Defence Staff, 2016) set the mandate for Canadian Forces College to integrate gender and cultural perspectives across learning in its Professional Military Education programming. Drawing from existing resources, talent, and the determination of staff, Canadian Forces College has the capacity to provide cutting edge and innovative learning about gender and cultural perspectives with focus on the military and security, taking the lead on this learning among other Professional Military Education institutes.

In the perspectives of many student and staff participants, the Canadian Forces College is a strategic conduit through which gender and cultural inclusion in the military can happen. An example of this perspective is illustrated by a student within a focus group:

I think if the Canadian Forces are serious about it, then this institution should be a leader because you've got the future COs in the room. Right? The future leaders. If you go to a unit and the commanding officer is not the one leading the charge [on gender and cultural equity and inclusion] then it's just going to fall to the wayside. If there is a place to dedicate time and energy to this topic, 
if it is truly important for the Forces, then it's natural that this is the place

(Man Student of the Joint Command and Staff Programme, 2018).

Gleaning from participants' responses, there are several reasons why many conceive the Canadian Forces College as poised to lead the charge on gender and cultural learning in military education.

First, the Canadian Forces College hosted a two-week NATO gender advisor course in the 2018-2019 academic year. This course produced thirty certified Gender Advisors across the Canadian Armed Forces. Since then, the Canadian Armed Forces have established the Dallaire Centre of Excellence for Peace and Security, with its research branch located at Canadian Forces College. This Centre draws on academic and military expertise to research and develop insights about children and armed conflict, the prevention of the recruitment and use of child soldiers as well as the implementation of the Women, Peace \& Security agenda in Canadian and United Nations Member State militaries.

Leveraging traction from the gender advisor course, the Centre of Excellence and the talent that exists among resident military and academic faculty, the Canadian Forces College could position itself as a potential hub of innovation and distinction in the areas of gender and cultural military education, providing professional and academic opportunities for advanced exploration and knowledge in the field. Second, with the planned restructuring of Joint Command and Staff Programme courses, there is opportunity to develop core curriculum with specific focus on gender and cultural perspectives in relation to the military and security. 
Third, evidence gleaned from the common perspectives of students, staff and faculty participants show growing social acceptance and expectation to learn about gender and cultural perspectives within the Joint Command and Staff Programme curriculum. While perceptions of 'fatigue' and some views that gender perspectives are low among other military priorities were observed, most staff and student participants argued that gender and cultural perspectives are significant to the military profession, pertinent to develop greater social inclusion in the military institution, and important to the success of the military institution's future leaders. Most participants also noted the benefits of learning about gender and cultural perspectives for military professionals to work towards gender equality and social justice in Canada and in the regions where the Canadian military is engaged.

Acceptance and the expectation of gender and cultural perspectives in Joint Command and Staff Programme curriculum were also commonly related to a shared desire to improve the climate present at Canadian Forces College. Many student and staff participants noted that these were central to creating cultural transformations that challenge dominant masculinist thinking and practices in the Canadian Armed Forces by educating the military's next generation of senior leaders to embrace diversity and create an inclusive institution. However, drawing from the ideas presented by military and academic faculty as well as civilian and military staff and students, there is underlying resistance to change. Addressing such resistance was noted to require the support of senior military leadership to integrate gender and cultural perspectives in curriculum and to increase the representation of women, Indigenous and racialized members at Canadian Forces College. 


\section{Chapter 5: Gender and Cultural Education and the Transformative Potential of Military Leaders}

Canada's Defence Policy makes several claims about the benefits of analyzing diverse gender and cultural perspectives by members of the Canadian Armed Forces and Department of National Defence. Some of its claims relate to the benefit of understanding gender and cultural diversity to operation and mission success (Government of Canada, $2017 b, 24)$. These claims argue that diversity and the integration of women equate to a more efficient and effective military (Ibid, 23). The Policy also claims that the Canadian Armed Forces ought to reflect the society it serves to better defend and protect the security of all Canadians (Government of Canada, 2017b, 20). Yet, little has been said about how learning about diverse gender and cultural perspectives might impact the thinking, behaviours, and practices of leaders within the Canadian military. Populating this conceptual and empirical gap, this chapter draws on qualitative data from in-depth individual interviews with Joint Command and Staff Programme graduates to investigate if and how existing Professional Military Education about gender and cultural perspectives has produced better leaders and feminist progress within the military's institutional culture and through the work of military personnel domestically and internationally.

This chapter draws on eight in-depth interviews with four women and four men at the Lieutenant Colonel or Lieutenant Commander rank. These interviewees were selected from the pool of students who participated in focus groups and demonstrated interest in 
participation in follow-up discussions about the use of gender and cultural perspectives in command and staff roles. These interviews took place after participants had graduated from the Joint Command and Staff Programme and had been appointed to command or staff positions for a minimum of 3 months. In the interviews, I specifically sought to discover what participants understood and retained from their learning about gender and cultural perspectives in the Joint Command and Staff Programme. Additionally, I explored how these leaders experienced the learning environment at Canadian Forces College with the benefit of hindsight, and whether the learning environment was conducive to the introduction of gender and cultural perspectives. Finally, I assessed if and how participants applied gender and cultural learning from the Joint Command and Staff Programme in their leadership decisions and practices as command and staff officers.

I conducted semi-structured interviews which allowed flexibility for participants to share their views on key ideas, to probe my questions, and elaborate on their answers (Marvasti and Freie, 2017, 629). I used Critical Discourse Analysis (CDA) (Dijk, 1993; Blommaert and Bulcaen, 2000) informed by intersectional, post-modern feminist and men and masculinities theories to identify and draw out repeated narratives and themes across interviews as well as to trace larger social processes and practices that were observed and experienced by participants (Rogers, 2011). Drawing from the perspectives and observations of these leaders allowed me to discover the ways in which learning about gender and cultural perspectives had set these professionals down diverse paths to 're-gendering' dominant military identities and to create feminist institutional and societal change. 
I used militarized masculinities theories to seek out narratives about the development of social hierarchies observed in the learning environment and the larger Canadian military. Drawing from the central tenets of intersectionality theory, I also traced if and how the gender and cultural learning of participants helped them to perceive the social construction of dominant and intersecting systems of power within the learning environment and within the larger military culture. Lastly, I applied post-modern feminist theory to discern if education on gender and cultural perspectives enabled leaders to identify and challenge patriarchal inequality and ultimately if this learning enabled them to make feminist interventions that challenge the patriarchal status quo institutionally, domestically, and internationally.

\subsection{The Paths of Military Change Agents}

Four key themes emerged from the narratives of follow-up interviews with these eight graduates. Emergent themes were divided as follows. Theme one illustrates a common narrative about when and how participants applied their learning about gender and cultural perspectives to their work. In this section, participants explored the unique ways in which they had been implementing gender-based and intersectional analysis in their command and staff tasks. The second theme identifies repeated perspectives about when and how participants applied gender and cultural learning to their leadership practices. This section demonstrates how learning about gender and cultural perspectives had shaped, in various ways, each participant's perception of leadership and guided the ways in which they led. 
The third theme identifies gaps, environmental barriers and resistance to gender and cultural education, as well as barriers to the implementation of gender and cultural perspectives in military work, norms, and power structures. This theme presents participants' perceptions about the positive and negative aspects of the learning environment for facilitating their gender and cultural education. It also highlights the gaps that participants perceived in the gender and cultural learning they received in the Joint Command and Staff Programme using hindsight from their experiences on the job. Lastly, this section makes visible the various ways in which participants experienced resistance to education about and implementation of these concepts both in the learning environment and more broadly as they applied them to military leadership and work.

Theme four comprises narratives on how learning about gender and cultural perspectives shifted participants' ideas about culture change in the Canadian Armed Forces. This theme illuminates common perspectives on how the application of gender and cultural learning made participants better leaders and change agents within the institution. The theme presents participants' thoughts on the extent to which education and applications of gender and cultural perspectives to military norms, practices, plans and policies have worked to challenge unequal power hierarchies and social orders both within and outside of the military. Importantly, the narratives presented in this section help to make visible the ways in which learning about gender and cultural perspectives in the Joint Command and Staff Programme contributed to localized and context specific work of military leaders towards intersectional equality in the institution, in Canada, and abroad. 
As the thematic areas presented signal, most participants noted inconsistent and ad hoc learning about gender and cultural perspectives in the Joint Command and Staff Programme. As such, most articulated the requirement for gender and cultural perspectives to be woven through major components of the programme, from leadership and command components to operational planning, targeting, military policy, warfighting, as well as international security and relations. Importantly, many participants noted that the learning environment at Canadian Forces College impacted students' reception of gender and cultural perspectives in the curriculum. For example, participants repeatedly noted that the syndicate environment, if led using inclusive classroom techniques, was optimal for addressing, debating, and coming to a mutual understanding about gender and cultural considerations, while promoting diversity in thought. Respondents noted that in syndicates that had less inclusive practices, their personal identities were heavily policed, silenced or admonished, and their raising of gender and cultural perspectives was sometimes met with intense resistance from faculty and peers.

To varying degrees, all participants discussed the development of a dominant masculinist identity and value system within the learning environment. While some perceived a concurrent variety of identities and values held among the student body and staff, 5 of 8 participants shared direct observations about how more antagonistic or cynical masculine practices and behaviours were valorized. Many noted that these practices and behaviours often rendered masculinist assumptions within the learning environment acceptable, and that these assumptions created propensities for opposition to and skepticism about diverse gender and cultural perspectives. Yet, despite observations 
of masculinist social barriers in the learning environment and perceptions of a nascent or ad hoc presentation of gender and cultural perspectives in the Joint Command and Staff Programme, all participants nevertheless spoke to the benefits of this learning. Indeed, most reported direct and lasting impacts on the way they think, how they approach their work, and ultimately, how they lead people and the institution.

Significantly, all participants demonstrated their application of gender and cultural perspectives in their leadership and work. All had specific reflections and experiences about applying gender and cultural perspectives either to highlight the intersectional injustices that exist within the military organization, and/or used their learning to renegotiate and work to change existing power structures and social hierarchies which they perceived make the institution, or the society in which they were engaged, unequal and unfair. Some of the reflections of participants show underlying cultural resistance to feminist, anti-racist and intersectional culture change and social transformations.

Some who faced resistance attested to remaining firm in their convictions to pursue social justice through their leadership practices and relations, while others noted doors being closed to them, or being pushed or silenced out of important decision points. The observations and experiences of this group of participants show how education on gender and cultural perspectives has already enabled some military leaders to use localized practices of feminist resistance to challenge and work to undermine patriarchal and racial hegemonic orders in the military and in those societies in which they work. In different ways, each participant indicated their very intentional work to create more democratic and equal arrangements of social power for all. 


\subsubsection{Theme 1: When and How Participants Applied Gender and Cultural}

\section{Learning in their Work}

Each participant of this study had a unique stance about how they applied learning about gender and cultural perspectives to their leadership thinking, relations, and practices. The diverse applications of this learning demonstrate the lasting impact of this education and the ways in which participants contributed to social change through their interventions. The following reflection from a participant shows her experience of mainstreaming gender and cultural perspectives in institutional policy:

I make sure it's included. It would be part of the GBA+ protocol, but nobody was doing it before I got here. I work mostly with the Gender Advisor of the Command. So, every time I've drafted something, I talk to them first, and make sure that I get her perspective. . I w will always make sure that there is a paragraph, at least, included on that piece. I find I often get the "Oh yeah we know, but we're not there yet." Yeah, but if we are not there yet then we should work towards getting there ... A good example, men are able to wear a beard now. So, the minute that conversion came out, I contacted the dress company and I asked "Ok so when are we going to do the full gender, like the GBA+ analysis and consider some changes for women?" And as an example, like the way women have to wear their hair. And they go "We're not ready for that." I'm like "I don't care if you are not ready, we as a society are there, so we need to move on with it" (Woman Graduate of the Joint Command and Staff Programme, 2018a). 
This example of the use of learning about gender and cultural perspectives in respect to military institutional policy illustrates how, in the face of resistance to thinking about the intersectional interests of members, this leader pushed for deeper analysis of systemic inequities and lobbied for change. Interestingly, GBA+ was subsequently applied for the needs and interests of women, resulting in institution-wide changes to policies about hairstyle, nylons, and footwear (Government of Canada/DND, 2018).

Gender and cultural perspectives were applied in the leadership of another respondent to thinking about family dynamics within their unit:

We needed to do a suicide awareness brief on the wing. The intent was to bring in the families. So, automatically . . .the idea was for the families, for the spouses, we would do a briefing at night because automatically that's the best option right? ... So that's when I stopped like “Ok, let's look at who we have. . . what about if the spouses are not working or they are at home during the day? It might be easier for them to come in [the day] because their kids are at school. And what about the ones that have a child at home?" ... So, it was kind of questioning the assumption that "the spouses will come at night and that's it." ... Outside of that, it's been mostly in terms of discussions with other soldiers ... [on] assumptions about recruitment, the quotas about how many women we need in the CF and things like this. So that's how I kind of include it in my daily work. . . the few times that it came up, it was obvious that what I've learned was of value (Man Graduate of the Joint Command and Staff Programme, 2018a). 
This participant applied gender and cultural learning to ensure that the needs and interests of military members' families were taken into account and that the most inclusive option for all members was chosen. In addition, this participant applied gender and cultural perspectives to interrupt bias and shift problematic philosophies about gender, sex, and the military institution.

Another illustration of the lasting impact of participants' formal and informal education about gender and cultural perspectives is presented in the following observation:

And not only did we have those discussions in class, but we also had those discussions outside the formal learning. So, for me, this is where it started and it keeps on ... developing. [In the] two last weeks of the exercise that we did [for the Institutional Policy Studies stream of JCSP], I was on the team that was looking at the diversity strategy. So those discussions were pursued during those two weeks. And this was like a change in my career, in my personal life, on how I see the integration of women in the Canadian Forces (Woman Graduate of the Joint Command and Staff Programme, 2018b). This participant notes the importance of having the space for discussion and collaboration about gender and cultural perspectives. This observation was repeated across the participant group and was also present across participants in previous rounds of interviews and focus groups. As students in the Institutional Policy Studies stream account for only a third of the student body, not all students have the same access to this learning, nor did all have access to the heutagogic framework used for the two-week exercise noted. This example highlights that deep learning and critical thought about 
gender, culture, intersectionality, diversity, and inclusion has a significant and lasting impact on the leadership approaches of military members. This positive outcome requires both an integration of these ideas in curriculum so that all members receive this learning, but also requires the appropriate pedagogic approach and social conditions within the learning environment.

Illustrative in the following reflections of two participants, another repeated narrative about the lasting impact of gender and cultural learning is its application to the analysis of military equipment and acquisitions. In both narratives, drawing on gender and cultural perspectives enabled more inclusive and effective analyses and decision making in acquisition processes. These concepts enabled military professionals to facilitate the selection of (and work to design) more inclusive materiel suitable for a broader range of demographics within the military. The following perspective illustrates the application of gender and cultural perspectives to thinking and analysis about the acquisition of military vessels:

If I'm bringing new equipment into service, or we think about new aircrafts, new modifications, but even if you are building a ship, especially for materiel, any tanks; whatever the service is, you need to be able to incorporate provisions for all genders so that everyone can use it the same... I'm left-handed, so maybe I'm more sensitive to it in a right-handed world, and the impacts that there can be if you don't fit in. Some of the risk assessment or equipment that we look at ... could depend on the person using it and their gender. .. Crew seats in the aircraft, how they might affect a different stature of person ... we might have widened it a little bit to account 
for changing demographics in the military (Man Graduate of the Joint

Command and Staff Programme, 2018b).

This perspective illuminates this participant's critical thinking about the material effects of not belonging, or, of literally not 'fitting in' to the world constructed for a particular intersectional group of people. In this perspective, there is great risk to individuals and the military institution in neglecting to account for and recognize the needs, perspectives, and interests of 'changing demographics' in the Canadian Armed Forces. This participant's observation implies that shifting demographics within the military equates to greater need to think about and practice inclusivity across the full range of planning, procurement, and functions of the organization.

A similar perspective is recounted by another participant:

So one of the things you have to understand when you start to try to make changes to the occupation is "what is the culture of that occupation and where will they resist change?" and also the particular trade I'm looking at is Canadian Forces Clearance Diver. . . and it's not the work, it's the equipment that would need to be examined in this particular case. ... You know, they don't necessarily have harnesses for your size, the female body. . . [And] why are you carrying around 85 lbs tanks when you could use [something lighter]? Usually not just lighter for women, but for everybody. So, from that perspective, if we are really trying to talk about gender and diversity and intersectionality, you know you're eliminating some of the population who might actually be really capable, because they can't do some of the heavy lifting that's required. But it's only required because we don't necessarily go 
out and get the equipment that isn't so heavy, because often it is the more expensive style (Woman Graduate of the Joint Command and Staff Programme, 2018c).

As this and the previous participant's statements demonstrate, the application of gender and cultural perspectives not only requires military members to consider the interests, needs, and perspectives of all members of the Canadian Armed Forces, but also requires deep thinking about the social and cultural forces that construct the military's culture and the structural choices the institution makes. The perspective offered in the preceding quote illustrates a deep understanding of occupational culture and where commitments to existing power arrangements often present barriers to gender equality and transformational shifts in conceptions of military identity. As reflected in the preceding chapters, this perspective illuminates why military professionals must be aware of culture and social power in the military if they are to make meaningful interventions towards social justice, even in the realm of structural change.

These examples provide evidence of how graduates of the Joint Command and Staff Programme are integrating their education on cultural and gender perspectives into their daily work. Some of their applications of this education include interventions to raise awareness about and mainstream gender and cultural perspectives across the workplace. Other examples demonstrate interventions in the form of bias interruption and attempts to facilitate shifts in thinking across military units, occupations as well as organizationally in policy and resource management. The examples presented provide evidence that graduate participants of this study are working to make localized social and cultural shifts by very intentionally applying their learning using all available resources, 
whether they be raising awareness or by seeking out sex, gender, and culturally specific disaggregated data to inform planning, policy decisions, and procurement.

Omitted from these excerpts, in the interest of anonymity and mission specific details, are the perspectives of two additional leaders, one woman Army Lieutenant Colonel in a gender advisor role on an international mission, and one man in a commanding role as Captain of a ship on a good will mission. Each described using gender and cultural perspectives to inform the ways in which they approached and conducted operations in various local communities in specific operational regions in Europe and Africa. Each recalled how they considered gender and age differences as well as competing cultural interests in specific territories (Woman Graduate of the Joint Command and Staff Programme, 2018d; Man Graduate of the Joint Command and Staff Programme, 2018c). Additionally, both informed me of the value they saw in applying gender and cultural perspectives to their work, but, reflected that gaps in education about how to apply gender and cultural perspectives to operations led them to do independent learning on the fly during the mission (Ibid).

A common frustration not explicitly stated, but inferred in the responses of participants, is that processes such as gender mainstreaming (Parpart, 2014) and tools such as GBA+ tend to be descriptive rather than prescriptive. For instance, conducting a gender based and intersectional analysis can offer military professionals insight through descriptions of the sorts of social injustices that exist in a particular context and among particular people. These frameworks can make visible the often tacit socially constructed and oppressive power systems that work to privilege some groups of people over others. Yet, these analyses and tools do not offer suggestions as to what military officers can and 
ought to $d o$ about inequality. There are no prescriptions offered, and no presentations of ways forward provided to students in most of the current curricula. In my experience, and as I and my colleague Alan Okros have argued elsewhere (Brown and Okros, 2020a; Brown and Okros, 2021; Brown, 2021), Professional Military Education about gender and cultural perspectives within the Joint Command and Staff Programme has often been conceptualized in depoliticized, masculinist, white supremacist, and militarized ways that are divorced from longstanding oppressions and struggle.

Indeed, institutional applications of GBA+ have often failed to recognize historical struggle. GBA+ has been useful in describing inequalities across demographic groups but has been less successful in understanding how these inequalities came to be, and, importantly, how to fix them. If connected to historical struggle and feminist as well as anti-racist visions for change, GBA+ can be a powerful tool for institutional transformations. Doing so would 're-politicize' these tools in a way that honours their original emergence through anti-racist, anti-colonial, and feminist work. Moreover, an important contribution to resolving inequality from critical disability studies has been the concept of 'nothing about us without us.' This approach uses a grounded entry point to understand inequality by learning from the perspectives of those who have been marginalized and are working collaboratively towards meaningful structural and culture change (Charlton, 1998).

As such, generic applications of GBA+ and surface articulations of gender and cultural perspectives within curriculum often enable military members to escape thinking through complex socio-cultural power arrangements such as patriarchy, racism, and global restructuring (Runyan and Marchand, 2011) using feminist, anti-racist, anti- 
colonial and anti-imperial standpoints. ${ }^{73}$ As the perspectives outlined in this study demonstrate, participants were able to apply their learning of gender and cultural perspectives to their work, however, for the more complex aspects of social justice in relation to gender and culture and what to do about it, participants recognized being unprepared. In this way, extant integration of these subjects has presented students with conceptual gaps in what military members can reasonably do and what tools they can be expected to leverage to advance equality. In particular, deployed participants observed a lack in capacity to incorporate gender and cultural perspectives to a range of peace and security contexts where systemic gender discrimination, classism, and racism were present.

\subsubsection{Theme 2: When and How Participants Applied Gender and Cultural}

\section{Learning to their Leadership}

In addition to applications to their work, participants commonly observed that they drew from education on gender and cultural perspectives to inform their thinking about and practice of leadership. The integration of these concepts, as observed in the following examples, enabled participants to consider social power in relation to gendered factors, ethnocentrism, cultural differences as well as differences in experience and worldview to better understand those they command and those they serve to protect. The reflection of this participant illustrates the effect that this learning has had on his leadership practices:

[You incorporate it by] observing leadership styles or things you want to adopt or not. I'm probably talking about people's different experiences with

\footnotetext{
${ }^{73}$ As applied in Whitworth, 2004 and Razack, 2004.
} 
different genders and how they approached that or their integration into units, those are the things that I consider and that I use to interact. It probably makes me, you know, raise more questions and considerations than I would have in the past (Man Graduate of the Joint Command and Staff Programme, 2018b).

This example demonstrates that learning about gender perspectives enabled critical thinking by developing skills that allowed this leader to analyse social relations through a gender lens.

Similar to the preceding example, the following perspective of this participant speaks to the inclusive choices he made as a result of learning about gender and cultural perspectives in the Joint Staff and Command Programme:

I guess that I'm a bit more aware of how my actions and comments can be taken. .. Actually going around the table .. .making that conscious action of saying "Ok, you and you and you" one after the other so people, they know that it's their turn and that I want them to speak. . . Because I'm just recognizing that sometimes people don't feel comfortable, they don't think that they have something of value to bring up and their first reaction is to just to go in the corner... When you start a meeting and you are asking for people to bring up ideas, if you are the person in charge, don't start with "We'll where I think we should be going is..." because you've just discarded a whole bunch of ideas that people have, because now they're saying "Well that's not where the boss wants to go, so now I'm not going to speak up" (Man Graduate of the Joint Command and Staff Programme, 2018a). 
As this reflection serves to illustrate, learning about gender and cultural perspectives has the potential to develop critical thinking skills in senior officers which may influence their intentional choices and practices towards inclusive leadership.

While the preceding examples in this section illuminate the benefits of gender and cultural learning in the thinking and leadership of participants, the following observation serves to demonstrate deep thinking about military and civilian socialization, social power, and culture:

I find that you have to bring two very different leadership styles depending on where you work. In this environment where I work, it's about who you are as a person as opposed to your uniform. So, you have to lead in a collaborative way. You are being a human being in this environment, you are not ordering anybody around. You're collaborating, working, and leveraging personal relationships. . You can't really order anyone to do anything here. You have to really influence and inspire. When I was on warships it was very simple. You had the rank, and rank meant everything. You just ordered people around. In this environment, it's all about diversity of thought and getting buy in. The constant challenge is getting buy in from the public service and to come up with unique and creative approaches to do that. To demonstrate that you are not just a warmonger with the civilians (Man Graduate of the Joint Command and Staff Programme, 2018c).

Gleaning from education about military socialization within the Joint Command and Staff Programme, this participant's reflection demonstrates continued critical thinking about military socialization and culture, the ways in which military culture is unique and 
distinct from the cultures found among public servants of the Department of National Defence, and how to lead effectively in different social environments.

Validating this perspective, the following statement highlights the leadership choices one participant made to integrate gender and cultural perspectives within military environments:

I force it down their throat. . I always bring it up. I like to bring that as part of the discussion, to get where they are coming from and try to change their mind by....by showing them the other side of the battle, I guess. You know shoving it down their throat would be a very military way of doing things. That's what the indoctrination did, that's what they are telling us to do, right? That's the problem with the way we do indoctrination. I think, in the Forces we don't explain why we do certain things. It's just like “you're doing it because I asked you to." "You're doing that because I said so." There's no explanation or logic behind it (Woman Graduate of the Joint Command and Staff Programme, 2018a).

As this and the preceding narrative show, education on gender and cultural perspectives as well as learning about how to create an inclusive environment that encourages diverse experiences and identities impacted the ways in which these participants led. Their observations of what leadership approaches are necessary, with what audience, and in what circumstances, also demonstrate critical thinking about institutional gender norms and culture, thinking that has influenced how these participants chose to perform as 
leaders. ${ }^{74}$ The two perspectives on leadership style tailored to the particular cultures of military and civilian audiences reveal the development of and capacity for critical and creative thinking about leadership and the construction of power in the military and the public service.

Yet, critical thinking about social power and culture by participants goes beyond examinations about military socialization versus socialization to the public service. The narratives from participants including the gender advisor as well as the Navy Captain also show critical thought about people's socialization to different ethnic and regional cultures and how gender roles, values, norms and power arrangements are contextual and culturally specific. In each case, the leadership practices and approaches applied by these participants show the development of tendencies to think critically about diversity, and to act with the aim of inclusion and equality.

In the process, drawing on gender and cultural perspectives has been observed by each participant to have made them more effective leaders. The application of education about gender and cultural perspectives has enabled them to better understand, anticipate and support the needs of their team, to draw out innovative and diverse perspectives of military members, security sector agents, civil society members and civilian populations, and to seek out, understand and account for diverse identities and experiences which may not be traditionally valued within the Canadian military and within the local societies in which they are engaged.

\footnotetext{
${ }^{74}$ I use the term 'perform' to denote the deeply gendered performance of leadership within culturally constructed constraints of appropriate and legitimate behaviours. This understanding helps to situate participants' social realities and borrows from Judith Bulter's (1990) conception of gender performativity as relational to constraining cultural constructions of gender, sexuality and power in what she defines the 'heterosexual matrix' as referenced in this dissertation's theory chapter.
} 


\subsubsection{Theme 3: Gaps, Environmental Barriers and Resistance to Gender and Cultural Education}

The reception of education on gender and cultural perspectives within the Joint Command and Staff Programme is exceedingly positive in this participant group. The remarkable optimism about this learning, however, may be related to a limitation of the methodological approach used in this project to solicit volunteers to participate in the study rather than compelling a randomized set of individuals from the student body to weigh in. As volunteers were made aware that this study investigates students' perception of the learning environment and education on gender and cultural perspectives, it may be that those who chose to participate were those students who perceive social inequalities at Canadian Forces College and/or are more likely to perceive the value in the continuation and expansion of gender and cultural education. The single most critical reflection of education on gender and cultural perspectives from this group came from one member. This 'critical' comment—-that 'there needn't be more content on gender and cultural perspectives integrated in the curriculum as the extant curriculum is very good'-is nevertheless a positive assessment of this learning.

A similar tendency can be noted in the previous reflections of academic faculty, where the participants who volunteered for this study from this professional group at the College were also those who viewed gender and cultural education as essential. However, as the narratives of academic faculty in the previous chapter and the observations of this group of graduates suggest, the presentation of gender and cultural perspectives in the Joint Command and Staff Programme is a somewhat polarizing issue between particular 
groups at Canadian Forces College. In this way, negative assessments about the integration of gender and cultural perspectives among this group of graduate participants were not so much about the ideas and theories within gender and cultural perspectives but more about the barriers to their presentation and resistance to them by staff and their peers. As such, more critical opinions about this learning were about its delivery by military faculty and the reception of its delivery among the student body.

Some participants reflected that skeptical military faculty and cynical members of the student body detrimentally influenced the reception of learning about gender and cultural perspectives. As one participant notes:

Well it's from the students, I mean. Because every time we had, like in the syndicate room before the professor or [military faculty] would come in, like the discussion we had before [would be]: "Well we are going to talk about gender again today. It's going to be boring. I'm so tired. Like we've talked about gender more than we talked about" and they'd point out a specific doctrine. [To which I replied] "we're supposed to know our doctrine. That's our job, but we [also] need to talk about the stuff that will make us stronger over there [on missions], that's what we're struggling with at this point." [then the military faculty] would come in and [students] would look like nothing happened and pretend like they cared, and then at the end when ... it was just the students, [they would be] like "Ugh, that was useless today. I didn't learn anything"... That's why I'm saying that there's a certain resistance (Woman Graduate of the Joint Command and Staff Programme, 2018a). 
In my observations of students in focus groups, and in particular among the women's student group, social divisions emerged where one group of students would defend learning about gender and cultural perspectives, and the other would attempt to make fun of, throw shade at, or trivialize the significance of this learning for military work. Within the women's focus group there was consistent tension, expressions of frustration, flushing of cheeks, raising of voices, posturing and eventually (after much back and forth) attempts to understand diverse perspectives.

More defensive standpoints about gender perspectives may stem from placing the spotlight on women and femininity in the military and could be experienced as gender 'outing'. For example, members of the women's focus group have been very successful in the military's male dominated and masculinized environment. They have risen to midsenior leadership positions in the Canadian Armed Forces and have done so in part by conforming to gender scripts in military socialization and indoctrination. The most ardent critics of gender perspectives in the women's focus group were also those that presented more masculine styles of communication, held operator occupations, and/or belonged to the Army service.

Drawing on Winslow and Dunn's (2002) study, occupations and services that are closer to combat roles have more limited integration of women and may produce more narrow idealizations of masculinity in relation to professional roles and responsibilities. It may be that women military members who display gender identities that align with the narrowed gender ideals in these occupations and trades have been rewarded. In this case, some women may wish to keep the existing gender order in place as they see themselves continuing to succeed within the existing system in the future. During focus groups and 
interviews, it was typically women military members who were the most vocal and passionate about gender perspectives. Women participants perceived gender perspectives as either a greatly beneficial thing to learn about, or, as a threatening thing to discuss depending on the degree to which they had benefitted from the status quo or experienced social inequality. Thus, while the experiences and opinions about gender and cultural learning among this set of participants tends to highlight the utility of this education, defending and justifying the benefits of gender and cultural perspectives for the profession of arms has proven to take a good deal of work, bravery, persistence, and consistent discussion on the part of students (and staff) who desire its continuation and/or its more consistent integration in the Joint Command and Staff Programme.

Justifying the requirement and benefit of this learning has been noted by the participants in this group, as well as some in focus groups, to be difficult work. Such work sometimes leads to a chilly climate, hostility, and the social policing of attitudes, worldviews, and behaviours. The following experience of the difficulties explaining the utility of learning about gender and cultural perspectives is noted by this participant:

There is such resistance amongst my peers and others to acknowledge even how something as simple as changing uniform or the equipment to size more than the average man or to pay attention, instead of trying to make everything unisex by making it male...Um...that people don't recognize that as an issue, that [they think] it is something that we shouldn't bother to spend any time on, that it is not actually linked to how people see the service as reflective of themselves, or to see themselves joining, because is still seems like a bit of a 
boys club (Man Graduate of the Joint Command and Staff Programme, 2018b).

This example may present a fundamental failing of those delivering curriculum on gender and cultural perspectives to offer a convincing narrative as to why the military is responsible for raising institutional awareness about, taking interest in, and drawing from gender and cultural perspectives in its planning, policies, and practices. This potential failing may be compounded by efforts to maintain the constructed social order present at the College, wherein learning about gender and cultural perspectives works to question and destabilize the foundations of this very order. It is also important to note that the gender order within the military that constructs men as 'naturally' more fit for battle than women has been normalized by patriarchal and militarist modes of social organization in the larger Canadian society.

Drawing on Jean Bethke Elshtain's Just Warrior/Beautiful Soul paradigm (1987), most military members will have joined the armed forces with some socialization to the patriarchal norm of men as 'natural' protectors and warriors and women as 'naturally' peaceful and in need of protection. This dissertation offers a significant contribution to this literature. Namely it forwards that there is the possibility, and indeed the material practice of some of this study's participants, that military members will challenge and change broader institutional and societal sexism. Participants of this study show that military members can work to champion culture change within the institution and in engagements outside of it, demonstrating that the military can be capable of reshaping social norms in armed forces, in Canada, and beyond in ways that work to transform inequitable social organization. 
The following example illustrates that resistance to gender and cultural perspectives manifests in particular cultural tendencies produced among some members of the student body and some staff at Canadian Forces College. Such tendencies include cynicism, skepticism, and dismissive attitudes towards gender and cultural perspectives within curriculum:

Yes, there is a whole subtext going on in the background regardless of the lecture. You have maybe a gender advisor come present, and what is simultaneously going on is hushed discussions or message threads critiquing that among the influential people in the group. And once that happens, if people have common sense, they see that it's a ridiculous thing to think about, but sometimes people just follow the crowd too. I think I told you in our class I found that it was hip to be cynical. I think that kind of carried through (Man Graduate of the Joint Command and Staff Programme, 2018c). As this experience as well as the observations within this section suggest, while participants of this study note the value of gender and cultural perspectives for their work and leadership practices, these perspectives are often resisted by others.

In response to the common observation of resistance to gender and cultural perspectives, the following participant argues that military faculty must bear much of the responsibility to shape students' reception to these areas by using their rank, experience, and the social power these afford to influence the classroom environment:

So, all it takes is a couple of key leaders in the group who don't buy-in . . . If and when that happens, it takes a strong leader in the [military faculty] to put this person....to not put them back in their place, but to use this person ... to 
create a positive outlook (Woman Graduate of the Joint Command and Staff Programme, 2018a).

As this participant suggests, paradoxically leveraging the social power of esteemed members of the Canadian Forces College culture (those who better fit hegemonic masculinity) may be a way to overcome resistance to the inclusion of diverse gender and cultural perspectives in curriculum.

However, as the observation of another participant suggests, the reception of gender and cultural perspectives depends on whether or not military and academic faculty are resistant to ideas of gender equality and inclusion or whether they are resisting the barriers that stand against feminist interventions:

I'm sorry but I'll go again to the instructors, the [military faculty]. In the first session I had someone very open-minded ... and was always seeking different points of view and having everybody participate. The second one was awful and was led by [a] strong 'Type A' Army personality. . . If instructors don't control that, then there are three months that we just lost in being inclusive. So, that means that concretely, on a daily basis, people are not respectful of differences (Woman Graduate of the Joint Command and Staff Programme, 2018b).

This observation, when taken together with the other reflections in this section works to illuminate the presence of competing forms of resistance at play within the culture of Canadian Forces College.

First, there are individuals that have a good deal at stake, a good degree of motivation and a great amount of investment in the maintenance and reproduction of the 
binary and unequal socially constructed gender order at Canadian Forces College. Drawing from the shared observations of participants across students and staff in the preceding chapters, the gender order that exists within the culture at Canadian Forces College tends to perpetuate the dominance of both masculinism and white supremacy. The dominance of these ideologies maintains and reproduces an observable social hierarchy at the College which manifests through the enactment of a culturally specific and idealized soldierly identity comprised of 'alpha', 'competitive', sometimes 'misogynist', 'operator' and Army qualities of masculinity which exists in dualistic relation to 'academic' and 'supporter' identities that are understood as 'feminine' and 'soft.'

Maintenance and reproduction of this hierarchical social order at Canadian Force College "heavily depends on gendered discourse and gender ideology for its own construction because" these make the constructed social order "appear natural and inevitable" (Marchand and Runyan, 2000, 18). As Marchand and Runyan suggest, the reproduction of gendered social orders, such as the one at Canadian Forces College, actively construct binary 'boundaries and meanings of private and public, domestic and international, local and global, feminine and masculine' (Ibid).

Ultimately, the observations and experiences of participants in this doctoral study unearth the cultural production of a hegemonic intersectional social hierarchy at Canadian Forces College. This social order has depended on cultural constructions of an ascendant intersectional identity which serves to delineate boundaries of and meaning making about 'lesser' and 'complimentary' identities. This hegemonic identity is at once actively constructed, policed, and resisted in the learning environment. In this way, 
individuals that are invested in the dominant social order at the College may resist presentations of gender and cultural perspectives that operate as 'counter hegemonic forces' (Marchand \& Runyan, 2000, 19), those which could probe and challenge the artificiality of constructed boundaries; those that contaminate and destabilize the ways in which (gendered, racialized, and sexualized) meaning is being made and offer up alternatives.

Second, and importantly, learning and then applying gender and cultural perspectives has enabled this chapter's group of participants to resist inequitable hegemonic gender orders within the military and within the societies in which they work using a variety of localized and contextually specific practices. The participants in this group are part of this second camp of resistance. They have shared a variety of experiences about how they have each gone on to challenge and sometimes rework binary understandings of masculinities and femininities, women's and men's roles and practices, as well as unequal gender relations and intersectional systems of power in ways that I as a scholar and an educator could never have anticipated. These contingent and unique perspectives bring to the fore the importance of using sociological ethnographic approaches to identify and understand smaller scale and contextually specific practices of resistance spread across a network of loosely connected actors.

The methodological and theoretical choices which constitute the conceptual and analytical foundation for this dissertation have contributed to overcoming a weakness traced to many international relations and international political economy studies about gender relations. Namely, that much of this work is gender blind—as demonstrated in this dissertation's theory chapter-and also that this work often takes for granted 
localized practices of resistance to structural and systemic inequality, prioritizing instead "large scale, (sometimes violent) counter-movements" (Marchand \& Runyan, 2000, 19). Moreover, and as Duncanson's research articulates, much work on militarized masculinity has presumed that shifts in military masculinities are merely signs that patriarchal gender hegemony is "adapting to incorporate whatever practices and styles are necessary for the retention of power" (Duncanson, 2015, 233-234).

What the narratives of participants in this doctoral research show, however, is that their practices of resistance to patriarchal, masculinist, heteronormative and racist hegemonic gender orders work against such retention of power, and instead aim to redistribute power on the bases of diverse interests, needs and identified inequalities. Rather than co-opting feminist ideas for military purposes, the results of this dissertation demonstrate that active resistance to hegemonic gender orders by some military members is a deliberate practice aiming to 'undo hierarchical gender relations' that create inequality. The research highlights that through their localized practices, military members are attempting, in their own unique ways, to undermine the mechanisms through which inequalities are maintained and reproduced culturally within the military and outside of it.

\subsubsection{Theme 4: On Culture Change}

In 2015 the Chief of Defence Staff gave direction in the form of an Operation Order on the elimination of harmful and inappropriate sexual behaviour in the Canadian Armed Forces. Contained within the Operation Order are specific lines of effort outlining how the institution would go about addressing this systemic organizational issue. One 
line of effort of particular relevance to the common narratives of participants of this dissertation is on education and culture change. This line of effort obligates the military to "institutionalize a cultural change framed by clear direction and training for leaders on how to better direct and effect culture change throughout the institution" (CDS, 2015, sec. 13.b). The content of this culture change is outlined in this Order's envisioned end state: "when members are able to perform their duties in an environment free of harmful and inappropriate sexual behaviour and are able to fully enjoy the support of an institution that fosters mutual trust, respect, honour, and dignity" (Ibid, sec. 15). According to Operation HONOUR, this end state can only be met through a "LeadershipDriven Culture Change" (Ibid). Thus, this operation order signals a nexus among education, leadership, and culture change, one in which participants within this group are reacting to.

In the 2018 update of Operation HONOUR, the Chief of the Defence Staff urged, once again, for this campaign to "consider much more significant investment in training at recruit and leadership stages" (Sec. 3.d). Contextually, additional resources were being incorporated in the time between the 2016 and 2018 directives. These resources included integrating UNSCR 1325 and related resolutions into Canadian Armed Forces' planning and operations, as well as incorporating GBA+ into the organization's day to day activities, policies, education, professional development and programs (CDS, 2016). The military continues to integrate these resources across the institution, and in particular, these resources constitute part of the Joint Command and Staff Programme curriculum on gender and cultural perspectives. 
These military directives are of great significance to this set of participants' understanding of gender and cultural perspectives and can be related to each participant's internalization of a responsibility to drive culture change within the Canadian Armed Forces. Of note, my interview questions avoided asking participants about culture change as I felt that doing so would connect dots for military leaders instead of giving them the space to draw their own conclusions. Thus, as this final section of these substantive chapters demonstrates, education about gender and cultural perspectives in the Joint Command and Staff Programme is being explored and used towards leaders' practices to transform Canadian Armed Forces culture, and to work towards social justice beyond the military more broadly.

As the reflection of this participant demonstrates, education on gender and cultural perspectives is perceived as an obvious launch point for larger transformational changes in military culture:

I think finding where we can add a little bit more value to what's already being taught. Like we talked about bringing other guest speakers to give us a gender perspective and how we interact in meetings or around the office. But, I think we are already doing much more than we had in the last few years. It's going to take years . . . before we've changed the culture, but if it starts as something with that course, it's already a plus, right? (Man Graduate of the Joint Command and Staff Programme, 2018d).

As demonstrated in the preceding sections, participants have reflected on their use of gender and cultural learning to create equality in the work environment, to dispel gender stereotypes and assumptions, and to create inclusive practices through their leadership. 
Another example from this participant shows how military members are drawing links between education on gender and cultural perspectives and culture change within the institution. However, the participant reflects that the ad hoc and superficial way in which gender and cultural perspectives are often integrated into the Joint Command and Staff Programme can act as barriers to meaningful social transformations:

This is the challenge. We are trying to provoke a culture change with giving two PowerPoint presentations. .. It has to be incorporated in everything that we do, otherwise we will never get there. We need to change the way leaders are thinking and the way that the troops are respectfully interacting with their peers. So that means everything we do should have a lens, call it GBA+ or diversity and inclusion, but I think if we could review the curriculum. . to bring that factor in just as any other consideration is something that leaders today need to take into account. Yeah it's important (Woman Graduate of the Joint Command and Staff Programme, 2018b).

A common narrative among this participant group, highlighted in this example, is the requirement for consistent and integrated Professional Military Education on gender and cultural perspectives. As this participant makes clear, the existing PowerPoint module on GBA+ by Status of Women Canada is insufficient for explaining the relevance of gender perspectives and intersectionality to military professionals. ${ }^{75}$ Yet, completing this module

\footnotetext{
${ }^{75}$ In my current role as an analyst for the Canadian Armed Forces Dallaire Centre of Excellence for Peace and Security, I have had ongoing discussions with representatives of Status of Women Canada (now renamed Women and Gender Equality Canada) and the Canadian Armed Forces Strategic Joint Staff about creating training and education on GBA+ that is specifically tailored to the military audience. There is acknowledgement from both departments that education about how to conduct GBA+ in the military is lacking and there is interest on the part of WAGE to support the military in the creation of this education.
} 
is one of the few opportunities for students of the Joint Command and Staff Programme to engage with gender and intersectional analysis.

Amplifying a repeated narrative about the lack of curriculum on gender and cultural perspectives is the following statement made by a participant in relation to sexual misconduct in the Canadian Armed Forces:

One of the things that we were looking at extensively was culture and how to make culture changes. The fact of the matter is that we don't do that well in the Canadian Forces because we don't completely understand what it means to do cultural change. And a lot of what we do is just superficial. So if the reality is that we want to be able to understand how to make culture change, we need to have a better and in-depth understanding of [military culture] and how it works to make the culture change and the culture shift. And we just... we didn't cover that at all. I thought gender was very superficial, again across the Programme. We needed to do the GBA+ training and then we just moved on. So, I didn't think either one of them were sufficient (Woman Graduate of the Joint Command and Staff Programme, 2018c).

Drawing again from common perspectives across participants in the preceding substantive chapters, members of this participant group are pointing to the significance of using gender and cultural perspectives to understand military socialization, social power, and culture. Four of the eight participants from this group directly explained that existing power arrangements within the military posed barriers to gender equality and social justice. 
As one participant suggests, rank, chain of command, and the primacy of mission command may act as structural barriers to more equitable socio-cultural power arrangements within the institution:

So we were talking about [a proposed initiative], and when they said "Ok let's go ahead", but then someone in the room said "Ok, but when we are on a parade then it will be at the discretion of the Commander to decide if women are allowed [to present themselves in a way not accepted at the time of the interview]." . . It should not be at the discretion of the commander for many of those aspects of the culture change, otherwise it will never change. . .If we always leave it to [the commander's] discretion ... the [usually] white fortyfive year old man may not have considered all the factors to become a more inclusive organization, then they will just continue to do what they are doing. At some point we need to impose, and it's against the military culture to impose, because we believe in mission command, especially in the Army. . . But when it comes to culture change, I think that it can't be mission command all the way, it has to be imposed in some aspects and we have to provide tools through, again, education, training, professional development to those commanders to help them become more inclusive (Woman Graduate of the Joint Command and Staff Programme, 2018c).

As this participant observes, and as Winslow and Dunn (2002) demonstrate, regulative changes, including changes to policy, do not necessarily equate to culture change. This idea constitutes legal determinism—a reliance on rules and regulations to change social 
behaviour, a reliance which does not adequately consider social mechanisms of change and the power of culture (Pahlavi and Ouellet, 2012).

As the observation of this participant articulates:

We can have the best policy in place to support both women and men, but if they are not applied like they are supposed to be at the other levels, then it is kind of defeating the purpose. . There's a definite gender bias when it comes to policy...it's something that is still happening now. A lot of the men are not even asking for parental leave, because [they think it's] going to affect their career, because ... people higher up [will say] "Well you're not dedicated enough to your unit if you are asking for parental leave.” There's still that mentality that "Well your wife is taking parental leave, why are you asking for the same thing" or "why are you asking?" It's not well perceived. So, it's nice for us to develop those policies, but I'm worried about how it's going to be implemented in the unit. A culture shift is required (Woman Graduate of the Joint Command and Staff Programme, 2018a).

This observation illustrates a repeated perception among this group of participants that culture change requires more than shifts in regulatory frameworks, and that in addition, culture change requires intentional thought about social norms and cultural perspectives (Pahlavi and Ouellet, 2012).

Offering a similar solution, this participant argues that agents with a good deal of social capital ${ }^{76}$ within the institution can be leveraged in support of culture change:

\footnotetext{
${ }^{76}$ Social capital is a term drawn from sociologist Pierre Bourdieu (1986). It refers to social privilege based on societal constructions of intersectional ideals including race, gender, sex, sexuality, ability and so on.
} 
I think if you wanted to facilitate a culture shift, you have got to target the change agents within the group dynamic. The influencers, if you can target the influencers and have them lead by example, that would be an approach to changing cultural dynamics. . . Having someone like General Vance, an infantry soldier, so that in terms of power dynamics you have the tippity top kinda deal. To have him buy into that is very important. Having a mechanism to identify who are the influencers and having frank discussions and winning them over and addressing that there's technology that can subvert the messaging. With social media, everyone's got their own kind of personal networks that can subvert the prevailing message. So, having an honest conversation about that would go a long way to enabling the culture (Man Graduate of the Joint Command and Staff Programme, 2018c).

Drawing from repeated perceptions that there is internal cultural resistance to changes in dominant power structures, this participant underscores the need for social ways of creating culture change. Leveraging existing social power arrangements to essentially undermine them is an interesting insight. What this participant is illuminating is that to transform power dynamics within the institution, the institution must draw from the influence of those members who best fit dominant understandings of ideal soldiers, masculinity, ethnicity, service, and occupation. In other words, the institution must leverage the social capital of those members who best fit its culturally constructed hegemonic masculinity to convince those within the military to undermine it. In this participant's perspective, it would take those who may benefit the most from hegemonic masculinity and power structures to show that these hegemonic qualities are in fact not 
ideal qualities for the institution and require to be expanded in order to set conditions for gender equality and the inclusion of members with diverse and intersecting identities and experiences.

Yet, changing the institutional culture of the Canadian Armed Forces may also require better understanding of the service and occupational subcultures (Irwin, 2009) that exist, and how best to transform these using more local, contextual practices of resistance (Marchand \& Runyan, 2000). This perception is explained by the following participant:

My key takeaways for cultural perspectives [are the] differences in the services, how they handle the culture. I think the Air Force might be a little further ahead in terms of gender perspectives and incorporating diversity into day-to-day business. I'd have to look up the exact statistics but, I think the Air Force and especially my trade of Aerospace Engineers are a little further ahead in representation for women especially... I think, from the college perspective... that was the biggest eye opener for me, is the roles that our women are actually in, the leadership roles, are actually more prevalent in the Air Force. Recognizing that the other services and the other trades have a little ways to go, to the cultural point of view, yeah, it's eye opening how far we haven't come. As personified by General Vance's recent statements in the Auditor General's Report into Op HONOUR, saying that [the institution] wasn't as far along as he'd expected in trying to change the culture. And I think that is reflected in what I've seen at the College and what I've seen 
coming back to the service outside the educational environment (Man

Graduate of the Joint Command and Staff Programme, 2018b).

This participant's perception is supported by Winslow and Dunn's (2002) empirical study of differential levels for the integration of women across the services as related to service cultures which idealize, to different degrees, men and masculinity. At the time of their writing in the early 2000s women's representation was highest in the Air Force, followed by the Navy and then the Army. As of September 2018, these rankings have altered slightly, where women represent $20.10 \%$ of total Navy members, $19.3 \%$ of total Air Force members, and $13.1 \%$ of total Army members (Government of Canada, 2019). As the Army represents roughly $60 \%$ of the Forces, women's total representation across all services amounts to $15.7 \%$ (Ibid).

In addition to women's low representation across the Canadian Armed Forces, the institution struggles to increase the representation of other Employment Equity groups including racialized and Indigenous-Inuit, First Nations and Metis populations. As of January 2019, 2.8\% of the total population of Canadian Armed Forces members identified as Indigenous, while $8.7 \%$ of the total Forces identified as being members of visible minority groups (House of Commons, 2019). Additionally, the low representation of Employment Equity group members only gets thinner moving up the ranks. As of January 2019, women accounted for 13 out of 129 General and Flag Officers, while only one General and Flag Officer identified as a member of an Indigenous community, and one identified as a member of a visible minority group (Ibid). The Canadian military is not yet tracking the sexual orientation of members and the inclusion of transgender members, but the public service is considering "the evolving 
societal and human rights context" and "has extended the spirit of equality and equity to other equity-seeking groups, such as the LGBTQ2 community" (Treasury Board of Canada Secretariat, 2018).

Ethnographic insights from this study indicate that there are horizontal as well as vertical patterns of intersectional social privilege within the Canadian Armed Forces. Analysis of the data collected for this dissertation suggests that while appropriate regulative means exist to increase the representation and roles of diverse members to the Canadian Armed Forces, systemic structural and cultural barriers persist which stand in the way of wider inclusion. Social stratification observed across this project's participants attests to a deeply gendered and white centering social order that is constructed through and within intersectional cultural idealizations of warrior identity. Social power, noted in reflections across participant groups, is reinforced and reproduced through the hegemony of specific ways of being, and results in transferred social hierarchies explained to be exacerbated at Canadian Forces College through heavy social policing of the expressions, behaviours, views, and relations of its members.

Yet, the observations of this chapter's group of participants provide hope that with increased and comprehensive professional development and education on gender and cultural perspectives, leaders can effectively drive social transformation and culture change in the Canadian Armed Forces. In essence, the narratives of these eight professionals suggest that education on gender and cultural perspectives has had a deep and powerful impact on their decision making in policy, plans, and operations. Moreover, the narratives presented provide observations and experiences which suggest that such education has created better understanding of the social forces which construct unequal 
power arrangements within the military and within societies. This understanding has enabled these leaders to be more strategic, more creative, more thoughtful, and more inclusive leaders as their thinking and practices draw from intersectional thinking and analyses of the ways in which power is constructed in the military and societies. Importantly, their observations and experiences demonstrate their active, contextual, and localized resistance to inequality through a range of interventions in military practices, relations, policy development, planning and conduct within the institution and on operations. Their stories can provide hope for feminist progress through informed military engagement. In this way, feminist scholarship should not so easily discount the powerful impact of feminist interventions originating from within militaries themselves. Given the right tools and enabling conditions, military members can be important contributors to feminist change.

As the Canadian military is increasing operational focus and education on humanitarian assistance, stabilization, and peacebuilding (CDS, 2016; Government of Canada, 2017b), the integration of gender and cultural perspectives in the Joint Command and Staff Programme will be of continued relevance. Greater and more intentional incorporation of these perspectives contribute to the development of skills to recognize inequalities in (in)security and to work towards progress within the military and societies. This feminist pedagogy is already of great benefit to the military's engagements in complex domestic and international operations, as it promotes critical thought about power, struggle and difference as well as encourages relations of "interdependence, empathy, respect, and equality” (Duncanson, 2015, 244). 
As demonstrated in perspectives across this study's participants, education on gender and cultural perspectives facilitates learners' capacities to understand, challenge and deconstruct social systems of oppression such as hegemonic masculinity and helps military members to work toward more democratic and horizontal relations of recognition and power. As Duncanson argues, oppressive gender orders can be upended when "traditionally disparaged, feminized traits are newly valued and incorporated into" (Ibid) idealized identity. The perspectives and experiences of these eight military leaders show that their education and resultant practices are doing exactly this. 


\section{Discussion and Conclusion}

When I began this journey, to write a dissertation on the impact of integrating gender and cultural perspectives in Professional Military Education, I had no sense of the magnitude of the social phenomena I would explore and no real understanding of the subsequent goals I would commit myself to. I could not have known that mutually constructed commitments to gender and intersectional equality within and outside of the military would be so moving and so beneficial for the participants of this study, members of the military, and the societies in which they are engaged. I had little foresight about the deep and lasting effect this project would have for those participants that would go on to lead, to support, and to serve.

Encapsulating advances made in the research, this summative chapter is divided into two parts. The first offers a discussion of the key takeaways that emerged from this project's analysis of gender and cultural education in a Professional Military Education learning environment. The second section provides concluding remarks detailing the larger contributions that this dissertation has made to the field of gender and the military as well as to the facilitation of culture change and feminist progress by Canadian Armed Forces professionals in the military and beyond.

\section{Discussion}

This dissertation investigates and invests in the possibility for feminist transformational change within militaries as well as the potential for militaries to be 'forces for good.' The research considers whether militaries can contribute to feminist progress and work towards the cultural inclusion of diverse members within militaries due to personnel's exposure to gender and cultural perspectives within Professional 
Military Education. The project narrows its investigation to the mid-to-senior graduate level education of Canadian military officers within the Joint Command and Staff Programme at Canadian Forces College. It applies post-modern feminist, intersectional and militarized masculinities theories to understand the military learning environment and to analyse the inclusion and reception of critical theory by military learners. The research draws on contemporary pedagogic literature to make recommendations for optimizing learning environments and professional competencies to facilitate inclusive security and organizational culture change.

Acknowledging the context of dominant masculinist and white centering constructions of military identity and socialization, this investigation asks: how are gender and cultural perspectives integrated into Canadian Professional Military Education? If and in what ways military socialization and culture shapes the learning environment and the reception of this education? Finally, if and in what ways such learning has facilitated feminist transformations in the military and beyond?

In answer to the first question, findings from qualitative data on the formal curriculum reveals that the content of the Joint Command and Staff Programme generally compliments dominant social hierarchies by positioning combat, warfighting, and operator trades and occupations as primary, while support trades and occupations as well as peace and security operations are often seen to be less important and perceived as less valued. The prioritization of the warrior identity and a warfighting purpose for the military constructs ideological and ontological barriers to the fulsome incorporation of gender and cultural perspectives in formal curriculum content. My research to investigate the degree to which gender and cultural perspectives are incorporated in curriculum 
shows the often misguided and ad-hoc presentation of these critical frameworks against the backdrop of masculinist prescriptions of what the military is and does as well as resistance to critical feminist and anti-racist concepts and the resultant poor presentation and delivery of these ideas to students by more reluctant faculty and staff.

Findings from the analysis of social relations in the learning environment demonstrate that military students engage in intense military socialization processes to construct the ideal soldier, sailor, aviator and professional. This socialization process involves the consistent social policing of attitudes, behaviours, and identities to fit a hegemonic intersectional social order within the learning environment. Conventional ideals of a warfighting and masculine military identity construct a narrow prototype for the military member centered on the dominance of men; aggressive, competitive (and often misogynist) masculinities; white centering norms and practices; as well as largely Anglo settler colonial worldviews and culture.

Many participants from faculty, staff, and the student body describe that the production and policing of social hierarchies is particularly acute in the learning environment and experienced as cultural exclusion especially for women, racialized members, Francophones, and students with greater familial and domestic obligations. The key gendered insight emergent from participants is that the dominant culture within the College presents an expectation that the military is the soldier's family, and that military culture and informal expectations pressure members to meet narrow visions of leadership and professionalism. Masculinist expectations noted repeatedly by participants are that military members are to essentially park their diverse identities and family responsibilities at the door in favour of achieving organizational aims. 
This insight continues to validate claims that the military is a total (Goffman, 1961) and greedy (Segal, 1986) institution that prioritizes loyalty to service above self. The military is total in that it is a profession that dictates aspects of a member's professional and personal life far beyond the bounds of other civilian organizations (including defining members' social, legal, health, and familial care obligations). The military is also a greedy institution in that it expects the member to sacrifice self and time with family in service of the mission and the organization. These sociological observations demonstrate that gender and cultural perspectives that are integrated into curriculum are competing with deeply masculine conceptions of the profession. The presentation of critical feminist perspectives to military members can at once challenge hegemonic military masculinity at Canadian Forces College and fuel participants' frustrations that they continue to encounter gender inequality in the military classroom and the learning environment.

Analysis from the experiences shared by military learners also indicates that how curriculum is taught can be equally important to what is taught. Reflections from student participants about the feminization and infantilization of learners due to an absence of learner-centric and adult learning teaching methodologies illuminates how teaching practices can also reproduce patriarchal, racialized, and oppressive social relations. In this way, a teaching approach that intentionally considers the positionality of the educator and the student is required. To erode hierarchical social relations in teaching and learning, a more collaborative methodology is necessary. The approach that I suggest is feminist and anti-racist informed heutagogy. This method for the delivery of learning situates the educator and the learner more horizontally, focuses on the sort of learning that can 
happen through collaborative and reflexive practices, and aims for a shift in personal philosophies towards a more inclusive understanding of complex issues and dilemmas.

Despite room for growth in gender and cultural related content and pedagogic style, the research ultimately illuminates how students exposed to extant gender and cultural perspectives within curriculum have gone on to make localized transformational changes within the military and the societies in which they operate. Graduates of the Joint Command and Staff Programme have worked, often through adversity, to create intersectional inclusion and equity within the military. They have also gone on to apply gender and cultural perspectives to domestic and international engagements, and in particular, have worked to facilitate gender and intersectional equality in conflict and crisis affected communities. Their applications of critical theory and analysis to military work demonstrates that given the right analytical frameworks and tools, military members can be forces for good and agents of feminist progress.

The work towards organizational change and inclusive security by these military leaders breaks with generalized narratives within many feminist studies in the field of international relations and military sociology that point only to the self-serving motivations of militaries and their members to employ gender perspectives. While gender perspectives have been instrumentalized to improve military operational effectiveness (Cockburn, 2011), and while it is true that militaries have coopted gender perspectives to win wars rather than create a more equal world (Kirby \& Shepherd, 2016), the reflections illuminated in this research show that there are alternative experiences to the dominant view presented across academe. 


\section{Conclusion}

This project has become a reference point and a work of hope that has already begun to make a difference in the Canadian Armed Forces and the Department of National Defence. The initial report I was commissioned to write (Brown 2018), the report that enabled me to collect data from this project's research participants, has worked its way up the military chain of command. It is being used as guidance for how to conduct research and make recommendations for gender and intersectional equality at other Canadian Military Colleges. Findings of the research have been applied by the Canadian Defence Academy to shape the future of how the Canadian Armed Forces understands and works to incorporate gender and cultural perspectives in professional development on culture change across all levels and at all ranks.

This project has also been highlighted as useful to understanding and preventing sexual harassment and professional misconduct across Canadian Military Colleges. The "Final Report to the Internal Review of Statistics Canada Report into Sexual Misconduct at Military Colleges" conducted by the Director General Professional Military Conduct notes that:

CMCs [Canadian Military Colleges] would benefit from a fuller examination of their culture and gender attitudes. The "Report on the Integration of Gender and Cultural Perspectives and Inclusive Learning Environment in the Joint Command and Staff Programme" (2018) provides a possible approach for CMCs to follow... The report provided a series of recommendations on the representation of women and visible minorities, pedagogy and course delivery, supporting Directing Staff, the integration of gender and cultural 
perspectives in [ ] curriculum, and on culture change. Recommendation:

Perform an in-depth examination of culture and gender attitudes at the CMCs, including an examination of CMC processes, practices, and curriculum

(DGPMC, 2021, sec. 10, t-u).

In addition to enabling further research within other Canadian Military Colleges and Professional Military Education programs, the theories and results of this research have been used to inform perspectives on inclusion and culture change across Level 2 and Level 1 departments within the Canadian Armed Forces and Department of National Defence. This research has been used to inform the work of the Canadian Defence Academy as well as the Anti-Racism Secretariat and has been used to support collaboration on research questions and methods associated with the newly established Chief Professional Conduct and Culture.

Beyond Professional Military Education, findings of the research have been used to understand the production of intersectional hegemonic social orders in the military and the public service. I have been called to present the findings and methodological approach of this research to the Minister of National Defence Advisory Committee on Systemic Racism and Discrimination. I was able to show, drawing from the empirical evidence gleaned, that racism and sexism in the Canadian Armed Forces and Department of National Defence are more than the actions of few bad apples.

As the key insights of this project demonstrate, much of the marginalization and discrimination experienced and identified by participants point to cultural and structural factors, where the key issues highlighted, such as sexual harassment and experiences of misogyny and racism, originate from the barrel. Participants of the study explained the 
ways in which exclusion within the learning environment ultimately emerged from the transfer of cultural and structural barriers produced in the larger military organization.

For example, they illuminate how hegemonic social orders that create inequality within the military are amplified in the military learning environment through a pervasive, but hidden curriculum. The valuation of certain groups and marginalization of others manifests culturally (in social relations) and is entrenched structurally (in regulations, procedures, customs, symbols, and bureaucratic systems). As suggested by other scholars in the field, these oppressive social hierarchies have negative implications for the ways in which the military engages with diverse populations domestically and internationally (Whitworth 2004; Razack 2004).

Despite the social construction of oppressive culture, systems, and structures within the Canadian Armed Forces and the military learning environment, central findings of the research show that military members can be important agents of change. Military members can be 'forces for good' (Duncanson and Woodward 2016) when they: identify and deconstruct masculinist and oppressive institutional norms and social hierarchies (Taber 2015; Razack 2004); work to 're-gender' the soldierly identity as inclusive of femininities, masculinities, women, men and non-binary people, as well as intersectional diversity (Duncanson and Woodward 2016; Razack 2004); construct professionalism around principles of inclusion, recognition, redistribution of power, equality, empathy, and compassion (Ibid); and draw on gender and cultural perspectives including critical feminist and anti-racist concepts to examine and work to address inequalities within the military and in societies. Yet, in order for military members to 
realize their transformative potential, this project underscores that enabling conditions can be set within the context of Professional Military Education.

As feminist scholars, it is easy to criticize the military and its efforts to make change within. It is easy to point out all the ways in which the military continues to fail to achieve expected progress, to produce meaningful change, and to see its failures as related to its culture, its structures, and customary power arrangements. Reflecting on the recent allegations of sexual misconduct against two successive Chiefs of the Defence Staff as well as a contingent of senior leaders, anger at the current state of gender relations within the organization is an acceptable response. Indeed, I am enraged. I am dismayed. Yet, as a consequence of this research I cannot say that I am surprised.

I have argued throughout this dissertation that sexism, racism, and intersectional inequalities (with sexual violence as an extreme but common manifestation) are longstanding parts of the Canadian Armed Forces' cultural and structural fabric. These issues are not the product of a few racists or misogynists. They are a consequence of institutional culture, structures, and systems long in need of fundamental change. I have argued that while tracing extreme acts of hate and violence in the military is important, it is perhaps more important to identify and address the everyday lived experiences of cultural and structural exclusion. It is often routine acts and normalized forces of marginalization that equate to experiences of total exclusion—or death by a thousand cuts - for so many members who navigate the institution from the margins of cultural significance. As Crenshaw argues (1991), mapping the experiences of those pushed to the margins is a good way to identify and then work to prevent oppression and extreme acts of hate. 
While experiences of sexism, racism, and exclusion were common across this study's participants, respondents also spoke to their practices of resistance and efforts towards change. Tracing participants' work to challenge the status quo provides a more hopeful perspective of gender relations in the military. Less common are studies that trace the struggles taking place within the military to transform. Rarely have investigations of gender and the military sought out if and how some members of the dominant group might recognize their privilege and work to redistribute their power. Few studies have examined the diverse representations of military identity that work to negotiate and disrupt hegemonic masculinities in armed forces. Indeed, the military's capacity to change, and its potential to support feminist transformations is a significant and glaring gap in the field. The findings of this dissertation diligently populate this void.

Military leaders exposed to gender and cultural perspectives in Professional Military Education have shared specific cases, practices, and examples of how they intentionally used a range of gender expressions and perspectives to promote peace and security and to work towards broader visions of intersectional equality. Their stories and experiences indicate that the integration of gender and cultural perspectives within Professional Military Education has more than transformative potential —it has helped to produce nascent localized change. The insights gleaned from this research contribute to a small but growing literature that views the military as a space worthy of feminist intervention and a site that can forward feminist progress (Duncanson and Woodward, 2016; Kronsell, 2012).

Specifically, the experiences and observations of this study's participants suggest that some are engaging in a process of challenging masculinist and white supremacist 
military identities and have made continuous efforts to disrupt inequitable social hierarchies within the military and societies. Their work to make "small changes that [may] seem superficial" (Duncanson and Woodward, 2016, 11) shows that some military members are drawing on feminist education for the intrinsic goal of achieving gender equality and peace rather than using gender perspectives solely to support military objectives and career advancement. The many references this study's participants have made about their localized interventions to affect change resists determinist thinking "even in an institution where change might appear least likely" (Ibid).

However, I want to acknowledge that gender and the military as a field of study, and feminists within male dominated social sciences such as international relations and military sociology, have historically been limited by what mostly white masculinist men with implicit militarist ideals have determined to be worthy of study. Critical race and feminist research in this domain, as well as paths for achieving success in academia, have been overwhelmingly constrained by disciplinary patriarchs. These forefathers have constructed a priori what warrants being measured based on what they deemed important. In this way, diverse political scientists and sociologists have tried to 'fit in' and to make successes of themselves according to the parameters of social hierarchy and power determined by a historically privileged class of scholars.

Yet, feminists within the discipline of international relations including Cynthia Enloe (2014), and feminists within the school of sociology like Dorothy Smith (1987), Mady Segal (1999), and Donna Winslow (1998) have broadened the field by empirically examining the practices of the everyday. Their work to understand culture and social relations by centering focus on the lived experiences of gendered individuals has 
revolutionized contemporary analyses of power and forms a feminist epistemology. If what we measure is what we make important, then we, contemporary feminist scholars must dismantle the old ways of research too. As Dorothy Smith notes:

To break out of our own complicity in such practices, and out of the ways in which we have joined in silencing ourselves through denying authority of our own voices as well as those of other women, is the first and essential step to the making of an intellectual and cultural discourse in which we are subjects and speak for ourselves $(1987,16)$.

Drawing from this call for a feminist sociology and epistemology, I have worked to center and elevate the voices of those most marginalized in Professional Military Education. I have also grounded this research in the processes and social relations of the everyday in order to make the social forces at work in common interactions, norms, discourses and practices visible, and to draw on the narratives of research participants to devise strategies for change.

Doing so has enabled me to show the ways in which the process of gender and cultural learning has set conditions for military members to make localized interventions that "re-gender" (Duncanson \& Woodward, 2016) the military by presenting alternative feminist visions to counter dominant patriarchal and white privileging constructions. Such intentional work to 're-gender' the military speaks positively and directly to Annica Kronsell's important question as to whether the military can support and work to achieve gender equality by confronting its reliance on masculinity constructs (2012). Feminist interventions by many of this study's military and civilian educators, students, and 
leaders have purposefully worked to disrupt and dismantle the constructions of masculinity that they have commonly identified as untenable with equality.

The second important question Kronsell poses is about whether military interventions can count as contributions to feminist progress or whether feminism must always and essentially be equated with anti-militarism. The research presented speaks directly to this second question by highlighting the change interventions of military members as feminist ones. Noting that the military is a large and complex institution made up of a range of identities, processes and systems, the objectives and relations of its members are also complex. Findings of the research indicate that some participants have made very intentional efforts to challenge oppressive conceptions of militarism and reconstitute military identity around the achievement of feminist goals. Importantly, the research suggests that military personnel are making efforts to erode militarism as a concept by negating the necessity of masculinist violence by the military.

In addition to her research that works to confront militarism in Canadian education (2015), Nancy Taber argues that the military “must fundamentally re-think what it means to be a man, a woman, or someone who does not fit into that binary" $(2018,105)$. She contends that "masculinization must be challenged as a route to successful military membership just as feminization must be challenged as a way to devalue and objectify people" (Ibid). The insights illuminated in this dissertation reveal that some senior officers have used gender and cultural learning to do precisely this. While limited, their internalization and practice of the few feminist, anti-racist, and intersectional theories presented to them have already allowed graduates to contribute to 
localized feminist progress. Their contributions have been made despite working within contexts often resistant to feminist theory and practice.

The findings of the research also suggest that respondents, both military and civilian, are beginning to think more expansively about culture change. A common narrative is that culture change is not only possible but required for gender and intersectional equality. Yet, throughout the reflections of respondents a key and problematic message took hold-that culture change takes time. Many participants believed that the institution would become a more welcoming place when the old guard have retired, and new generations enter military leadership. This narrative is generationally determinist.

The idea that culture change takes time comes with the implicit warning that as feminists, anti-racists, and revolutionaries, we must take pains to constrain ourselves so that the dominant group feels comfortable with the pace of change. However, making change comfortable does not lend itself well to feminist transformation. In fact, slowing the pace, reining it in, and being a 'nice' feminist is stifling of change. From my experience with teaching mid-to-senior level military members, comfortable change does not work, nor is it what most learners desire. Instead, honesty about the root causes of inequality resonates well with military members, even if an honest look at the military's role in inequality means a reassessment of members' success within the profession.

Indeed, graduate respondents of this study commonly expressed that inclusive and compassionate leadership, self-reflection, immediate and sustained action, calling out injustice, as well as courage to do what is right were requisite for meaningful change. Repeated narratives among this group determined that many perceived themselves as 
agents of organizational transformation. Some argued that using a range of leadership qualities and dialogue was key to getting buy-in within the chain of command and among subordinates for feminist progress. Many reflected that working for change was a constant, but important struggle. Graduate participants often spoke to their determination and willingness to push forward and to model the behaviours and expectations they understood to be inclusive and transformative.

Their stories highlight that as a society, we have often been conditioned to think that the current social order is too big to change. Yet, 'we' the many individuals that constitute the military institution, academia, and society, shape and define culture. Thus, as we are responsible for reproducing and maintaining culture, we also have the means to shape it differently. I suppose this message, that culture change is in the realm of the possible through the localized practices of its constituents, is the hopeful contribution respondents have offered using this dissertation as both a sounding board and a platform for continued action. However, we, as scholars and investigators, must also work conscientiously to understand organizational structures and cultures to effectively support feminist change. We must deliberate, particularly with those most negatively and disproportionately impacted by the status quo, on the best ways to make their visions of progress happen.

As such, this project has proven the utility of a grounded approach to understanding what must be changed, particularly from the perspectives of those who have been most discriminated against structurally and culturally. Findings from the examination of the application of learning by military members with exposure to gender and cultural perspectives in Professional Military Education show that it is possible to 
shape the content and process of military engagements in peace and security for good. But feminist progress by military members can only be done well by attending to the perspectives, experiences, and desires of those oppressed by the dominant social order. Participants of this study, particularly students who have gone on to employ gender and cultural perspectives in their work, have understood this point.

Influences from feminist advances in international, national, and institutional policy have presented the Canadian Armed Forces, Canadian military members, and their educators with a solid foundation from which some have already begun the work to make change. Drawing from the insights offered by militarized masculinities, intersectionality, and post-modern feminist frameworks, this research has provided an approach to understand how, and under what conditions, militaries can be forces for good (Duncanson \& Woodward, 2016, 11) and contribute to feminist progress (Kronsell, 2012).

The findings of the research have shown that any forward momentum of the yardstick has been achieved against the backdrop of a production of military identity that centers masculinism and whiteness. Feminist progress made by some military and civilian respondents has come at the cost of battling against dominant gendered, racialized, sexualized, and abled social forces that are produced and reproduced in the context of military socialization and education. These constructions of military ontology are difficult to shake as they have taken shape under the conditions of the longstanding patriarchal and white supremacist rule of the state.

As in all Canadian institutions, but particularly for the male dominated and traditionally masculinist domain of the military, more work is required to integrate gender and cultural perspectives fully and meaningfully "to the degree that [they are] 
always considered as an essential and integral element of all CAF activities" (Chief of Defence Staff, 2016). This research was limited to the study of Professional Military Education of officers at the mid-to-senior level of leadership yet has highlighted the important difference the presentation of critical theory can make for the thinking and practices of military members. Questions beyond the scope of this project that would be important contributions to the field, military culture change, and feminist progress include examinations of the integration of critical feminist perspectives as well as the learning environment within other Professional Military Education institutes. Moreover, a study of the incorporation of gender and cultural perspectives in Professional Development as well as tracing intersectional experiences according to service, occupation, and trade training, including basic to advanced training, could identify similar or different cultural, systemic, and structural areas requiring change.

For meaningful feminist progress to be made, masculinist and white supremacist social orders within the military must be consistently identified and dismantled across all ranks and levels. To do this, gender and cultural perspectives and analysis must be formally and systematically built into core elements of Canadian Armed Forces processes, structures, and systems, including training and education. Education and training must be delivered by military and civilian faculty with demonstrated knowledge and expertise in relation to gender and cultural theory and tools. Facilitating learning on more challenging topics like intersectional inequality requires educators to utilize appropriate pedagogies - those that enable self-insight, collaboration, and shifts in personal philosophies, such as feminist and anti-racist informed heutagogy. 
Importantly, education drawing on gender and cultural perspectives must work to identify and challenge patriarchal power arrangements, masculinist constructions of military identity, and cultural resistance to intersectional equity. The use of gender and cultural approaches by some military and civilian faculty at Canadian Forces College has already enabled significant strides by military leaders, but the military as an organization needs to do more. While the inclusion of these perspectives within Professional Military Education has influenced localized and diffuse feminist progress within the military made by informed leaders, these advances were enabled by the hard and ongoing work of a few military and civilian educators and staff. Formal direction to support, resource, and monitor this work would contribute to the broader impact of Professional Military Education on organizational culture change and contributions to the Women, Peace and Security agenda, Indigeneity, Equity, Diversity, and Inclusion goals, as well as feminist progress within and beyond the institution.

The limited learning some military leaders have received on gender and culture has set conditions for some to support feminist progress domestically and internationally. The results of this initial ad-hoc undertaking at Canadian Forces College signal that members of the military, provided with the appropriate learning, pedagogic approach, and social conditions, can work to support, and perhaps beneficially shape feminist progress in civilian societies. Yet, without sustained efforts to maintain the current momentum of these perspectives within Professional Military Education, resultant feminist progress within the military and contributions made by graduates towards inclusive security and feminist change in societies may become tenuous and could be subject to fail. 
To build on current momentum, military training and education must work to incorporate gender and cultural perspectives including critical feminist and anti-racist thought as a routine and ongoing practice. Efforts to incorporate and consistently update gender and cultural perspectives in military learning must be done systematically and with an enduring approach. Such education must continuously encourage equity, recognition, and redistribution of power in relation to the evolving inequities and aspirations of the day. In this way, the work of creating and maintaining an inclusive military culture will never be done. There is no end state for this mission. Hence, this education must be evergreen and representative of current intersectional struggles institutionally, domestically, and internationally. It must be grounded in the practices of the everyday to promote empowerment and participation through the elevation of marginalized voices so that these perspectives play a central role in organizational decision making and leadership. Finally, this education must fully position military members within the process of transformative feminist progress, so that military members can see themselves as important agents of change. 


\section{Appendices}

Appendix A Ethics Approvals and Supporting Documents 


\title{
A.1 Certification of Institutional Ethics Clearance
}

\author{
Office of Research Ethics \\ 503 Robertson Hall | 1125 Colonel By Drive \\ Ottawa, Ontario K1S 5B6 \\ 613-520-2600 Ext: 2517 \\ ethics@carleton.ca
}

\section{CERTIFICATION OF INSTITUTIONAL ETHICS CLEARANCE}

The Carleton University Research Ethics Board-A (CUREB-A) has closed the research project detailed below. As per Tri-Council Policy on Ethical Conduct for Research Involving Humans (TCPS2), no further research interactions with participants under this protocol are permitted.

Project \#: 106844

Project Team Members: Vanessa Brown (Primary Investigator) Neil Gerlach (Research Supervisor)

Protocol Title: Integrating gender and culture in Canada's professional military education: transforming military culture through leadership [Vanessa Brown]

Funding Source: (If applicable):

Effective: July 11, 2019

Project Status: Closed

\section{Restrictions:}

This certification is subject to the following conditions:

$\S$ An Annual Status Report may be submitted to re-open the protocol. Justification should be provided to renew a protocol that has been closed for more than a oneyear period. If there are major changes to the original protocol, the research team will be required to submit a new protocol.

Please email the Research Compliance Coordinators at ethics@carleton.ca if you have any questions. 


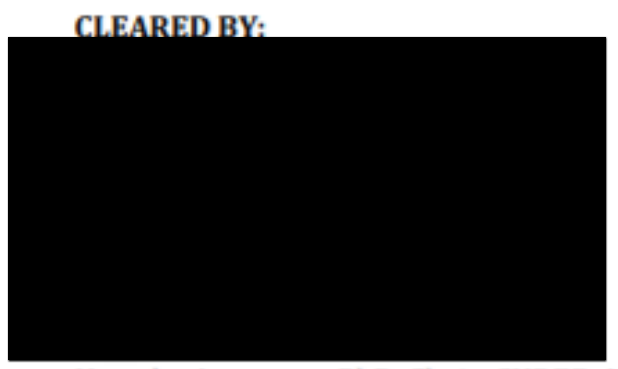

Date: July 11, 2019

Natasha Artemeva, PhD, Chair. CUREB-A

Janet Mantler, PhD, Vice Chair, CUREB-A 


\section{A.2 Sub-Appendix Consent Form}

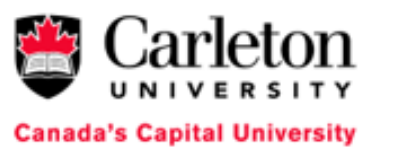

Title: Integrating gender and culture in Canada's professional military education: transforming military culture through leadership

Date of ethics clearance: November 14, 2017.

Ethics Clearance for the Collection of Data Expires: July 31, 2018.

I , choose to participate in a study

on the integration of qender and cultural teaching and learning in Canada's professional military education. This study aims to assess gendered and cultural learning and teaching at the Canadian Forces College and determine if and how this teaching and learning influences cultural change in the military through informed leadership. The researcher for this study is PhD student Vanessa Brown of Carleton University's Sociology Department. She is working under the supervision of Dr. Neil Gerlach in Carleton University's Sociology Department.

This study involves one 60 minute focus group. If you are a student at the Canadian Forces Colleqe, you may be asked to participate in two 60 minute one on one follow up interviews over the phone. With your consent, interviews will be audio-recorded. Once the recording has been transcribed, the audio-recording will be destroyed.

As this project will ask you about your professional or academic experience at the Canadian Forces College, I will take precautions to protect your identity. This will be done by keeping all responses anonymous and allowing you to request that certain responses not be included in the final project.

You have the right to end your participation in the study at any time, for any reason. If you are a student, you may withdraw up until four weeks after your second phone interview. You can withdraw by phoning or emailing the researcher or the research supervisor. If you withdraw from the study, all information you have provided will be immediately destroyed where possible (not possible for focus group participation).

All research data, including audio-recordings and any notes will be encrypted. Any hard copies of data (including any handwritten notes or USB keys) will be kept in a locked cabinet at Carleton University. Research data will only be accessible by the researcher and the research supervisor. Data may be used for presentations or publication.

Once the project is completed, all research data will be kept indefinitely and potentially used for other research projects by the researcher.

This document has been printed on both sides of a single sheet of paper. Please retain a copy of this document for your records. 
If you would like a copy of the finished research project, you are invited to contact the researcher to request an electronic copy which will be provided to you.

The ethics protocol for this project was reviewed by the Carleton University Research Ethics Board, which provided clearance to carry out the research. If you have any ethical concerns with the study, please contact Dr. Andy Adler, Chair, Carleton University Research Ethics Board-A (by phone at 613-520-2600 ext. 2517 or via email at ethics@carleton.ca).

Researcher contact information:

Vanessa Brown

Sociology Department

Carleton University

Email: vanessaabrown@cmail.carleton.ca
Supervisor contact information:

D. Neil Gerlach

Sociology Department

Carleton University

Tel: (613) 520-2600 x 1331

Email: neil.qerlach@carleton.ca

Do you agree to be audio-recorded: Yes _ No

Signature of participant

Date

Siqnature of researcher

Date 


\section{Bibliography}

Academic Faculty Canadian Forces College (2018). Focus Group Interview, April.

Al-Oraimi, S. (2008). "Defying the prohibited arena: Women in the UAE military," in in Kümmel, G. \& Carreiras, H. Women in the military and in armed conflict. 1st;1. Aufl.; ed. Vol. Bd. 6. Wiesbaden: VS Verl. für Sozialwiss, pp. 129-160.

Ainsworth, Claire. 2015. Sex Redefined. Nature 518 (7539): 288-291.

Ashe, F. (2012). Gendering war and peace: Militarized masculinities in Northern Ireland. Men and Masculinities, 15(3): 230-248.

Baaz, E. \& Stern, M. (2009). “Why Do Soldiers Rape? Masculinity, Violence and Sexuality in the Armed Forces in the Congo.' International Studies Quarterly, 53: $495-518$.

Beauvoir, S. (1949). The Second Sex. Translation by Constance Borde and Sheila Malovany-Chevallier, New York: Vintage Books.

Berlant, L. (1997). “The Theory of Infantile Citizenship.” In her The Queen of America Goes to Washington City: Essays on Sex and Citizenship, 25-54. Durham, N.C.: Duke University Press, as referenced in Young, 2003, p. 9.

Blaschke, L. (2012). Heutagogy and lifelong learning: A review of heutagogical practice and self-determined learning. International Review of Research in Open and Distance Learning, 13(1): 56-71.

Blommaert, J. \& Bulcaen, C. (2000). "Critical Discourse Analysis” Annual Review of Anthropology, 29: 447-466. 
Bourdieu, P. (1986). The Forms of Capital, pp. 241-58 in Handbook of theory and research for the sociology of education, edited by J. G. Richardson. New York: Greenwood Press.

Braudy, L. (2003). From chivalry to terrorism: War and the changing nature of masculinity. New York: Alfred A. Knopf.

Brod, H. (1994). 'Some Thoughts on Some Histories of Some Masculinities: Jews and Other Others', in David, D. \& Brannon, R. (eds), Theorizing Masculinities. Thousand Oaks, CA: Sage.

Brown, A., Cervero, R., \& Johnson-Bailey, J. (2000). Making the Invisible Visible: Race, Gender, and Teaching in Adult Education. Adult Education Quarterly, 50(4): 273288.

Brown, V. (2017). "I was furious that whole roto": Gender dynamics and hidden learning at the Canadian Forces College. Report on gender dynamics and hidden learning in Institutional Policy Studies Stream, Joint Command and Staff Programme 43, Prepared for Canadian Forces College, Toronto.

Brown, V. (2018). Report on the Integration of Gender and Cultural Perspectives and an Inclusive Learning Environment in the Joint Command and Staff Programme. Prepared for Canadian Forces College, Toronto.

Brown, V. (2021). Considerations for Anti-Racism in the Defence Team. Paper presented to Minister of National Defence Advisory Panel on Systemic Racism and Discrimination, Toronto, Ontario, February 11.

Brown, V. (2020). “The Gendered Division of Emotional Labour and Post Pandemic Reconstruction," in Military Psychology Response to Post Pandemic 
Reconstruction. Volume 2. Rawat, S., Boe, O. \& Piotrowski, A. Eds. Jaipur: Rawat Publications.

Brown, V. and Okros, A. (2019). "Dancing Around Gender: Changing Identity in a PostDeschamps Military," in Culture and the Soldier: How Identity, Values, and Norms Intersect with Contemporary Military Engagements, Breed, H.C. Ed. Vancouver: University of British Columbia Press.

Brown, V. \& Okros, A. (2018). New Leaders, 'New Wars': A Reflective Approach to Applying Gender and Cultural Perspectives," in Watola, Daniel \& MacIntyre, Allister Eds. From Knowing to Doing: International Perspectives on Leading Effectively, Canadian Defence Academy Press: Kingston: pp. 235-289.

Brown, V. \& Okros, A. (2020a). Disrupting Social Constructions in the Profession of Arms, in Hachey, K. Ed. Rethinking Military Professionalism for the Changing Armed Forces. Cham: Springer International Publishing AG.

Brown, V. \& Okros, A. (2020b). Unlearning 'Stranger Danger': Developing Cultural Competence in Canadian Military Professionals through Collective Learning and Self-Reflection, In Enstad, K., \& Holmes-Eber, P. Eds. Warriors or peacekeepers?: Building military cultural competence. Cham: Springer International Publishing AG.

Brown, K. \& Syme-Taylor, V. (2012). "Women academics and feminism in professional military education.” Equality, Diversity and Inclusion: An International Journal, 31(5/6): 452-466.

Butler, J. (1990). Gender trouble: Feminism and the subversion of identity. New York: Routledge. 
Butler, J. (1986). Sex and Gender in Simone de Beauvoir's Second Sex. Yale French Studies, (72):35-49.

Canada. Department of National Defence. (2017). Canadian Forces College Joint Command and Staff Programme, available at https://www.cfc.forces.gc.ca/226eng.html

Canadian Armed Forces (2020). CAF Code of Professional Conduct, Director General Military Personnel Strategy.

Canning, N. (2010). "Playing with heutagogy: exploring strategies to empower mature learners in higher education," Journal of Further and Higher Education, 34(1): $59-71$.

Carlson, Å. (2016). Sex, Biological Functions and Social Norms: A Simple Constructivist Theory of Sex, NORA - Nordic Journal of Feminist and Gender Research, 24(1): $18-29$.

Carpenter, C. (2016). Innocent women and children: Gender, norms and the protection of civilians, Taylor and Francis.

Carreiras, H. (1995). "Female Soldiers or Women in the Military? A Sociological Approach to Gender Relations in the Armed Forces." in Gender, Management and Science, eds Lígia Amâncio and Conceição Nogueira. Braga: Instituto de Educação e Psicologia da Universidade do Minho.

Carreiras, H. (1998). "Gender, Power and the Military. A Comparative Study of the Participation of Women in the Armed Forces of Western Democracies, Unpublished Paper ('June Paper’).” EUI, Florence.

Carreiras, H. (1999). "The Role of Women in the Armed Forces of NATO Countries: 
Military Constraints and Professional Identities." Minerva, Quarterly Report on Women in the Military 16(3-4): 46-57.

Castro, C. (2013). Qualitative Methods in Military Studies : Research Experiences and Challenges. London: Routledge.

Charlton, J. I. (1998). Nothing about us without us: Disability oppression and empowerment (1st ed.). University of California Press.

Chief of Military Personnel (2016). Canadian Armed Forces Progress Report on Addressing Inappropriate Sexual Behaviour, http://www.forces.gc.ca/en/cafcommunity-support-services/sexual-misconduct-progress-report.page\#viprevent;

Chief of the Defence Staff (CDS). (2016, January). Directive for integrating UNSCR 1325 and related resolutions into CAF planning and operations. Ottawa, ON: Chief of the Defence Staff.

Chief of the Defence Staff (CDS). (2015, August). Op Order-Op HONOUR. Ottawa, ON: Chief of the Defence Staff.

Chief of the Defence Staff (CDS). (2018). Intent - Operation HONOUR. Ottawa, ON: Chief of the Defence Staff.

Cockburn, C. (2010). Gender Relations as Causal in Militarization and War, International Feminist Journal of Politics, 12(2):139-157.

Cockburn, C. (2011). 'Snagged on the Contradiction: NATO UNSC Resolution 1325, and Feminist Responses'. Originally presented at the Annual Meeting of No to War - No to NATO Dublin. 15-17 April 2011, Unpublished manuscript. http://www.cynthiacockburn.org/BlogNATO1325.pdf. 
Cockburn, C. (2004). “The Continuum of Violence: A Gender Perspective on War and Peace." In Sites of Violence: Gender and Conflict Zones, edited by W. Giles and J. Hyndman, 24-44. Berkeley, CA: University of California Press.

Cohn, C. (2008). 'Mainstreaming Gender in UN Security Policy: A Path to Political Transformation' in Rai, Shirin M. and Georgina Waylen (eds) Analysing and Transforming Global Governance: Feminist Perspectives. Cambridge: Cambridge University Press, as referenced in Cockburn, 2011, p. 7.

Connell, R. (2005). Change amongst the Gatekeepers: Men, Masculinities, and Gender Equality in the Global Arena, Signs: Journal of Women in Culture and Society 30: $1802-25$.

Connell, R. (1987). Gender and Power: Society, the Person and Sexual Politics, Stanford, Stanford University Press.

Connell, R. (1995). Masculinities. Cambridge, UK: Polity Press.

Connell, R \& Messerschmidt, J. (2005). "Hegemonic Masculinity: Rethinking the Concept." Gender and Society, 19(6):829-859.

Cook, N. (2007). Gender Relations in Global Perspective: Essential Readings, Toronto: Canadian Scholars Press Inc.

Cornwall A, Correa S, Jolly S. (eds.). (2008). Development with a Body. Zed Books: London.; Cornwall A, Harrison E, Whitehead A. (2008). Gender myths and feminist fables: the struggle for interpretive power in gender and development. In Gender Myths and Feminist Fables, Cornwall A, Harrison E, Whitehead A (eds). Blackwell Publishing: Oxford, pp. 1-19. 
Cornwall, A., Edstrom, J. \& Greig, A. (2011). "Politicizing Masculinities in Development", in Men and Development Politicizing Masculinities, Cornwall, A., Edstrom, J. \& Greig, A. Eds., London: Zed Books, pp. 1-18, 2011., p. 2-4, as referenced in Brown \& Okros, 2019, p. 42.

Coulter, C. (2008). Female Fighters in the Sierra Leone War: Challenging the Assumptions? Feminist Review, 88 (1): 54-73.

Crenshaw, K. (1989). Demarginalizing the Intersection of Race and Sex: A Black Feminist Critique of Antidiscrimination Doctrine, Feminist Theory, and Antiracist Politics, University of Chicago Press.

Crenshaw, K. (1991). Mapping the Margins: Intersectionality, Identity Politics, and Violence Against Women of Color. Stanford Law Review. 43(6):1241-1299.

Cuadraz, G. \& Uttal, L. (1999). "Intersectionality and in-Depth Interviews: Methodological Strategies for Analyzing Race, Class, and Gender." Race, Gender \& Class 6 (3): 156

Curriculum Developers of the Joint Command and Staff Programme, 2018, Focus Group Interview, March.

Dharmapuri, S. (2011). Just add women and stir? Parameters, 41(1): 56-70, p. 58.

Davis, K. (2007). Women and Leadership in the Canadian Forces, Kingston: Canadian Defence Academy Press.

Davis, K. (2009). Sex, Gender and Cultural Intelligence in the Canadian Forces, Commonwealth \& Comparative Politics, 47:4, 430-455.

Davis, K. \& McKee, B. (2006). "Women in The Military: Facing the Warrior Framework", in Challenge and Change in The Military: Gender and Diversity 
Issues, Franklin Pinch, Allister MacIntyre, Phyllis Browne, and Alan Okros Eds. Kingston: Canadian Defence Academy Press, pp. 52-75.

Dean, J. (1995). "Reflective Solidarity,” Constellations. 2(1): pp.114-140.

Demetriou, D. (2001). 'Connell's Concept of Hegemonic Masculinity: A Critique', Theory and Society, 30(3): 337-61, as referenced in Parpart \& Partridge, 2015, p. 3 of 15

Deschamps, M. (2015). External Review into Sexual Misconduct and Sexual Harassment in the Canadian Armed Forces. National Defence and the Canadian Armed Forces. Available at:

https://www.canada.ca/en/department-national-defence/corporate/reports-publicat ions/sexual-misbehaviour/external-review-2015.html.

Deschaux-Beaume, D. (2012). "Investigating the Military Field: Qualitative Research Strategy and Interviewing in the Defence Networks." Current Sociology, 60(1): 101-117.

Director General Professional Military Conduct (DGPMC) (2021). "Final Report to the Internal Review of Statistics Canada Report into Sexual Misconduct at Military Colleges," Canadian Armed Forces, Government of Canada.

Dijk, T. (1993). "Principles of Critical Discourse Analysis," Discourse \& Society, 4(2): 249-283.

Duncanson, C. (2015). Hegemonic Masculinity and the Possibility of Change in Gender Relations. Men and Masculinities, 18(2), 231-248.

Duncanson, C. \& Woodward, R. (2016). Regendering the military: Theorizing women's military participation. Security Dialogue 47 (1): 3-21. 
Duriesmith, D. (2017) Masculinity and New War: The Gendered Dynamics of Contemporary Conflict, New York: Routledge.

Eichler, M. (2014). Militarized Masculinities in International Relations, The Brown Journal of World Affairs, 21(1): 81-93.

Elshtain, J. (1987). Women and War. Chicago: University of Chicago Press; Elshtain, J. (1992). “Sovereignty, Identity, Sacrifice.” In Gendered States: Feminist (Re)visions of International Relations Theory, ed. V. Spike Peterson, 141-54. Boulder, Colo.: Lynne Rienner.

Ender, M. (2013). Military Sociology, Oxford University Press.

Enloe, C. (2014). Bananas, beaches and bases: Making feminist sense of international politics (2nd ed.). Berkeley, Calif: University of California Press.

Enloe, C. (2000). Maneuvers: The International Politics of Militarizing Women's Lives. Berkeley: University of California Press.

Enloe, C., Lacey, A., \& Gregory, T. (2016). Twenty-five years of Bananas, Beaches and Bases: A conversation with Cynthia Enloe. Journal of Sociology, 52(3):537-550.

Enns, C., Sinacore, A. \& Scholars Portal. (2005). Teaching and social justice: Integrating multicultural and feminist theories in the classroom (1st ed.). Washington, D.C: American Psychological Association.

Fairclough, N. (1995). Critical Discourse Analysis: The Critical Study of Language, 2nd Ed. Pearson Education Ltd.: New York.

Febbraro, A. (2007). "Gender and Leadership in the Canadian Forces Combat Arms: Perspectives of Women Leaders", in Davis Ed. Women and Leadership in the Canadian Forces, Kingston: Canadian Defence Academy Press, pp. 93-138. 
Fontana, A. \& Borer, M. (2012). Postmodern trends: Expanding the horizons of interviewing practices and epistemologies, SAGE Publications, Inc.

Fox Keller, E. \& Longino, H. (1996). Feminism and science. New York: Oxford University Press.

Fraser, N. (1997). "From Redistribution to Recognition? Dilemmas of Justice in a "Postsocialist" Age," in Justice Interruptus: Critical Reflections on the PostSocialist Condition, Routlege: New York.

Gavey, N. (2011). Feminist Poststructuralism and Discourse Analysis Revisited. Psychology of Women Quarterly, 35(1): 183-188.

George, N. \& Shepherd, L. (2016). Women, Peace and Security: Exploring the implementation and Integration of UNSCR 1325. International Political Science Review, 37(3), 297-306.

George, T. (2016). Be all You can be Or Longing to be: Racialized Soldiers, the Canadian Military Experience and the Im/Possibility of Belonging to the Nation. ProQuest Dissertations Publishing.

George, T. (2019). Race and Belonging. In Alistair Edgar, Rupinder Mangat \& Bessma Momani (eds) Strengthening the Canadian Armed Forces through Diversity and Inclusion. Toronto, University of Toronto Press.

Ginach, M. (2004). "War Against or for Terrorism? The Underlying Fantasy Behind the Israeli Pattern of Encounter with the Palestinians" The Discourse of Sociological Practice, 6(1): 1-12.

Giroux, H \& Penna, A. "Social Education in the Classroom: The Dynamics of the Hidden Curriculum." The Hidden Curriculum and Moral Education. Ed. Giroux, Henry 
and David Purpel. Berkeley, California: McCutchan Publishing Corporation, 1983. $100-121$.

Goffman, E. (1961). Asylums: Essays on the Social Situation of Mental Patients and Other Inmates. Anchor Books. New York.

Goldenberg, I. (2006). Special Selection Program for Female Selection to Canadian Forces Command and Staff Course. Report submitted to Department of National Defence, Canada.

Goldstein, J. (2001). War and gender: how gender shapes the war system and vice versa. Cambridge: Cambridge University Press.

Government of Canada. (2017a). Canada's National Action Plan for the Implementation of the United Nations Security Council Resolutions on Women, Peace and Security 2017-2022. Ottawa: Global Affairs Canada.

Government of Canada. (2018). Creation of the Department for Women and Gender Equality. 2018 MENA Report. Available at: https://search-proquestcom.cfc.idm.oclc.org/trade-journals/canada-creation-department-women-genderequality/docview/2158018931/se-2?accountid=9867.

Government of Canada. Department of National Defence (DND). (1997). Canadian Forces General Orders (CANFORGEN) \#053/97- Special Selection Measure for Women: CF Command and Staff Course.

Government of Canada. Department of National Defence (DND). (2018). CANFORGEN 048/19 - Changes to CAF Dress Instructions Specific to Women's Service Dress, Canadian Armed Forces. 
Government of Canada. Department of National Defence (DND). (2009). Duty with Honour: The Profession of Arms in Canada.

Government of Canada. Department of National Defence (DND). (2006). Special Selection Program for Female Selection to Canadian Forces Command and Staff Course (An Analysis), Ottawa: Government of Canada.

Government of Canada. Department of National Defence (DND). (2017) Joint Command and Staff Programme Residential and Joint Command and Staff Programme Distance Learning Syllabus, Version 17, Toronto: Canadian Forces College.

Government of Canada. (2019). Statistics on the representation of women in the CAF as of September 2018, Canadian Armed Forces, available at: https://www.canada.ca/en/department-national-defence/services/women-in-theforces/statistics.html

Government of Canada. (2019b). Joint Command and Staff Programme, Canadian Forces College, available at: cfc.forces.gc.ca

Government of Canada. (2017b). Strong, secure, engaged: Canada's defence policy. Ottawa: Minister of National Defence.

Gray, S. (2008). Discontinuing the Canadian military's 'Special selection' process for staff college and moving toward a viable and ethical integration of women into the senior officer corps. Journal of Military Ethics, 7(4), 284-301.

Hacking, I. (1999). The Social Construction of What? Cambridge, Mass: Harvard University Press.

Haddad, Said. (2013). "Interviewing a Group: a Social Dramatic Art, A Few Remarks on Dynamic and Stakes of Military Groups," in Castro, C. (2013). Qualitative 
Methods in Military Studies : Research Experiences and Challenges. London:

Routledge. Retrieved from

http://search.ebscohost.com.cfc.idm.oclc.org/login.aspx?direct=true\&db=nlebk\& $\mathrm{AN}=513603 \&$ site $=$ ehost-live $\&$ scope $=$ site

Haraway, D. (1988). "Situated Knowledges: The Science Question in Feminism and the Privilege of Partial Perspective.” Feminist Studies 14(3): 575-599.

Harding, S. The Science Question in Feminism. Ithaca, NY: Cornell University Press, 1986.

Hase, S., \& Kenyon, C. (2007). Heutagogy: A child of complexity theory. Complicity: An International Journal of Complexity and Education, 4(1), 111-118.

Hearn, J. (2004). From Hegemonic Masculinity to the Hegemony of Men, Feminist Theory 5:49-72.

Higate, P. (2003). Military Masculinities: Identity and the State, Westport: Praeger.

Higate, P. (2007). Peacekeepers, masculinities, and sexual exploitation, Men and Masculinities 10(1): 99-119.

Holvikivi, A. (2019). Fixing Gender: The Paradoxical Politics of Peacekeeper Training. ProQuest Dissertations Publishing.

Holvikivi, A. (2021). Training the Troops on Gender: The Making of a Transnational Practice. International Peacekeeping (London, England) ahead-of-print (ahead-ofprint), 1-25.

Hooper, C. (1998). "Masculinist Practices and Gender Politics: The Operation of Multiple Masculinities in International Relations," in The "Man" Question in International Relations, ed. Zalewski, M. \& Parpart, J. Boulder, CO: Westview 
Press, 31, as referenced in Eichler, M. (2014). Militarized Masculinities in International Relations, The Brown Journal of World Affairs, 21(1): 81-93.

hooks, b. (2016). Section II: \#BlackGirlFeminism: Existing, teaching, and learning on the edges and beyond. Meridians: Feminism, Race, Transnationalism, 15(1): 109. Hooper, C. (2001). Manly States: Masculinities, International Relations, and Gender Politics. New York: Columbia University Press.

House of Commons. (2019). Improving Diversity and Inclusion in the Canadian Armed Forces: Report of the Standing Committee on National Defence, Chair, Fuhr, S. 42nd Parliament, 1st Session, available at: https://www.ourcommons.ca/Content/Committee/421/NDDN/Reports/RP105737 00/nddnrp17/nddnrp17-e.pdf.

Information Resource Centre Staff, 2018, Focus Group Interview, April. Irwin, A. (2009). Diversity in the Canadian Forces: Lessons from Afghanistan. Commonwealth and Comparative Politics, 47(4), 494-505. Jansen, M. \& Kramer, E. H. (2019). Military mores - an institutional ethnography, Ethnography and Education, 14(4): 512-526.

Joint Command and Staff Residential Programme Officer. (2017). Joint Command and Staff Programme Directing Staff Handbook, Canadian Forces College, p. 40, Annex K.

Jung, F. (2008). “Unsung heroes: Women's Contributions in the military and why their song goes unsung," in Kümmel, G. \& Carreiras, H. (2008). Women in the military and in armed conflict. 1st;1. Aufl.; ed. Vol. Bd. 6. Wiesbaden: VS Verl. für Sozialwiss, pp. 49-62. 
Kaldor, M. (2006). New \& Old Wars. Organized Violence in a Global Era, 2nd ed. Cambridge: Polity Press.

Kaufman, J. \& Williams, K. (2016). Women, Gender Equality, and Post-Conflict Transformation: Lessons Learned, Implications for the Future. New York: Routledge.

Kenyon, C. \& Hase, S. (2001). Moving from andragogy to heutagogy in vocational education, Research to Reality: Putting VET Research to Work. Proceedings of the Australian Vocational Education and Training Research Association (AVETRA) Conference (4th, Adelaide, Australia, March 28-30.

Kirby, P. \& Shepherd, L. (2016). The Futures Past of the Women, Peace and Security Agenda. International Affairs, 92(2), 373-92.

Knowles, M., Holton III, E. \& Swanson, R. (2015). The adult learner: The definitive classic in adult education and human resource development (8th ed.). New York: Routledge.

Kozina, A. (2015). "Hidden Curriculum in Military Schools," Security and Defence Quarterly, 1 (6): 89-104.

Kronsell, A. (2012). Gender, Sex, and the Post-national Defense: Militarism and Peacekeeping. New York: Oxford University Press.

Krylova, A. (2010). Soviet Women in Combat: A History of Violence on the Eastern Front. North Carolina: Duke University Press.

Kümmel, G. (2002). When Boy Meets Girl: The `Feminization’ of the Military. Current Sociology, 50(5): 615-639.

Madsen, C. (1999). Another kind of justice: Canadian military law from confederation to 
Somalia. Vancouver: UBC Press.

Maringira, G. (2017). "Gendered Military Identities: Army Deserters in Exile," in Woodward, R., \& Duncanson, C., The palgrave international handbook of gender and the military (1st 2017 ed.). London: Palgrave Macmillan, pp. 289-302.

Man Graduate of the Joint Command and Staff Programme, (2018a). Individual Interview.

Man Graduate of the Joint Command and Staff Programme, (2018b). Individual Interview.

Man Graduate of the Joint Command and Staff Programme, (2018c). Individual Interview.

Man Graduate of the Joint Command and Staff Programme, (2018d). Individual Interview.

Man Student Joint Command and Staff Programme, (2018a). Individual Interview, June. Man Student Joint Command and Staff Programme, (2018b). Individual Interview, June. Man Student Joint Command and Staff Programme, (2018c). Individual Interview, June. Men Students of the Joint Command and Staff Programme, (2018). Focus Group Interview, January.

Marchand, H. \& Runyan, A. (2000). Gender and Global Restructuring: Sightings, Sites and Resistances. New York: Routledge.

Margolis, E., Soldatenko, M., Acker, S., \& Gair. M. "Peekaboo: Hiding and Outing the Curriculum." The Hidden Curriculum in Higher Education. Ed. Margolis, Eric. New York: Routledge, 2001. 
Marvasti, A. \& Freie, C. (2017). Research interviews. In D. Wyse, N. Selwyn \& E. Smith The BERA/SAGE Handbook of educational research (Vol. 2, pp. 624-639), London: SAGE Publications Ltd, p. 629.

Masters, C. (2005). "Bodies of Technology: Cyborg Soldiers and Militarized Masculinities.” International Feminist Journal of Politics. 7(1): 117. McCarry, M. (2010). ‘Becoming a 'Proper Man’: Young People's Attitudes about Interpersonal Violence and Perceptions of Gender', Gender and Education, 22(1): 17-30, as referenced in Parpart \& Partridge, 2015, p. 3 of 15.

Messerschmidt, J. (2010). Hegemonic Masculinities and Camouflaged Politics: Unmasking the Bush Dynasty and Its War Against Iraq. Boulder: Paradigm Publishers.

Military Faculty Member of the Joint Command and Staff Programme, 2018, Individual Interview, March.

Military Faculty of the Joint Command and Staff Programme, 2018, Focus Group Interview, March.

Miller, L. (1997). 'Not just weapons of the weak: gender harassment as a form of protest for Army men', Social Psychology Quarterly 60, pp. 32-51. As referenced in Woodward \& Winter, 2007, p. 58.

Morgan, D. (1996). "Focus Groups” Annual Review of Sociology, 22: 129-52.

Morgan, D. (1994). “Theatre of War: Combat, the Military, and Masculinities.” In Theorising Masculinities, edited by Harry Brod and Michael Kaufman, 165-82. London, UK. 
Muir, K. (1993). Arms and the Woman. London, UK: Coronet Books.; Morgan, D. (1994). “'Theatre of War: Combat, the Military, and Masculinities.' In Theorising Masculinities, edited by Brod, H. \& Kaufman, M., pp. 165-82. London, UK: Sage.

Muzio, D., Brock, D. \& Suddaby, R. (2013). Professions and Institutional Change: Towards an Institutionalist Sociology of the Professions. Journal of Management Studies, 50(5): 699-721.

National Defence. (2017). Strong, Secure, Engaged: Canada's National Defence Policy. National Defence.

National Inquiry into Missing and Murdered Indigenous Women and Girls. (2019). Reclaiming Power and Place: The Final Report of the National Inquiry into Missing and Murdered Indigenous Women and Girls, Volume $1 \mathrm{~b}$. 9780660304892. Ottawa.

NDDN (2019). Standing Committee on National Defence, Session 131, LGen Wynnyk on $\mathrm{GBA}+$, Feb. 28th. Available at:

https://www.ourcommons.ca/DocumentViewer/en/42-1/NDDN/meeting$\underline{131 / \text { evidence }}$

North Atlantic Treaty Organization/Euro-Atlantic Partnership Council (EAPC). (2016). Women, Peace, and Security Agenda 2016-2018: Policy, Action Plan, and Strategic Report. Brussels: NATO.

North Atlantic Treaty Organization (NATO). (2012). Integrating UNSCR 1325 and Gender Perspectives into the NATO Command Structure Bi-Strategic Command Directive (Bi-SC) 40-1. 
Olesen, V. (2007). Feminist qualitative research and grounded theory: complexities, criticisms, and opportunities. In A. Bryant \& K. Charmaz The SAGE Handbook of Grounded Theory, SAGE Publications Ltd, pp. 417-435.

Pahlavi, P., \& Ouellet, E. (2012). Institutional analysis and irregular warfare: Israel Defense Forces during the 33-Day War of 2006. Small Wars \& Insurgencies, 23(1), 32-55.

Park, You-me. (2016). The crucible of sexual violence: Militarized masculinities and the abjection of life in post-crisis, neoliberal South Korea. Feminist Studies, 42(1), $17-40$.

Parpart, J. (2010). “Choosing Silence: Rethinking Voice, Agency and Women’s Empowerment," in Ryan-Flood, R. \& Gill, R. Secrecy and silence in the research process: Feminist reflections. Abingdon, Oxon ; New York, NY: Routledge.

Parpart, J. (2010). Masculinity, Poverty and the 'New Wars'. In S. Chant, ed. The International Handbook of Gender and Poverty. Northampton, MA: Edward Elgar, 85-99.

Parpart, J. (2014). Exploring the Transformative Potential of Gender Mainstreaming in International Development Institutions. Journal of International Development. 26, 382-395.

Parpart, J. (2016). “Imagined peace, gender relations and post-conflict transformation: Anti-colonial and post-Cold War conflicts," in Kaufman, J. \& Williams, K. (2016). Women, Gender Equality, and Post-Conflict Transformation: Lessons Learned, Implications for the Future. New York: Routledge, pp. 57-74. 
Parpart, J. (2015). Militarized Masculinities, heroes and gender equality during and after the nationalist struggle in Zimbabwe, NORMA: International Journal for Masculinity Studies, 10(3-4), 312-325.

Parpart, J. (2020). Rethinking silence, gender, and power in insecure sites: Implications for feminist security studies in a postcolonial world. Review of International Studies, 46(3), 315-324.

Parpart, J. \& Partridge, K. "Soldiering On: Pushing Militarized Masculinities into new Territories" in Evans, M. ed. The SAGE handbook of feminist theory. Thousand Oaks, California; London;: SAGE Publications, 2014: 550-565.

Parpart, J. \& Parashar, S. eds. (2019). Rethinking Silence, Voice and Agency in Contested Gendered Terrains. Routledge.

Personal Correspondence with a CAF member (2021). GBA+ and the Pandemic Response by the Canadian Armed Forces, February.

Peterson, S. V. (1997). "Whose crisis? Early and post-modern masculinism," in Gill, S. \& Mittleman, J. (eds.) Innovation and Transformation in International Studies, Cambridge: Cambridge University Press. p. 185, as referenced in Runyan \& Marchand, 2011.

Puar, J. (2007). Terrorist Assemblages: Homonationalism in Queer Times. London: Duke University Press.

Rabinow, P. Ed. (1980). Truth and power: The Foucault Reader, Toronto: Penguin.

Razack, S. (2004). Dark Threats and White Knights: the Somalia Affair, peacekeeping, and the New Imperialism. Toronto: University of Toronto Press. 
Reardon, B. (1985). Sexism and the War System, New York: Teachers College Press.

Reiffenstein, A. (2007). Gender Integration- As Asymmetric Environment, in Karen D. Davis Ed. Women and Leadership in the Canadian Forces: Perspectives and Experience, Canadian Defence Academy Press.

Rogers, R. (2011). Becoming Discourse Analysts: Constructing Meaning and Identities, Critical Inquiry in Language Studies, 8(1): 72-104.Lanham, Md: University Press of America.

Roach Pierson, R. (1986). "they're still women after all": The second world war and canadian womanhood. Toronto: McClelland and Stewart.

Roach Pierson, R. ed. (1987) Women and Peace: Theoretical, Historical and Practical Perspectives. London, New York, Sydney: Croom Helm.

Rosen L. \& Martin, L. (1997). 'Sexual harassment, cohesion and combat readiness in US Army support units', Armed Forces \& Society 24: 221-244.

Runyan, A. \& Marchand, M. (2011). Gender and Global Restructuring: Sightings, Sites, and Resistances. 2nd ed. V. 30. New York: Routledge.

Sage; Niva, S. (1998). "Tough and Tender: New World Order, Masculinity and the Gulf War.' In The 'Man Question' in International Relations, edited by Zalewski, M. \& Parpart, J., pp. 109-28. Boulder, CO: Westview.

Samaroo, S. (2012). An investigation into the practicality and applicability of the pedandragogic framework: A case study of faculty attitude toward a learnercentered model of teaching and learning at a university in the southern United States. ProQuest Dissertations Publishing. 
Sasson-Levy, O. (2003). Feminism and Military Gender Practices: Israeli Women Soldiers in "Masculine" Roles. Sociological Inquiry. 73: 440-465.

Scheibelhofer, E. (2008). International Journal of Social Research Methodology, 11(5): 403-416.

Scott, R. (1995). Institutions and Organizations. Thousand Oaks, CA, SAGE.; Palthe, J. (2014). Regulative, Normative and Cognitive Elements of Organizations: Implications for Managing Change. Management and Organizational Studies, 1(2): p. 59.

Segal, L. (1997). Slow Motion: Changing Masculinities, Changing Men (Vol. 2). 2nd ed. London, UK: Virago. As referenced in Duncanson, 2015, p. 232.

Segal, M. (1999). Gender and the Military. In Handbook of the Sociology of Gender, edited by Janet S. Chafetz, 563-81. New York: Kluwer Academic/Plenum Publishers.

Segal, M. (1986). The Military and the Family as Greedy Institutions. Armed Forces \& Society, 13(1), 9-38.

Segal, M. (1983). “Women's Roles in the US Armed Forces: An Evaluation of Evidence and Arguments for Policy Decisions." in Conscripts and Volunteers: Military Requirements, Social Justice and the All-Volunteer Force, ed. Fullinwider, R., New Jersey, NJ: Rowan \& Allanheld, pp. 20013.

Schippers, M. (2007). Recovering the Feminine Other: Masculinity, Femininity, and Gender Hegemony. Theoretical Sociology, 36, 85-102. 
Schiebinger, L. (1987). "Skeletons in the Closet: The First Illustrations of the Female Skeleton in Eighteenth Century Anatomy", in Sexuality and Society in the Nineteenth Century, Gallagher, C. \& Laqueur, T. eds. Berkley: University of California Press, pp. 25-57.;

Shekhawat, S. \& Saxena, C. (2015). Victims or Victimizers? Naxal Women, Violence and the Reinvention of Patriarchy. In Shekhawat, S. (ed.) Female Combatants in Conflict and Peace: Challenging Gender in Violence and Post-conflict Reintegration. London: Palgrave Macmillan, pp. 117-131.

Shildrick, M. (1997). Leaky Bodies and Boundaries: Feminism, Postmodernism, and (bio)Ethics, London: Routledge.

Sjoberg, L. (2007). “Agency, Militarized Femininity and Enemy Others”, International Feminist Journal of Politics, 9 (1): 82-101.

Sjoberg, L. (2009). 'Introduction to Security Studies: Feminist Contributions,' Security Studies 18(2): 183-213.

Sjoberg, L. (2011). Gender, the state, and war redux: Feminist International Relations across the 'Levels of analysis'. International Relations, 25(1), 108-134.

Sjoberg, L. (2017). Theories of War, in Ní Aoláin, Fionnuala et al. Eds. The oxford handbook of gender and conflict. US: Oxford University Press, pp. 3-16.

Sjoberg, L. \& Via, S. (2010). Gender, war, and militarism: Feminist perspectives. Santa Barbara, Calif: Praeger.

Smith, D. (1987). Everyday World as Problematic: A Feminist Sociology, Boston: Northeastern University Press. 
Smith, D. (1991). Writing Women's Experience into Social Science. Feminism \& Psychology 1(1), 155-69.

Statistics Canada (2016). "Sexual Misconduct in the Canadian Forces, 2016"

November 28, http://www.statcan.gc.ca/dailyquotidien/161128/dq161128a-eng.htm

Taber, N. (2009). The Profession of Arms: Ideological Codes and Dominant Narratives of Gender in the Canadian Military. Atlantis 34 (1), 27-36.

Taber, N. (2010). Institutional ethnography, autoethnography, and narrative: an argument for incorporating multiple methodologies, Qualitative Research, 10(1), 5-25.

Taber, N. (2015). Gendered Militarism in Canada: Learning Conformity and Resistance. Edmonton: The University of Alberta Press.

Taber, N. (2017). The Canadian Armed Forces: battling between Operation HONOUR and Operation Hop on Her, Critical Military Studies.

Tait, V. (2020). Gender Stereotyping in the Canadian Combat Arms, in Justin Wright \& Felix Fonseca Eds. Making Sense of Diversity in the Profession of Arms. Canadian Defence Academy Press.

Tiessen, R. (2007). Everywhere/Nowhere: gender mainstreaming in development agencies. Bloomfield, CT: Kumarian Press.

Tiessen, R. (2015). "Gender Essentialism in Canadian Foreign Aid Commitments to Women, Peace, and Security." International Journal, 70(1): 84-100.

Tiessen, R. (2018). Improving Student Reflection in Experiential Learning Reports in Post-Secondary Institutions, Journal of Education and Learning, 7(3): 1-10. 
Treasury Board of Canada Secretariat. (2018). Employment Equity in the Public Service of Canada for Fiscal Year 2016 to 2017.

Turshen, M. (1998). Women's War Stories. In Turshen, M. and Twagiramariya, C. (eds) What Women Do in Wartime: Gender and Conflict in Africa. London \& New York: Zed Books.

Welland, J. (2013). Militarised violences, basic training, and the myths of asexuality and discipline. Review of International Studies, 39(4):881-902.

Whitworth, S. (2004). Men, Militarism, and UN Peace Keeping: A Gendered Analysis, Boulder: Lynne Rienner Publishers.

Whitworth, S. (2005). Militarized Masculinities and the Politics of Peacekeeping: The Canadian Case. In Ken Booth (ed.), Critical Security Studies in World Politics, Boulder: Lynne Rienner Publishers, p. 89-106.

Wibben, A. (2011). Feminist politics in feminist security studies. Politics \& Gender, 7(4): 590-595.

Winslow, D. (1998). Misplaced Loyalties: The Role of Military Culture in the Breakdown of Discipline in Peace Operations. The Canadian Review of Sociology and Anthropology 35(3), 345.

Winslow, D. (2009). Gender and Military Sociology, Swedish National Defence College, Department of Leadership and Management.

Winslow, D. \& Dunn, J. (2002). "Women in the Canadian Forces: Between Legal and Social Integration" Current Sociology, 50(5): 641-667.

Winkel, H. (2019) Religious cultures and gender cultures: tracing gender differences across religious cultures, Journal of Contemporary Religion, 34(2): 241-251. 
Woman Graduate of the Joint Command and Staff Programme, (2018a). Individual Interview, October.

Woman Graduate of the Joint Command and Staff Programme, (2018b). Individual Interview, October.

Woman Graduate of the Joint Command and Staff Programme, (2018c). Individual Interview, October.

Woman Graduate of the Joint Command and Staff Programme, (2018d). Individual Interview, November.

Women Students of the Joint Command and Staff Programme (2018). Focus Group Interview, January.

Woman Student the of Joint Command and Staff Programme, (2018a). Individual Interview, June.

Woman Student of the Joint Command and Staff Programme, (2018b). Individual Interview, June.

Woodward, R., \& Winter, T. (2007). Sexing the soldier: the politics of gender and the contemporary British Army. London; Routledge.

Woodward, R. \& Duncanson, C. (2017). The Palgrave international handbook of gender and the military (1st 2017 ed.). London: Palgrave Macmillan.

Von Hlatky, S. (2019). WPS and the North Atlantic Treaty Organization, in The Oxford Handbook of Women, Peace, and Security, Davies, Sara \& True, Jacqui Eds. New York: Oxford University Press.

Young, I. (2003). The logic of masculinist protection: Reflections on the current security state. Signs, 29(1): 1-25. 
Zarkov, D. \& Dudink, S. Association of World Council of Churches related Development Organisations in Europe. (2001). "Beyond Victims and Villains: Gender and Armed Conflict." Paper presented at the GOOD Conference on Gender and Armed Conflict, Uppsala, Sweden, Sept. 2001, p. 47, available at: https://repository.ubn.ru.nl/bitstream/handle/2066/62064/pubversion_2066_62064 -20141015120302.pdf?sequence $=1$

Zeigler, S., \& Gunderson, G. (2005). Moving beyond G.I. Jane: women and the U.S. military. 